\title{
DIETARY NUTRIENTS IMPLICATED IN THE ETIOPATHOGENESIS OF HUMAN AND ANIMAL DISEASES
}

\author{
A Dissertation \\ presented to the \\ Faculty of the Graduate School \\ University of Missouri
}

In Partial Fulfillment of the Requirements for the Degree

Doctor of Philosophy

\author{
By \\ SARAH E. HOOPER \\ Dr. Robert Backus, Dissertation Supervisor
}

December 2017 
The undersigned, appointed by the Dean of the Graduate School, have examined the dissertation entitled

\section{DIETARY NUTRIENTS IMPLICATED IN THE ETIOPATHOGENESIS OF HUMAN AND ANIMAL DISEASES}

Presented by Sarah E. Hooper,

A candidate for the degree of doctor of, and hereby certify that, in their opinion, it is worthy of acceptance.

Dr. Robert Backus, MS, DVM, PhD, DACVN

Associate Professor and Director of the Nestlé Purina Endowed Program in Small Animal Nutrition

Dr. Sybill Amelon, MS, PhD

Cooperative Associate Professor and USDA Forest Service Northern Research

Station Wildlife Biologist

Dr. Craig Franklin, DVM, PhD, ACLAM

Professor and Director of the Comparative Medicine Program, MMRRC

Dr. Kevin Fritsche, PhD

Professor Nutrition and Exercise Physiology

Dr. Jeff Henegar, PhD

Associate Professor Medical Pharmacology and Physiology 


\section{DEDICATION}

"The fear of the Lord is the beginning of knowledge, but fools despise wisdom

and instruction."

Proverbs 1:7 


\section{ACKNOWLEDGEMENTS}

Completion of this research and $\mathrm{PhD}$ were only possible through the relentlessness of God's grace, forgiveness, and his constant guidance. While I faltered and strayed from Him, he continued to bless me by providing a wonderful opportunity to pursue a residency and $\mathrm{PhD}$ in a stellar program.

During my residency and doctoral research, I have had the privilege to work with numerous individuals who have contributed to both my education and my success. I owe a great amount of appreciation to the mentorship, friendship, and patience of Dr. Robert Backus for agreeing to undertake a PhD student who was challenging on many levels. Development of my analytical research skills and knowledge of the fundamental research techniques would not have been possible without his mentorship. I also wish to thank Dr. Craig Franklin and the Comparative Medicine Program Faculty for allowing me to be part of the Comparative Medicine Program. I particularly want to recognize the dedication

of Dr. Scott Korte, Dr. Erin O'Connor, and Dr. Lon Dixon to my residency training and their assistance for the ceftiofur pharmacokinetic study that became my first peer-reviewed first-author manuscript. In particular, I wish to thank Dr. Scott Korte for his advice and at least pretending to be a good listener. And Dr. Pat Farrar for introducing me to Dr. Sybill Amelon.

The support, expertise, and approachability of my committee members Dr. Sybill Amelon, Dr. Craig Franklin, Dr. Kevin Fritsche, and Dr. Jeff Heneger, deserve to be recognized. Thank you for tolerating my numerous research 
interests and projects that I concurrently engaged in throughout my time here at Mizzou.

And lastly, I would like to recognize my parents for their love, support, and a homeschool education that taught me to become a critical thinker and problem solver—core competencies for a veterinarian and scientist. 


\section{TABLE OF CONTENTS}

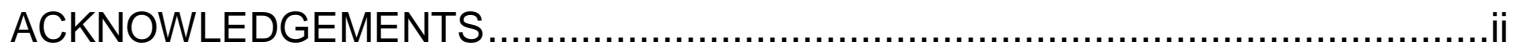

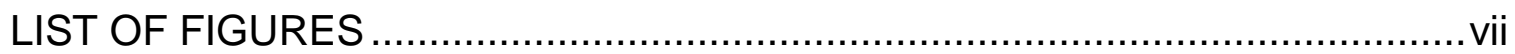

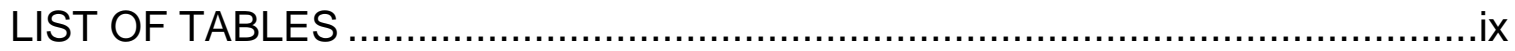

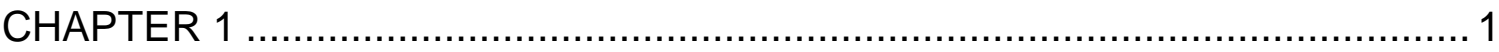

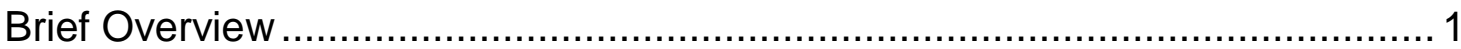

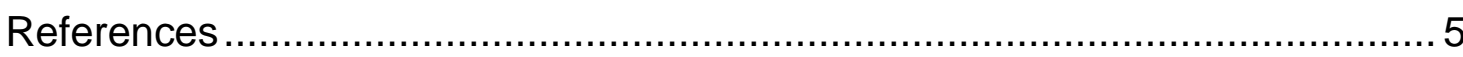

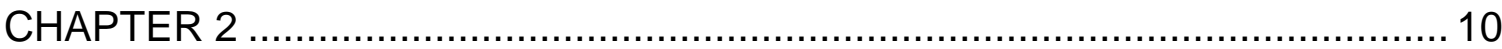

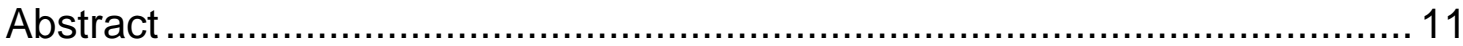

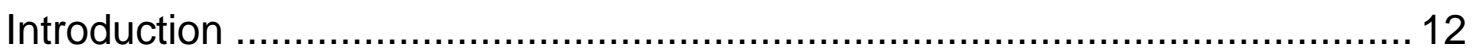

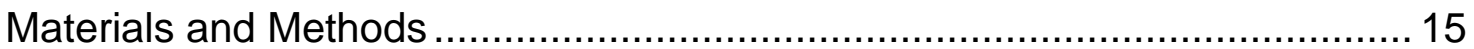

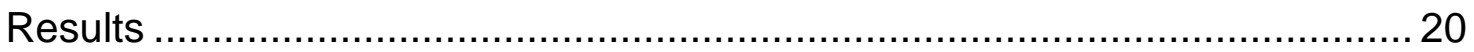

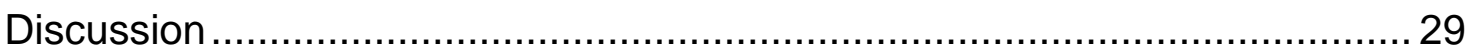

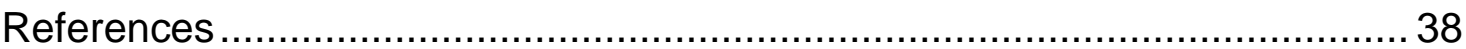

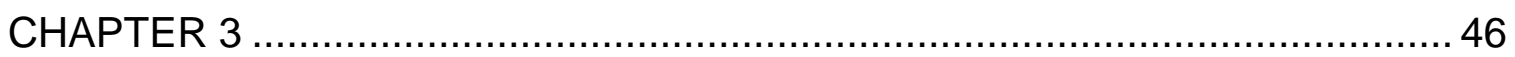

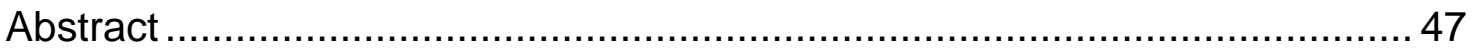

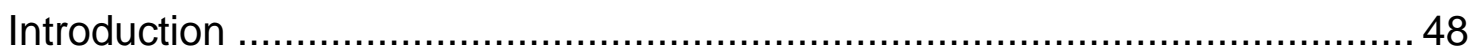

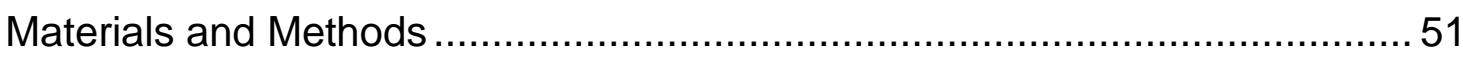

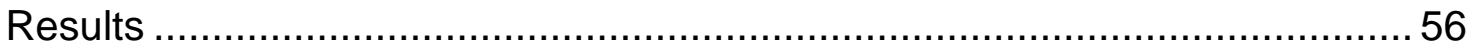

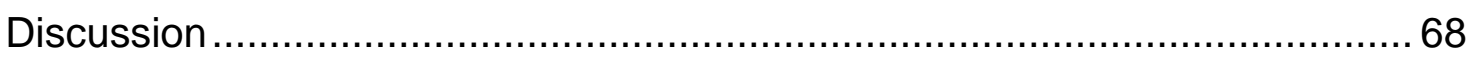

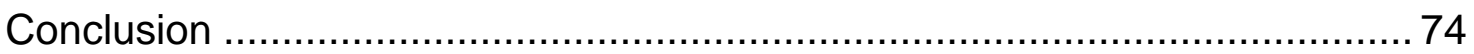

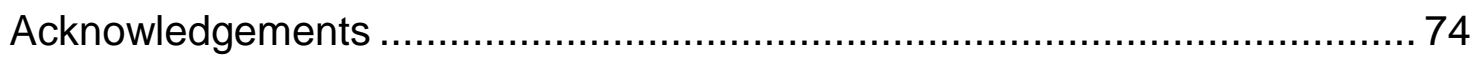




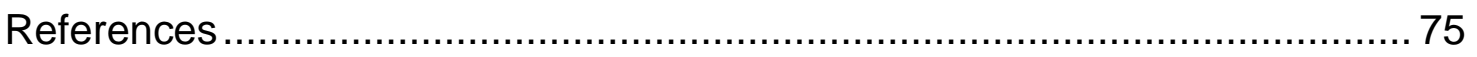

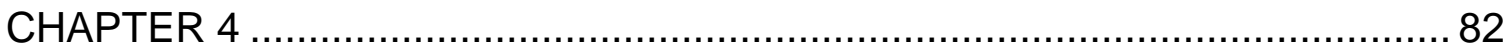

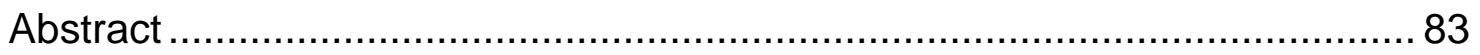

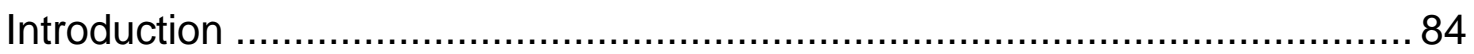

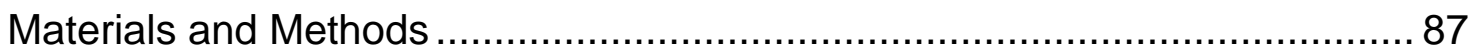

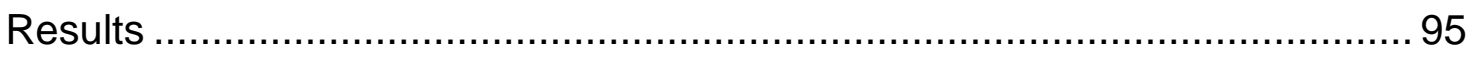

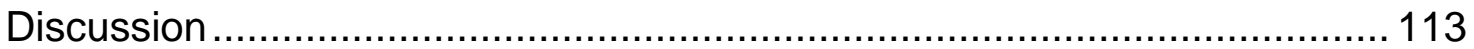

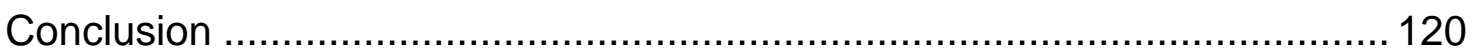

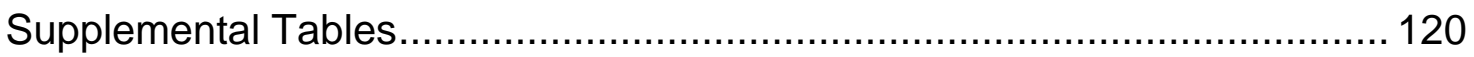

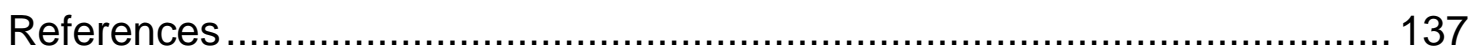

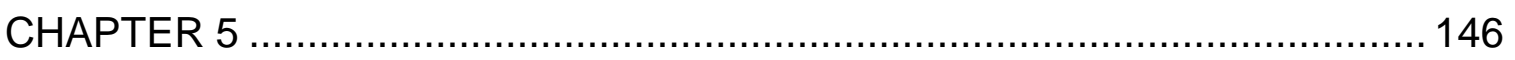

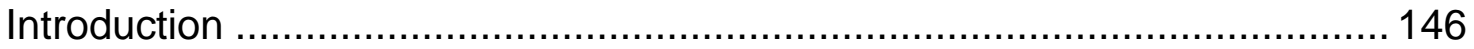

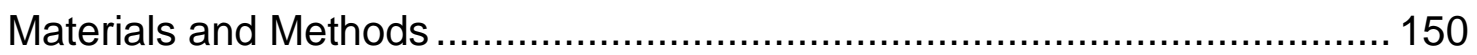

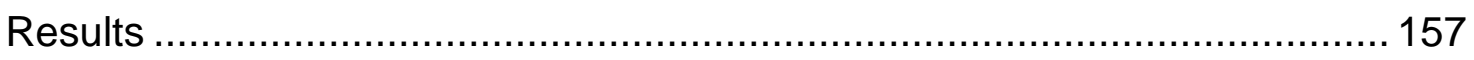

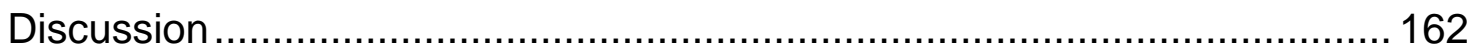

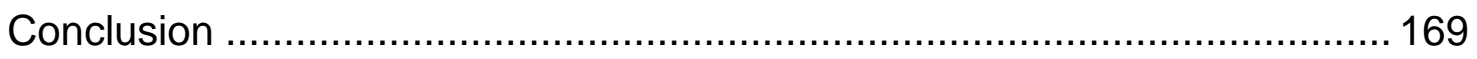

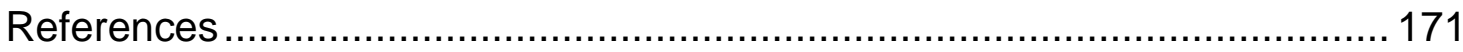

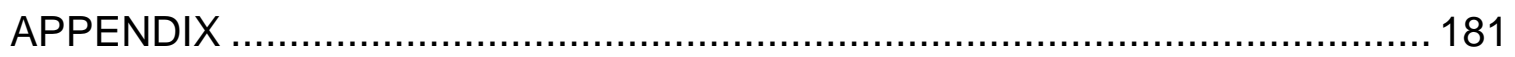

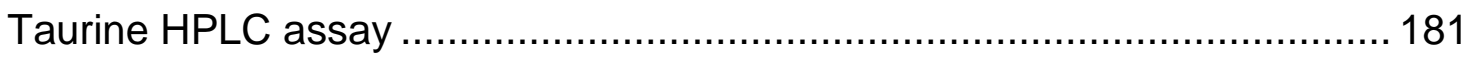

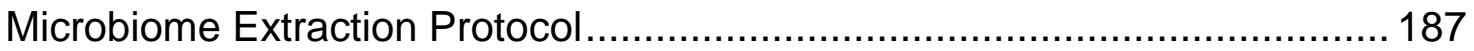

Thyroid hormone liver extraction protocol ................................................ 190

Validation of MP Biomedicals total thyroxine and triiodothyronine radioimmunoassay (RIA) kit ............................................................... 194 


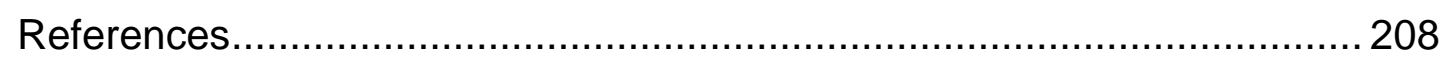

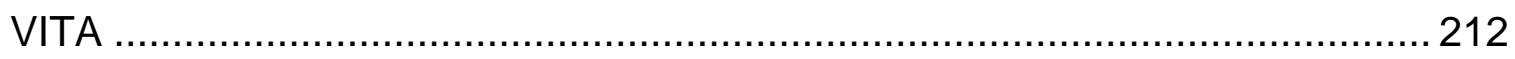




\section{LIST OF FIGURES}

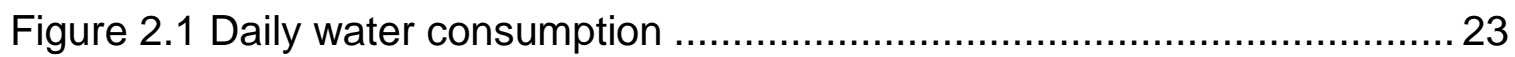

Figure 2.2 TRH stimulation test mean circulating serum T3 concentrations....... 25

Figure 2.3 TRH stimulation test T4, FT4, and FT3 circulating serum

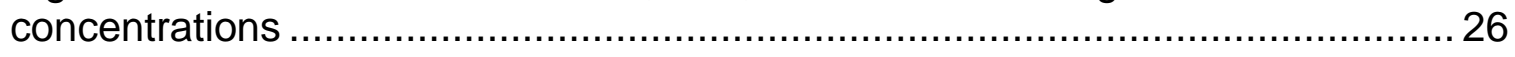

Figure 2.4 TRH Stimulation test circulating serum TSH concentrations ............ 27

Figure 2.5 Activity counts during each dietary treatment block........................ 28

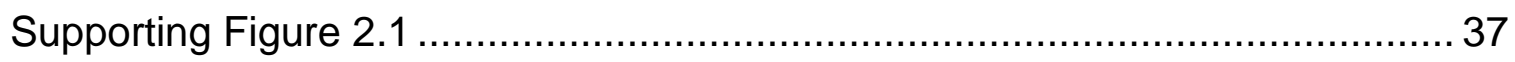

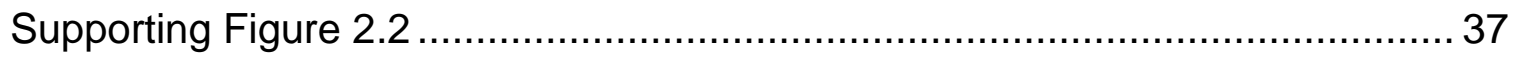

Figure 3.1 Circulating serum thyroid hormones .............................................5

Figure 3.2 Circulating serum concentrations of T3 …................................... 60

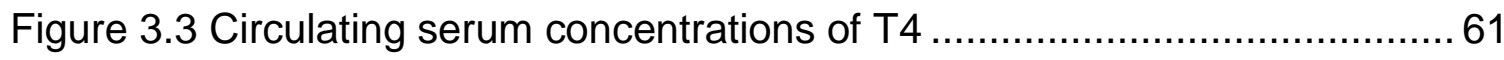

Figure 3.4 Post-prandial plasma taurine concentrations................................... 63

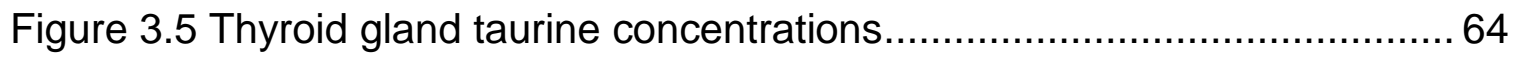

Figure 3.6 Periodic acid-Schiff stained thyroid glands .................................. 67

Figure 4.1 Whole blood taurine concentrations ........................................... 100

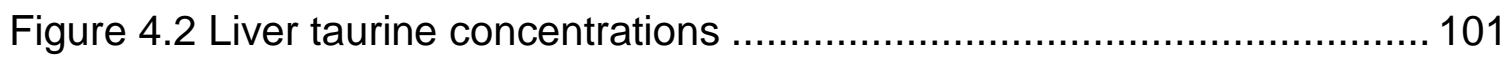

Figure 4.3 Quadriceps muscle taurine concentrations................................. 102

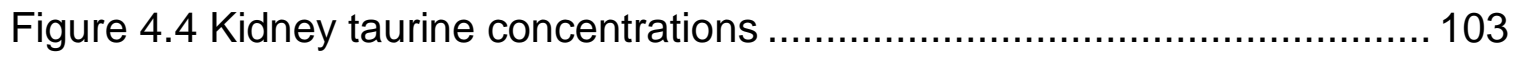

Figure 4.5 Circulating serum IGF-1 concentrations .................................... 104

Figure 4.6 Relative abundance at taxonomic level of phyla............................. 106

Figure 4.7 Relative abundance at taxonomic level of OTU ............................. 107

Figure 4.8 Principal component analysis ................................................. 113

Figure 5.1 Plasma and whole blood taurine concentrations ........................... 159 
Figure 5.2 Day 0 and 42 fasting and post-prandial thyroid hormone

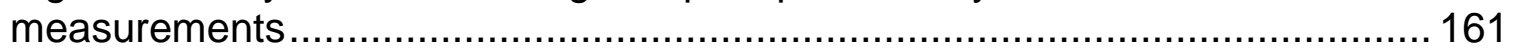

HPLC Appendix Figure 1 Example chromatograph ...................................... 186

RIA Validation Appendix Figure 1 Schematic diagram of a radioimmuno assay 196

RIA Validation Appendix Figure 2 Chemical structure of the thyroid hormones T4 and T3 


\section{LIST OF TABLES}

Table 2.1 Proximate analysis and select nutrients of the control diet

Table 2.2 Feed intake, weight, and percent weight change over each dietary treatment block

Table 2.3 Serum Se, TT4, and TT3 over the duration of each dietary treatment block

Table 3.1: Crude protein and taurine content of diets................................... 52

Table 3.2 Circulating serum TT3 concentrations .......................................... 58

Table 3.3 Circulating serum TT4 concentrations …...................................... 58

Table 3.4 Circulating serum TSH concentrations .......................................... 59

Table 3.5 Summary of weights, feed intake, and feed conversion...................... 65

Table 4.1 Summary of weights, and feed intake ........................................... 95

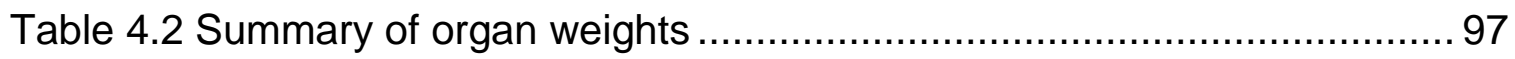

Table 4.3 Summary of DXA variables by sex and treatment ........................... 98

Table 4.4 Relative abundance at the taxonomic level of phyla in female rats .. 108

Table 4.5 Relative abundance at the taxonomic level of phyla in male rats ..... 109

Table 4.6 Relative abundance at the taxonomic level of OTU that were altered by high dietary taurine in the female rats ........................................... 110

Table 4.7 Relative abundance at the taxonomic level of OTU that were altered by high dietary taurine in the male rats.

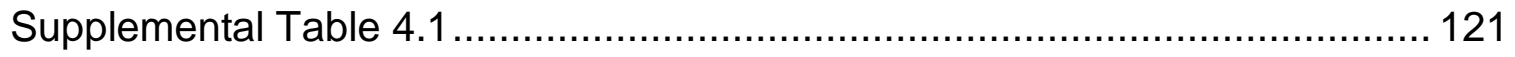

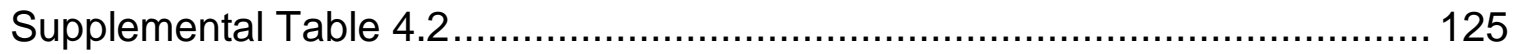

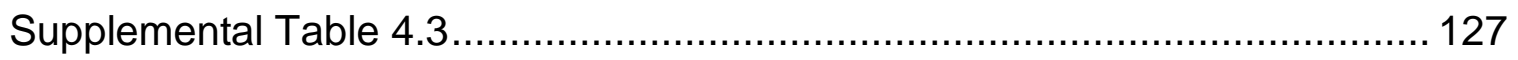

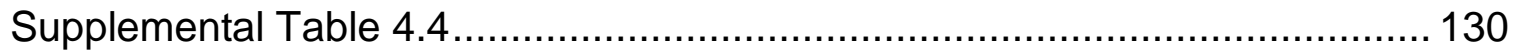

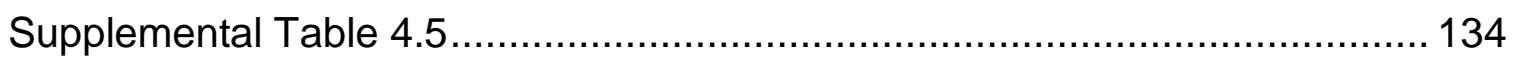


Table 5.1 Feline purified diet

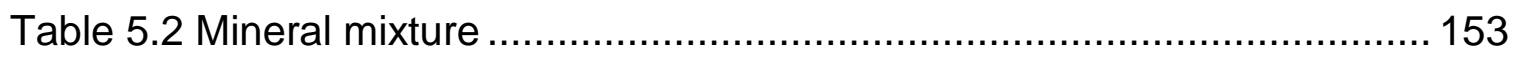

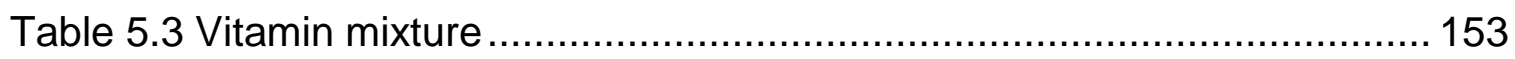

Table 5.4 Proximate and taurine analysis of the control (low taurine diet) ....... 154

Table 5.3 Summary of food intake, metabolizable energy, and weight over the duration of the study ........................................................................ 158

Table 5.4 Thyroid hormone concentrations of morning fasted samples .......... 160

Table 5.5 Circulating serum IGF-1 concentration ...................................... 161

RIA Validation Appendix Table 1 Serial dilution of feline serum samples expected concentrations

RIA Validation Appendix Table 2 Serial dilution of pooled feline serum samples measured T4 concentrations 201

RIA Validation Appendix Table 3 Serial dilution of pooled feline serum samples measured T3 concentrations.

RIA Validation Appendix Table 4 Serial dilution of pooled feline serum samples measured T4 concentrations 203

RIA Validation Appendix Table 5 Serial dilution of pooled feline serum samples measured T3 concentrations

RIA Validation Appendix Table 6 Comparison of T3 concentrations measured by RIA 205

RIA Validation Appendix Table 7 T3 concentration measured after resin purrification 206 


\section{CHAPTER 1}

\section{Brief Overview}

Hyperthyroidism, also referred to as thyrotoxicosis, is a spontaneous

disease affecting both humans and domestic cats. The disease, characterized by an abnormal elevation of circulating concentrations of one or more thyroid hormones (Broussard et al. 1995; Peterson et al. 2001), has become one of the most commonly diagnosed endocrine disorders in middle and senior age cats (Broussard et al. 1995; Kohler et al. 2016; Mooney 2012; Peterson 2012; Thoday and Mooney 1992). It is estimated over $10 \%$ of cats in the US over age 10 will be diagnosed with the disease (Peterson 2012).

Feline hyperthyroidism is clinically and pathologically similar to toxic nodular goiter or Plummer's disease (Peterson 2014; Wakeling et al. 2007), one of the most common types of hyperthyroidism in humans (Vanderpump 2011). It has been suggested that domestic cats could be a spontaneous animal model of toxic nodular goiter due to the high incidence of feline hyperthyroidism and the long subclinical state caused by the development of small automatous thyroid nodes that gradually increase (Peterson 2014; Wakeling et al. 2007).

Diagnosing subclinical disease is challenging in cats as the commercially available thyroid stimulating hormone (TSH) assay currently used is canine specific (Rayalam et al. 2006) rather than feline specific. Because the homology of feline TSH is $96 \%$ identical to that of canine TSH (Rayalam et al. 2006), the first-generation commercial assay can be used to measure feline TSH; however, the low sensitivity limits the ability to distinguish TSH concentrations of euthyroid 
and subclinical hyperthyroid cats. Furthermore, the circulating total thyroxine (T4) and triiodothyronine (T3) serum concentrations during the subclinical state are within the reference intervals for euthyroid cats (Wakeling et al. 2007).

Once the disease progresses to overt hyperthyroidism, feline TSH concentrations remain at or below the detection limits of currently utilized canine TSH assays (Peterson 2014; Wakeling et al. 2007) while the circulating serum T4 and, in some cats, T3 concentrations are elevated (Broussard et al. 1995; Peterson et al. 2001). In human toxic multinodular goiter patients, the clinical thyroid progression from subclinical to overt hyperthyroidism is nearly identical including other clinical signs such as hyperphagia and weight loss (Kravets 2016; Mooney 2012). Fortunately, a third-generation TSH assay is available that allows differentiation between euthyroid and subclinically affected patients (Peterson 2014).

The histopathology of thyroid glands from both human toxic multinodular goiter patients and feline hyperthyroid patients reveal automatous single or multiple hyperplastic or adenomatous nodules ranging from $<1 \mathrm{~mm}$ to $3 \mathrm{~cm}$ (Hoenig et al. 1982; Peterson 2014). The majority of these nodules are benign, with approximately $2 \%$ advancing into follicular, papillary, or mixed thyroid carcinoma in feline patients (Hibbert et al. 2009; Turrel et al. 1988), and up to $9 \%$ developing into thyroid cancer in human patients (Cerci et al. 2007). These benign nodules are in a hypersecretory state as evidenced by periodic acid Schiff (PAS) stains showing reduced storage of thyroglobulin, the precursor of thyroid hormones (Peter et al. 1987; Peter et al. 1991; Peterson 2014). 
Identification of risk factors and the etiopathogenesis have been sought after mainly through the use of epidemiological studies. lodine deficiency is the best studied human risk factor for toxic nodular goiter (Krohn et al. 2005d), yet thyroid nodules still occur in iodine replete areas (Vanderpump 2011). Other factors have been proposed or identified through cross-sectional epidemiological studies (Edinboro et al. 2004; Kass et al. 1999; Martin et al. 2000; van Hoek et al. 2015; Vanderpas 2006), however they have been minimally investigated in prospective studies. In felines, both nutritional and thyroid-disrupting compounds in the environment have been suggested as risk factors (Peterson 2012; van Hoek et al. 2015).

The proposed risk factors for feline hyperthyroidism rely upon the assumption that the pathogenesis is due to chronic thyroid overstimulation that results in hypertrophy followed by hyperplasia of thyroid follicular cells (Peterson 2012; van Hoek et al. 2015). This mechanism has never been investigated in felines, but is a reasonable hypothesis since most cases of hyperthyroidism are bilateral and the follicular tissue has altered expression of $G$ proteins in both thyroid glands (Hammer et al. 2000; Ward et al. 2005).

The proposed nutritional risk factors are largely untested in prospective feline studies. Rather dietary constituents such as isoflavones, selenium, and iodine are routinely hypothesized to contribute to the pathogenesis of feline hyperthyroidism because they are known to affect thyroid hormones in felines or other species (Doerge and Sheehan 2002; Tarttelin et al. 1992; van Hoek et al. 2015; White et al. 2004; Yu et al. 2002). Additionally, it is attributed that the 
highly variable concentrations within commercial cat food could be the inciting factor (Edinboro et al. 2013). These particular nutrients, and the amino acid taurine, which I propose may also contribute to the pathogenesis, are found at high concentrations within canned commercial feline diets. It is important to recognize that the consumption of canned cat food, regardless of the ingredients, has been the only consistently identified nutritional risk factor in all epidemiological studies conducted to date in the US (Edinboro et al. 2004; Kass et al. 1999; Martin et al. 2000; Scarlett et al. 1988). While these studies do not cite specific ingredients as risk factors, two of the epidemiological studies did find that pop-top cans (Edinboro et al. 2004) and fish- and liver and giblets-flavored canned food further increase the risk of developing the disease (Martin et al. 2000).

The purpose of this work was two-fold. The first was to investigate whether the proposed dietary risk factor, selenium, and two nutrients found in high levels within canned diets, water (moisture) and taurine, cause an overstimulation of the thyroid gland and alter the function of the hypothalamicpituitary-thyroid axis. The second purpose was to determine if cats are a better animal model than rats when investigating dietary causes of hyperthyroidism. 


\section{References}

Broussard JD, Peterson ME, Fox PR (1995) Changes in clinical and laboratory findings in cats with hyperthyroidism from 1983 to 1993 Journal of the American Veterinary Medical Association 206:302-305

Cerci C, Cerci SS, Eroglu E, Dede M, Kapucuoglu N, Yildiz M, Bulbul M (2007) Thyroid cancer in toxic and non-toxic multinodular goiter J Postgrad Med $53: 157-160$

Doerge DR, Sheehan DM (2002) Goitrogenic and estrogenic activity of soy isoflavones Environmental health perspectives 110:349-353

Edinboro CH, Pearce EN, Pino S, Braverman LE (2013) lodine concentration in commercial cat foods from three regions of the USA, 2008-2009 J Feline Med Surg 15:717-724 doi:10.1177/1098612X13477855

Edinboro CH, Scott-Moncrieff JC, Janovitz E, Thacker HL, Glickman LT (2004) Epidemiologic study of relationships between consumption of commercial canned food and risk of hyperthyroidism in cats Journal of the American Veterinary Medical Association 224:879-886 doi:10.2460/javma.2004.224.879

Hammer KB, Holt DE, Ward CR (2000) Altered expression of G proteins in thyroid gland adenomas obtained from hyperthyroid cats American journal of veterinary research $61: 874-879$

Hibbert A, Gruffydd-Jones T, Barrett EL, Day MJ, Harvey AM (2009) Feline thyroid carcinoma: diagnosis and response to high-dose radioactive iodine treatment J Feline Med Surg 11:116-124 doi:10.1016/j.jfms.2008.02.010 
Hoenig M, Goldschmidt MH, Ferguson DC, Koch K, Eymontt MJ (1982) Toxic nodular goitre in the cat The Journal of small animal practice 23:1-12 Kass PH, Peterson ME, Levy J, James K, Becker DV, Cowgill LD (1999) Evaluation of environmental, nutritional, and host factors in cats with hyperthyroidism Journal of veterinary internal medicine / American College of Veterinary Internal Medicine 13:323-329

Kohler I, Ballhausen BD, Stockhaus C, Hartmann K, Wehner A (2016) Prevalence of and risk factors for feline hyperthyroidism among a clinic population in Southern Germany Tierarztl Prax Ausg K Kleintiere Heimtiere 44 doi:10.15654/TPK-150590

Kravets I (2016) Hyperthyroidism: Diagnosis and Treatment Am Fam Physician 93:363-370

Krohn K, Führer D, Bayer Y, Eszlinger M, Brauer V, Neumann S, Paschke R (2005) Molecular Pathogenesis of Euthyroid and Toxic Multinodular Goiter Endocrine reviews 26:504-524 doi:10.1210/er.2004-0005

Martin KM, Rossing MA, Ryland LM, DiGiacomo RF, Freitag WA (2000) Evaluation of dietary and environmental risk factors for hyperthyroidism in cats Journal of the American Veterinary Medical Association 217:853-856 Mooney CT, Peterson M (2012) Feline Hyperthyroidism. In: Peterson M, Mooney CT (ed) Manual of Canine and Feline Endocrinology. 4th edn. British Small Animal Veterinary Association, Quedgeley, Gloucester, UK, pp 199203 
Peter HJ, Gerber H, Studer H, Becker DV, Peterson ME (1987) Autonomy of growth and of iodine metabolism in hyperthyroid feline goiters transplanted onto nude mice The Journal of clinical investigation 80:491-498 doi:10.1172/JCl113097

Peter HJ, Gerber H, Studer H, Peterson ME, Becker DV, Groscurth P (1991) Autonomous growth and function of cultured thyroid follicles from cats with spontaneous hyperthyroidism Thyroid : official journal of the American Thyroid Association 1:331-338 doi:10.1089/thy.1991.1.331

Peterson M (2012) Hyperthyroidism in cats: what's causing this epidemic of thyroid disease and can we prevent it? J Feline Med Surg 14:804-818 doi:10.1177/1098612X12464462

Peterson ME (2014) Animal models of disease: feline hyperthyroidism: an animal model for toxic nodular goiter The Journal of endocrinology 223:T97-114 doi:10.1530/JOE-14-0461

Peterson ME, Melian C, Nichols R (2001) Measurement of serum concentrations of free thyroxine, total thyroxine, and total triiodothyronine in cats with hyperthyroidism and cats with nonthyroidal disease Journal of the American Veterinary Medical Association 218:529-536

Rayalam S, Eizenstat LD, Hoenig M, Ferguson DC (2006) Cloning and sequencing of feline thyrotropin (fTSH): heterodimeric and yoked constructs Domestic animal endocrinology 30:203-217 doi:10.1016/j.domaniend.2005.07.002 
Scarlett JM, Moise NS, Rayl J (1988) Feline hyperthyroidism: A descriptive and case-control study Preventive veterinary medicine 6:295-309

Tarttelin MF, Johnson LA, Cooke RR, Ford HC, Feek CM (1992) Serum free thyroxine levels respond inversely to changes in levels of dietary iodine in the domestic cat New Zealand veterinary journal 40:66-68

doi:10.1080/00480169.1992.35700

Thoday K, Mooney C (1992) Historical, clinical and laboratory features of 126 hyperthyroid cats The Veterinary record 131:257-264

Turrel JM, Feldman EC, Nelson RW, Cain GR (1988) Thyroid carcinoma causing hyperthyroidism in cats: 14 cases (1981-1986) Journal of the American Veterinary Medical Association 193:359-364

van Hoek I, Hesta M, Biourge V (2015) A critical review of food-associated factors proposed in the etiology of feline hyperthyroidism J Feline Med Surg 17:837-847 doi:10.1177/1098612X14556558

Vanderpas J (2006) Nutritional epidemiology and thyroid hormone metabolism Annual review of nutrition 26:293-322 doi:10.1146/annurev.nutr.26.010506.103810

Vanderpump MPJ (2011) The epidemiology of thyroid disease British medical bulletin 99:39-51 doi:10.1093/bmb/ldr030

Wakeling J, Smith K, Scase T, Kirkby R, Elliott J, Syme H (2007) Subclinical hyperthyroidism in cats: a spontaneous model of subclinical toxic nodular goiter in humans? Thyroid : official journal of the American Thyroid Association 17:1201-1209 doi:10.1089/thy.2007.0225 
Ward CR, Achenbach SE, Peterson ME, Drobatz KJ, Holt D (2005) Expression of inhibitory G proteins in adenomatous thyroid glands obtained from hyperthyroid cats American journal of veterinary research 66:1478-1482

White HL, Freeman LM, Mahony O, Graham PA, Hao Q, Court MH (2004) Effect of dietary soy on serum thyroid hormone concentrations in healthy adult cats American journal of veterinary research 65:586-591

Yu S, Howard KA, Wedekind KJ, Morris JG, Rogers QR (2002) A low-selenium diet increases thyroxine and decreases 3,5,3'triiodothyronine in the plasma of kittens Journal of Animal Physiology and Animal Nutrition 86:36-41 doi:10.1046/j.1439-0396.2002.00338.x 


\title{
CHAPTER 2
}

\section{Effects of dietary selenium and moisture on the physical activity and thyroid axis of cats}

This chapter has been accepted for publication in the Journal of Animal

Physiology and Animal Nutrition

\author{
Sarah E. Hooper ${ }^{1}$, Robert Backus², Sybill Amelon ${ }^{3}$ \\ 1Department of Veterinary Pathobiology, College of Veterinary Medicine, \\ University of Missouri, Columbia, Missouri, USA \\ ${ }^{2}$ Department of Veterinary Medicine and Surgery, College of Veterinary Medicine, \\ University of Missouri, Columbia, Missouri, USA \\ ${ }^{3}$ USDA Forest Service, Northern Research Station, Columbia, Missouri, USA
}




\section{Abstract}

Consumption of canned cat food is considered a risk factor for the development of feline hyperthyroidism. Because selenium and water are substantially higher in canned diets compared to dry diets, objectives of this study were to determine if increased dietary selenium or water alter the function of the hypothalamic-pituitary-thyroid axis and lead to an increase in activity level. Employing a 28-day Latin Square design with a 14-day washout, 6 lean, neutered male domestic shorthair cats were fed 1) commercially available adult dry feline diet containing $0.8 \mathrm{ppm}$ selenium (control), 2) control diet with added sodium selenite to achieve a dietary selenium concentration of $1.125 \mathrm{ppm}$ (selenium treatment), and 3) the control diet with additional water to achieve a moisture content of $75 \% \mathrm{wt} / \mathrm{wt}$ (water treatment). Water consumption was determined using deuterium oxide washout. Actical activity monitors were placed on each cat's collar to allow quantification of the activity of each cat. Circulating serum T3 and T4, were measured on day 0,14 , and 28 . On day 28 , a thyrotropin releasing hormone $(\mathrm{TRH})$ stimulation test was conducted to determine treatment effects on serum concentrations of thyroid hormones. There was a significant increase in daily water consumption with dietary water treatment $(192 \mathrm{~mL} \pm 7.9$ SEM) compared to the control $(120 \mathrm{~mL} \pm 20.4)$ and selenium $(116 \mathrm{~mL} \pm 14.6)$ treatments. Both water and selenium treatments were associated with greater $(p<0.05)$ activity over that of the control treatment by $20.5 \%$ and $11 \%$ respectively. Serum TT3 AUC concentrations ( 0 to $4 \mathrm{hr}$ ) of TRH stimulation tests were greater $(p<0.05)$ by $16 \%$ with water compared to control treatments. The results of this study indicate that dietary water content may alter the function of 
the thyroid axis and that this effect is associated with an increase in physical activity.

\section{Introduction}

Hyperthyroidism is a condition observed in domestic cats defined by the abnormal elevation of circulating concentrations of one or more thyroid hormones. The elevation of circulating thyroxine (T4), the thyroid hormone most commonly elevated, occurs from hyperfunctioning single or multiple hyperplastic nodules in the feline thyroid gland that autonomously proliferate (Gerber et al. 1994; Peterson et al. 1987). Since the first case report of spontaneously occurring hyperthyroidism in cats in 1979 (Peterson et al. 1979), the prevalence of feline hyperthyroidism has skyrocketed (Edinboro et al. 2004; Scarlett et al. 1988). Hyperthyroidism is now considered the most common feline endocrine disorder in the USA (Mooney 2012; Peterson 2012) with an estimated $10 \%$ of cats over 10 years old are diagnosed with the disease (Peterson 2012). Beyond the USA, feline hyperthyroidism is present world-wide with varying prevalence rates, ranging from $0.1 \%$ to $20.14 \%$ (Gójska-Zygner et al. 2014; Kohler et al. 2016), depending on the inclusion criteria for the study.

Many epidemiological studies have been undertaken in attempts to determine the etiopathogenesis and risk factors associated with feline hyperthyroidism. These studies have not identified a cause or a single risk factor. The veterinary community currently believes that the etiopathogenesis is likely multifactorial, with the risk factors being classified under two main categories: 1) nutritional and 2) thyroid-disrupting compounds in the environment (Peterson 2012; van Hoek et al. 2015). 
Epidemiological studies conducted in the US have consistently identified consumption of canned commercial cat food to be a significant risk factor for development of feline hyperthyroidism (Edinboro et al. 2004; Kass et al. 1999; Martin et al. 2000; Scarlett et al. 1988). Some studies have found increasing risk if the canned food was in a pop-top can (Edinboro et al. 2004), and increasing if the flavor was fish or liver and giblets (Martin et al. 2000). The consumption of canned cat food has also been identified world-wide as a risk factor for feline hyperthyroidism (Gójska-Zygner et al. 2014; Kohler et al. 2016; Olczak et al. 2005; Wakeling et al. 2009). However, a single study conducted in Hong Kong did not report canned food as a significant risk factor. The sample size of this study was limited to 12 hyperthyroid cats (De Wet et al. 2009). With a lack of prospective studies, there have only been suggested hypotheses as to why the consumption of canned cat food is linked to an increase risk of hyperthyroidism. Isoflavones, selenium, and iodine are known to be incorporated into feline canned diets at highly variable concentrations (Court and Freeman 2002; Johnson et al. 1992; Simcock et al. 2005). These three dietary constituents are routinely hypothesized to contribute to the pathogenesis of feline hyperthyroidism (van Hoek et al. 2015). Simcock et al. (2005) reported canned cat food contains significantly higher concentrations of selenium than dry cat diets, with "seafood" and "chicken and seafood" flavored diets consistently containing the highest selenium concentrations. This association is of particular interest since consumption of fish, liver, and giblets-flavored canned cat food further increases risk of hyperthyroidism (Martin et al. 2000). Dietary selenium content has been 
shown to influence the conversion of T4 to triiodothyronine (T3) through the selenoenzymes, iodothyronine deiodinase types I, II, and III (Wedekind et al. 2003). It is unknown whether selenium directly alters the function of the hypothalamic-pituitary-thyroid axis.

Most domestic pet cats are maintained on dry-expanded diets, canned diets, or a combination of both diets. It is unknown if the high dietary moisture content of canned diets alters the production, secretion, or metabolism of thyroid hormones. Water, as a nutrient, is often overlooked in research studies (Sawka et al. 2005), however water intake can have profound impacts on a variety of physiological processes including metabolism (Boschmann et al. 2003). Deng et al. (2014) demonstrated that a diet with $70 \%$ moisture content increased the activity of cats when compared to a diet with a moisture content of $8 \% \mathrm{w} / \mathrm{w}$. The mechanism of this increased activity has not been determined, but perhaps the increased dietary water consumption altered the production of thyroid hormones resulting in the observed increase in activity level. Increased activity, or hyperactivity, is clinically observed in cats with hyperthyroidism (Thoday and Mooney 1992) which is also observed in rats rendered hyperthyroid through administration of T3. However the mechanism as to how thyroid hormones increase spontaneous physical activity is unknown (Levine et al. 2003).

The present study sought to determine whether the dietary nutrients, selenium and water, alter the function of the hypothalamic-pituitary-thyroid axis. Encompassing this objective were three hypothesis. The first hypothesis was that a diet high in selenium would result in an increase in T3 production by the thyroid 
gland, and that this production would be revealed by a thyrotropin release hormone (TRH) stimulation test. The second hypothesis was that the moisture content of a typical feline canned diet $(\sim 75 \% \mathrm{w} / \mathrm{w})$ would alter the function of the hypothalamic-pituitary-thyroid axis and cause an increase in T4 production. The third hypothesis was that the increase secretion of thyroid hormones from the dietary treatments would result in a significant increase in physical activity.

\section{Materials and Methods}

All procedures performed were approved by the University of Missouri Animal Care and Use Committee in accordance with the Guide for the Care and Use of Laboratory Animals (Institute for Laboratory Animal Research 2011), Public Health Service policy (Public Health Service 2015), and the Animal Welfare Act and Regulations (United States Department of Agriculture 2013).

Animals: Six, adult (3-5 yr), lean (16-25\% body fat [w/w] based upon deuterium oxide body composition and a BCS of 4-5/9), purpose bred, neutered male, domestic short-haired cats were deemed healthy on physical exam, complete blood cell count, and serum clinical biochemistry (University of Missouri Veterinary Diagnostic Laboratory, Columbia, MO, USA) findings. All cats had ad lib access to water and were socially housed in a room $(3.2 \times 4.8 \mathrm{~m})$ with free access to four adjacent cubicles $(1.1 \times 1.6 \times 2.4 \mathrm{~m})$. Two cats were individually housed in stainless steel cages $(0.9 \times 0.7 \times 1.2 \mathrm{~m})$ and four cats were individually housed in cubicles during food presentation. All cats were consistently housed in the same cubicle or cage during food presentation.

Diets: A commercially available feline adult maintenance dry-expanded diet (Purina Pro Plan Urinary Tract Health Formula, Nestlé Purina PetCare 
Company, Saint Louise, MO, USA) that was nutritionally complete and balanced as substantiated from passage of feeding trials as described by American Association of Feed Control Officials (AAFCO) served as the base and control diet (Table 2.1). Reverse osmosis water which did not contain substantive amounts of selenium or iodine was continuously provided. The base/control diet contained selenium at $0.8 \mathrm{ppm}$ and $10 \%$ moisture. There were two dietary nutrient variables, selenium and water. The increased-selenium content diet of $1.25 \mathrm{ppm}$ selenium was made by top-dressing the base diet with sodium selenite (Dyets Inc, Bethlehem, PA, USA) dispersed in dyetrose (Dyets Inc, Bethlehem, PA, USA) to ensure even distribution and coating of the kibble during batch mixing. The increased-moisture content diet of $75 \%(\mathrm{w} / \mathrm{w})$ water was achieved by adding water purified by reverse osmosis to the base diet the evening before presentation. The food remained covered and refrigerated $\left(4^{\circ} \mathrm{C}\right)$ overnight to allow the kibble to absorb the water. Selenium contents of the diets were determined by the South Dakota Agricultural Laboratories (Brookings, SD, USA) and proximate analysis of the diets was completed at the University of MissouriColumbia Agricultural Experiment Station Chemical Laboratories (Columbia, MO, USA). lodine contents of the diets were determined by neutron activation analysis (Spate et al. 1995) by the University of Missouri-Columbia Research Reactor Center (Columbia, MO, USA). 


\section{Table 2.1 Proximate analysis and select nutrients of the control diet}

\begin{tabular}{ll}
\hline Nutrient & Amount \\
\hline Crude protein $\mathrm{g} / 100 \mathrm{~g}$ & 31 \\
Crude fat $\mathrm{g} / 100 \mathrm{~g}$ & 14 \\
Crude fiber $\mathrm{g} / 100 \mathrm{~g}$ & 2 \\
Moisture $\mathrm{g} / 100 \mathrm{~g}$ & 10 \\
Ash g/100 g & 6.2 \\
Selenium ppm & 0.857 \\
lodine ppm $\dagger$ & 2.27 \\
\hline
\end{tabular}

Ingredients: Corn gluten meal, chicken, wheat flour, brewers rice, ground yellow corn, animal fat preserved with mixed-tocopherols (form of Vitamin E), egg product, sodium caseinate, phosphoric acid, calcium carbonate, potassium chloride, animal digest, salt, L-Lysine monohydrochloride, dried whey, choline chloride, dicalcium phosophate, taurine, zinc sulfate, ferrous sulfate, manganese sulfate, Vitamin E supplement, niacin, citric acid, Vitamin A supplement, calcium pantothenate, thiamine mononitrate, copper sulfate, riboflavin supplement, Vitamin B-12 supplement, pyridoxine hydrochloride, folic acid, Vitamin D-3 supplement, calcium iodate, biotin, menadione sodium bisulfite complex (source of Vitamin $\mathrm{K}$ activity), and sodium selenite *As determined by the South Dakota Agricultural Laboratories Agricultural Experiment Station Chemical Lab, on a dry matter basis. †As determined by the University of Missouri-Columbia Research Reactor Center, on dry matter basis.

Study design: Using a Latin Square design, each cat was randomly assigned to one of three dietary treatments, 1$)$ control ( $0.8 \mathrm{ppm}$ selenium, $10 \%$ moisture), 2) high selenium (1.25 ppm, $10 \%$ moisture), or 3 ) high moisture (0.8 pm, $75 \%$ moisture). Diet-presentation blocks were 28 days in duration. Following 
each block were 14 day washout periods during which cats were presented with the base diet. Cats were presented daily an allotted amount of diet in order to maintain a stable weight and an ideal body condition score of 5/9 (Laflamme 1997). The dry matter amount of diet offered to each cat was not changed during the study and dietary intake was recorded daily. Cats were weighed weekly. Jugular venous blood was collected on day 0,14 , and 28 of each dietary block. Blood was allowed to clot at room temperature for 1 hour prior to centrifugation at $1200 \mathrm{xg}$ for $10 \mathrm{~min}$. Extracted serum was stored in $1 \mathrm{~mL}$ aliquots at $-20^{\circ} \mathrm{C}$ until analyses.

Thyroid Releasing Hormone (TRH) Stimulation Tests: On day 28 of each diet block, a thyrotropin releasing hormone $(\mathrm{TRH})$ stimulation test was conducted using previously described methods (Peterson et al. 1994; Sparkes et al. 1991). Briefly, jugular venous blood was collected prior to each cat intravenously receiving $0.1 \mathrm{mg} / \mathrm{kg}$ Proteirelin (TRH) (Wedgewood Pharmacy, Swedesboro, NJ, USA) (time 0). Jugular venous blood was thereafter collected at $0.5,1,2$, and 4 hours post-TRH injection. Blood was kept on ice for up to 2.5 hours before being centrifuged at $1200 \mathrm{xg}$ for $10 \mathrm{~min}$ to extract serum, which was stored at $-20^{\circ} \mathrm{C}$ until analyses of thyroid hormones.

Activity Monitoring: Three weeks prior to the start of the study, all cats were habituated to wearing collars to which was attached an accelerometer (Actical Activity Monitoring Devices, Mini Mitter, Bend, OR, USA). The accelerometer devices were previously validated for use in measuring the physical activity of cats (Lascelles et al. 2008). Motion was registered as an 
activity count, a unit-less measure. Activity counts were continuously logged at 15 second intervals throughout each diet block on days 1 through 27. Each cat wore the same Actical unit for the duration of the study. Sums of activity counts per day was determined for each cat for each block with and without periods of human interaction. A period of human interaction was defined as when any husbandry staff or laboratory staff entered the housing room which was tracked by key card access and a room door sign-in sheet.

Thyroid hormone and selenium analysis: Serum samples were sent overnight on dry ice to Michigan State University's Diagnostic Center for Population and Animal Health (DCPAH) for measurements of total T4 (TT4), and total T3 (TT3) on day 0 and 14; and TT4, TT3, TSH, free T4 (fT4), and free T3 (fT3) on day 28. Day 0 and 28 serum samples were sent on dry ice to South Dakota Agricultural Laboratories (Brookings, SD, USA) for selenium analysis.

Water consumption: Water consumption was estimated using the deuterium oxide (D2O) washout method (Lifson and McClintock 1966). Body composition was determined as previously described (Backus et al. 2010). Briefly, on day 0 of each block, jugular venous blood was collected and subsequently cats received $0.7 \mathrm{~g} / \mathrm{kg}$ of sterile filtered, salinated $(9 \mathrm{~g} / \mathrm{L}$ sodium chloride), D2O (99.8\% Sigma-Aldrich, St. Louis, USA) subcutaneously. Jugular venous blood was collected 4-6 hours after injection of the D2O for determination of D2O enrichment in serum after equilibration. Jugular venous blood was collected again on day 14 and 28. Aliquots of serum were stored in $1.5 \mathrm{~mL}$ microcentrifuge screw top tubes (USA Scientific, Ocala, FL, USA) at $-20^{\circ} \mathrm{C}$ until 
analysis. In duplicate, deuterium oxide enrichment was determined in water distilled from serum using Fourier Transform infrared spectrophotometry (Jennings et al. 1999). A first-order wash-out curve was assumed to correctly model rate of water turnover of the cats. Water consumption during each block in milliliters per day was determined from the fractional change in D2O enrichment during blocks and from body water mass estimated from D2O dilution on day 1 of blocks. Body lean mass of cats was assumed to equal body water mass divided by 0.732 , the fractional moisture mass of lean tissue reported applicable to many species. Body fat mass was assumed to equal body weight minus body lean mass.

Statistical Analyses: We used SAS 9.3 software package (SAS Institute Inc., Cary, NC, USA) to perform all statistical analysis and significance was calculated at alpha $=0.05$. All outcome variables were determined to be normally distributed, except for the activity data which was transformed through log10. The Proc GLM procedure and differences of the least square means was used to compare the variables of interest: TT4, TT3, TSH, fT4, fT3, activity counts, water consumption, diet consumption, body weight, and cat and the interactions of cat $^{\star}$ dietary treatment, dietary treatment*block, dietary treatment ${ }^{\star}$ lock $^{\star}$ time.

\section{Results}

The dietary treatments did not significantly $(p>0.05)$ alter the amount of diet consumed or weights throughout the study (Table 2.2). When the cats were given the high moisture diet, their total water consumption was significantly increased $(p<0.001)$ by a mean of $72.6 \mathrm{~mL}$ per day compared to the control diet. One cat consumed more water than the other cats $(p<0.01)$ when they were on 
the high selenium and control diets (Figure 2.1). When data from this cat was excluded from analyses, the mean water consumption among the other cats was greater $(p<0.001)$ by a mean of $86.2 \mathrm{~mL}$ per day when they were when given the high moisture diet compared to when they were given the control diet. A urinalysis and serum chemistry analysis were repeated for the cat with extraordinary water consumption. Serum creatinine and urea nitrogen concentrations were within the reference interval of the clinical laboratory. Results of the urinalysis revealed a low urine osmolality with no bacteria or crystals observed in sediment. It is possible the cat with extraordinary water consumption was in a very early stage of chronic renal failure. Nevertheless, observations from this cat were included in all statistical analyses as removing his data did not change the outcomes of the study.

Throughout each dietary block, serum selenium concentrations were highly variable within each cat. The mean serum selenium concentration did not significantly increase $(p=0.98)$ when the cats were on the selenium-added dietary treatment (Table 2.3). The TT4 and TT3 serum concentrations of the cats were not significantly different $(p>0.05)$ between any of the dietary treatments on any of the sampling days during the treatment blocks (days 0,14 , and 28 ) (Table 2.3). 
Table 2.2 Feed intake, weight, and percent weight change over each dietary treatment block

\begin{tabular}{lccccccc}
\hline $\begin{array}{c}\text { Dietary } \\
\text { Treatment }\end{array}$ & $\begin{array}{c}\text { Dietary } \\
\text { Moisture } \\
(\% \mathrm{w} / \mathrm{w})\end{array}$ & $\begin{array}{c}\text { Dietary } \\
\text { Se } \\
(\mathrm{ppm})^{*}\end{array}$ & $\begin{array}{c}\text { Food } \\
\text { Intake } \\
(\mathrm{g} \mathrm{DM} / \mathrm{day})\end{array}$ & $\begin{array}{c}\text { Metabolizable } \\
\text { energy } \\
(\mathrm{kcal} / \mathrm{day})\end{array}$ & $\begin{array}{c}\text { Weight } \\
\text { Day 0 } \\
(\mathrm{kg})\end{array}$ & $\begin{array}{c}\text { Weight } \\
\text { Day 28 } \\
(\mathrm{kg})\end{array}$ & $\begin{array}{c}\text { Weight } \\
\text { change } \\
(\%)\end{array}$ \\
\hline Control & 10 & 0.8 & $52 \pm 3.1$ & $87 \pm 5.1$ & $4.7 \pm 0.23$ & $4.7 \pm 0.28$ & $-0.02 \pm 0.03$ \\
Selenium & 10 & 1.25 & $52 \pm 3.0$ & $87 \pm 5.0$ & $4.7 \pm 0.35$ & $4.8 \pm 0.24$ & $0.01 \pm 0.04$ \\
Moisture & 75 & 0.8 & $52 \pm 3.2$ & $86 \pm 5.3$ & $4.8 \pm 0.20$ & $4.7 \pm 0.27$ & $-0.02 \pm 0.02$
\end{tabular}

*Provided as sodium selenite on a per dry matter basis.

$\approx$ Table 2.3 Serum Se, TT4, and TT3 over the duration of each dietary treatment block

\begin{tabular}{ccccccccc}
\hline $\begin{array}{c}\text { Dietary } \\
\text { Treatment }\end{array}$ & $\begin{array}{c}\text { Serum Se } \\
\text { Day 0 } \\
(\mu \mathrm{mol} / \mathrm{L})\end{array}$ & $\begin{array}{c}\text { Serum Se } \\
\text { Day 28 } \\
(\mu \mathrm{mol} / \mathrm{L})\end{array}$ & $\begin{array}{c}\text { Serum TT4 } \\
\text { Day 0 } \\
(\mathrm{nmol} / \mathrm{L})\end{array}$ & $\begin{array}{c}\text { Serum TT4 } \\
\text { Day 14 } \\
(\mathrm{nmol} / \mathrm{L})\end{array}$ & $\begin{array}{c}\text { Serum } \\
\text { TT Day } \\
(\mathrm{nmol} / \mathrm{L})\end{array}$ & $\begin{array}{c}\text { Serum TT3 } \\
\text { Day 0 } \\
(\mathrm{nmol} / \mathrm{L})\end{array}$ & $\begin{array}{c}\text { Serum TT3 } \\
\text { Day 14 } \\
(\mathrm{nmol} / \mathrm{L})\end{array}$ & $\begin{array}{c}\text { Serum TT3 } \\
\text { Day 28 } \\
(\mathrm{nmol} / \mathrm{L})\end{array}$ \\
\hline Control & $6.6 \pm 1.3$ & $6.3 \pm 0.93$ & $18 \pm 4.9$ & $16 \pm 4.5$ & $20 \pm 5.0$ & $0.83 \pm 0.39$ & $0.73 \pm 0.12$ & $0.70 \pm 0.09$ \\
Selenium & $6.6 \pm 0.73$ & $6.8 \pm 0.75$ & $18 \pm 3.8$ & $17 \pm 1.9$ & $17 \pm 2.1$ & $0.72 \pm 0.14$ & $0.75 \pm 0.18$ & $0.63 \pm 0.05$ \\
Moisture & $6.6 \pm 0.71$ & $7.1 \pm 0.93$ & $17 \pm 4.4$ & $16 \pm 3.9$ & $18 \pm 3.0$ & $0.67 \pm 0.12$ & $0.73 \pm 0.10$ & $0.73 \pm 0.14$ \\
\hline
\end{tabular}


Figure 2.1 Daily water consumption

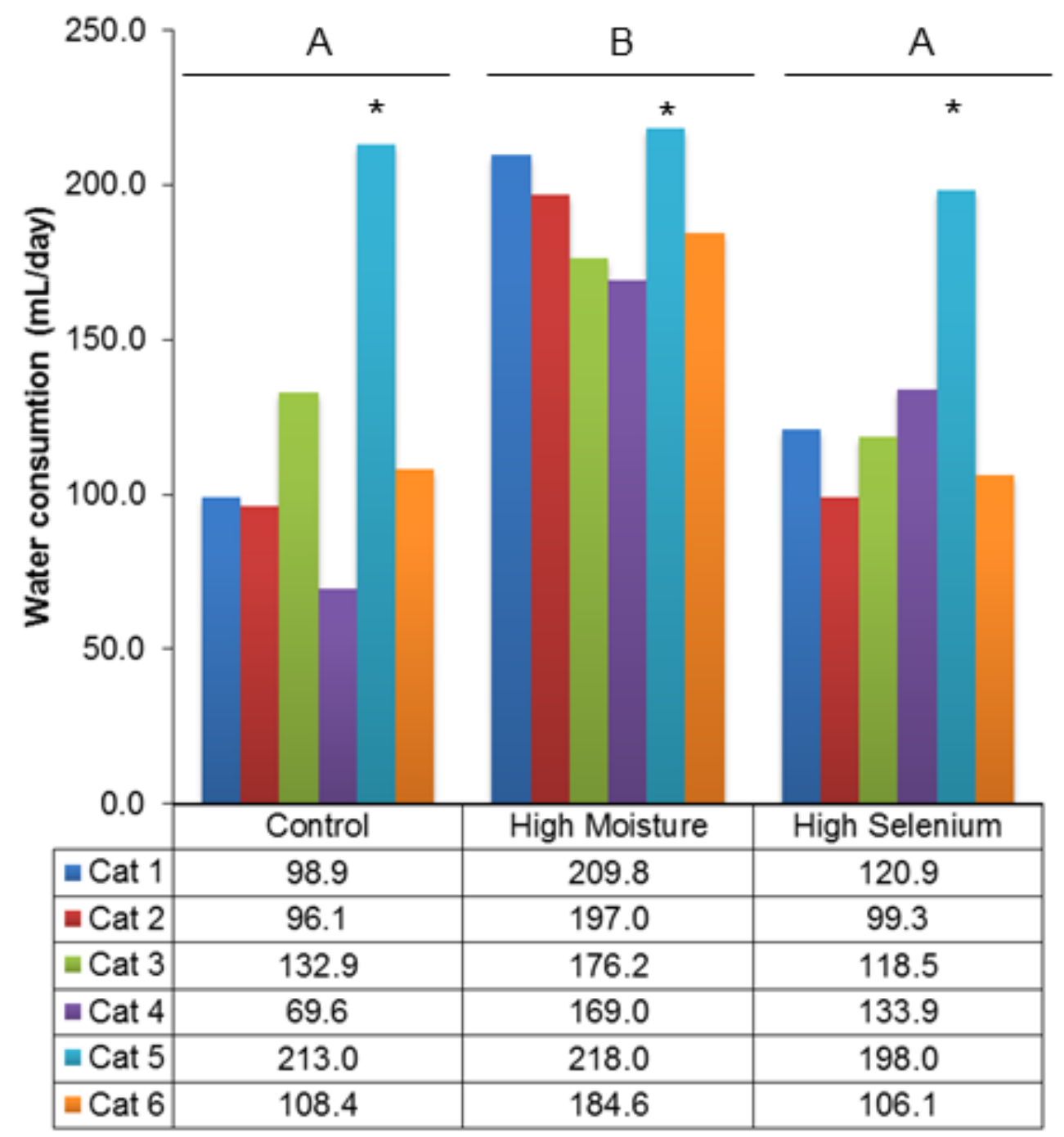

Dietary treatments and water consumption $(\mathrm{mL} /$ day)

Daily water consumption of each cat as measured by deuterium oxide dilution method. The cats consumed significantly more water on the high moisture diet compared to the control $(p<0.01)$ and high selenium $(p<0.01)$ diets. Cat five consumed more water than all other cats $\left({ }^{*}, p<0.01\right)$. 
On day 28 of dietary blocks, prior to TRH injection of TRH-stimulation tests, baseline serum concentrations of TT4, TT3, fT4, fT3, and TSH were not significantly different $(p>0.05)$ between the control, high selenium, and high moisture dietary treatments. Immediately after each cat received their dose of TRH for TRH stimulation test, the cats immediately began to exhibit ptyalism with one to two of the cats vomiting frothy fluid each block. During the first two hours all the cats exhibited lethargy and during the second two hours only two cats remained lethargic.

When the cats were on the high dietary moisture treatment, serum TT3 concentrations were greater $(p<0.001)$ post-TRH infusion (Figure 2.2) compared to when they were on the other diets $(p<0.01)$. Consumption of the high moisture diet resulted in a sixteen percent increase in serum TT3 area under the curve when compared to the control dietary treatment. There were no significant dietary treatment effects on the serum concentrations of TT4 $(p=0.94)$, fT4 $(p=$ $0.88)$, and fT3 $(p=0.68)$ following TRH injection (Figure 2.3). 
Figure 2.2 TRH stimulation test mean circulating serum T3 concentrations

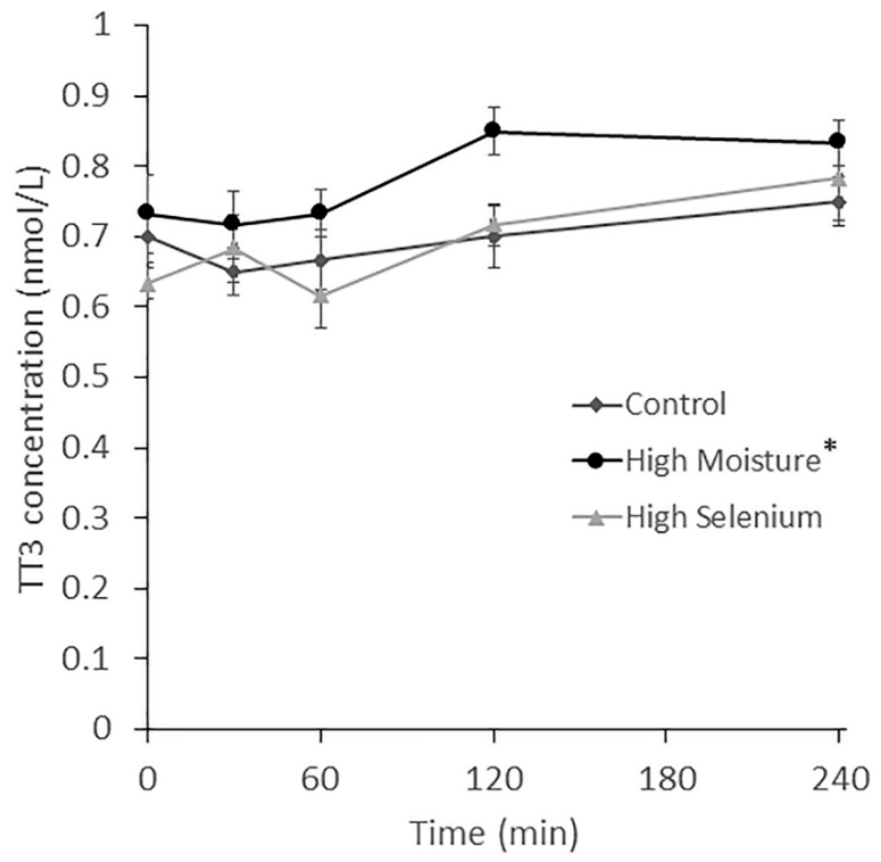

Mean total T3 serum concentration prior to intravenous administrations of TRH and post-injection. There was a significant difference found between the high dietary moisture diet compared to the control diet $\left({ }^{*}, p<0.05\right)$. 
Figure 2.3 TRH stimulation test T4, FT4, and FT3 circulating serum concentrations
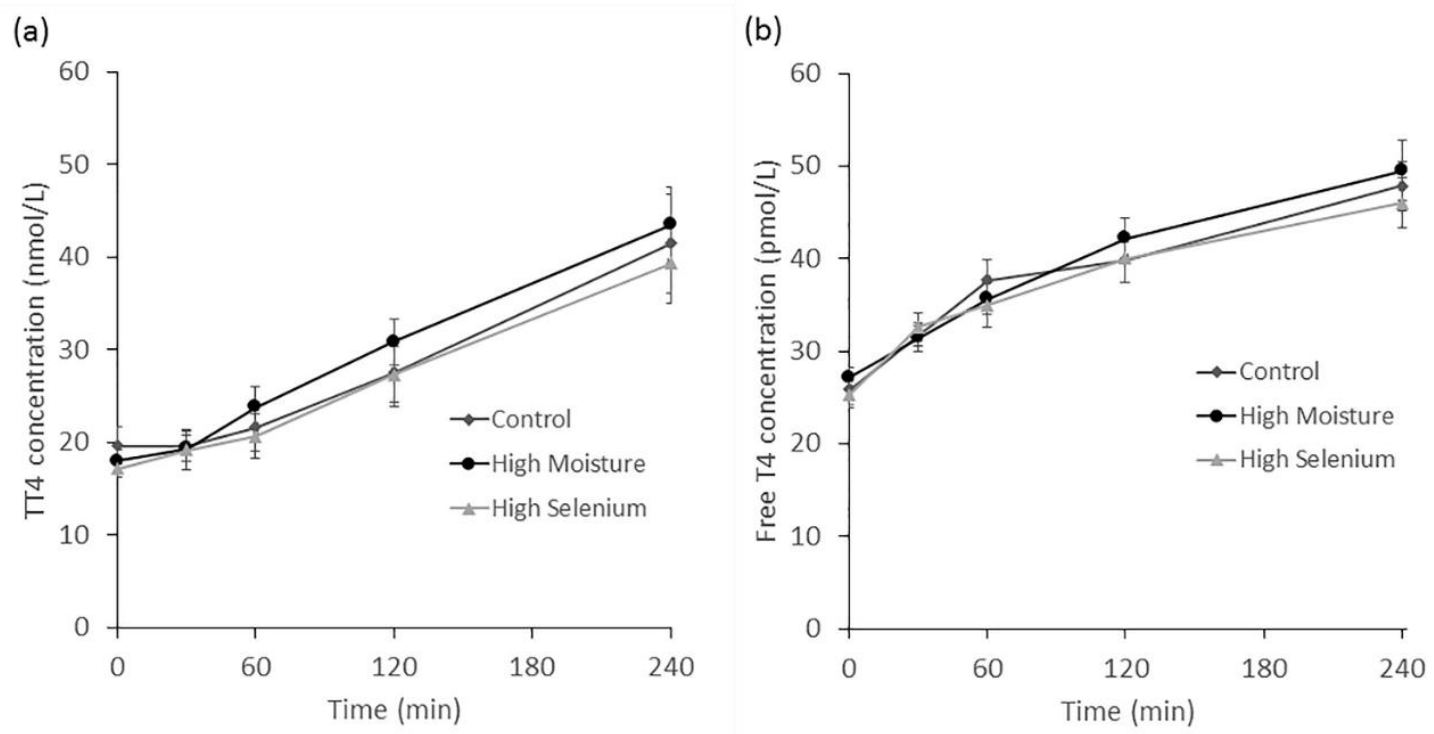

(c)

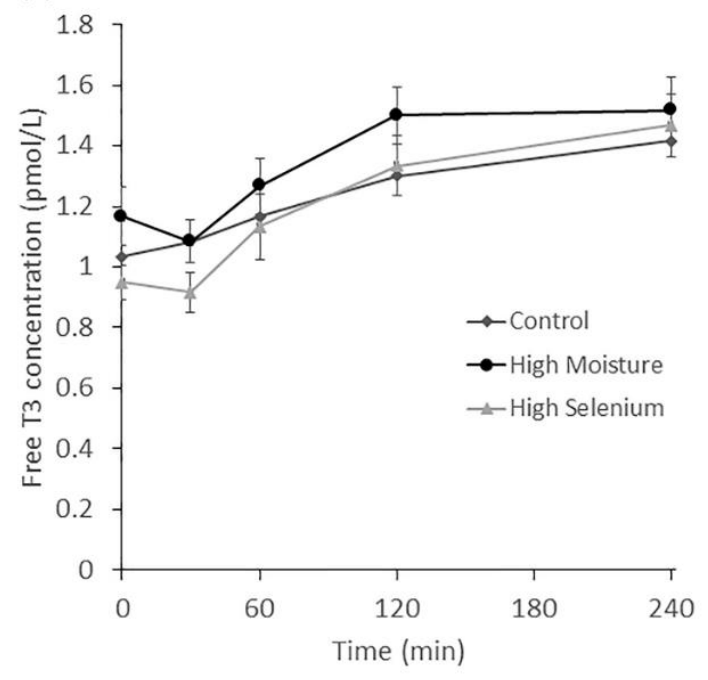

Mean total T4 (a), free T4 (b), and free T3 (c) serum concentration prior to intravenous administration of $\mathrm{TRH}$ and post-injection. 
There was no significant dietary treatment effects seen with serum TSH concentrations $(p=0.80)$ following TRH injection. Each cat's TSH concentrations peaked at 30 minutes post-TRH infusion, however there was great betweenindividual variability in serum TSH concentrations among the cats with two cats consistently exhibiting the highest of serum TSH concentrations during each dietary block (Figure 2.4).

Figure 2.4 TRH Stimulation test circulating serum TSH concentrations

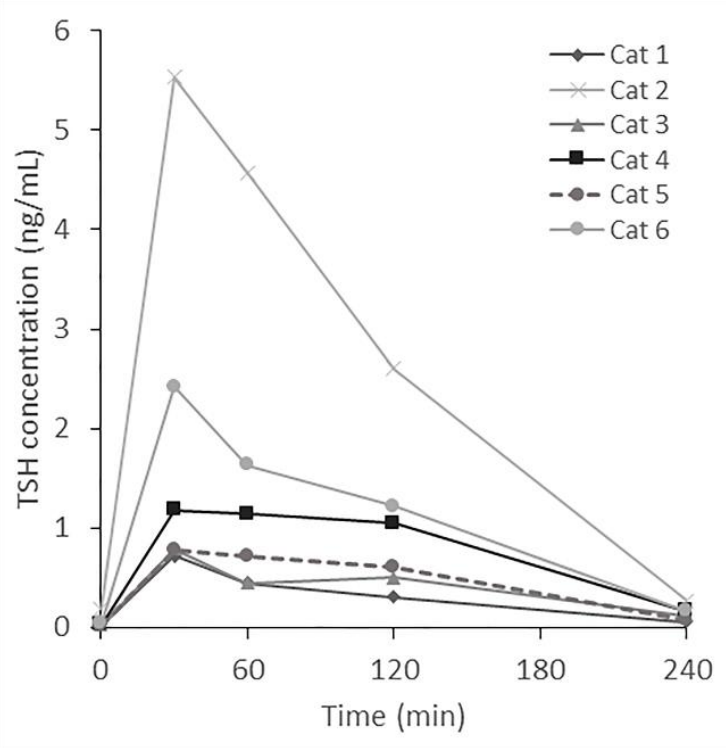

Figure 4: Individual serum TSH concentrations prior to intravenous administration of TRH and post-injection when cats were receiving the (a) control diet, (b) high selenium diet, and (c) high moisture diet.

The cats accepted the Actical activity monitors on their collars. One monitor malfunctioned on day $14-28$ of the high moisture dietary treatment, therefore only data from 5 cats were included for the activity analysis of this 
dietary treatment. Additionally, there was one cat whose collar was found to be on the floor during an approximately 4 hour timespan. The data for all cats during this specific 4 hour timespan during each dietary block was eliminated prior to analysis. Activity counts were highly variable between cats and within cats, and activity counts greatly varied each day $(p<0.01)$. A significant increase in physical activity without human interaction was observed in the high moisture dietary treatment and the high dietary selenium treatment compared to the control dietary treatment $(p<0.05$, Figure 2.5$)$. Activity counts were not found to significantly vary with dietary treatment unless activity counts recorded during periods of human interaction were omitted from analyses. The authors would like to highlight that with our data, there was large variability between days and between cats which lead us to incorporate the entire block into our analysis rather than only the last week. We also chose to use the sum of the daily activity counts instead of the mean activity counts.

\section{Figure 2.5 Activity counts during each dietary treatment block}

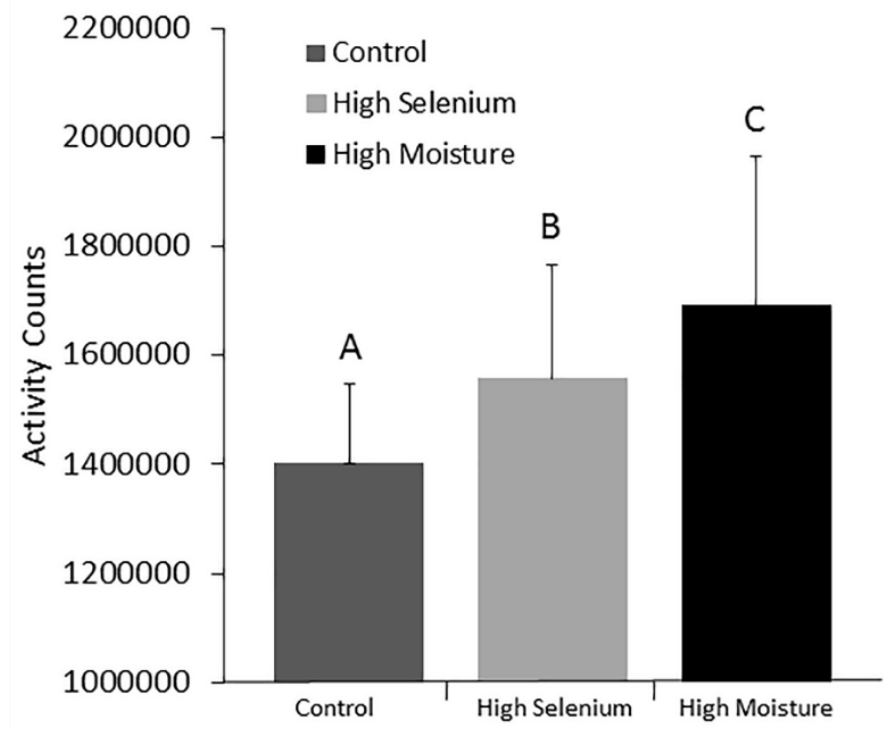

Figure 5: Mean sum of the activity counts during the entire dietary treatment block. Control and high selenium dietary treatments $n=6$ whereas high dietary moisture $\mathrm{n}=5$ due to the malfunction of one of the units. 


\section{Discussion}

With nearly all epidemiological studies universally identifying commercial canned cat food as a risk factor for feline hyperthyroidism (Gójska-Zygner et al. 2014; Kohler et al. 2016), there has been much speculation on whether the increased risk is due to the nutrient composition of canned food or contaminants in the diet (van Hoek et al. 2015). It has been largely assumed that canned cat food is a "causation" factor whereas few have reflected on the possibility that it may be simply "guilty by association" rather than an actual cause of hyperthyroidism. Most studies that investigate possible causes of feline hyperthyroidism have focused on measuring blood biomarkers (nutrients or contaminants) in hyperthyroid and euthyroid cats. One such example is (Foster et al. 2001) who measured the plasma concentrations of selenium and glutathione peroxidase (GPX) activity. These studies are of limited value because they report on effects pre- and post-diagnosis rather than physiological changes that are occurring during the early pathogenesis of feline hyperthyroidism.

Our study was unique as it examines potential nutritional etiologies of hyperthyroidism in a prospective investigation. The aims were to determine if high dietary selenium or high dietary moisture, equivalent to those typically found in canned cat foods (Simcock et al. 2005), alter the function of the hypothalamicpituitary-thyroid axis, leading to an increase in thyroid hormone production, and this increase in thyroid hormone would be reflected in the measurable outcome of increased physical activity, as increased activity is a commonly described clinical sign of feline hyperthyroidism. 
Our hypothesis that the increase secretion of thyroid hormones from the dietary treatments would result in a significant increase in physical activity, was partially supported by our results as we observed a significant increase $(p<0.05)$ in activity when the cats were on the high selenium and high dietary moisture treatments compared to the control treatment, but only when they were socially housed without human interaction (Figure 2.5). Including human interaction time along with when the cats were housed socially together, yielded results similar to Deng et al. (2014), who reported a trending increase in the mean activity of cats fed a $70 \%(\mathrm{w} / \mathrm{w})$ high moisture diet compared to the control dry diet when fed twice daily. Since our cats' personalities are highly variable, with only some of the cats seeking attention and playing with the care staff and laboratory staff, it was important to eliminate this uncontrollable variable by controlling access to the vivarium room and eliminating all data that was collected while there was a human in the room. This allowed us to find a difference between dietary treatments. A limitation of our study, was the lack of video recording to pair with the activity data in order to determine the type of physical activity the cats engaged in; however, with a $20 \%$ increase of total non-human interaction activity when the cats were on the high moisture diet, we do not believe it was solely due to increased litter box usage as Deng et al (2014) suggests.

Our results warrant further investigation into the mechanisms underlying the increase in activity that was observed, particularly when cats consume a diet high in selenium as there was not a significant increase in T4 or T3 during the dietary treatment blocks nor did we detect an increase in serum selenium (table 
2.3). While only TSH has been found to be impacted by food consumption in humans (Nair et al. 2014), in cat's it has been shown that TT4 increases 4 hours postprandial, and TT3 increases postprandial 4, 8, 12, and 16 hours (Hooper SE 2014). All of the thyroid hormones measured within this study, were done on fasted samples. Perhaps if we had measured postprandial samples, an increase in TT3 may have been recorded that could be directly linked to the increased activity level.

Additionally, we did not observe any changes in the peripheral serum TT3:TT4 ratio when the cats were on the high dietary selenium treatment. This could reflect directly on the deiodinase activity not increasing due to the uptake of selenium, as detected by the selenium content of the blood, did not change significantly between day 0 and day 28 (table 2.3). Since we utilized sodium selenite which is absorbed through passive diffusion, the blood selenium content may have increased if an organically bound selenium was incorporated into the diet as this form is actively transported in the cat (Todd et al. 2012). Despite not observing an increase in serum content, the tissue selenium concentration could have been increased, resulting in increased TT3 cellular concentration, however the tissue levels were not measured. Alternatively, the lack of changes in TT3, could be attributed to the deiodinase enzymes already being fully activated on the control diet as our dietary selenium concentration of $0.8 \mathrm{mg} / \mathrm{kg}$ was greater than the breakpoint of $0.05 \mathrm{mg} / \mathrm{kg}$ for the TT4/TT3 ratio that is reported for kittens (Wedekind et al. 2003). The iodothyronine deiodinases are present in both the tissue and the thyroid gland (Salvatore et al. 1996). lodothyronine deiodinase I 
(IDI) is attributed to the main production source of plasma TT3 in human hyperthyroid patients and has been documented in the thyroid gland of some species (Bianco and Kim 2006). IDI has not been found in the feline thyroid gland (Foster et al. 2001) and could help explain why we did not detect an increase in circulating T3. lodothyronine deiodinase II (IDII) mRNA has been detected in the thyroid gland of humans (Salvatore et al. 1996), but there have been no reports of the IDII enzyme detected in the feline thyroid gland and typically tissue only expresses one type of deiodinase at a given time (Arthur and Beckett 1999). Although since IDII is a major source of plasma T3 in euthyroid patients (Bianco and Kim 2006), it would be of value to determine if the feline thyroid contains IDII. lodothyronine deiodinase III (IDIII) is not found in the thyroid gland but solely in the tissue, and is responsible for converting T4 to rT3 and T3 to T2 (Bianco and Kim 2006).

To determine if selenium upregulated the deiodinases within the thyroid or altered the function of the hypothalamic-pituitary-thyroid axis, we conducted a $\mathrm{TRH}$ stimulation test at the end of each dietary block. This allowed differentiation between increased T3 production by the thyroid versus increased peripheral conversion of T4 to T3. Contrary to our hypothesis, the high dietary selenium treatment did not significantly affect the serum TT3 concentration during the TRH stimulation test (Figure 2.2). The selenium content of the thyroid is one of the highest out of all the organs in the body (Kohrle 1999), which may be due to its role as an anti-oxidant. In humans there is no correlation established between selenium content of thyroid tissues and the expression of functional IDI activities 
(Kohrle 1999), which along with the lack of IDI enzymes within feline thyroids (Foster et al. 2001), could explain why there was no impact seen during the $\mathrm{TRH}$ stim test. Alternatively the lack of effect could be due to the excessive selenium promoting iodine excretion as has been shown in the mouse (Xu et al., 2010). If iodine was reduced in the thyroid, it may reduce the amount of thyroid hormone produced. Future research on the interaction of iodine with other dietary nutrients such as selenium would be of value.

One of the most interesting findings of this study was that the consumption of high dietary moisture resulted in a significant increase of TT3 production during the TRH stimulation test (Figure 2.2). The 16\% difference in the TT3 AUC between the high moisture versus the control diet found during the $\mathrm{TRH}$ stimulation test, may provide a potential mechanism for the observed increased activity level (Figure 2.5), as only in the past few years has it become recognized that the thyroid hormones have a large role in the central nervous system, and do not just act peripherally (Lopez et al. 2013; Mullur et al. 2014). To the authors knowledge there are no known reports of increased water consumption altering the production or regulation of thyroid hormones. However, our results should be carefully interpreted. Our findings do not indicate that the high moisture diets induce feline hyperthyroidism, especially when considering cats consuming prey are consuming diets with a similar moisture content. Rather our results indicate future studies on the relationship between water consumption and feline physiology including the thyroid axis are needed. 
In cats, increase production of T3 has been only attributed to an upregulation of the selenoenzymes iodothyronine deiodinases, which convert T4 to T3 (Wedekind et al. 2003). Upregulation of these iodothyronine deiodinases have been solely attributed to increased dietary intake of selenium (Wedekind et al. 2003), as consumed selenium is metabolized by the body into hydrogen selenide, which in turn can be utilized for selenoprotein synthesis (Suzuki 2005), hence the hypothesis that increased dietary selenium would alter the function of the thyroid axis.

Since our study was conducted in a high selenium area of the US (Survey 2016), the water provided to the cats ad lib as well as the water added to the base diet, during creation of the high moisture diet, underwent filtering followed by reverse osmosis. Reverse osmosis water purification is routinely used effectively in mining operations to remove selenium (Santos et al. 2015), and ensured our cat's did not consume any additional selenium. Therefore, our TRH stimulation test results showing an increase in TT3 production when the cats were fed a diet with high dietary moisture (Figure 2.2) were not likely due to increased selenium intake nor an upregulation of deiodinases secondary to selenium ingestion. Future studies should be conducted to determine what physiological alterations may be occurring both on the central as well as peripheral or cellular level with the increased water consumption.

While no dietary treatment effects were found on the other thyroid parameters measured during the TRH stimulation test, the $\mathrm{TSH}$ results are of particular interest. There were significant inter-cat differences found as four of the 
cats exhibited similar TSH levels throughout the test while two individuals had repeatedly higher TSH values (Figure 2.4, 2.S1). Although it is difficult to conduct long-term studies, it may be worthwhile to design a lifetime prospective study to determine if cats with high TSH values are at an increased risk for the development of hyperthyroidism. It is suspected that cats have a long subclinical state of hyperthyroidism, before developing overt hyperthyroidism (Wakeling et al. 2007). During this subclinical state, TT4 and TT3 will be within the normal range while TSH will be low or undetectable (Peterson 2014; Wakeling et al. 2007). However, due to the lack of available feline specific TSH assays (Peterson et al. 1994), laboratories use canine TSH assays since feline TSH has 96\% homology to canine TSH (Rayalam et al. 2006). These assays unfortunately lack sensitivity, and cause both hyperthyroid and some euthyroid cats to both have TSH below the limit of quantification (Wakeling et al. 2007) which the authors have experienced. As an attempt to avoid this, we predicted that the TRH stimulation test would to allow us to measure TSH in our research colony cats. While this was successful, our results also suggest cats may have individual set points for thyroid function similar to humans as it has been documented that individuals have different set points which result in unique thyroid functions (Andersen et al. 2002). There has been recent interest in using cats as an animal model for human thyroid research, particularly for toxic multinodular goiter as the subclinical, clinical, and histological progression of the human disease is nearly identical to feline hyperthyroidism (Peterson 2014; 
Wakeling et al. 2007), and our results also provide further support that cats may be an excellent animal model for thyroid diseases.

Since canned cat food diets are considered a risk factor for developing feline hyperthyroidism (Gójska-Zygner et al. 2014; Kohler et al. 2016), our study sought to provide insights into the role selenium and moisture may have into the etiopathogensis of feline hyperthyroidism. This study highlighted that high dietary moisture is capable of altering the thyroid hormone production in cats and could be the underlying mechanism explaining why increased dietary moisture has been linked to an increase in physical activity (Deng et al. 2014). Additionally, to the author's knowledge, this is the first report of TSH being described during a TRH stimulation test in cats. Our results suggest cats may have individual set points for thyroid function, which should be investigated to determine if different set points can be attributed to an increased risk of hyperthyroidism or if high TSH indicates early stages of feline hyperthyroidism. Further studies into the mechanisms of this increased TT3 would also be of great value, including the risks of long term increased TT3 production since excessive T4 production, thyrotoxicosis, is attributed to multiple health conditions such as hypertension and osteoporosis (Bassett et al. 2007; Kobayashi et al. 1990). 


\section{Supporting Figure 2.1}

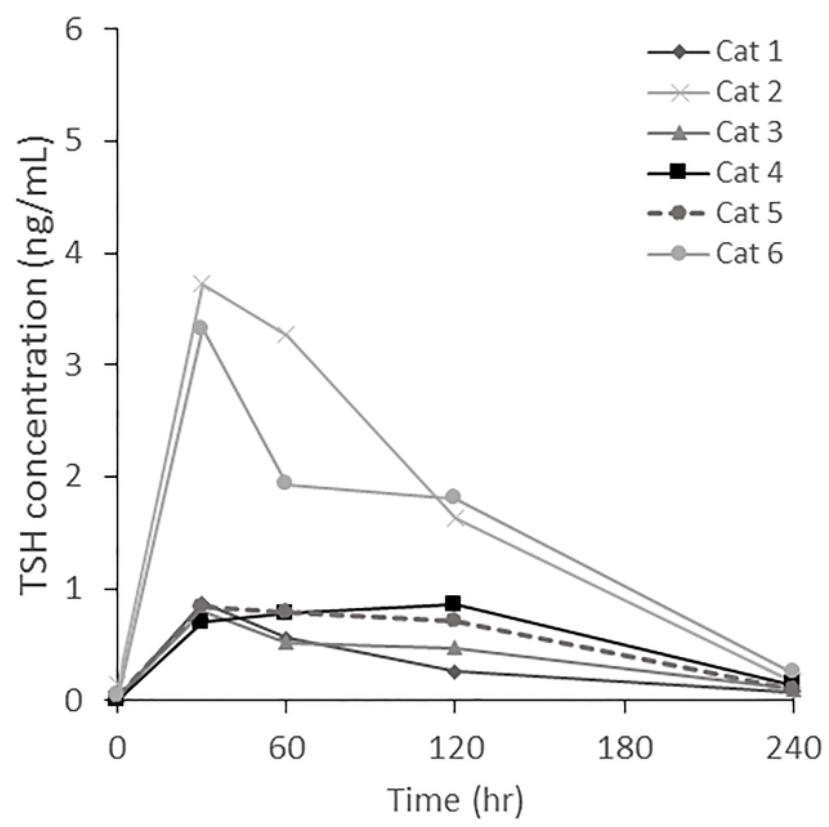

Individual serum TSH concentrations prior to intravenous administration of TRH when cats were receiving the high selenium diet.

\section{Supporting Figure 2.2}

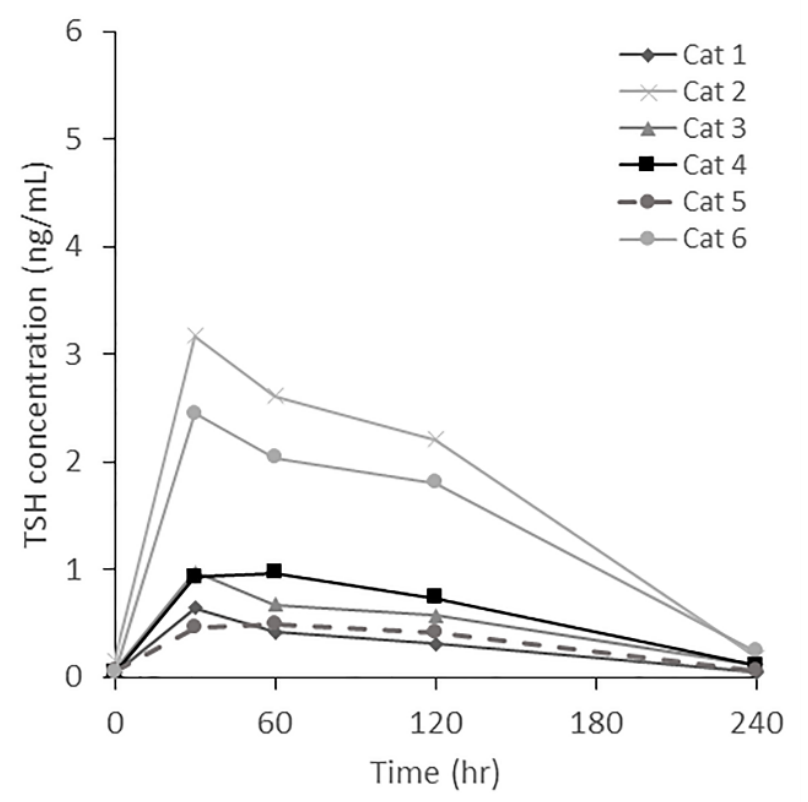

Individual serum TSH concentrations prior to intravenous administration of TRH when cats were receiving the high moisture diet. 


\section{References}

Andersen, S.; Pedersen, K.M.; Bruun, N.H.; Laurberg, P., 2002: Narrow individual variations in serum $\mathrm{T}(4)$ and $\mathrm{T}(3)$ in normal subjects: a clue to the understanding of subclinical thyroid disease. The Journal of Clinical Endocrinology and Metabolism 87, 1068-1072.

Arthur, J.R.; Beckett, G.J., 1999: Thyroid function. British Medical Bulletin 55, 658-668.

Backus, R.C.; Cave, N.J.; Ganjam, V.K.; Turner, J.B.; Biourge, V.C., 2010: Age and body weight effects on glucose and insulin tolerance in colony cats maintained since weaning on high dietary carbohydrate. Journal of Animal Physiology and Animal Nutrition (Berl) 94, e318-328.

Bassett, J.H.D.; O'Shea, P.J.; Sriskantharajah, S.; Rabier, B.; Boyde, A.; Howell, P.G.T.; Weiss, R.E.; Roux, J.-P.; Malaval, L.; Clement-Lacroix, P.; Samarut, J.; Chassande, O.; Williams, G.R., 2007: Thyroid Hormone Excess Rather Than Thyrotropin Deficiency Induces Osteoporosis in Hyperthyroidism. Molecular Endocrinology 21, 1095-1107.

Bianco, A.C.; Kim, B.W., 2006: Deiodinases: implications of the local control of thyroid hormone action. Journal of Clinical Investigation 116, 2571-2579.

Boschmann, M.; Steiniger, J.; Hille, U.; Tank, J.; Adams, F.; Sharma, A.M.; Klaus, S.; Luft, F.C.; Jordan, J., 2003: Water-induced thermogenesis. The Journal of Clinical Endocrinology and Metabolism 88, 6015-6019.

Court, M.H.; Freeman, L.M., 2002: Identification and concentration of soy isoflavones in commercial cat foods. American Journal of Veterinary Research 63, 181-185. 
De Wet, C.S.; Mooney, C.T.; Thompson, P.N.; Schoeman, J.P., 2009:

Prevalence of and risk factors for feline hyperthyroidism in Hong Kong. Journal of Feline Medicine and Surgery 11, 315-321.

Deng, P.; Iwazaki, E.; Suchy, S.A.; Pallotto, M.R.; Swanson, K.S., 2014: Effects of feeding frequency and dietary water content on voluntary physical activity in healthy adult cats. Journal of Animal Science 92, 1271-1277.

Edinboro, C.H.; Scott-Moncrieff, J.C.; Janovitz, E.; Thacker, H.L.; Glickman, L.T., 2004: Epidemiologic study of relationships between consumption of commercial canned food and risk of hyperthyroidism in cats. Journal of the American Veterinary Medical Association 224, 879-886.

Foster, D.J.; Thoday, K.L.; Arthur, J.R.; Nicol, F.; Beatty, J.A.; Svendsen, C.K.; Labuc, R.; McConnell, M.; Sharp, M.; Thomas, J.B.; Beckett, G.J., 2001: Selenium status of cats in four regions of the world and comparison with reported incidence of hyperthyroidism in cats in those regions. American Journal of Veterinary Research 62, 934-937.

Gerber, H.; Peter, H.; Ferguson, D.C.; Peterson, M.E., 1994: Etiopathology of feline toxic nodular goiter. The Veterinary Clinics of North America. Small animal practice $\mathbf{2 4}, 541-565$.

Gójska-Zygner, O.; Lechowski, R.; Zygner, W., 2014: Prevalence of feline hyperthyroidism in mature cats in urban population in Warsaw. Bulletin of the Veterinary Institute in Puławy 58, 267-271. 
van Hoek, I.; Hesta, M.; Biourge, V., 2015: A critical review of food-associated factors proposed in the etiology of feline hyperthyroidism. Journal of Feline Medicine and Surgery 17, 837-847.

Hooper, S.E.; Mori, L.; Backus, R.C., 2014: Effects of bisphenol-A and estradiol ingested with food on plasma concentrations of glucose, insulin, and thyroid-axis hormones in cats. Journal of Animal Physiology and Animal Nutrition 98, 1188.

Institue for Laboratory Animal Research, 2011: Guide for the care and use of laboratory animals. 8th Edition. U.S. Dept. of Health and Human Services, Public Health Service, Bethesda, Md.

Jennings, G.; Bluck, L.; Wright, A.; Elia, M., 1999: The use of infrared spectrophotometry for measuring body water spaces. Clinical Chemistry 45, 1077-1081.

Johnson, L.A.; Ford, H.C.; Tarttelin, M.F.; Feek, C.M., 1992: lodine content of commercially-prepared cat foods. New Zealand Veterinary Journal 40, 1820.

Kass, P.H.; Peterson, M.E.; Levy, J.; James, K.; Becker, D.V.; Cowgill, L.D., 1999: Evaluation of environmental, nutritional, and host factors in cats with hyperthyroidism. Journal of Veterinary Internal Medicine 13, 323-329.

Kobayashi, D.L.; Peterson, M.E.; Graves, T.K.; Nichols, C.E.; Lesser, M., 1990: Hypertension in Cats With Chronic Renal Failure or Hyperthyroidism. Journal of Veterinary Internal Medicine 4, 58-62. 
Kohler, I.; Ballhausen, B.D.; Stockhaus, C.; Hartmann, K.; Wehner, A., 2016:

Prevalence of and risk factors for feline hyperthyroidism among a clinic population in Southern Germany. Tierarztl Prax Ausg K Kleintiere Heimtiere 44, e1-8.

Kohrle, J., 1999: The trace element selenium and the thyroid gland. Biochimie 81, 527-533.

Laflamme, D., 1997: Nutritional management. The Veterinary Clinics of North America. Small Animal Practice 27, 1561-1577.

Lascelles, B.D.; Hansen, B.D.; Thomson, A.; Pierce, C.C.; Boland, E.; Smith, E.S., 2008: Evaluation of a digitally integrated accelerometer-based activity monitor for the measurement of activity in cats. Veterinary Anaesthesia and Analgesia 35, 173-183.

Levine, J.A.; Nygren, J.; Short, K.R.; Nair, K.S., 2003: Effect of hyperthyroidism on spontaneous physical activity and energy expenditure in rats. Journal of Applied Physiology 94, 165-170.

Lifson, N.; McClintock, R., 1966: Theory of use of the turnover rates of body water for measuring energy and material balance. Journal of Theoretical Biology 12, 46-74.

Lopez, M.; Alvarez, C.V.; Nogueiras, R.; Dieguez, C., 2013: Energy balance regulation by thyroid hormones at central level. Trends in Molecular Medicine 19, 418-427.

Martin, K.M.; Rossing, M.A.; Ryland, L.M.; DiGiacomo, R.F.; Freitag, W.A., 2000: Evaluation of dietary and environmental risk factors for hyperthyroidism in 
cats. Journal of the American Veterinary Medical Association 217, 853856.

Mooney, C.T.; Peterson, M.E.; 2012: Feline Hyperthyroidism, In: Mooney, C.T.; Peterson, M.E.; (ed.), Manual of Canine and Feline Endocrinology, 4th edn. British Small Animal Veterinary Association, Quedgeley, Gloucester, UK. 199-203.

Mullur, R.; Liu, Y.-Y.; Brent, G.A., 2014: Thyroid Hormone Regulation of Metabolism. Physiological Reviews 94, 355.

Nair, R.; Mahadevan, S.; Muralidharan, R.S.; Madhavan, S., 2014: Does fasting or postprandial state affect thyroid function testing? Indian Journal of Endocrinology and Metabolism 18, 705-707.

Olczak, J.; Jones, B.R.; Pfeiffer, D.U.; Squires, R.A.; Morris, R.S.; Markwell, P.J., 2005: Multivariate analysis of risk factors for feline hyperthyroidism in New Zealand. New Zealand Veterinary Journal 53, 53-58.

Peterson, M.; Johnson, G.; Andrews, L., 1979: Spontaneous hyperthyroidism in the cat, Proceedings of the American College of Veterinary Internal Medicine Forum. 108.

Peterson, M.E.; Graves, T.K.; Cavanagh, I., 1987: Serum thyroid hormone concentrations fluctuate in cats with hyperthyroidism. Journal of veterinary internal medicine / American College of Veterinary Internal Medicine 1, 142-146. 
Peterson, M.E.; Broussard, J.D.; Gamble, D.A., 1994: Use of the thyrotropin releasing hormone stimulation test to diagnose mild hyperthyroidism in cats. Journal of Veterinary Internal Medicine 8, 279-286.

Peterson, M., 2012: Hyperthyroidism in cats: what's causing this epidemic of thyroid disease and can we prevent it? Journal of Feline Medicine and Surgery $14,804-818$.

Peterson, M.E., 2014: Animal models of disease: feline hyperthyroidism: an animal model for toxic nodular goiter. The Journal of Endocrinology 223, T97-114.

Public Health Service, 2002: Public Health Service Policy on Humane Care and Use of Laboratory Animals, Public law 99-158, Health Research Extension Act of 1985. Washington DC: US Department of Health and Human Services.

Rayalam, S.; Eizenstat, L.D.; Hoenig, M.; Ferguson, D.C., 2006: Cloning and sequencing of feline thyrotropin (fTSH): heterodimeric and yoked constructs. Domestic Animal Endocrinology 30, 203-217.

Salvatore, D.; Tu, H.; Harney, J.W.; Larsen, P.R., 1996: Type 2 iodothyronine deiodinase is highly expressed in human thyroid. Journal of Clinical Investigation 98, 962-968.

Santos, S.; Ungureanu, G.; Boaventura, R.; Botelho, C., 2015: Selenium contaminated waters: An overview of analytical methods, treatment options and recent advances in sorption methods. Science of The Total Environment 521-522, 246-260. 
Sawka, M.N.; Cheuvront, S.N.; Carter, R., 2005: Human water needs. Nutrition reviews 63 , S30-S39.

Scarlett, J.M.; Moise, N.S.; Rayl, J., 1988: Feline hyperthyroidism: A descriptive and case-control study. Preventive veterinary medicine 6, 295-309.

Simcock, S.E.; Rutherford, S.M.; Wester, T.J.; Hendriks, W.H., 2005: Total selenium concentrations in canine and feline foods commercially available in New Zealand. New Zealand Veterinary Journal 53, 1-5.

Sparkes, A.H.; Jones, B.R.; Gruffydd-Jones, T.J.; Walker, M.J., 1991: Thyroid function in the cat: assessment by the TRH response test and the thyrotrophin stimulation test. Journal of Small Animal Practice 32, 59-63.

Spate, V.L.; Morris, J.S.; Chickos, S.; Baskett, C.K.; Mason, M.M.; Cheng, T.P.; Reams, C.L.; West, C.; Furnee, C.; Willett, W.; Horn-Ross, P., 1995: Determination of iodine in human nails via epithermal neutron activation analysis. Journal of Radioanalytical and Nuclear Chemistry 195, 21-30.

Suzuki, K.T., 2005: Metabolomics of selenium: Se metabolites based on speciation studies. Journal of Health Science 51, 107-114.

Thoday, K.; Mooney, C., 1992: Historical, clinical and laboratory features of 126 hyperthyroid cats. The Veterinary Record 131, 257-264.

Todd, S.E.; Thomas, D.G.; Hendriks, W.H., 2012: Selenium balance in the adult cat in relation to intake of dietary sodium selenite and organically bound selenium. Journal of Animal Physiology and Animal Nutrition 96, 148-158. United States Department of Agriculture, 2008: Animal Welfare Act and Animal Welfare Regulations. As Amended. United States Code §2131-2159. 
United States Geological Survey, 2016: Average concentrations of elements in Boone County, Missouri. U.S. Department of the Interior, http://mrdata.usgs.gov/geochem/county.php?place=f29019\&el=Se\&rf=cen tral. May 16, 2016.

Wakeling, J.; Everard, A.; Brodbelt, D.; Elliott, J.; Syme, H., 2009: Risk factors for feline hyperthyroidism in the UK. The Journal of small animal practice $\mathbf{5 0}$, 406-414.

Wakeling, J.; Smith, K.; Scase, T.; Kirkby, R.; Elliott, J.; Syme, H., 2007: Subclinical hyperthyroidism in cats: a spontaneous model of subclinical toxic nodular goiter in humans? Thyroid 17, 1201-1209.

Wedekind, K.J.; Howard, K.A.; Backus, R.C.; Yu, S.; Morris, J.G.; Rogers, Q.R., 2003: Determination of the selenium requirement in kittens. Journal of Animal Physiology and Animal Nutrition (Berl) 87, 315-323.

Xu, J.; Liu, X.-L.; Yang, X.-F.; Guo, H.-L.; Zhao, L.-n.; Sun, X.-F., 2011: Supplemental Selenium Alleviates the Toxic Effects of Excessive lodine on Thyroid. Biological trace element research 141, 110-118. 


\section{CHAPTER 3}

\section{Inter- and intra-individual variation in circulating thyroid hormones of Sprague Dawley rats (Rattus norvegicus) with circulating serum triiodothyronine correlating with plasma taurine in female rats}

This chapter is under review for publication in a peer review journal

Authors Sarah E. Hooper ${ }^{1 *}$, Sybill K. Amelon², Erin K. O'Connor ${ }^{3}$, Scott W. Korte $^{3}$, Robert. C. Backus ${ }^{4}$

\section{Affiliations and addresses}

${ }^{1}$ Department of Veterinary Pathobiology, College of Veterinary Medicine, University of Missouri, 4011 Discovery Drive S129, Columbia, Missouri 65201, United States of America

2 USDA Forest Service, Northern Research Station, 202 Anheuser-Busch Natural Resources Building, Columbia, Missouri 65211, United States of America

${ }^{3}$ Office of Animal Resources, University of Missouri, 1720 East Campus Loop, Columbia, Missouri, 65211, United States of America

${ }^{4}$ Department of Veterinary Medicine and Surgery, College of Veterinary Medicine, University of Missouri, A384 Clydesdale Hall, Columbia, Missouri 65211, United States of America 


\section{Abstract}

Research in animal models has demonstrated many beneficial effects of taurine supplementation. These findings have generated much interest in supplementing humans with taurine, however it is unknown if high dietary taurine intake affects physiological processes. We proposed that high levels of dietary taurine would affect the homeostasis of the hypothalamic-pituitary-thyroid axis by causing a proliferation of thyroid cells, leading to an increase in circulating thyroid hormones. Using a parallel design of 12-week duration, 12 male and 12 female sexually mature Sprague Dawley rats were randomly assigned to a $0 \%$ taurine or a $0.7 \%$ taurine diet. Plasma taurine and circulating serum thyroxine (T4), triiodothyronine (T3), thyroid stimulating hormone (TSH) were measured every 2 to 4 weeks. Thyroids were collected at week 12 , with one thyroid from each rat undergoing analysis for taurine content and the other thyroid undergoing histological analysis. Intra- and inter- individual variation was observed in all thyroid hormone parameters measured with the range for $\mathrm{T} 3$ in the female rats $0.75 \pm 0.06$ (mean \pm SEM) to $1.16 \pm 0.17 \mathrm{ng} / \mathrm{mL}$ and in the male rats $0.47 \pm 0.06$ to $0.84 \pm 0.08 \mathrm{ng} / \mathrm{mL}$; for $\mathrm{T} 4$ in the female rats $4.1 \pm 0.32$ to $5.4 \pm 0.69 \mu \mathrm{g} / \mathrm{dL}$ and in the male rats $4.7 \pm 0.43$ to $8.4 \pm 0.38 \mu \mathrm{g} / \mathrm{dL}$, and for $\mathrm{TSH}$ in the female rats $34.3 \pm 4.8$ to $70.8 \pm 12.4 \mathrm{pg} / \mathrm{mL}$ and in the male rats $45.7 \pm 4.3$ to $90.6 \pm 18.4$ $\mathrm{pg} / \mathrm{mL}$. There was a significant positive correlation $(r=0.55, p<0.002)$ between serum T3 and plasma taurine concentrations in the female rats. The female rats on the high dietary taurine gained $27.8 \pm 4.3$ grams which was significantly more weight than the $9.3 \pm 3.6$ grams the female control rats gained $(p<0.01)$. It was also determined that thyroid glands need to be immediately removed and 
preserved in formalin as follicular colloid loss and subsequent collapse begin to occur within 30 minutes post-euthanasia. Our results indicate a larger study evaluating the effects of taurine on the female thyroid axis is warranted.

\section{Introduction}

lodine deficiency is one of the best studied nutritional epidemiological risk factors for the development of nodular thyroid diseases (Krohn et al. 2005a). However thyroid diseases, including toxic multinodular goiter, a type of hyperthyroidism, occur in iodine replete areas in non-iodine deficient individuals (Vanderpump 2005). Other dietary constituents such as selenium, thiocyanate, and flavonoids (Vanderpas 2006) have been investigated as potential risk factors for development of thyroid nodules and goiter since they are known to effect thyroid hormone metabolism through a variety of mechanisms (de Souza Dos Santos et al. 2011; Kohrle 1999; Vanderpas 2006). However, epidemiologic and animal model studies focused on these nutritional risk factors have failed to provide a direct dietary link to the development of hyperthyroidism independent of iodine and the investigators have failed to explain why the prevalence of hyperthyroidism and other thyroid diseases are higher in women than men (Krohn et al. 2005a).

Taurine, a sulfur-containing amino acid, is acquired directly through the diet or is synthesized by adults from dietary methionine and cysteine (Lourenco and Camilo 2002). Once thought to be an inert waste product, taurine is now recognized to have a diversity of biological actions including modulation of neurotransmitters and hormone release (Huxtable 1992). In vitro work by Jhiang et al. (1993) identified a taurine transporter in thyroid cells and demonstrated that 
the proliferation rate of thyroid cells from two human cell lines increased with increasing taurine uptake. Since taurine is found in high concentrations in tissues that generate free radicals and oxidants (Jacobsen and Smith 1968; Wright et al. 1986) it has been suggested that taurine may be protective of thyroid cellular proliferation through its role in membrane stabilization, detoxification, antioxidation, and osmoregulation (Jhiang et al. 1993). Through the use of rodent animal models, taurine has been shown to be protective within other cells such as pancreatic beta cells in type 1 diabetic animal models (Chang and Kwon 2000; Gavrovskaya et al. 2008; Ito et al. 2012) and has been shown to reduce insulin resistance. These findings have generated much interest in supplementing humans with large amounts of taurine when suffering from certain disease such as diabetes to help manage insulin resistance, diabetic nephropathy, and other complications (Ito et al. 2012).

Food manufacturers have begun supplementing various products with taurine, particularly those produced for infants and young children, such as baby formula and complete nutrition beverages, because taurine biosynthesis from dietary methionine and cysteine is poor to absent in infants (Lambert et al. 2015). Additionally, taurine is routinely added to dietary food supplements for adults such as protein bars as it is well established that adult biosynthesis capability is low (Ito et al. 2012), whereas other products, such as energy drinks, contain tremendous amounts of taurine as it is touted to have beneficial effects such as improving mental performance (Alford et al. 2001). 
Consumption of a single 16 ounce energy drink, such as Red Bull or Monster, typically provides $2000 \mathrm{mg}$ of taurine (Higgins et al. 2010). In contrast, it has been reported the average taurine intake by European adults on an omnivore diet is $58 \mathrm{mg}$ per day, with a range of 9 to $372 \mathrm{mg}$ per day (Schaffer et al. 2014). The variation is dependent upon the dietary consumption of animal proteins, as meat and seafood contain high levels of taurine whereas the taurine content of fruits and vegetables is typically below detection limits (Lourenco and Camilo 2002). It remains unknown whether a high dietary taurine intake or an exceptionally low taurine intake (e.g. vegan diets) affect physiological processes (Lambert et al. 2015).

We propose that high levels of dietary taurine could affect thyroid axis homeostasis, because in vitro evidence suggests that thyroid cells exposed to higher levels of taurine will have increased proliferation rates (Jhiang et al. 1993). Additionally, nuclear magnetic resonance studies have revealed that malignant thyroid tumors contain relatively higher concentrations of taurine compared to benign thyroid tumors (Torregrossa et al. 2012). With the prevalence of hyperthyroidism and thyroid diseases higher in women, there is evidence in rodent animal models, specifically in the rat, that female thyroid glands contain significantly higher concentrations of taurine compared to male thyroid glands (Jacobsen and Smith 1968). Therefore, our study incorporated both sexes to determine if taurine exerted any sex-specific effects on the function of the thyroid axis which could help to explain the increased incidence of hyperthyroidism in females. We hypothesized that excessive dietary taurine would result in a 
proliferation of thyroid cells. This cellular proliferation would result in the formation of hyperfunctioning thyroid nodules which would lead to a rise in the production of the circulating thyroid hormones triiodothyronine (T3) and thyroxine (T4).

\section{Materials and Methods Ethical Statement}

This study was conducted at an animal facility accredited by AAALAC International. All procedures performed were under an approved University of Missouri Animal Care and Use Committee Protocol and adhered to the Guide for the Care and Use of Laboratory Animals (National Institutes of Health 2011).

\section{Animals}

Twelve male, ten-week-old sexually mature Sprague Dawley rats and twelve, seventeen-week-old sexually mature female Sprague Dawley rats (Hsd: Sprague Dawley rats, Envigo, USA) were pair housed in a temperaturecontrolled rodent housing facility under a $12 \mathrm{hr}$ light-dark cycle. Rats were requested from Harlan Laboratories Inc. (now Envigo, Indianapolis, Indiana, USA) to be at the top of the growth curve, therefore different ages were used. To minimize stress that could alter the biological parameters measured, rats were acclimated to handling, restraint, and meal feeding for a minimum of 8 days prior to the start of the study. At the end of the study, animals were anesthetized with isoflurane and euthanized by cardiac exsanguination.

\section{Diets and study design}

All rats underwent an adaptation period to meal-feeding using standard rodent chow (Lab Diet Rat Diet 5012, St. Louis, MO, USA). After their body 
weight stabilized, rats were randomly assigned to 2 dietary treatment groups, AIN-93M purified diet (Reeves et al. 1993) with 0\% taurine (control) (Modified AIN-93M 0.7\% cornstarch Dyets \#103967, Dyet's Inc., Bethlehem, PA, USA) or 0.7\% DM taurine (high taurine) (Modified AIN-93M 0.7\% taurine Dyets \#103968, Dyets Inc., Bethlehem, PA, USA). Crude protein and taurine analyses of the diets were completed by the University of Missouri Experimental Station Chemical Laboratories (Columbia, MO, USA), results of which are shown in table 3.1. Dietary treatment groups were balanced for sex and starting body weight. Using a parallel design of 12-week duration, the rats were individually housed from 800 to $1200 \mathrm{hr}$ and presented with $\sim 50$ grams of diet to simulate meal feedingdefined as a fixed window of time in which animals receive the entirety of their daily food ration (Vahl et al. 2014). At all other times, rats were housed in pairs. Food intake was determined daily from the weight of the diet presented minus weight of the diet remaining after individual housing. The cage litter was manually sifted by hand to ensure all feed was weighed after removal. The amount of taurine consumed was calculated every two weeks (weeks $2,4,6,8,10,12$ ) by multiplying the amount of food consumed by the amount of taurine in the diet using the as is basis values reported for the proximate and taurine analyses.

Table 3.1: Crude protein and taurine content of diets.

\begin{tabular}{ccc} 
Diet & $\begin{array}{c}\text { Crude protein } \\
(\mathrm{w} / \mathrm{w})\end{array}$ & $\begin{array}{c}\text { Taurine } \\
(\mathrm{w} / \mathrm{w})\end{array}$ \\
\hline AIN-93 0.7\% Taurine & $12.8 \%$ & $0.59 \%$ \\
AIN-93 0.7\% Cornstarch & $13.0 \%$ & $0.00 \%$ \\
\hline Crude protein and taurine content reported on an is basis.
\end{tabular}




\section{Blood collection}

On day $0,14,28,42,56,70$, and 84 , between 600 and $800 \mathrm{hr}$ rats were briefly restrained in a DecapiCone (Braintree Scientific Inc., Braintree, MA) to allow pre-feeding blood collection from the saphenous vein. Two hours after removal of the daily feed allotment (1400 hrs), rats were anesthetized using isoflurane and up to $7 \%$ of each animals' blood volume was collected from the jugular vein. Two-hundred and fifty microliter lithium heparin Terumo Capiject ${ }^{\odot}$ capillary blood collection tubes (Terumo Medical, Elkton, MD, USA) were used to allow extraction of plasma. Plain five-hundred microliter Terumo Capiject ${ }^{\odot}$ capillary blood collection tubes were used to allow extraction of serum. All blood samples were allowed to clot for a minimum of one hour prior to centrifugation at $2000 \times$ g. All samples were frozen at $-20^{\circ} \mathrm{C}$ until analysis.

\section{Thyroid hormones}

T4 and thyroid stimulating hormone (TSH) were measured in duplicate on pre-feeding (fasted) serum samples using the Milliplex Map Rat Thyroid Magnetic Bead Panel (RTHYMAG-30K EMD Millipore, Billerica, MA, USA). T3 was measured using a human $\mathrm{I}^{125}$ radioimmunoassay kit (MP Biomedicals, Irvine, CA, USA). All samples were run according to each manufacturer's directions.

\section{Taurine analysis}

Plasma taurine was measured on day $0,14,28,42,56,70$, and 84 postprandial blood samples. Taurine concentration of a single thyroid gland of each rat was determined. For this, one whole thyroid gland was homogenized in $1 \mathrm{~mL}$ of distilled water, and homogenates were frozen and thawed three times to help 
ensure lysis of the cells. Taurine concentration in all samples was measured using high pressure liquid chromatography (HPLC) method modified from Sarwar and Botting (1990). Reagents were HPLC grade purchased from Sigma Aldrich (St. Louis, MO, USA) unless otherwise noted. Prior to HPLC analysis, samples were deproteinized by adding $50 \mu \mathrm{L}$ of acetonitrile to $50 \mu \mathrm{L}$ of plasma or tissue homogenate with trans-4-hydroxy-L-proline at a concentration of $100 \mathrm{ng} / \mathrm{mL}$ added for internal standard. After thoroughly mixing, samples were centrifuged for 15 min at $16,000 \times g$ and $50 \mu \mathrm{L}$ of the supernatant was transferred to a $13 \times$ $100 \mathrm{~mm}$ glass tube. Samples were evaporated to dryness at $35^{\circ} \mathrm{C}$ in a centrifugal evaporator (SpeedVac ${ }^{\circledR}$ Concentrator, Savant $\AA$ SPD 111V, Thermo Electron Corp., Milford, MA, USA). Derivatization was performed in two steps. First, $50 \mu \mathrm{L}$ of a coupling solution (1:1:1, v/v, triethylamine:water:methanol) was added to the dried residue, mixed, and then evaporated to dryness in the evaporator. Subsequently, $50 \mu \mathrm{L}$ of derivatization solution (20:5:5:2, v/v, methanol:water:triethylamine:phenylisothiocyanate) was added to each tube, covered with parafilm, and left for 20 minutes at ambient temperature $\left(20-24^{\circ} \mathrm{C}\right)$. Samples were then evaporated to dryness and redisolved in $200 \mu \mathrm{L}$ (thyroid) or $400 \mu \mathrm{L}$ (plasma) of sample diluent (710 mg disodium hydrogen phosphate, 950 $\mathrm{mL}$ water, $5 \mathrm{~mL}$ acetonitrile, adjusted to $\mathrm{pH} 5.4$ with phosphoric acid). Samples were transferred to an Eppendorf tube with a $0.2 \mu \mathrm{m}$ centrifuge tube filter (Corning ${ }^{\circledR}$ Costar ${ }^{\circledR}$ SpinX centrifuge tube filters, Sigma Aldrich, St. Louis, MO, USA) and centrifuged for $15 \mathrm{~min}$ at $15,000 \times \mathrm{g}$. Five $\mu \mathrm{L}$ was injected onto a heated $\left(45^{\circ} \mathrm{C}\right)$ column (Microsorb-MV ${ }^{\mathrm{TM}} 100-5 \mathrm{C} 18,250 \times 4.6 \mathrm{~mm}$ Varian Inc, 
Lake Forest, CA, USA) equilibrated with buffer $A$ at $1.0 \mathrm{~mL} / \mathrm{min}$. The phenylisothiocyanate derivatives of taurine and the internal standard were detected by UV absorbance at $254 \mathrm{~nm}$ as eluted with an increasing amount of Buffer "B" (1:1, v/v, acetonitrile:water). Buffer "A" was prepared by adding $11.45 \mathrm{~g}$ sodium acetate, $900 \mathrm{~mL}$ water, $15 \mathrm{~mL}$ acetonitrile (Optima ${ }^{\mathrm{TM}} \mathrm{LC} / \mathrm{MS}$, Fisher Chemical, Waltham, MA, USA), and $0.5 \mathrm{~mL}$ of trimethylamine adjusted to $\mathrm{pH} 5.4$ with glacial acetic acid. The buffer gradient was $0 \%$ B from 0 to $5 \mathrm{~min}, 10 \%$ B for 5 to $9 \mathrm{~min}, 48 \% \mathrm{~B}$ for 9 to $17 \mathrm{~min}, 100 \% \mathrm{~B}$ for 17 to $20,100 \%$ B for $20-35 \mathrm{~min}$, $0 \% \mathrm{~B}$ for 35 to $38 \mathrm{~min}$, and $0 \% \mathrm{~B}$ for 38 to $45 \mathrm{~min}$. Intra-assay variation was $6.05 \%$.

\section{Tissue protein analysis}

Protein was measured in the thyroid homogenate solutions by Bradford assay (Bradford 1976) (BioRad USA Microplate BSA Hercules, California 94547). Lyophilized, essentially fat free, bovine serum albumin (Sigma Aldrich, St. Louis, MO, USA) was used to establish the standard curve from 0 to 1000 $\mu \mathrm{g} / \mathrm{mL}$. Samples were diluted to ensure protein analysis was conducted between $200-600 \mu \mathrm{g} / \mathrm{mL}$. Samples were processed according to the manufacturer's directions for the standard microplate assay.

\section{Histological analysis}

One thyroid gland of each rat was fixed in $10 \%$ buffered formalin. The fixed tissues were submitted to a commercial laboratory (IDEXX Bioresearch, Columbia, MO, USA) for embedding and hematoxylin and eosin staining. Using a light microscope with built-in software, 3 photographs at 20x magnification were 
taken to capture the entire longest diameter of the thyroid gland. Follicles were numbered and the follicular diameter was measured using NIH ImageJ 1.50b (National Institutes of Health, Bethesda, MD, USA).

\section{Statistical analysis}

We used SAS 9.3 (SAS Institute Inc., Cary, NC, USA) to perform all statistical analysis and significance was calculated at alpha $=0.05$. Data was tested for normality using the Shapiro-Wilk, Kolmogorov-Smirnov, and AndersonDarling tests. Non-normally distributed data was transformed using log10 or square root. The Proc GLM and GLMMix procedure with repeated measures, and differences of the least square means was used to compare the variables of interest (time, treatment, sex) and the interactions. The Proc Correlation procedure and Pearson correlation coefficients were used to examine any potential correlations between the circulating thyroid hormone serum concentrations, taurine consumed every 2 weeks, and plasma taurine concentrations.

\section{Results}

\section{Thyroid hormones}

Over the 12 weeks, the rats exhibited intra- and inter-individual variation of serum T3, T4, and TSH concentrations, with sex-effects found for T3 $(p<0.001)$, T4 $(p<$ $0.001)$, and TSH $(p<0.001)$ (Fig 3.1, tables 3.2-3.4). There were no dietary treatment effects found for T3 $(p=0.21)$, T4 $(p=0.28)$ and TSH ( $p=0.54)$ (Fig. 3.2-3.3) and there were no sex $x^{*}$ reatment effects for T3 $(p=0.35)$, T4 $(p=0.87)$, TSH $(p=0.36)$. 
Figure 3.1 Circulating serum thyroid hormones
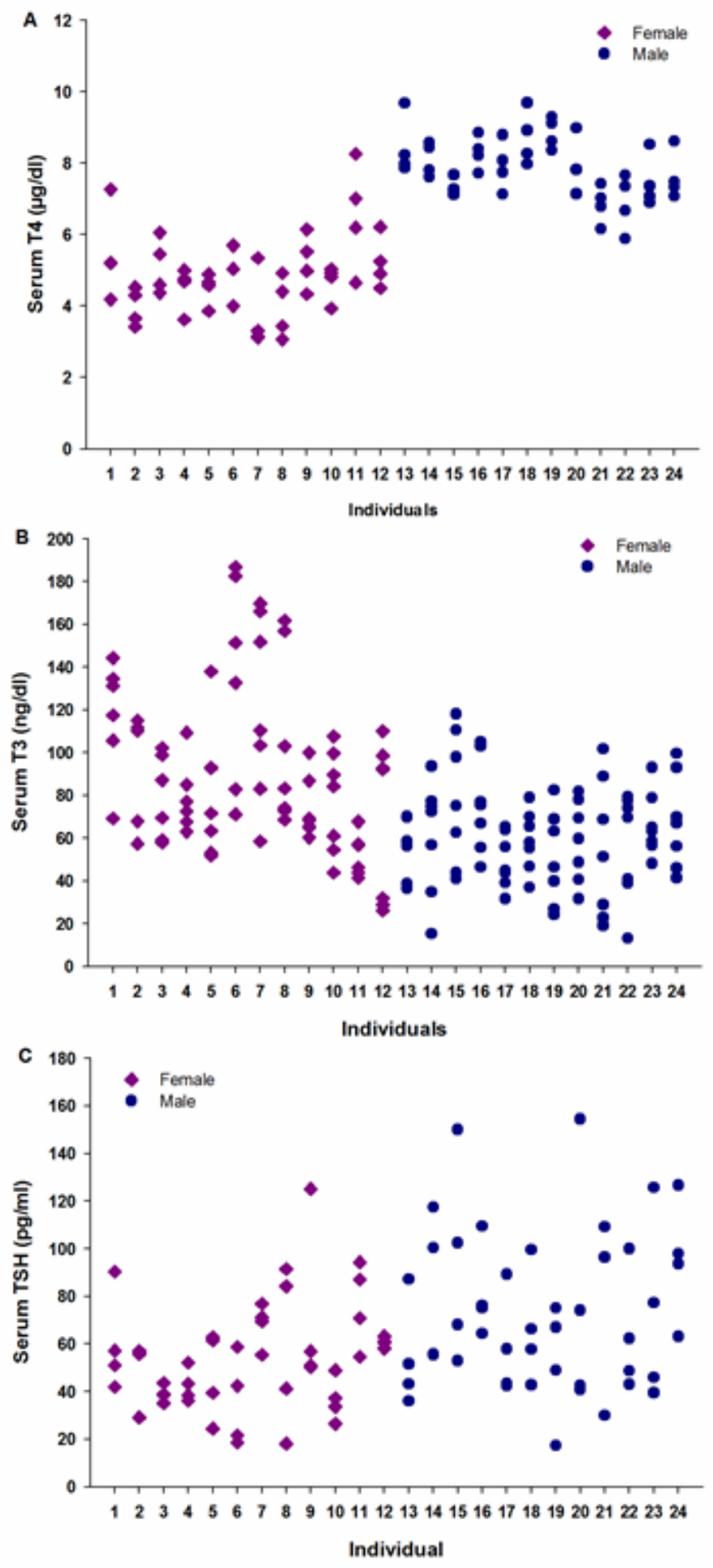

Circulating serum concentrations of (A) T4 and (B) T3 were measured at weeks $0,4,8$, and 12.

Circulating serum concentration of (C) TSH were measured at weeks $0,2,4,6,8,10,12$. Each sample time point for each individual is represented by $\bullet$ for females and $\bullet$ for males Circulating serum concentrations of T4 and TSH were significantly higher than in the male rats compared to the female rats $(p<0.001)$. Circulating serum concentrations of T3 were significantly higher in the female rats compared to the male rats $(p<0.001)$. 
Table 3.2 Circulating serum TT3 concentrations

\begin{tabular}{|c|c|c|c|c|c|c|c|c|c|c|}
\hline Sex & $\begin{array}{l}\text { Dietary } \\
\text { treatment }\end{array}$ & $\begin{array}{l}\text { Week } 0 \\
(\mathrm{ng} / \mathrm{mL})\end{array}$ & $\begin{array}{l}\text { Week } 2 \\
\text { (ng/mL) }\end{array}$ & $\begin{array}{l}\text { Week } 4 \\
\text { (ng/mL) }\end{array}$ & $\begin{array}{l}\text { Week } 6 \\
\text { (ng/mL) }\end{array}$ & $\begin{array}{l}\text { Week } 8 \\
\text { (ng/mL) }\end{array}$ & $\begin{array}{l}\text { Week } 10 \\
(\mathrm{ng} / \mathrm{mL})\end{array}$ & $\begin{array}{c}\text { Week } 12 \\
(\mathrm{ng} / \mathrm{mL})\end{array}$ & $\begin{array}{l}\text { Dietary } \\
\text { treatment } \\
\text { p-value }\end{array}$ & $\begin{array}{c}\text { Sex } \\
\text { effect } p- \\
\text { value }\end{array}$ \\
\hline Female & Control & $0.87 \pm 0.14$ & $0.76 \pm 0.19$ & $0.97 \pm 0.09$ & $0.86 \pm 0.22$ & $0.90 \pm 0.12$ & $0.82 \pm 0.20$ & $0.85 \pm 0.10$ & \multirow{4}{*}{0.21} & \multirow{4}{*}{$<0.001$} \\
\hline Female & Taurine & $0.75 \pm 0.06$ & $0.90 \pm 0.19$ & $0.88 \pm 0.12$ & $1.16 \pm 0.17$ & $0.90 \pm 0.25$ & $1.07 \pm 0.18$ & $0.78 \pm 0.08$ & & \\
\hline Male & Control & $0.66 \pm 0.07$ & $0.57 \pm 0.06$ & $0.46 \pm 0.04$ & $0.59 \pm 0.12$ & $0.58 \pm 0.07$ & $0.70 \pm 0.08$ & $0.50 \pm 0.06$ & & \\
\hline Male & Taurine & $0.50 \pm 0.03$ & $0.84 \pm 0.08$ & $0.47 \pm 0.06$ & $0.94 \pm 0.07$ & $0.42 \pm 0.04$ & $0.80 \pm 0.06$ & $0.48 \pm 0.08$ & & \\
\hline
\end{tabular}

Circulating serum TT3 mean \pm SEM concentrations measured in non-anesthetized rats ( $\mathrm{n}=6$ per sex per treatment group).

\section{Table 3.3 Circulating serum TT4 concentrations}

\begin{tabular}{|c|c|c|c|c|c|c|c|}
\hline Sex & $\begin{array}{l}\text { Dietary } \\
\text { treatment }\end{array}$ & $\begin{array}{l}\text { Week } 0 \\
(\mu \mathrm{g} / \mathrm{dL})\end{array}$ & $\begin{array}{l}\text { Week } 4 \\
(\mu \mathrm{g} / \mathrm{dL})\end{array}$ & $\begin{array}{l}\text { Week } 8 \\
(\mu \mathrm{g} / \mathrm{dL})\end{array}$ & $\begin{array}{c}\text { Week } 12 \\
(\mu \mathrm{g} / \mathrm{dL})\end{array}$ & $\begin{array}{c}\text { Dietary } \\
\text { treatment } \\
\mathrm{p} \text {-value }\end{array}$ & $\begin{array}{c}\text { Sex } \\
\text { effect } \\
p \text {-value }\end{array}$ \\
\hline Female & Control & $5.4 \pm 0.5$ & $5.4 \pm 0.69$ & $4.7 \pm 0.43$ & $4.9 \pm 0.51$ & \multirow{4}{*}{0.28} & \multirow{4}{*}{$<0.001$} \\
\hline Female & Taurine & $4.7 \pm 0.32$ & $4.6 \pm 0.40$ & $4.1 \pm 0.32$ & $4.8 \pm 0.21$ & & \\
\hline Male & Control & $8.4 \pm 0.38$ & $8.3 \pm 0.33$ & $4.7 \pm 0.43$ & $7.9 \pm 0.30$ & & \\
\hline Male & Taurine & $7.0 \pm 0.38$ & $8.1 \pm 0.27$ & $7.7 \pm 0.38$ & $7.6 \pm 0.37$ & & \\
\hline
\end{tabular}

Circulating serum TT4 mean \pm SEM concentrations measured in non-anesthetized rats $(\mathrm{n}=6$ per sex per treatment group). 
Table 3.4 Circulating serum TSH concentrations

\begin{tabular}{|c|c|c|c|c|c|c|c|}
\hline Sex & $\begin{array}{c}\text { Dietary } \\
\text { treatment }\end{array}$ & $\begin{array}{l}\text { Week } 0 \\
(\mathrm{pg} / \mathrm{mL})\end{array}$ & $\begin{array}{l}\text { Week } 4 \\
(\mathrm{pg} / \mathrm{mL})\end{array}$ & $\begin{array}{l}\text { Week } 8 \\
(\mathrm{pg} / \mathrm{mL})\end{array}$ & $\begin{array}{c}\text { Week } 12 \\
(\mathrm{pg} / \mathrm{mL})\end{array}$ & $\begin{array}{c}\text { Dietary } \\
\text { treatment } \\
\mathrm{p} \text {-value }\end{array}$ & $\begin{array}{c}\text { Sex } \\
\text { effect } p \\
\text { value }\end{array}$ \\
\hline Female & Control & $64.80 \pm 9.81$ & $57.25 \pm 8.92$ & $52.14 \pm 2.98$ & $57.38 \pm 5.63$ & \multirow{4}{*}{0.54} & \multirow{4}{*}{$<0.001$} \\
\hline Female & Taurine & $70.82 \pm 12.47$ & $35.03 \pm 7.04$ & $34.32 \pm 4.78$ & $58.51 \pm 7.12$ & & \\
\hline Male & Control & $90.56 \pm 18.42$ & $45.68 \pm 4.31$ & $52.14 \pm 11.51$ & $76.21 \pm 12.73$ & & \\
\hline Male & Taurine & $86.21 \pm 15.70$ & $58.18 \pm 7.04$ & $68.38 \pm 15.91$ & $84.04 \pm 11.00$ & & \\
\hline
\end{tabular}

Circulating serum TSH mean \pm SEM concentrations measured in non-anesthetized rats $(n=6$ per sex per treatment group). 
Figure 3.2 Circulating serum concentrations of T3
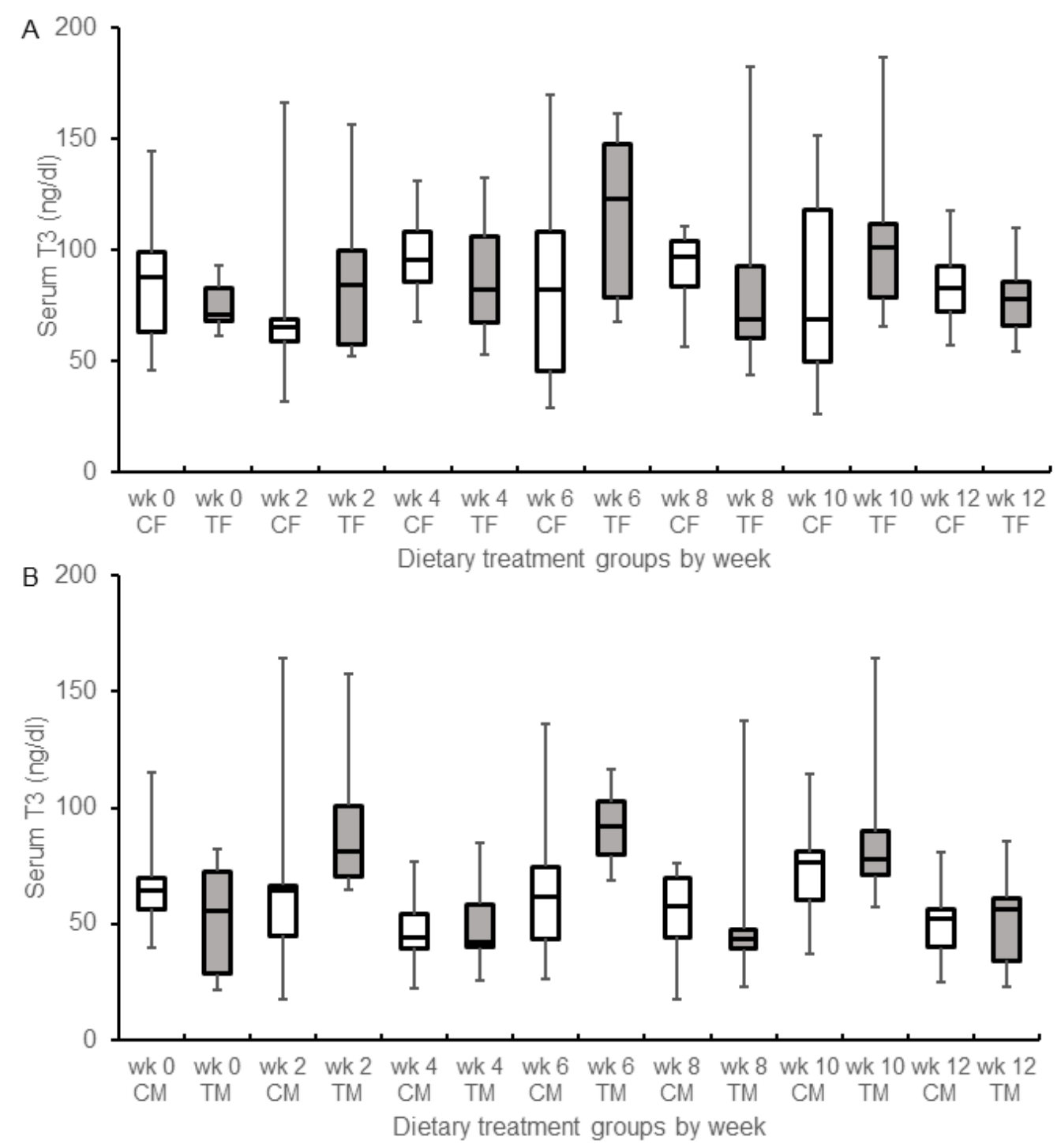

Circulating serum concentrations of T3 at weeks $0,4,8$, and 12 in (A) the control (CF) $(n=6)$ and high dietary taurine (TF) $(n=6)$ females and in (B) the control (CM) $(n=6)$ and high dietary taurine (TM) $(n=6)$ males. There were no significant dietary treatment effects over the twelve weeks $(p=0.21)$. 
Figure 3.3 Circulating serum concentrations of T4
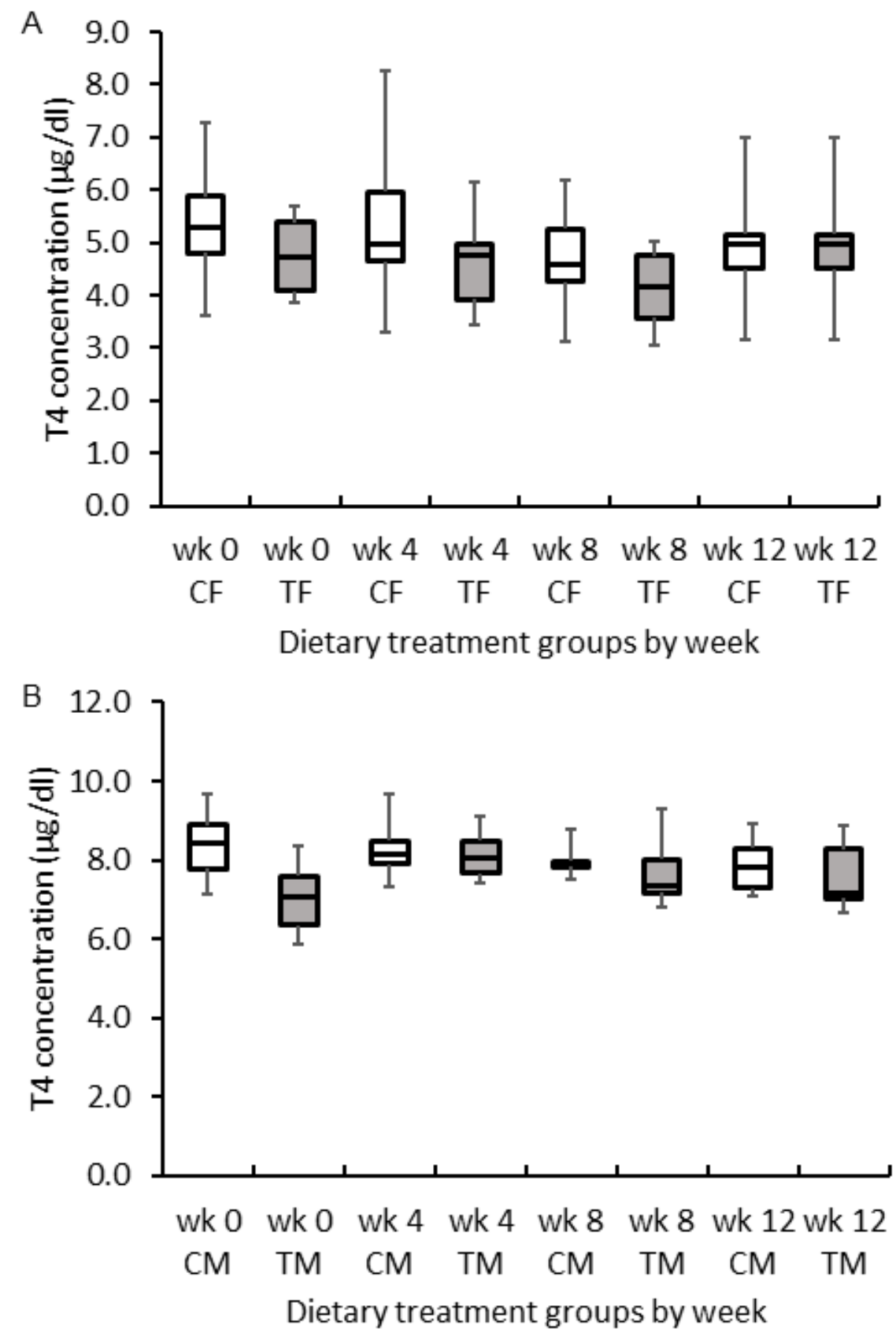

Circulating serum concentrations of T4 at weeks $0,4,8$, and 12 in (A) the control (CF) $(n=6)$ and high dietary taurine (TF) $(n=6)$ females and in (B) the control $(\mathrm{CM})(\mathrm{n}=6)$ and high dietary taurine $(\mathrm{TM})(\mathrm{n}=6)$ males. There were no significant dietary treatment effects over the twelve weeks $(p=0.28)$. 
There was a positive correlation found between serum T3 and taurine consumed every two weeks $(r=0.55, p<0.002)$ and serum T3 and plasma taurine concentrations $(r=0.50, p<0.001)$ for the female rats, but not for the male rats $(r=0.02, p=0.91 ; r=0.04, p=0.079)$. There were no correlations found between serum T4 and taurine consumed every 2 weeks (females $r=0.19$, $p=0.27$; males $r=-0.21, p=0.22)$ and between serum T4 and plasma taurine concentration (females $r=-0.01, p=0.94$; males $r=-0.25, p=0.09$ ). There were also no correlations between serum TSH and taurine consumed every two weeks (females $r=0.43, p=0.22$; males $r=0.09, p=0.58$ ) and serum TSH and plasma taurine concentration (females $r=-0.19, p=0.19$, males $r=-0.11, p=$ $0.44)$.

\section{Taurine concentrations}

The amount of taurine consumed correlated with the plasma taurine concentrations (females $r=0.88, p<0.001$; males $r=0.80, p<0.001$ ). Taurine post-prandial plasma concentrations were significantly higher in the female high dietary taurine treatment group $(p<0.001)$ and male high dietary taurine treatment group ( $p<0.001$ ) when compared to the control groups (Fig 3.4). There were no significant treatment effects found in the taurine content of the thyroid gland when normalized by the wet organ weight $(p=0.18)$ and the protein concentration $(p=0.43)($ Fig 3.5). 
Figure 3.4 Post-prandial plasma taurine concentrations

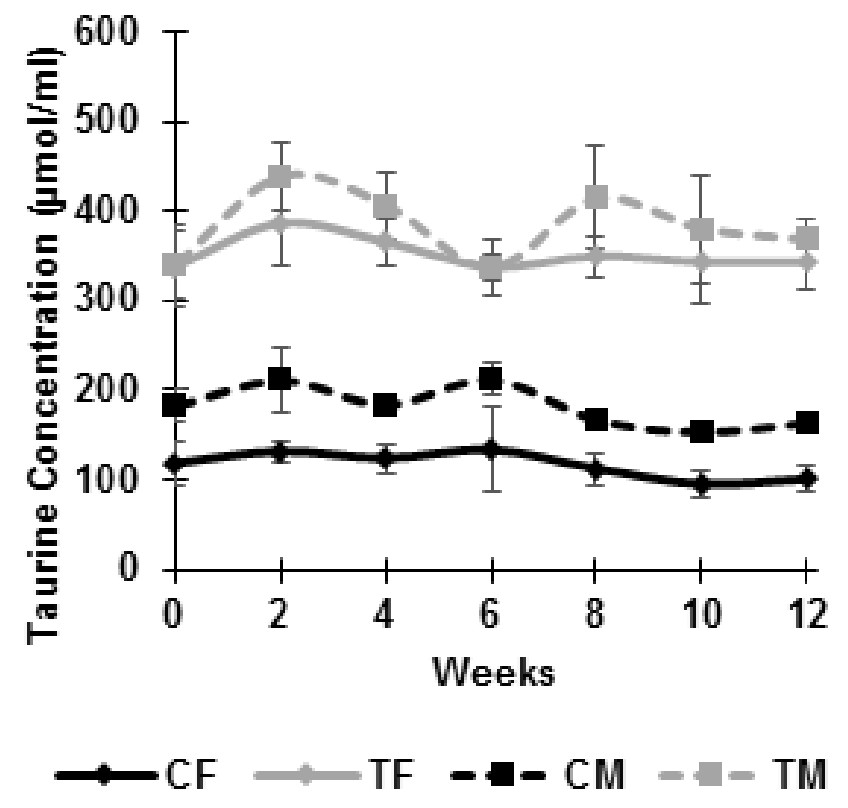

Post-prandial plasma taurine concentrations in control females (CF) $(n=6)$, control males (CM) $(n=6)$, high dietary taurine females (TF) $(n=6)$, and high dietary taurine males (TM) $(n=6)$. 
Figure 3.5 Thyroid gland taurine concentrations
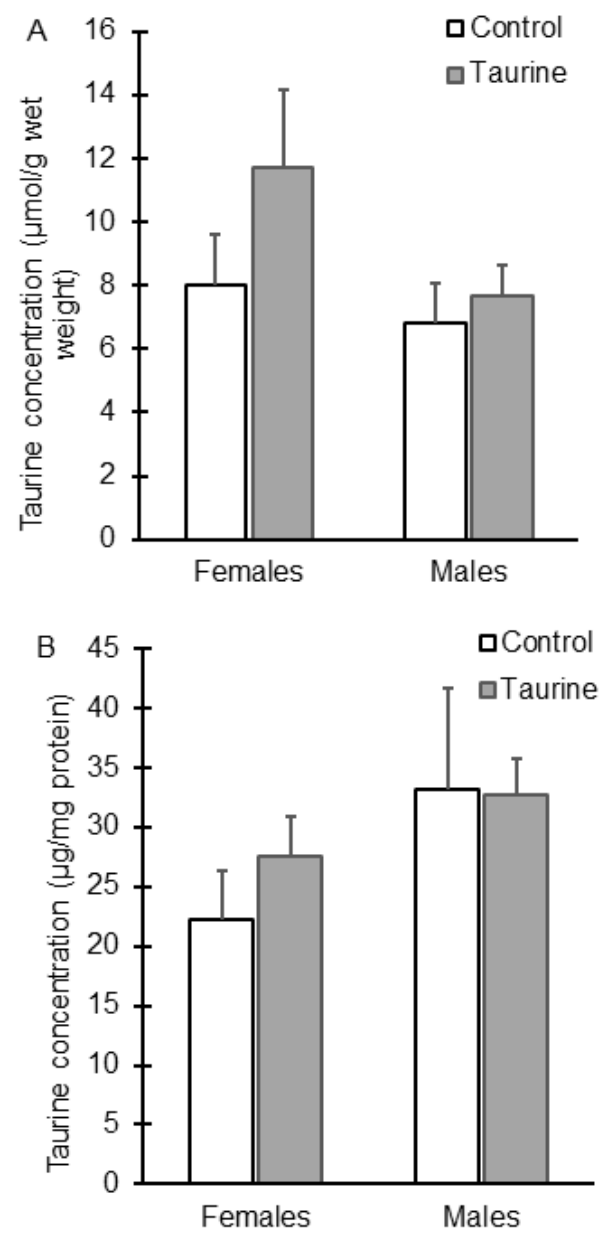

There were no significant treatment effects found in the taurine content of the thyroid gland when normalized by $(A)$ the wet organ weight $(p=0.18)$ and $(B)$ the protein concentration $(p=0.43)$.

\section{Feed intake}

Over the entire 12-week study, the female high dietary taurine rats consumed $855 \pm 12.9$ grams (SEM) which was significantly more than the female control rats who consumed an average of $795 \pm 26.9$ grams $(p<0.05)$ (table 3.5). The female high dietary taurine rats body mass significantly increased compared to the body mass of the female control rats $(p<0.01)$. There was not a significant difference $(p=0.68)$ between the feed consumption of the control 
males compared to the male high dietary taurine treatment group (table 3.5) nor a significant difference in weight gain $(p=0.44$; control $98.0 \pm 4.7$ grams; taurine $107.0 \pm 8.2$ grams).

Table 3.5 Summary of weights, feed intake, and feed conversion

\begin{tabular}{|c|c|c|c|c|c|c|}
\hline Treatment & Control & Taurine & Control & Taurine & \multirow{2}{*}{$\begin{array}{c}\text { Treatment } \\
\text { p-value }\end{array}$} & \multirow{2}{*}{$\begin{array}{l}\text { Sex- } \\
\text { effect } \\
\text { p-value }\end{array}$} \\
\hline Sex & $\begin{array}{c}\text { Female } \\
(\mathrm{n}=6)\end{array}$ & $\begin{array}{c}\text { Female } \\
(n=6)\end{array}$ & $\begin{array}{l}\text { Male } \\
(n=6)\end{array}$ & $\begin{array}{l}\text { Male } \\
(n=6)\end{array}$ & & \\
\hline $\begin{array}{c}\text { Starting } \\
\text { weight }(\mathrm{g})\end{array}$ & $207 \pm 10.6$ & $202 \pm 8.33$ & $319 \pm 8.50$ & $315 \pm 4.83$ & 0.35 & 0.001 \\
\hline $\begin{array}{c}\text { Ending } \\
\text { Weight }(\mathrm{g})\end{array}$ & $216 \pm 5.54^{*}$ & $230 \pm 8.29^{*}$ & $417 \pm 15.5$ & $422 \pm 24.1$ & 0.02 & 0.001 \\
\hline $\begin{array}{c}\text { Weight } \\
\text { Gain (\%) }\end{array}$ & $4.68 \pm 0.05^{*}$ & $13.9 \pm 0.06^{*}$ & $30.1 \pm 0.04$ & $34.0 \pm 0.06$ & 0.001 & 0.001 \\
\hline $\begin{array}{c}\text { Feed } \\
\text { intake }(g)\end{array}$ & $795 \pm 26.9^{*}$ & $854+12.9^{*}$ & $1267 \pm 63.8$ & $1310 \pm 71.4$ & 0.03 & 0.001 \\
\hline
\end{tabular}

* Denotes significance difference in females only. Dietary taurine treatment resulted in an increase ending weight, an increase in percent weight gain, and an increase in feed intake.

\section{Histology}

All 24 thyroid glands examined had evidence of partial or complete follicular collapse which altered the follicular diameter and sometimes caused indistinct margins of the follicular cells, prohibiting measurement of the follicular diameter and epithelium height. To determine if this was autolysis, another investigator euthanized 8 adult, male, Wistar rats (Crl:WI Charles River, Wilmington, MA, USA) and allowed us to collect the thyroid glands from 2 rats at each of the following time points: $0,30,60$, or 90 minutes post-euthanasia. The glands were immediately fixed in $10 \%$ buffered formalin and submitted as previously described for periodic acid-Schiff staining. The thyroids among the 8 
rats harvested at $0,30,60$, and 90 minutes after euthanasia had evidence of partial follicular collapse with loss of colloid at 30 minutes post-euthanasia with carbon dioxide (Fig 3.6). Due to unexpectedly rapid autolysis affecting the thyroid glands, histological analysis of the follicles was not continued as the observer could not differentiate between morphological changes caused by autolysis or possible treatment effects. 


\section{Figure 3.6 Periodic acid-Schiff stained thyroid glands}

9
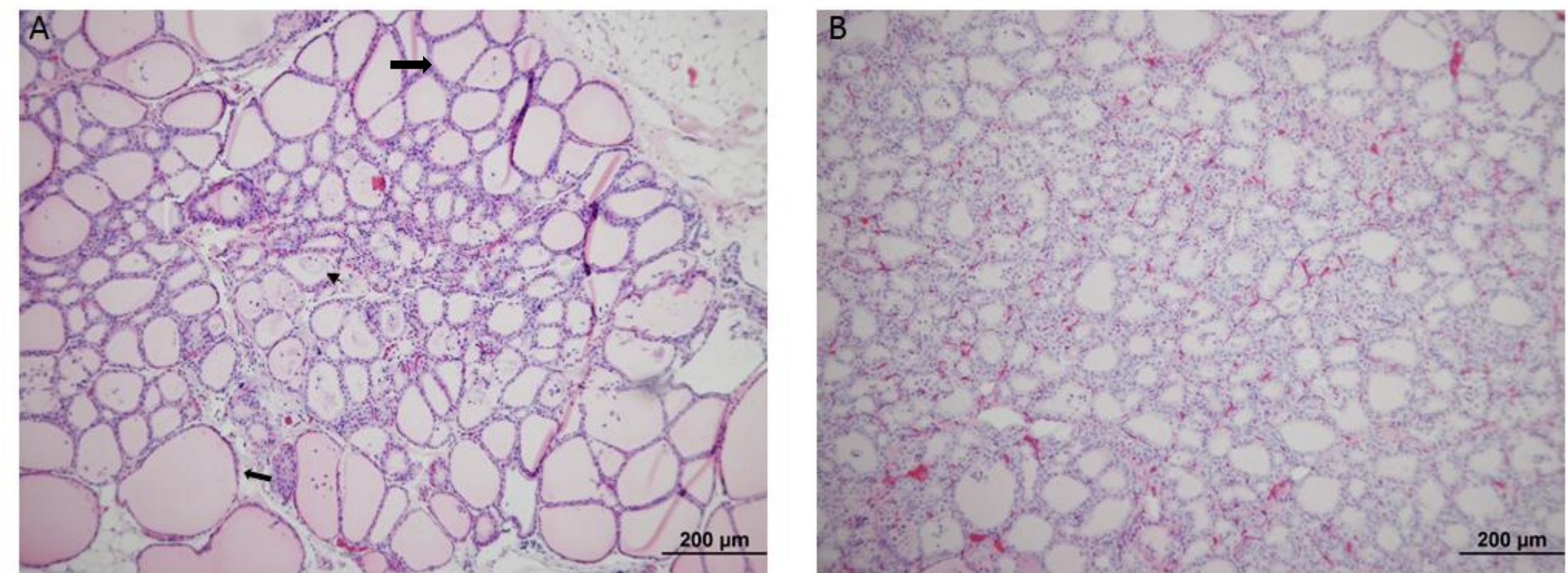

(A) Photomicrograph of a PAS stained Wistar rat thyroid gland, collected 30 minutes after euthanasia. An example of a large follicle filled with colloid designated by $(\vec{b})$. The arrowhead points to a small amount of colloid that is left in a follicle as it begins to collapse. (B) A PAS stained Wistar rat thyroid gland collected 90 minutes after euthanasia. There is no colloid in the follicles, and they are partially to completely collapsed. 


\section{Discussion}

Rodent animal models are heavily utilized in thyroid research including studies focused on the effects of dietary constituents on the hypothalamicpituitary-thyroid axis (Gallaher 1992; Vanderpas 2006). Animal models are also utilized in nutrition research, and most of our knowledge on tolerance of amino acid excess has come from animal studies (Baker 2008). Rats in particular have been heavily utilized in taurine research (Huxtable 1992). Since rats readily consume purified diets and our control rats would not become taurine deficient, as rodents can adequately synthesize taurine from dietary methionine and cysteine (Huxtable 1992; Ito et al. 2012), we selected to use the rat as an animal model to test our hypothesis that excessive dietary taurine would alter the homeostasis of the thyroid axis. Furthermore, we selected a rat model because it is considered a sensitive mammalian model for detecting changes in the thyroid axis when screening for endocrine disrupting compounds that alter the production of thyroid hormones (Pickford 2010). The underlying physiology of the rat including high numbers of sodium iodide symporters on thyroid follicular cells (Josefsson et al. 2002), low amounts of colloid stores in the thyroid gland (McClain 1995), and short half-lives of the thyroid hormones due to thyroid binding globulin transporter being absent in rats age $2-7$ months old (Lewandowski et al. 2004) are all thought to contribute to the sensitivity of the rat by limiting their ability to compensate for compounds that disrupt the thyroid axis (Pickford 2010).

Our rats exhibited inter- and intra-individual variation of circulating serum thyroid hormone concentrations (Fig 3.1) similar to the variation reported in 
humans (Maes et al. 1997). This finding was unexpected due to the low amount of colloid store in the rat thyroid gland and the reported limited ability of rats to compensate for thyroid axis disruptions (Pickford 2010). While rats on the high taurine diet had significantly increased post-prandial concentrations of taurine (Fig 3.4), we did not detect an increased uptake of taurine by the thyroid gland (Fig 3.5) nor did taurine elucidate a treatment effect on the circulating concentrations of T4, T3, and TSH (Fig 3.2-3.3). However, the biological variation in our thyroid hormone data may be masking a dietary treatment effect, and therefore future studies should have a larger sample size.

Typically, most rodent studies only measure circulating concentrations of thyroid hormones at the endpoint of a study, as to the authors' knowledge, there are no reports of rodent studies evaluating variation in concentrations of circulating levels of thyroid hormones over time (Pickford 2010). Even established guidelines set forth by the US Environmental Protection Agency (EPA) pertaining to pesticide-induced alterations of the thyroid axis and the guidelines set forth by the Organization for Economic Co-operation and Development (OECD) for reproduction/developmental toxicity screening of endocrine disruptors do not address the biological variation we observed and only recommend measuring thyroid hormones at the terminal endpoints. Additionally, the guidelines dedicate a section to hormone analysis, with both organizations highlighting only the importance of drawing blood at the same time of day due to circadian rhythm of thyroid hormones and recommend to minimize any stress that could affect circulating thyroid hormones (OECD 2015; EPA 
2005). EPA also mentions that if animals are anesthetized, then documentation should be provided that anesthetic does not exert an effect on the circulating thyroid hormones (EPA 2005).

Our study addressed the factors outlined in the EPA and OECD guidelines by collecting blood samples for each animal at the same time of day, not using anesthesia while collecting blood samples used for thyroid hormone analysis, and the animals were acclimated to handling and the restraint prior to the start of the study. If we had selected only a single time point for measuring the circulating thyroid hormones as other studies, our data could have shown a significant effect between groups (Fig. 3.2-3.3) which clearly would have been the natural variation of the individuals rather than a true effect. Therefore, the biological variability in circulating thyroid hormones is important to consider when designing studies aimed at detecting treatment effects in the functioning of the thyroid axis. Well-designed human clinical studies provide additional support for this concept as the goal of most animal model studies are to identify endocrine disrupting compounds that could cause effects in humans. Of particular note are the human clinical studies that focused on how biological variation affects interpretation of thyroid function tests (Andersen et al. 2003; Benhadi et al. 2010), as it is well recognized within the population that large inter- and intraindividual variation of serum T3, T4, and TSH exists in healthy human subjects. These studies have resulted in some physicians developing "rule of thumbs" for assessing changes in circulating thyroid hormone concentrations, such as a change of $40 \mathrm{nmol} / \mathrm{L}$ in T4 is needed to achieve a beta of 0.90 (Andersen et al. 
2003). Changes in circulating thyroid hormones, considered to represent a true, clinically significant change, should be established for rodent studies where circulating thyroid hormones are a measured outcome.

Despite the high biological variation that we observed, effects of sex were found. The circulating serum concentrations of T4 and TSH in the male rats were significantly higher than in the female rats, and the circulating serum T3 concentrations in the female rats were significantly higher than in the male rats (Fig 3.1). These sex differences have been previously reported in many other studies (Marassi et al. 2007; Rapp and Pyun 1974) and it has been suggested that greater hepatic sulfotransferase activity in males (Gong et al. 1992) could explain why the serum T3 in males is lower (Marassi et al. 2007). There are additional, well established sex-related differences in thyroid function such as increased T3 and TRH receptors in the adenohypophysis of female rats (Donda et al. 1990). Unfortunately, none of these sex-related differences have provided insight into why there is a higher prevalence of hyperthyroidism and thyroid diseases in females (Krohn et al. 2005a).

Our study incorporated both sexes to determine if taurine exerted any sexspecific effects on the function of the thyroid axis which could help to explain the increased incidence of hyperthyroidism in females. In other studies investigating taurine supplementation, sex-specific effects have been found. One such study by Roysommuti et al. (2009) found that supplementing Sprague-Dawley rats with taurine alters arterial blood pressure control depending upon the sex of the rat (Roysommuti et al. 2009). 
Interestingly, only in the female rats was there a significant correlation between circulating serum T3 and the amount of taurine consumed. This was also true for the correlation between circulating serum T3 and circulating plasma taurine concentrations. While sex hormones influence the deiodinase enzymes that are responsible for converting T4 to T3 (Marassi et al. 2007), it is unknown if taurine has any regulation of deiodinase activity. It could be that taurine alters the gene expression of the deiodinases found within the thyroid gland as it has been shown that gene expression can be influenced through high dietary taurine consumption (Yokogoshi et al. 1999). Since the thyroid gland is responsible for $40 \%$ of daily T3 production in the rat (Bianco et al. 2002), perhaps with larger samples sizes, we could have clearly detected an increased concentration of taurine in the female thyroids. Increased taurine content in female thyroid glands has been reported in a larger study (Jacobsen and Smith 1968) and could help explain as to why circulating T3 concentrations in the female rats are correlated with taurine. The sex difference found in taurine content could also help explain why circulating T3 concentrations are significantly higher in female rats compared to the male rats.

Another sex-specific taurine effect in our study was the significant increase in feed intake and body weight gain in the female high dietary taurine treated rats. Taurine has been shown to improve growth and feed conversion efficiency in a variety of species within the aquaculture industry (Johnson et al. 2015; Matsunari et al. 2008), although the mechanism remains unknown. Dietary taurine has been shown to increase amylase, lipase, trypsin, and pepsin 
enzyme activity in larval cobia which has led to the thought perhaps taurine increases the nutrient availability within the diet (Salze et al. 2012). Another possible mechanism is that dietary taurine alters the bile acid composition leading to an alteration in the microbial community in the gut. It is thought that bile acids are responsible for controlling some aspects of the microbial community (Ridlon et al. 2014).

Another important study finding was how quickly the post-mortem changes altered the morphology of the thyroid glands. Multiple studies have indicated that histopathological analysis in mammalian models is one of the most sensitive outcomes for evaluation of changes in the thyroid axis (Pickford 2010). None of these studies discuss how quickly autolysis affects the thyroid glands of rats. Several studies have utilized human thyroids collected during autopsies for histological studies including one report by De Jongh et al. (2001) that showed there were no changes in follicular diameter of the thyroid gland up to 48 hours post-mortem (De Jongh et al. 2001). The post-mortem collapse of the follicular cells and loss of distinct cellular borders that we observed (Fig 3.6) may have been due to a species differences. Rats have cuboidal follicular epithelium and small amounts of colloid compared to those in the thyroid glands of primates who have large amounts of colloid and a thin cuboidal follicular epithelium (McClain 1995). The post-mortem changes in the rats prohibited us from being able to detect histopathologically identifiable treatment effects such as follicular hypertrophy. In rats, there are few studies that incorporate histopathological data at the endpoints (Pickford 2010). This absence of reporting may reflect on the 
challenge of preserving the thyroid glands without artefactual post-mortem changes. Many researchers, including our laboratory group, specifically harvest tissue for immediate freezing to measure time-sensitive biomarkers such as mRNA. Similar expedience appears to be needed for histological evaluation of the thyroid glands of rats.

\section{Conclusion}

Our study sought to determine if the consumption of high levels of dietary taurine affected the homeostasis of the thyroid axis. While there was a significant positive correlation between serum T3 and plasma taurine concentrations in the female rats, we did not observe this in the male rats.

Additionally, the female high dietary taurine rats exhibited a significant increase in body weight and food consumption compared to the control female rats. With the unexpectedly large intra- and inter-individual variation of serum T3, T4, and $\mathrm{TSH}$, our results indicate a larger study evaluating the effects of taurine on the female thyroid axis is warranted.

\section{Acknowledgements}

The authors also thank Matt Myles and Corri Philips for their assistance with this project. 


\section{References}

Alford C, Cox H, Wescott R (2001) The effects of red bull energy drink on human performance and mood Amino acids 21:139-150

Andersen S, Bruun NH, Pedersen KM, Laurberg P (2003) Biologic variation is important for interpretation of thyroid function tests Thyroid : official journal of the American Thyroid Association 13:1069-1078 doi:10.1089/105072503770867237

Baker DH (2008) Animal models in nutrition research J Nutr 138:391-396

Benhadi N, Fliers E, Visser TJ, Reitsma JB, Wiersinga WM (2010) Pilot study on the assessment of the setpoint of the hypothalamus-pituitary-thyroid axis in healthy volunteers European journal of endocrinology / European Federation of Endocrine Societies 162:323-329 doi:10.1530/eje-09-0655

Bianco AC, Salvatore D, Gereben B, Berry MJ, Larsen PR (2002) Biochemistry, cellular and molecular biology, and physiological roles of the iodothyronine selenodeiodinases Endocrine reviews 23:38-89

doi:10.1210/edrv.23.1.0455

Bradford MM (1976) A rapid and sensitive method for the quantitation of microgram quantities of protein utilizing the principle of protein-dye binding Analytical biochemistry 72:248-254

Chang KJ, Kwon W (2000) Immunohistochemical localization of insulin in pancreatic beta-cells of taurine-supplemented or taurine-depleted diabetic rats Advances in experimental medicine and biology 483:579-587 doi:10.1007/0-306-46838-7_62 
De Jongh FE, Jobsis AC, Elte JW (2001) Thyroid morphology in lethal nonthyroidal illness: a post-mortem study European journal of endocrinology / European Federation of Endocrine Societies 144:221-226

de Souza Dos Santos MC, Goncalves CF, Vaisman M, Ferreira AC, de Carvalho DP (2011) Impact of flavonoids on thyroid function Food and chemical toxicology : an international journal published for the British Industrial Biological Research Association 49:2495-2502 doi:10.1016/j.fct.2011.06.074

Donda A, Reymond F, Rey F, Lemarchand-Beraud T (1990) Sex steroids modulate the pituitary parameters involved in the regulation of TSH secretion in the rat Acta endocrinologica 122:577-584

Environmental Protection Agency (2005) Guidance for Thyroid Assays in Pregnant Animals, Fetuses, and Postnatal Animals, and Adult Animals. Environmental Protection Agency, Washington, DC Gallaher DD (1992) Animal Models in Human Nutrition Research Nutrition in Clinical Practice 7:37-39 doi:doi:10.1177/011542659200700137 Gavrovskaya LK, Ryzhova OV, Safonova AF, Matveev AK, Sapronov NS (2008) Protective effect of taurine on rats with experimental insulin-dependent diabetes mellitus Bulletin of experimental biology and medicine 146:226228 doi:10.1007/s10517-008-0258-4

Gong DW, Murayama N, Yamazoe Y, Kato R (1992) Hepatic triiodothyronine sulfation and its regulation by growth hormone and triiodothyronine in rats J Biochem 112:112-116 
Higgins JP, Tuttle TD, Higgins CL (2010) Energy beverages: content and safety Mayo Clinic proceedings 85:1033-1041 doi:10.4065/mcp.2010.0381 Huxtable RJ (1992) Physiological actions of taurine Physiological reviews 72:101-163

Ito T, Schaffer SW, Azuma J (2012) The potential usefulness of taurine on diabetes mellitus and its complications Amino acids 42:1529-1539 doi:10.1007/s00726-011-0883-5

Jacobsen JG, Smith LH (1968) Biochemistry and physiology of taurine and taurine derivatives Physiological reviews 48:424-511

Jhiang SM, Fithian L, Smanik P, McGill J, Tong Q, Mazzaferri EL (1993) Cloning of the human taurine transporter and characterization of taurine uptake in thyroid cells FEBS letters 318:139-144

Johnson RB et al. (2015) Effects of dietary taurine supplementation on growth, feed efficiency, and nutrient composition of juvenile sablefish (Anoplopoma fimbria) fed plant based feeds Aquaculture 445:79-85 doi:http://dx.doi.org/10.1016/j.aquaculture.2015.03.030

Josefsson M, Grunditz T, Ohlsson T, Ekblad E (2002) Sodium/iodide-symporter: distribution in different mammals and role in entero-thyroid circulation of iodide Acta physiologica Scandinavica 175:129-137 doi:10.1046/j.1365201X.2002.00968.x

Kohrle J (1999) The trace element selenium and the thyroid gland Biochimie $81: 527-533$ 
Krohn K, Fuhrer D, Bayer Y, Eszlinger M, Brauer V, Neumann S, Paschke R (2005) Molecular pathogenesis of euthyroid and toxic multinodular goiter Endocrine reviews 26:504-524 doi:10.1210/er.2004-0005

Lambert IH, Kristensen DM, Holm JB, Mortensen OH (2015) Physiological role of taurine - from organism to organelle Acta Physiologica 213:191-212 doi:10.1111/apha.12365

Lewandowski TA, Seeley MR, Beck BD (2004) Interspecies differences in susceptibility to perturbation of thyroid homeostasis: a case study with perchlorate Regul Toxicol Pharmacol 39:348-362

doi:10.1016/j.yrtph.2004.03.002

Lourenco R, Camilo ME (2002) Taurine: a conditionally essential amino acid in humans? An overview in health and disease Nutricion hospitalaria 17:262270

Maes $\mathrm{M}$ et al. (1997) Components of biological variation, including seasonality, in blood concentrations of TSH, TT3, FT4, PRL, cortisol and testosterone in healthy volunteers Clinical endocrinology 46:587-598

Marassi MP, Fortunato RS, da Silva ACM, Pereira VS, Carvalho DP, Rosenthal D, da Costa VMC (2007) Sexual dimorphism in thyroid function and type 1 iodothyronine deiodinase activity in pre-pubertal and adult rats Journal of Endocrinology 192:121-130 doi:10.1677/joe.1.06901

Matsunari H, Yamamoto T, Kim S-K, Goto T, Takeuchi T (2008) Optimum dietary taurine level in casein-based diet for juvenile red sea bream Pagrus major Fisheries Science 74:347-353 doi:10.1111/j.1444-2906.2008.01532.x 
McClain RM (1995) Mechanistic considerations for the relevance of animal data on thyroid neoplasia to human risk assessment Mutat Res 333:131-142

National Institutes of Health (2011) Guide for the care and use of laboratory animals. 8th Edition. NIH publication. U.S. Dept. of Health and Human Services, Public Health Service, Bethesda, Md.

OECD Test No. 421: Reproduction/Developmental Toxicity Screening Test. OECD Publishing, http://dx.doi.org/10.1787/9789264242692-en

Pickford DB (2010) Screening chemicals for thyroid-disrupting activity: A critical comparison of mammalian and amphibian models Crit Rev Toxicol 40:845-892 doi:10.3109/10408444.2010.494250

Rapp JP, Pyun LL (1974) A sex difference in plasma thyroxine and thyroid stimulating hormone in rats Proceedings of the Society for Experimental Biology and Medicine Society for Experimental Biology and Medicine $146: 1021-1023$

Reeves PG, Nielsen FH, Fahey GC, Jr. (1993) AIN-93 purified diets for laboratory rodents: final report of the American Institute of Nutrition ad hoc writing committee on the reformulation of the AIN-76A rodent diet $\mathrm{J}$ Nutr $123: 1939-1951$

Ridlon JM, Kang DJ, Hylemon PB, Bajaj JS (2014) Bile Acids and the Gut Microbiome Current opinion in gastroenterology 30:332-338 doi:10.1097/MOG.0000000000000057

Roysommuti S, Suwanich A, Lerdweeraphon W, Thaeomor A, Jirakulsomchok D, Wyss JM (2009) Sex dependent effects of perinatal taurine exposure on 
the arterial pressure control in adult offspring Advances in experimental medicine and biology 643:135-144 doi:10.1007/978-0-387-75681-3_14

Salze G, McLean E, Craig SR (2012) Dietary taurine enhances growth and digestive enzyme activities in larval cobia Aquaculture 362-363:44-49 doi:http://dx.doi.org/10.1016/j.aquaculture.2012.07.021

Sarwar G, Botting HG (1990) Rapid analysis of nutritionally important free amino acids in serum and organs (liver, brain, and heart) by liquid chromatography of precolumn phenylisothiocyanate derivatives Journal Association of Official Analytical Chemists 73:470-475

Schaffer SW, Shimada K, Jong CJ, Ito T, Azuma J, Takahashi K (2014) Effect of taurine and potential interactions with caffeine on cardiovascular function Amino acids 46:1147-1157 doi:10.1007/s00726-014-1708-0

Torregrossa L et al. (2012) Toward the reliable diagnosis of indeterminate thyroid lesions: a HRMAS NMR-based metabolomics case of study J Proteome Res 11:3317-3325 doi:10.1021/pr300105e

Vahl TP et al. (2014) Meal feeding improves oral glucose tolerance in male rats and causes adaptations in postprandial islet hormone secretion that are independent of plasma incretins or glycemia American journal of physiology Endocrinology and metabolism 307:E784-792

doi:10.1152/ajpendo.00339.2014

Vanderpas J (2006) Nutritional epidemiology and thyroid hormone metabolism Annual review of nutrition 26:293-322 doi:10.1146/annurev.nutr.26.010506.103810 
Vanderpump MPJ (2005) The Epidemiology of Thyroid Diseases. In: Werner SC, Ingbar SH, Braverman LE, Utiger RD (eds) Werner \& Ingbar's the Thyroid: A Fundamental and Clinical Text. vol v. 549. Lippincott Williams \& Wilkins, USA, pp 398-406

Wright CE, Tallan HH, Lin YY, Gaull GE (1986) Taurine: biological update Annu Rev Biochem 55:427-453 doi:10.1146/annurev.bi.55.070186.002235

Yokogoshi H, Mochizuki H, Nanami K, Hida Y, Miyachi F, Oda H (1999) Dietary taurine enhances cholesterol degradation and reduces serum and liver cholesterol concentrations in rats fed a high-cholesterol diet J Nutr $129: 1705-1712$ 


\section{CHAPTER 4}

\section{Increased lean muscle mass and body fat in adult female Sprague Dawley rats (Rattus norvegicus) fed a high taurine diet}

This chapter is under review for publication at a peer review journal

Authors: Sarah E. Hooper ${ }^{1}$, Sybill K. Amelon², Scott W. Korte ${ }^{3}$, Erin K. O'Connor ${ }^{3}$, Robert. C. Backus ${ }^{4}$

\section{Affiliations and addresses}

1 Department of Veterinary Pathobiology, College of Veterinary Medicine, University of Missouri, 4011 Discovery Drive S129, Columbia, Missouri 65201, USA

2 USDA Forest Service, Northern Research Station, 202 Anheuser-Busch Natural Resources Building, Columbia, Missouri 65211, USA 3 Office of Animal Resources, University of Missouri, 1720 East Campus Loop, Columbia, Missouri, 65211, USA

4 Department of Veterinary Medicine and Surgery, College of Veterinary Medicine, University of Missouri, A384 Clydesdale Hall, Columbia, Missouri 65211, USA 


\section{Abstract}

High doses of oral taurine, a $\beta$-amino acid, are recommended to help mitigate certain diseases; however, little is known about possible negative side effects of these large doses. The purpose of our study was to determine if taurine-induced increases in the body weight of female rats was due to an increase in muscle mass, an increase fat mass, or both. We hypothesized that dietary taurine would cause an increase in circulating insulin-like growth factor-1 (IGF-1) yielding to an increase in lean muscle mass. Furthermore, we hypothesized that taurine would cause an increase in Firmicutes and decrease in Bacteroides and the changes could be correlated to an increase in body fat. To test these hypothesis, 12 male and 12 female sexually mature Sprague Dawley rats were randomly assigned to a $0 \%$ taurine or a $0.7 \%$ taurine diet for 12 weeks. Circulating IGF-1 concentrations were measured at day $0,14,28,42,56,70$, and 84. Fecal microbiome analysis was completed on fecal pellets collected on Day 0 and Day 84. On Day 85, dual x-ray absorptiometry (DXA) scans were completed and revealed a trend of increased fat $(p=0.09)$ and lean + bone mineral content $(p=0.10)$ in female rats consuming the high taurine diet. The female rats consuming the high dietary taurine diet had an increase in Firmicutes and a decrease in Bacteroidetes phyla $(p<0.05)$. The $\beta$-diversity at the OTU level was different between males and females at day $0(p<0.001)$, but the sexdifference was lost by day $84(p=0.12)$. Taurine did not increase the circulating serum IGF-1 concentrations ( $p=0.42)$, but sex- effects were observed $(p<$ 0.001 ) with mean circulating concentrations of IGF-1 with $863 \pm 24.1 \mathrm{ng} / \mathrm{mL}$ in the females and $1284 \pm 21.95 \mathrm{ng} / \mathrm{mL}$ in the males. Our results suggest that the 
AIN-93 purified diet and high levels of dietary taurine may promote an increase in Firrmicutes phylum and a decrease in Bacteroides phylum that is associated with obesity.

\section{Introduction}

Amino acids, once considered simply building blocks for proteins, are now recognized to have funcational roles in metabolism such as lipid and glucose metabolic pathways, anti-oxidative reactions, and generation of physiologically important peptides and nitrogenous substances (Wu et al. 2014). This new perception of amino acids challeges the traditional classifications of essential or nonessential amino acids. Amino acids classified as essential must be acquired in the diet as they are not synthesized de novo or cannot be synthesized in adequate amounts to meet the animal or human's needs (Wu 2009).

Nonessential amino acids are synthesized de novo in adequate amounts and are not required to be consumed in the diet (Wu 2009). A third category, conditionally essential amino acids, are synthesized de novo; however, there are limits to the rate at which they can be synthesized (Reeds 2000).

Taurine, a $\beta$-amino acid, is classified as a conditionally essential amino acid in some species while in other species it is either nutritionally essential or non-essential (Jacobsen and Smith 1968). Healthy adult individuals in some species can biosynthesize adequate amounts of taurine to meet their needs from dietary cysteine and methionine (Jacobsen and Smith 1968; Wu et al. 2014) while individuals undergoing certain stresses (e.g. severe infection) or during certain life stages (e.g. neonates) cannot adequately synthesize taurine to meet the body's biological needs (Lourenco and Camilo 2002). Therefore, taurine 
must be acquired through the diet under these conditions. With the recognition of the functional roles of amino acids beyond their nutritional essentiality (Wu 2010) there is a developing interest in providing taurine to optimize health in adults and treat diseases. Clinicians have recommended supplemental oral taurine to help mitigate certain diseases such as hypertension (Militante and Lombardini 2002), and are beginning to recommend taurine to treat secondary disease complications such as endothelial dysfunction in diabetes (Ito et al. 2012). Clinical research evaluating taurine supplementation in diseased individuals have evaluated oral doses of up to 10 grams per day (Durelli et al. 1983). These taurine doses are much higher than the average dietary taurine consumption of $58 \mathrm{mg}$ per day in Europe (Schaffer et al. 2014) or $123 \mathrm{mg}$ per day in America (Laidlaw et al. 1990). It is largely unknown if there are risks associated with these high doses of taurine as clinical studies have been short duration, and typically data provided for evaluating possible negative side effects of taurine administration is limited to self-reporting within these studies (Shao and Hathcock 2008).

Recently, using a rat model, our laboratory sought to test the hypothesis that extraordinary high dietary taurine could alter the activity of the hypothalamicpituitary-thyroid axis. Our hypothesis stemmed from in-vitro evidence that taurine increases proliferation rates of thyroid cells when cultured in taurine-containing media (Jhiang et al. 1993). In our study, we determined that there was a positive correlation between circulating concentrations of plasma taurine and serum triiodothyronine (T3), but only in female rats (Hooper et al. 2017). Interestingly, 
we also observed that the female rats consuming high dietary taurine diet gained significantly more weight compared to the control females. The weights of the male rats consuming high dietary taurine were not significantly different compared to the control rats (Hooper et al. 2017). Therefore, the purpose of our study presented here was to determine if the taurine-induced increase in body weight among the female rats was due to increased lean muscle mass or increased fat mass and to investigate two alternative mechanisms that could explain the observed gain in body weight.

We hypothesized that the rats given high dietary taurine would have increased lean muscle mass and that the effect may be caused by an increase in circulating insulin-like growth factor-1 (IGF-1). Both IGF-1 and growth hormone are recognized to play a role in post-natal growth (Lupu et al. 2001), and intravenous taurine has been shown to increase circulating IGF-1 (Ikuyama et al. 1988). Additionally, IGF-1 is known to play a role in thyroid function (Ock et al. 2013), and could help explain the correlation between circulating T3 and plasma taurine.

Furthermore, liver taurine concentration is known to be elevated with high dietary taurine intake (Satsu et al. 2002). It is also known that taurine conjugation of bile acids is strongly correlated to the taurine content in the liver (Martin et al. 2007), and that alterations in bile acid composition leads to an alteration in the microbial community in the gut (Ridlon et al. 2014). Therefore, our second mechanistic hypothesis was that rats consuming the high taurine diet would have an alteration in the composition of bacteria in the gut, causing an 
increase in bacterial phyla associated with weight gain (e.g. an increase in Firmicutes and decrease in Bacteroides) (Holmes et al. 2011) that could help explain the increase in weight gain.

\section{Materials and Methods}

Descriptions of animals, study design, blood collection methods, and taurine analysis are described in brief. Detailed descriptions are in the companion report Hooper et al. (2017).

\section{Ethics statement}

This study was carried out in an AALAAC accredited animal facility in accordance to the Guide for the Care and Use of Laboratory Animals of the National Institutes of Health. All activities were conducted under an approved University of Missouri-Columbia Animal Care and Use Committee animal use protocol.

\section{Animals}

Twelve male, ten-week-old Sprague Dawley rats and twelve, seventeenweek-old female Sprague Dawley rats (Hsd: Sprague Dawley rats, Envigo, USA) were acclimated to handling, restraint, and meal feeding prior to the start of the study. The male rats were younger, as rats were requested from Harlan Laboratories Inc. (now Envigo, Indianapolis, Indiana, USA) to be at the top of the growth curve rather than a specific age. Rats were pair housed in an animal facility that was temperature controlled and under a $12 \mathrm{hr}$ light-dark cycle (light 600 to $1800 \mathrm{hrs})$. 


\section{Diets and study design}

The study began after all rats underwent adaption to a daily 4-hour period during which a standard rodent chow was presented for ad libitum consumption (Lab Diet Rat Diet 5012, St. Louis, MO, USA). Once body weights stabilized, the rats were randomly assigned to one of two dietary treatment groups that were balanced for sex and starting body weight. Using a parallel design of 12 weeks duration (84 days), the rats were individually housed from 800 to $1200 \mathrm{hrs}$ and presented with $\sim 50$ grams of their assigned diet, which was either a purified diet with $0 \%$ taurine (no taurine diet) (Modified AIN-93M 0.7\% cornstarch Dyets \#103967, Dyet's Inc., Bethlehem, PA, USA) or $0.7 \%$ of the dry matter (DM) weight in which corn starch was substituted with a weight equivalence in taurine (high taurine diet) (Modified AIN-93M 0.7\% taurine Dyets \#103968, Dyets Inc., Bethlehem, PA, USA). During the 4-hour feeding periods, each rat was placed in a solid-bottom, plastic cage with a wire-bar lid fashioned with a hopper for diet pellets and mount for a water bottle (static interchangeable plastic rat cage, Allentown Inc, Allentown, NJ, USA). Cage litter was hand-sifted to ensure all feed that was not consumed was removed. The difference between weight of food presented and removed was counted as food intake.

\section{Blood collection}

Between 600 and 800 hrs on days $0,14,28,42,56,70$, and 84 , the rats were briefly restrained without anesthesia for blood collection from a saphenous vein. A second, post-prandial blood sample was collected from the jugular vein between 1400 and 1700 hrs while the animals were anesthetized using 
isoflurane. Blood samples were allowed to clot for a minimum of one hour prior to serum extraction. Serum samples were frozen at $-20^{\circ} \mathrm{C}$ until analysis.

\section{Fecal collection}

On days 0 and 84 , the rats were individually housed in clean cages from 600 to 1800 for fecal pellet collection. Samples were immediately placed into a $20^{\circ} \mathrm{C}$ freezer, and were moved to a $-80^{\circ} \mathrm{C}$ freezer after the collection window. Some animals did not defecate during the collection window. As a result, these animals were excluded from the analysis of the specific time point.

\section{Dual energy X-ray absorptiometry}

The rats were anesthetized with isoflurane on day 85 , and were euthanized through exsanguination. Immediately after euthanasia, all rats had duplicate dual energy X-ray absorptiometry (DXA) scans (Hologic Discovery A, Hologic Company, Bedford, USA) performed from the tip of the nose to the end of the tail (Rose et al. 1998). The rats were positioned on a bare scan table in ventral recumbancy using a laser for positioning guidance. Quality control checks were performed prior to completion of the scans using a spine and rat step phantom as recommended by the manufacturer. Analysis for whole body bone mineral content (BMC), bone mineral density (BMD), fat mass, lean mass plus $\mathrm{BMC}$, total mass, and percent fat was completed using built-in Hologic software.

\section{Tissue collection}

Subsequently to the DXA scan, the following organs of the rats were removed and weighed: liver, fat pads, heart, lungs, kidney, adrenal glands, spleen, brain, ovary, uterus, testis, epididymis, thyroid, thymus, extensor muscle, 
and soleus muscle. Immediately after weighing, liver and kidney was flash frozen using liquid nitrogen. Quadriceps muscle was removed and samples stored at $20^{\circ} \mathrm{C}$ until analysis. Liver and kidney samples were stored at $-80^{\circ} \mathrm{C}$.

\section{IGF-1 serum concentrations}

IGF-1 was measured in duplicate in morning-collected serum samples when the rats were briefly restrained without use of anesthesia. For the IGF-1 measurements, a R\&D Systems Mouse/Rat IGF-1 Quantikine ELISA kit (R\&D Systems, Minneapolis, MN, USA) was used following the kit directions.

\section{Tissue and whole blood taurine concentrations}

Taurine concentration was measured on day 84 post-prandial blood samples. To ensure cells were lysed the whole blood samples were frozen and thawed 3 times before extraction for taurine analysis. For taurine analysis, approximately 50 milligrams of thawed liver or kidney samples were homogenized in $1.5 \mathrm{~mL}$ of distilled water, and approximately 25 milligrams of thawed quadriceps muscle was homogenized in $500 \mu \mathrm{L}$ of distilled water. The homogenates were frozen and thawed three times, deproteinized, and their taurine concentration measured using high pressure liquid chromatography (HPLC) methods described by Hooper et al. (2017). In brief, the samples were deproteinized by adding $50 \mu \mathrm{L}$ of acetonitrile to $50 \mu \mathrm{L}$ of plasma, whole blood, or tissue homogenate. Prior to the extraction to remove protein trans-4-hydroxy-Lproline was added as internal standard. Samples were centrifuged for $15 \mathrm{~min}$ at $16,000 \times \mathrm{g}$. Fifty microliters of resulting supernatant were transferred to a $13 \mathrm{x}$ $100 \mathrm{~mm}$ glass tube and evaporated by centrifugal evaporation. Fifty microliters of 
a coupling solution (1:1:1, v/v, triethylamine:water:methanol) was added to the dried residue, and subsequently evaporated to dryness. Then, $50 \mu \mathrm{L}$ of derivatization solution $(20: 5: 5: 2, \mathrm{v} / \mathrm{v}$, methanol:water:triethylamine:phenylisothiocyanate) was added to each tube and tubes were covered with parafilm and left at ambient temperature. After 20 minutes, samples were evaporated to dryness and redisolved in $400 \mu \mathrm{L}$ of sample diluent $(710 \mathrm{mg}$ disodium hydrogen phosphate, $950 \mathrm{~mL}$ water, $5 \mathrm{~mL}$ acetonitrile, adjusted to $\mathrm{pH} 5.4$ with phosphoric acid). The reconstituted samples were transferred to centrifuge tube with a $0.2 \mu \mathrm{m}$ centrifuge tube filter (Corning $\AA^{\circledR}$ Costar ${ }^{\circledR}$ SpinX centrifuge tube filters, Sigma Aldrich, St. Louis, MO, USA) and spun for $15 \mathrm{~min}$ at $15,000 \times \mathrm{g}$. Samples were injected into a C18 column (Microsorb 100-5 C18, 250 x 4.6 mm Varian Inc. Lake Forest, CA, USA) and the $U V_{265 n m}$ absorbance of the phenylisothiocyanate derivatives of taurine and internal standard were quantified.

\section{Tissue protein determination}

Protein was measured in the liver, kidney, and muscle homogenate solutions by Bradford assay (Bradford 1976)(BioRad USA Microplate BSA Hercules, California 94547) following the manufacturer's directions for the standard microplate assay. Lyophilized, essentially fat free, bovine serum albumin (Sigma Aldrich, St. Louis, MO, USA) was used to establish the standard curve from 0 to $1000 \mu \mathrm{g} / \mathrm{mL}$. All homogenate solutions were diluted to ensure protein analysis was conducted between $400-800 \mu \mathrm{g} / \mathrm{mL}$, a linear range found for the assay. 


\section{Fecal DNA extraction and sequencing}

DNA extraction was modified from the methods described by Ericson et al. (2015). One fecal pellet was placed into a sterile $2 \mathrm{~mL}$ round-bottom tube with a $0.5 \mathrm{~cm}$ diameter stainless steel bead. Eight-hundred microliters of $37^{\circ} \mathrm{C}$ lysis buffer $(500 \mathrm{mM} \mathrm{NaCl}, 50 \mathrm{mM}$ Tris-HCl pH 8.0, $50 \mathrm{mM}$ EDTA, and 4\% sodium dodecyl sulfate) was placed into each tube and homogenized for 3 minutes at 30 $\mathrm{Hz}$ in TissueLyser II (Qiagen, Venlo, Netherlands). Tissue samples were incubated for $70^{\circ} \mathrm{C}$ for 20 minutes with periodic vortexing. After incubation, samples were centrifuged at room temperature for $5 \mathrm{~min}$ at $5,000 \mathrm{xg}$. The supernatant was transferred to a new sterile $1.5 \mathrm{~mL}$ Eppendorf tube before adding $200 \mu \mathrm{L}$ of $10 \mathrm{mM}$ ammonium acetate. The mixture was vortexed, incubated on ice for $5 \mathrm{~min}$, and centrifuged at room temperature for $5 \mathrm{~min}$ at $5,000 \times \mathrm{g}$. Seven-hundred and fifty microliters of supernatant was transferred to a new $1.5 \mathrm{~mL}$ Eppendorf tube containing $750 \mu \mathrm{L}$ of ice-chilled isopropanol. The samples were incubated for a minimum of $30 \mathrm{~min}$ on ice, and subsequently centrifuged at $4 \mathrm{C}^{\circ}$ for $15 \mathrm{~min}$ at $16,000 \times \mathrm{g}$. The supernatant was aspirated and discarded. The resulting DNA pellet was washed with $150 \mu \mathrm{L}$ of $70 \%$ ethanol, and resuspended with $150 \mu \mathrm{L}$ of Tris-EDTA (10 mM Tris and $1 \mathrm{mM}$ EDTA). Occasionally incubation of DNA pellets in a $37^{\circ} \mathrm{C}$ water bath for 20 min with intermittent vortexing was required to fully resuspend pellet. After pellet resuspension, $15 \mu \mathrm{L}$ of proteinase $\mathrm{K}$ and $200 \mu \mathrm{L}$ of $\mathrm{AL}$ Buffer (Qiagen DNeasy Blood and Tissue kit, Qiagen) were added to the mixture and thoroughly vortexed. The mixture was incubated at $70^{\circ} \mathrm{C}$ for $10 \mathrm{~min}$ before adding $200 \mu \mathrm{L}$ of 
$100 \%$ ethanol and mixing by gently aspirating and eluting of the contents multiple times in a pipette. Subsequently, the contents were transferred to a spin column in the DNeasy kit and centrifuged at room temperature for $1 \mathrm{~min}$ at $16,000 \mathrm{xg}$. Using the Qiagen kit reagents, the flow-through and collection tube were discarded, the column retained, and $500 \mu \mathrm{L}$ of Buffer AW1 was added before spinning for $1 \mathrm{~min}$ at $16,000 \times \mathrm{g}$. The flow through-and collection tube were discarded, the column retained, and $500 \mu \mathrm{L}$ of Buffer AW2 was added before spinning for $3 \mathrm{~min}$ at $16,000 \times \mathrm{g}$. The column was transferred to a clean $1.5 \mathrm{~mL}$ Eppendorf tube and $200 \mu \mathrm{L}$ of EB buffer was added. Samples were incubated at room temperature for 2 min prior to centrifuging for $1 \mathrm{~min}$ at $16,000 \mathrm{xg}$. DNA concentrations were determined fluorometrically (Qubit dsDNA BR assay, Life Technologies, Carlsbad CA).

The DNA was submitted to the University of Missouri Metagenomics Center for $16 \mathrm{~S}$ rRNA sequencing and informatics analysis as previously described (Ericsson et al. 2015; Hart et al. 2015). In summary, DNA concentrations were normalized to $3.51 \mathrm{ng} / \mu \mathrm{l}$ in EB buffer at a volume of $60 \mu \mathrm{l}$. The University of Missouri DNA Core facility performed the library construction and sequencing. Bacterial 16S rDNA amplicons were constructed by the amplification of the V4 hypervariable region of the $16 \mathrm{~s}$ rRNA with universal primers (U515F/806R) (Caporaso et al. 2011; Walters et al. 2011) flanked by Illumina standard adapter sequences. Amplicons were pooled for sequencing with an Illumina MiSeq platform and V2 chemistry with $2 \times 250$ bp paired-end reads. The University of Missouri Informatics Research Core Facility assembled, 
binned, and annotated the DNA sequences. Contiguous DNA sequences are assembled using FLASH software (Magoc and Salzberg 2011), with sequences eliminated from analysis if they had a base quality less than 31 after trimming. Representative operational taxonomic sequences (OTUs) were selected using Qiime v1.8. Selected OTUs were annotated to the Greengenes database (DeSantis et al. 2006) of 16S rRNA gene sequences using BLAST (Altschul et al. 1997) and taxonomy assigned. Relative abundance of OTU data was transformed by using $1 / 4$ root before principal component analysis (PCAs) were performed in PAST (Hammer 2001).

\section{Statistical analysis}

We used SAS 9.3 (SAS Institute Inc., Cary, NC, USA) and PAST 3.14 (Øyvind Hammer, University of Oslo, Norway) to perform all statistical analysis and significance was calculated at alpha $=0.05$. Alpha values of $0.06-0.10$ were considered indicative of a trend. Data was tested for normality using the Shapiro-Wilk, Kolmogorov-Smirnov, and Anderson-Darling tests. Non-normally distributed data was transformed using log 10 , square root, or $1 / 4$ root. The Proc GLM and Proc GLMMix procedure and differences of the least square means was used to compare the variables of interest, the interactions, and for alphadiversity of phyla and OTUs. For beta-diversity of phyla and OTUs, two-way PERMANOVA using the Bray-Curtis Similarity Index was completed for time vs diet and diet vs sex at day 0 and day 84 . 


\section{Results}

\section{Body weight and feed intake}

Body weights and feed intakes were previously reported by Hooper et al (2017) are summarized in Table 4.1. In brief, both male and female rats, irrespective of diet, were heavier on day 84 compared to day $0(p<0.05)$. The female rats consuming the high taurine diet gained significantly more weight compared to the control females $(p<0.02)$. The mean feed intake was $7 \%$ greater compared to the dietary control females $(p<0.001)$. In the male rats, there were no dietary treatment effects observed on food intake and body weight.

Table 4.1 Summary of weights, and feed intake

\begin{tabular}{|c|c|c|c|c|c|c|}
\hline Treatment & Control & Taurine & Control & Taurine & Treatment & $\begin{array}{c}\text { Sex- } \\
\text { effect }\end{array}$ \\
\hline Sex & $\begin{array}{c}\text { Female } \\
(\mathrm{n}=6)\end{array}$ & $\begin{array}{c}\text { Female } \\
(\mathrm{n}=6)\end{array}$ & $\begin{array}{c}\text { Male } \\
(\mathrm{n}=6)\end{array}$ & $\begin{array}{c}\text { Male } \\
(\mathrm{n}=6)\end{array}$ & p-value & $\mathrm{p}$-value \\
\hline $\begin{array}{c}\text { Starting } \\
\text { weight }(\mathrm{g})\end{array}$ & $207 \pm 10.6$ & $202 \pm 8.33$ & $319 \pm 8.50$ & $315 \pm 4.83$ & 0.35 & 0.001 \\
\hline $\begin{array}{c}\text { Ending } \\
\text { Weight (g) }\end{array}$ & $216 \pm 5.54^{*}$ & $230 \pm 8.29^{*}$ & $417 \pm 15.5$ & $422 \pm 24.1$ & 0.02 & 0.001 \\
\hline $\begin{array}{c}\text { Weight } \\
\text { Gain (\%) }\end{array}$ & $4.68 \pm 0.05^{*}$ & $13.9 \pm 0.06^{*}$ & $30.1 \pm 0.04$ & $34.0 \pm 0.06$ & 0.001 & 0.001 \\
\hline $\begin{array}{c}\text { Feed } \\
\text { intake (g) }\end{array}$ & $795 \pm 26.9^{*}$ & $854+12.9^{*}$ & $1267 \pm 63.8$ & $1310 \pm 71.4$ & 0.03 & 0.001 \\
\hline
\end{tabular}

${ }^{*}$ Denotes significance difference in females only

Summary of data from Hooper et al 2017. Dietary taurine treatment resulted in an increase in ending weight, an increase in percent weight gain, an increase in feed intake, and a decrease in feed conversion ratio. 


\section{Organ weight}

All organs except the brain and thymus were of significantly greater weight in the male rats compared to the female rats (Table 4.2). The weights of the high dietary taurine female rats' spleens were greater compared to the control females $(p<0.02)$. The high dietary taurine female rats' ovaries were trending towards being heavier than those in control rats $(p=0.06)$. 
Table 4.2 Summary of organ weights

\begin{tabular}{|c|c|c|c|c|c|c|}
\hline \multirow{2}{*}{ Organ } & Control & Taurine & Control & Taurine & Treatment & $\begin{array}{c}\text { Sex- } \\
\text { effect }\end{array}$ \\
\cline { 2 - 7 } & Female & Female & Male & Male & p-value & p-value \\
\hline Adrenal gland $(\mathrm{mg})$ & $62.9 \pm 58$ & $57.3 \pm 65.1$ & $83.1 \pm 67.1$ & $61.2 \pm 70.5$ & 0.96 & 0.03 \\
\hline Brain $(\mathrm{g})$ & $1.71 \pm 0.03$ & $1.75 \pm 0.03$ & $1.92 \pm 0.02$ & $1.65 \pm 0.29$ & 0.46 & 0.71 \\
\hline Epididymus (g) & $1.22 \pm 0.05$ & $1.24 \pm 0.09$ & & & 0.83 & \\
\hline Fat pads (g) & $4.07 \pm 0.46$ & $4.70 \pm 0.26$ & $12.13 \pm 0.86$ & $12.70 \pm 2.00$ & 0.6 & 0.001 \\
\hline Heart (g) & $0.79 \pm 0.03$ & $0.83 \pm 0.03$ & $1.31 \pm 0.04$ & $1.33 \pm 0.55$ & 0.48 & 0.001 \\
\hline Kidney $(\mathrm{g})$ & $1.17 \pm 0.04$ & $1.20 \pm 0.04$ & $2.15 \pm 0.06$ & $2.23 \pm 0.07$ & 0.28 & 0.001 \\
\hline Liver (g) & $5.495 \pm 0.19$ & $5.97 \pm 0.37$ & $12.66 \pm 0.41$ & $12.41 \pm 0.46$ & 0.90 & 0.001 \\
\hline Lungs (g) & $0.99 \pm 0.03$ & $1.08 \pm 0.08$ & $1.36 \pm 0.07$ & $1.40 \pm 0.07$ & 0.33 & 0.001 \\
\hline Ovary (mg) & $101.8 \pm 90.7$ & $124.9 \pm 15.0$ & & & 0.06 & \\
\hline Spleen $(\mathrm{g})$ & $0.40 \pm 0.01^{*}$ & $0.49 \pm 0.01^{*}$ & $0.66 \pm 0.02$ & $0.68 \pm 0.03$ & 0.02 & 0.001 \\
\hline Thyroid $(\mathrm{mg})$ & $15.3 \pm 0.64$ & $14.8 \pm 0.75$ & $19.1 \pm 0.77$ & $19.08 \pm 1.56$ & 0.79 & 0.001 \\
\hline Testis $(\mathrm{g})$ & & & $3.72 \pm 0.08$ & $3.77 \pm 0.12$ & 0.75 & \\
\hline Thymus $(\mathrm{mg})$ & $0.16 \pm 0.02$ & $0.20 \pm 0.03$ & $0.25 \pm 0.04$ & $0.24 \pm 0.07$ & 0.90 & 0.14 \\
\hline Uterus $(\mathrm{g})$ & $0.54 \pm 0.16$ & $0.56 \pm 0.06$ & & & 0.65 & \\
\hline
\end{tabular}

${ }^{*}$ Denotes significant difference in females only.

Gross organ weights by sex and treatment ( $n=6$ per treatment per sex). High dietary taurine significantly increased spleen weight in the females and the high dietary taurine rats' ovaries were trending towards being heavier than the control rats. 


\section{DXA}

There were significant sex-effect differences in all DXA parameters, except percent fat (Table 4.3). Males compared to females had greater $(p<$ 0.001) lean and fat masses as well as bone mineral content (BMC). Although there was a trend for greater fat mass $(p=0.09)$ and lean mass + BMC $(p=0.1)$ in the high dietary taurine female rats compared to the controls, there was no significant dietary treatment effects on DXA variables found in females and males.

Table 4.3 Summary of DXA variables by sex and treatment

\begin{tabular}{|c|c|c|c|c|c|c|}
\hline \multirow{2}{*}{$\begin{array}{c}\text { DXA } \\
\text { parameter }\end{array}$} & Control & Taurine & Control & Taurine & Treatment & $\begin{array}{c}\text { Sex- } \\
\text { effect }\end{array}$ \\
\cline { 2 - 7 } & $\begin{array}{c}\text { Female } \\
(\mathrm{n}=6)\end{array}$ & $\begin{array}{c}\text { Female } \\
(\mathrm{n}=6)\end{array}$ & $\begin{array}{c}\text { Male } \\
(\mathrm{n}=6)\end{array}$ & $\begin{array}{c}\text { Male } \\
(\mathrm{n}=6)\end{array}$ & p-value & $\begin{array}{c}\mathrm{p} \text { - } \\
\text { value }\end{array}$ \\
\hline $\begin{array}{c}\text { Area } \\
\left(\mathrm{cm}^{2}\right)\end{array}$ & $43.3 \pm 0.33$ & $43.5 \pm 0.61$ & $61.5 \pm 0.74$ & $61.26 \pm 1.04$ & 0.98 & 0.001 \\
\hline BMC $(\mathrm{g})^{1}$ & $8.02 \pm 0.07$ & $8.14 \pm 0.09$ & $12.5 \pm 0.22$ & $12.5 \pm 0.22$ & 0.75 & 0.001 \\
\hline $\begin{array}{c}\text { BMD } \\
\left(\mathrm{g} / \mathrm{cm}^{2}\right)^{2}\end{array}$ & $0.19 \pm 0.001$ & $0.19 \pm 0.002$ & $0.20 \pm 0.003$ & $0.20 \pm 0.003$ & 0.62 & 0.001 \\
\hline Fat $(\mathrm{g})$ & $19.27 \pm 1.83$ & $21.7 \pm 1.33$ & $46.0 \pm 3.50$ & $44.6 \pm 6.9$ & 0.09 & 0.001 \\
\hline $\begin{array}{c}\text { Lean }+ \\
\text { BMC }(\mathrm{g})\end{array}$ & $197 \pm 2.83$ & $210 \pm 2.69$ & $374 \pm 4.61$ & $377 \pm 6.42$ & 0.1 & 0.001 \\
\hline $\begin{array}{c}\text { Total } \\
\text { mass }(\mathrm{g})\end{array}$ & $217 \pm 2.90$ & $231 \pm 3.14$ & $420 \pm 6.44$ & $421 \pm 9.10$ & 0.23 & 0.001 \\
\hline \begin{tabular}{c}
$\%$ fat \\
\hline
\end{tabular} & $8.87 \pm 0.81$ & $9.33 \pm 0.47$ & $10.9 \pm 0.72$ & $10.5 \pm 1.44$ & 0.98 & 0.1 \\
\hline
\end{tabular}

${ }^{1}$ bone mineral content

2 bone mineral density

DXA variables were measured post-euthanasia on day 85 . Fat and lean + bone mineral content $(\mathrm{BMC})$ were trending towards significantly different in the female high dietary taurine rats. 


\section{Whole blood and tissue taurine concentrations}

Day 85, post-prandial whole blood taurine concentrations were

significantly higher in the female high dietary taurine treatment group (344 \pm 42.8 $\mu \mathrm{mol} / \mathrm{mL})$ and male high dietary taurine treatment group $(264.81 \pm 31.3 \mu \mathrm{mol} / \mathrm{mL})$ when compared to their respective control groups $(124 \pm 14.0 \mu \mathrm{mol} / \mathrm{mL}$ females, $120 \pm 17.6 \mu \mathrm{mol} / \mathrm{mL}$ males; $p<0.001)$ (Fig 4.1). The liver taurine concentrations were significantly higher in the male and female high taurine dietary treatment groups when compared to the controls $(p=0.01)$ (Fig 4.2). The quadriceps muscle taurine content was significantly greater in the female and male high taurine compared to control when normalized by wet weight $(p<0.001)$ and protein concentration $(p<0.01)($ Fig4. 3). There was an interaction trend between sex and treatment for the muscle taurine content normalized by wet weight $(p=0.08)$, but not when normalized by protein concentration $(p=0.48)$. There were trends of greater taurine content in the kidney in the high taurine compared to control male and female rats when normalized by the wet organ weight $(p=0.07)$ and the protein concentration $(p=0.10)($ Fig 4.4). 
Figure 4.1 Whole blood taurine concentrations

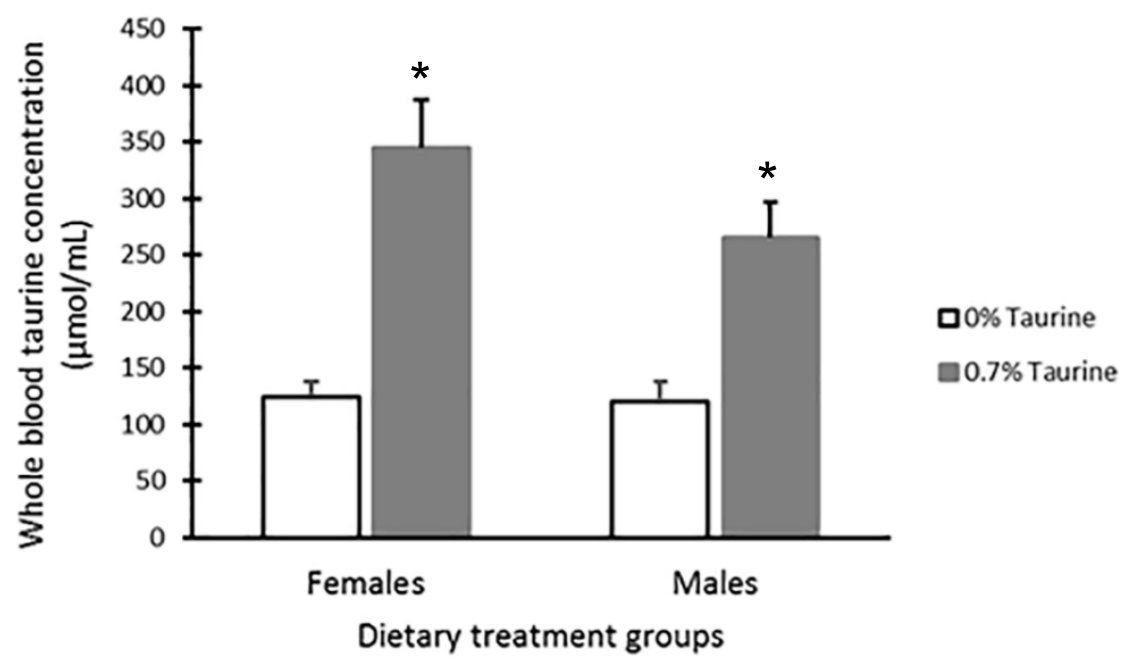

On day 84 , the whole blood taurine concentration in the male $(n=6)$ and female $(n=6)$ rats on the high taurine dietary treatment were significantly higher than the control rats $(n=6$ per sex $)(p<0.001)$. 
Figure 4.2 Liver taurine concentrations
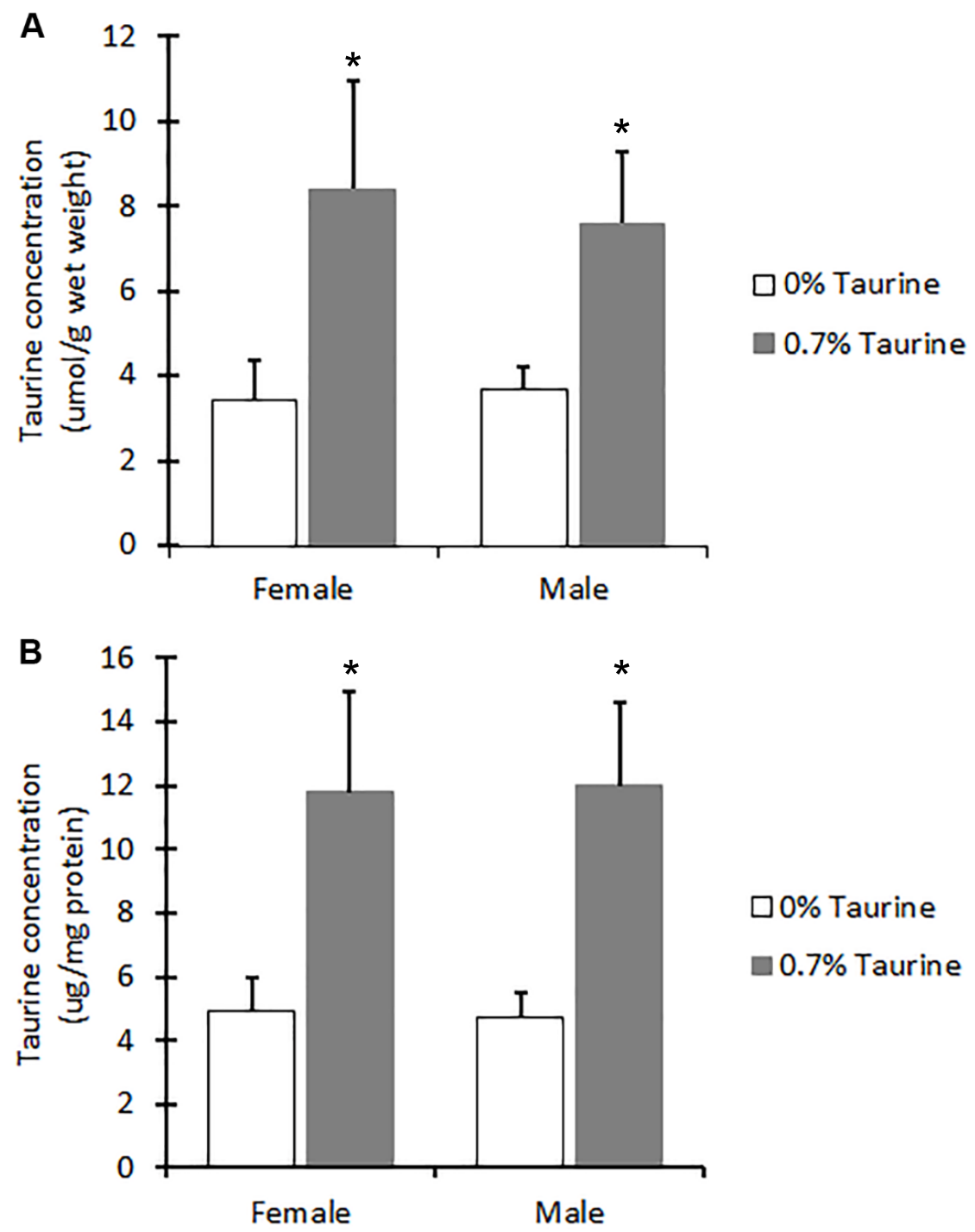

The liver taurine concentration when normalized by $(A)$ wet weight $(p=0.01)$ and (B) protein concentration $(p<0.01)$ was significantly increased in the high dietary taurine treated rats compared to the controls ( $n=6$ per sex per treatment). 
Figure 4.3 Quadriceps muscle taurine concentrations
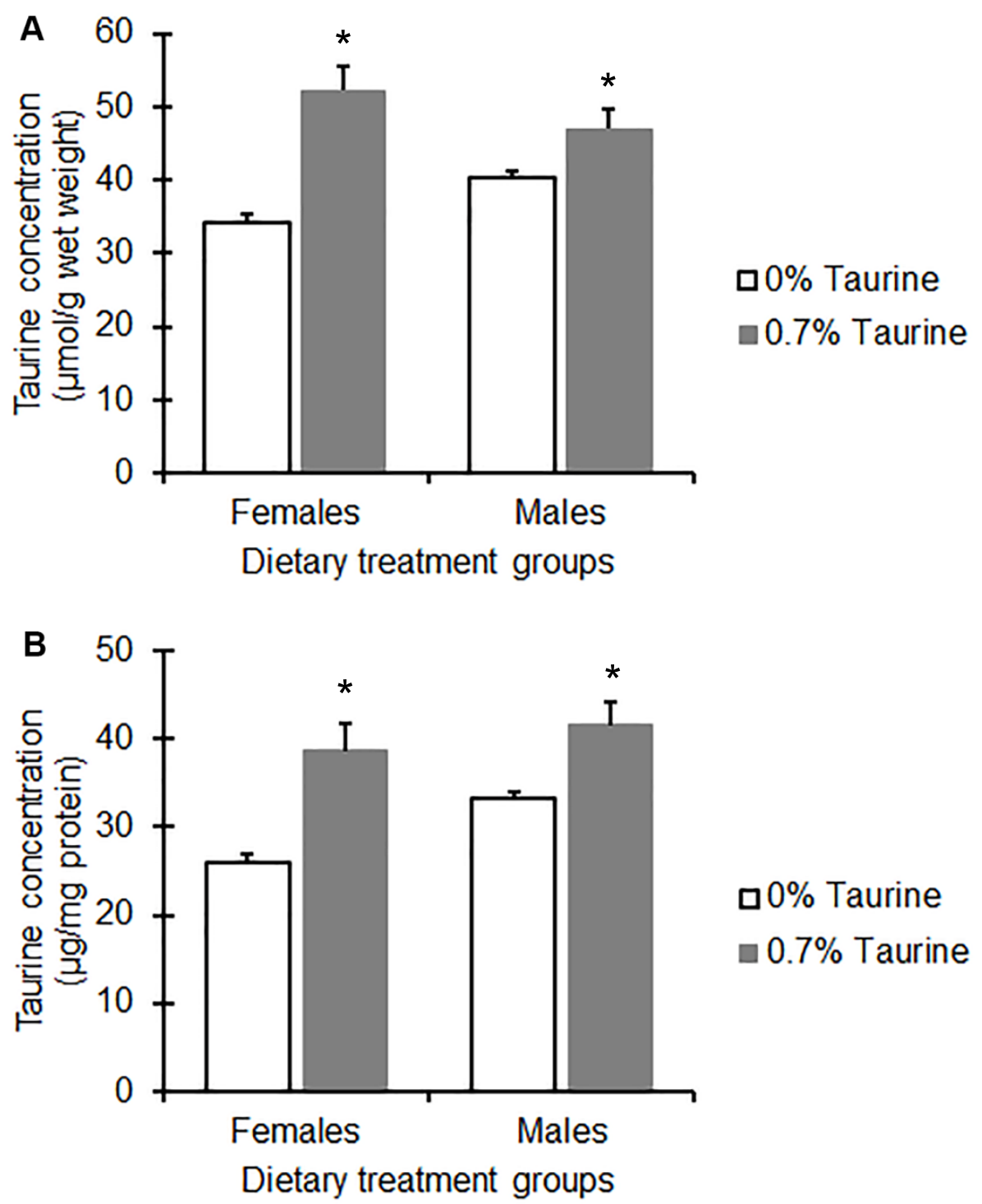

The quadriceps muscle taurine concentration when normalized by $(A)$ wet weight and (B) protein concentration was significantly increased in the high dietary taurine treated rats compared to the controls (wet weight $p<0.001$; protein concentration $p<0.003)$ ( $n=6$ per sex per treatment). 
Figure 4.4 Kidney taurine concentrations
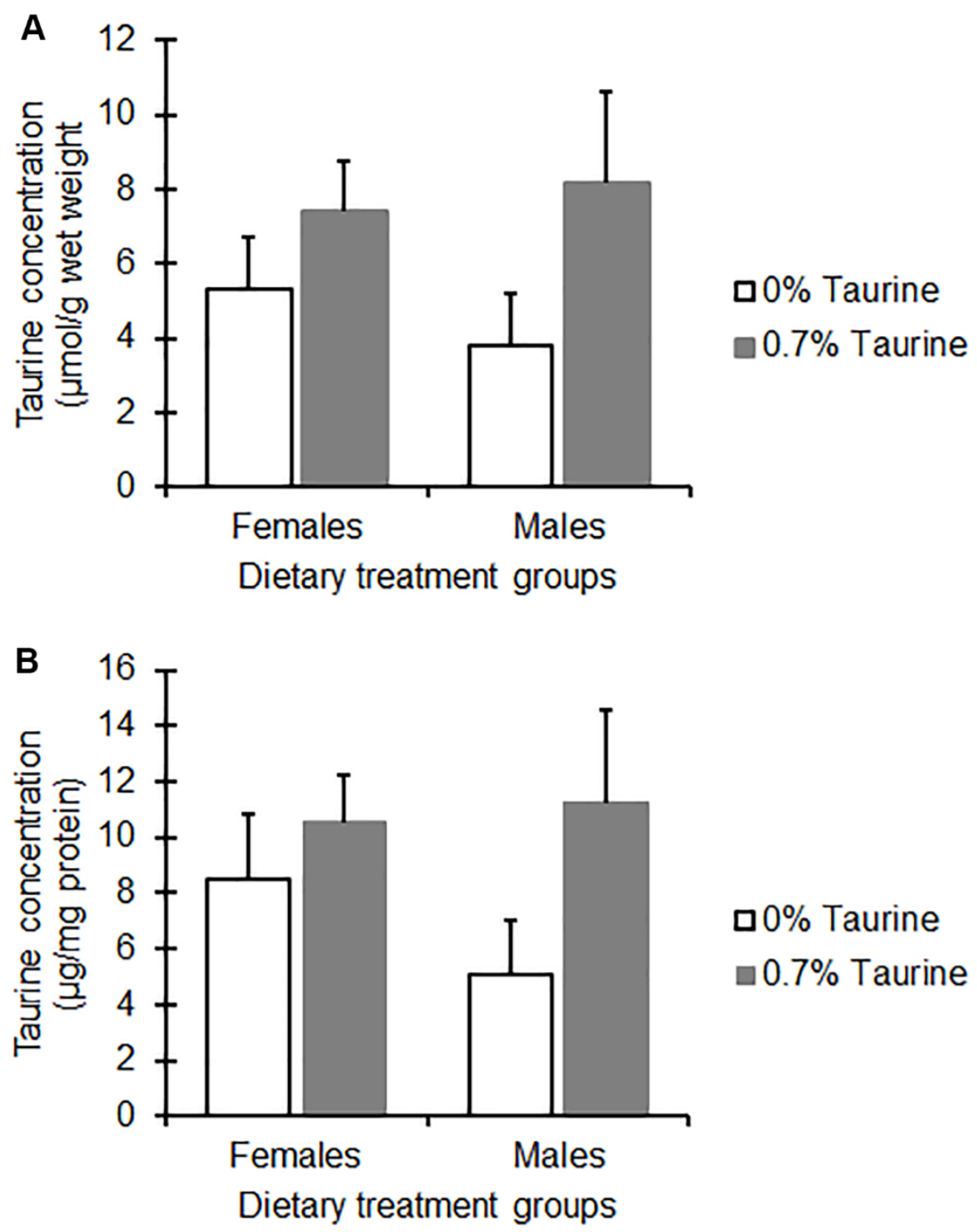

The kidney taurine concentration when normalized by $(A)$ wet weight and $(B)$ protein concentration was not increased in the high dietary taurine treated rats compared to the controls (wet weight $p=0.07$; protein concentration $p=0.10$ ) ( $n=6$ per sex per treatment). 
IGF-1

There was no dietary treatment effect $(p=0.42)$ or interaction between dietary treatment and $\operatorname{sex}(p=0.49)$ on serum concentrations of IGF-1. However all male IGF-1 concentrations (mean $1284 \pm 21.95 \mathrm{ng} / \mathrm{mL}$ ) were significantly higher than all female IGF-1 concentrations (mean $863 \pm 24.1 \mathrm{ng} / \mathrm{mL})(p<0.001)$ (Fig 4.5).

Figure 4.5 Circulating serum IGF-1 concentrations

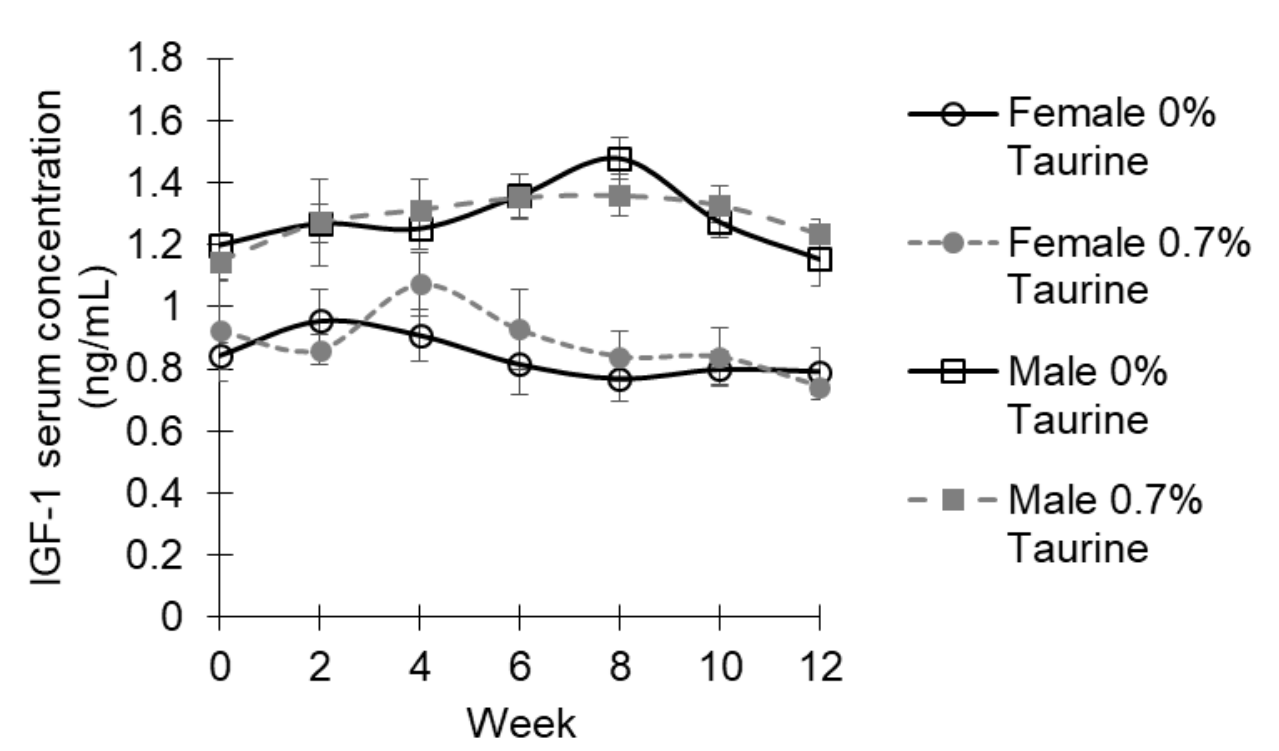

All male ( $\mathrm{n}=6$ per diet) IGF-1 serum concentrations were significantly higher than all female ( $n=6$ per diet) IGF-1 concentrations $(p<0.001)$.

\section{Microbiome}

Within the 12 hour window for fecal collection, 1 female rat in the high taurine dietary treatment group did not did not defecate on day 0 or day 84 and 1 male rat in the high taurine dietary treatment group did not defecate on day 0 . A total of 45 fecal samples were collected. Over 3.75 million 16S rRNA gene sequences were obtained from bacterial DNA extracted from the feces using from Illumina MiSeq sequencing. A total of 124 OTUs were identified from the 
sequences representing 13 bacterial phyla and 51 bacterial families (Fig 4.6-4.7, Table S4.1). Four of the bacteria phyla, Bacteroidetes, Firmicutes, Proteobacteria, and Tenericutes, accounted for $98.3 \%$ of the sequences obtained from both males and females.

The rats given the high taurine diet had an altered abundance of 9 bacteria including 6 within the Bacteroidetes phylum and 2 within the Firmicutes phylum ( $p<0.05$; Table 4.4-4.7) compared to the rats on the control diet. While taurine altered the abundance of Bacteroidetes phylum $(p=0.02)$ and the Firmicutes phylum $(p=0.03)$, there was a significant change in the abundance of Actinobacteria, Spirochaetes, TM7, and Tenericutes phyla caused by transition from the standard rodent chow to the purified diet (Table 4.4-4.5). An interaction between diet and time was found to affect the abundance of the Barnesiellaceae family $(p<0.05)$ within Bacteroidetes phyla and Gracilibacter genus $(p<0.01)$ and Allobaculum genus $(p<0.001)$ within the Firmicutes family. An interaction between diet and sex was found to affect the abundance of 9 Bacteroidetes ( $p$ $<0.001), 1$ Cyanobacteria $(p=0.05), 9$ Firmicutes $(p<0.05)$, and 2 Proteobacteria $(p<0.05$; Table S4.2). The abundance of 56 OTUs were altered by the transition of the rats from the standard rodent chow to the purified diet and the subsequent twelve weeks of consuming the purified diet $(p<0.05$, Table S4.3). There were 41 OTUs affected by the sex of the animal $(p<0.05, S 4.4)$. An interaction between time, diet, and sex were found to affect the abundance of 21 OTUs representing Bacteroidetes, Firmicutes, Proteobacteria, Spirochaetes, and Tenericutes phylum $(\mathrm{p}<0.05, \mathrm{~S} 4.5)$. 


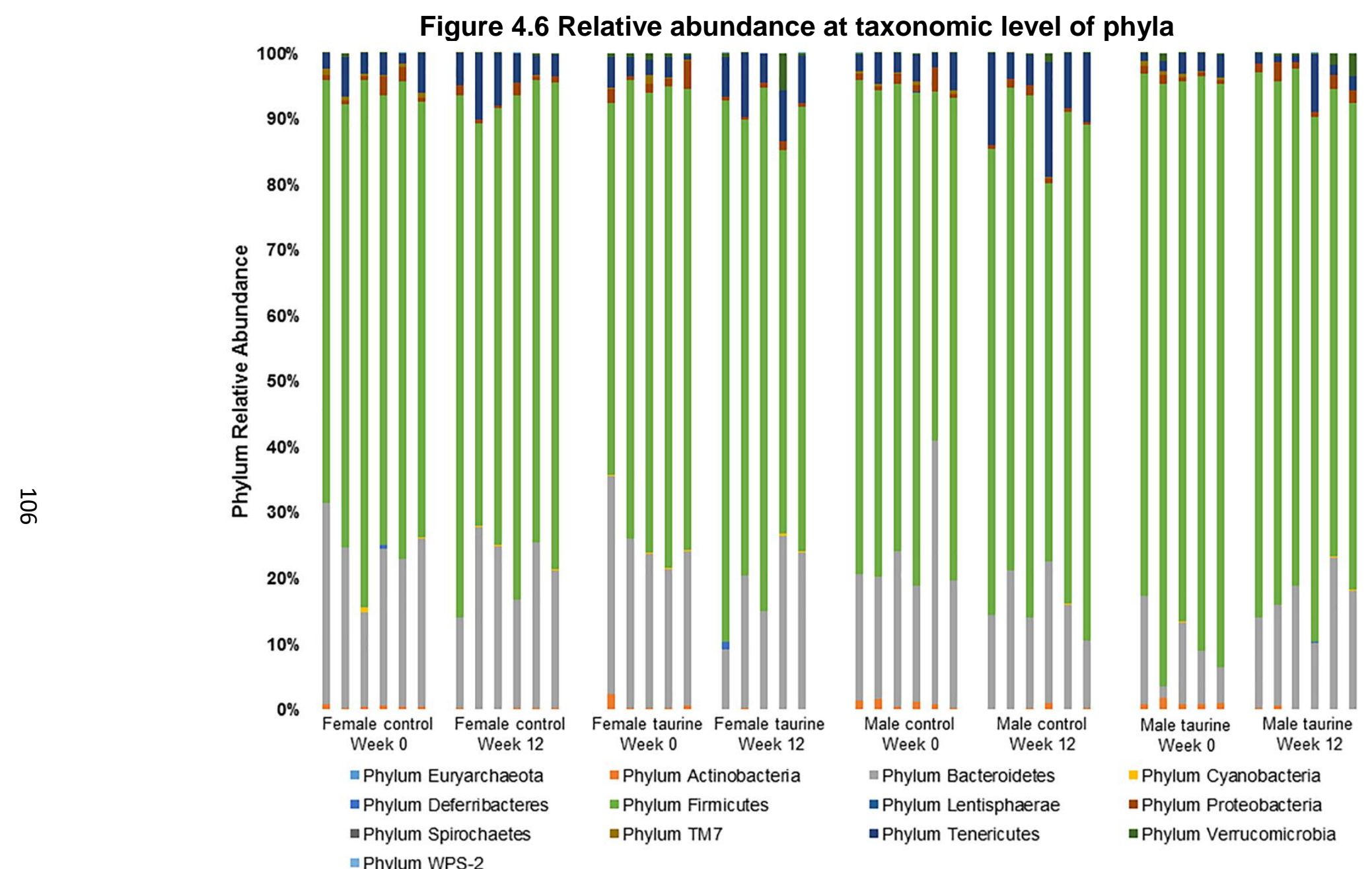

Bacterial phyla in fecal samples collected from day $0(n=6$, female $0 \%$ taurine and male $0 \%$ taurine; $n=5$, female $0.7 \%$ taurine and male $0.7 \%$ taurine) and day $84(n=6$, female $0 \%$ taurine, male $0 \%$ taurine, and male $0.7 \%$ taurine; $n=5$, female $0.7 \%$ taurine). Bacteroidetes and Firmicutes were the most abundant phyla, and their relative abundance was altered by dietary taurine $(p<0.05)$. 
Figure 4.7 Relative abundance at taxonomic level of OTU

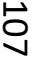

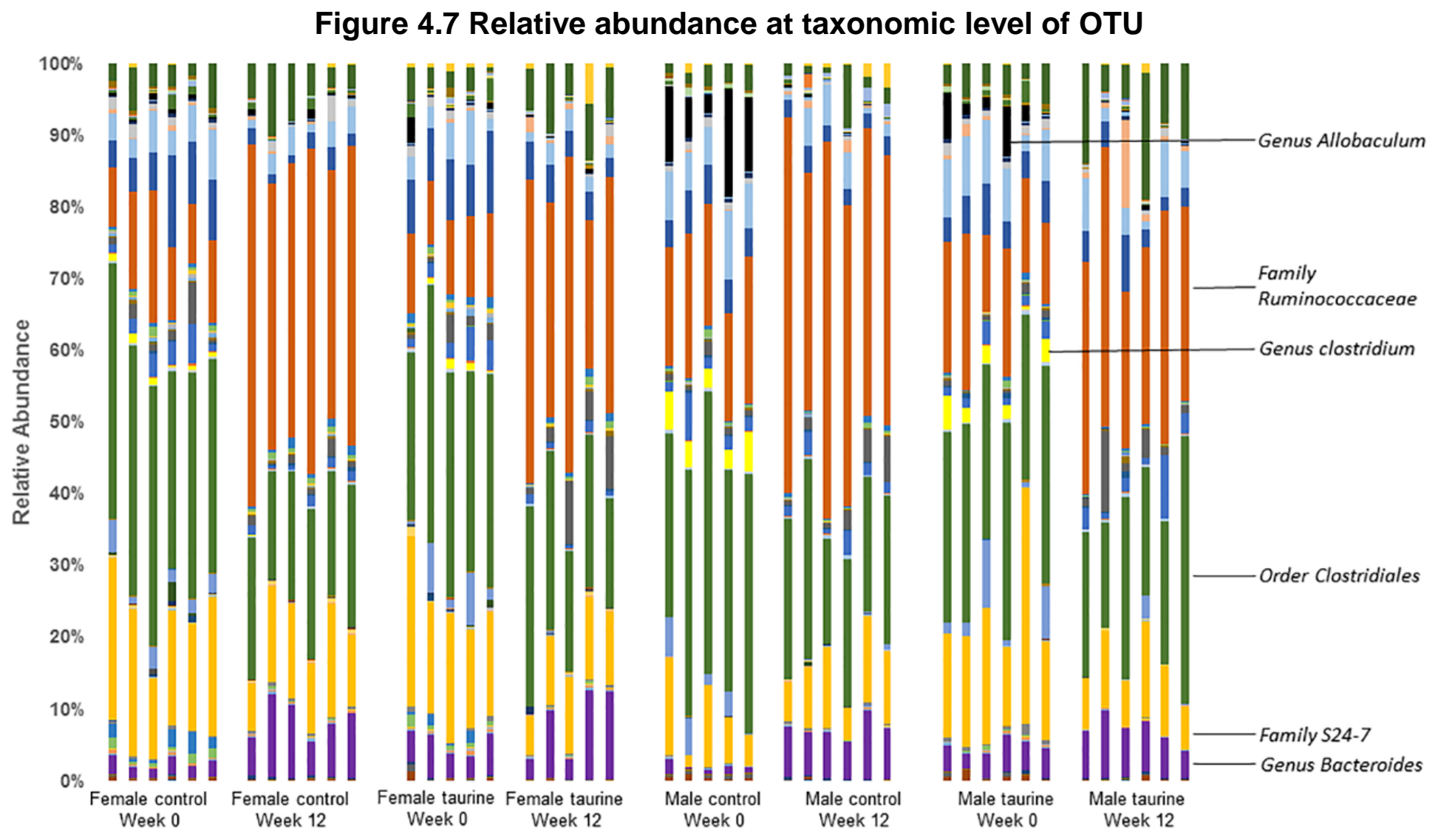

Bacterial OTUs collected in fecal samples collected from day $0(n=6$, female $0 \%$ taurine and male $0 \%$ taurine; $n=5$, female $0.7 \%$ taurine and male $0.7 \%$ taurine $)$ and day $84(n=6$, female $0 \%$ taurine, male $0 \%$ taurine, and male $0.7 \%$ taurine; $n=5$, female $0.7 \%$ taurine). The abundance of nine OTUs including Family S24-7, Genus Bacteroides, Genus Allobaculum, and Genus Clostridium were altered by dietary taurine. The abundance of 56 OTUs including Order Clostridiales were affected by the transition onto the purified diet $(p<0.001)$ and the abundance of 41 OTUs including Family Ruminococca were different based upon the sex of the rat $(p<0.03)$. 
Table 4.4 Relative abundance at the taxonomic level of phyla in female rats

\begin{tabular}{|c|c|c|c|c|c|c|c|c|c|c|c|c|c|c|c|}
\hline \multirow{3}{*}{$\begin{array}{c}\text { Phylum } \\
\text { Euryarchaeota }\end{array}$} & \multicolumn{9}{|c|}{ Female } & \multirow{2}{*}{\multicolumn{2}{|c|}{ Dietary taurine }} & \multirow{2}{*}{\multicolumn{2}{|c|}{ Sex }} & \multirow{2}{*}{\multicolumn{2}{|c|}{ Time }} \\
\hline & \multicolumn{3}{|c|}{ Day 0} & \multirow{2}{*}{\multicolumn{3}{|c|}{$\begin{array}{l}\text { Day } 84 \\
\text { Control }\end{array}$}} & \multirow{2}{*}{\multicolumn{3}{|c|}{$\begin{array}{l}\text { Day } 84 \\
\text { Taurine }\end{array}$}} & & & & & & \\
\hline & 0.00 & \pm & 0.00 & & & & & & & $\begin{array}{c}\text { F- } \\
\text { value }\end{array}$ & $\begin{array}{c}P_{-} \\
\text {value }\end{array}$ & $\begin{array}{c}\text { value } \\
1.28\end{array}$ & $\begin{array}{c}\begin{array}{c}P- \\
\text { value }\end{array} \\
0.27 \\
\end{array}$ & $\begin{array}{c}\begin{array}{c}\mathrm{F}- \\
\text { value }\end{array} \\
1.43 \\
\end{array}$ & $\frac{\text { P-value }}{0.24}$ \\
\hline Actinobacteria & 0.60 & \pm & 0.00 & 0.20 & \pm & 0.00 & 0.14 & \pm & 0.00 & 1.09 & 0.30 & 4.65 & 0.04 & 23.99 & $<0.001$ \\
\hline Bacteroidetes & 24.40 & \pm & 0.01 & 21.50 & \pm & 0.02 & 18.86 & \pm & 0.03 & 6.12 & 0.02 & 11.60 & $<0.01$ & 1.27 & 0.27 \\
\hline Firmicutes & 69.07 & \pm & 0.02 & 71.48 & \pm & 0.03 & 71.60 & \pm & 0.04 & 5.20 & 0.03 & 9.38 & $<0.01$ & 0.02 & 0.9 \\
\hline Lentisphaerae & 0.00 & \pm & 0.00 & 0.00 & \pm & 0.00 & 0.00 & \pm & 0.00 & 1.14 & 0.29 & 0.95 & 0.34 & 0.43 & 0.52 \\
\hline Proteobacteria & 1.55 & \pm & 0.00 & 0.95 & \pm & 0.00 & 0.70 & \pm & 0.00 & 0.07 & 0.8 & 1.64 & 0.21 & 1.37 & 0.25 \\
\hline Spirochaetes & 0.00 & \pm & 0.00 & 0.00 & \pm & 0.00 & 0.00 & \pm & 0.00 & 0.26 & 0.61 & 1.62 & 0.21 & 5.88 & 0.02 \\
\hline TM7 & 0.51 & \pm & 0.00 & 0.00 & \pm & 0.00 & 0.00 & \pm & 0.00 & 0.50 & 0.49 & 0.40 & 0.53 & 60.44 & $<0.001$ \\
\hline Tenericutes & 3.26 & \pm & 0.01 & 5.60 & \pm & 0.01 & 7.00 & \pm & 0.01 & 0.94 & 0.34 & 0.03 & 0.87 & 14.31 & $<0.001$ \\
\hline Verrucomicrobia & 0.35 & \pm & 0.00 & 0.15 & \pm & 0.00 & 1.40 & \pm & 0.01 & 0.82 & 0.37 & 0.21 & 0.65 & 2.15 & 0.15 \\
\hline WPS-2 & 0.00 & \pm & 0.00 & 0.00 & \pm & 0.00 & 0.00 & \pm & 0.00 & 1.43 & 0.24 & 0.00 & 0.96 & 0.63 & 0.43 \\
\hline
\end{tabular}

Relative abundance at the taxonomic level of phyla of female rats on day 0 [ $n=6$, female control $(0 \%$ taurine); $n=5$, female

$0.7 \%$ taurine] and day $84(n=6$, female control; $n=5$, female $0.7 \%$ taurine). Dietary taurine altered the relative abundance of

Bacteroidetes. The relative abundance of Actinobacteria was significantly different between the male and female rats and was altered by the transition between standard chow to the purified diet. The relative amount of Spriochaetes, TM7, and

Tenericutes was significantly altered by the transition between standard chow to the purified diet.

Interactions reported in the supplementary tables. Complete dataset available through the MOspace Institutional Repository. 
Table 4.5 Relative abundance at the taxonomic level of phyla in male rats

\begin{tabular}{|c|c|c|c|c|c|c|c|c|c|c|c|c|c|c|c|}
\hline \multirow{4}{*}{$\begin{array}{c}\text { Phylum } \\
\text { Euryarchaeota }\end{array}$} & \multicolumn{9}{|c|}{ Male } & \multirow{2}{*}{\multicolumn{2}{|c|}{ Dietary taurine }} & \multirow{2}{*}{\multicolumn{2}{|c|}{ Sex }} & \multirow{2}{*}{\multicolumn{2}{|c|}{ Time }} \\
\hline & \multicolumn{3}{|c|}{ Day 0} & \multirow{2}{*}{\multicolumn{3}{|c|}{$\begin{array}{l}\text { Day } 84 \\
\text { Control }\end{array}$}} & \multirow{2}{*}{\multicolumn{3}{|c|}{$\begin{array}{c}\text { Day } 84 \\
\text { Taurine }\end{array}$}} & & & & & & \\
\hline & \multirow[b]{2}{*}{0.00} & \multirow[b]{2}{*}{ \pm} & \multirow[b]{2}{*}{0.00} & & & & & & & \multirow{2}{*}{$\begin{array}{c}\begin{array}{c}F- \\
\text { value }\end{array} \\
1.28\end{array}$} & \multirow{2}{*}{$\begin{array}{c}\begin{array}{c}P_{-} \\
\text {value }\end{array} \\
0.27\end{array}$} & \multirow{2}{*}{$\begin{array}{c}\begin{array}{c}F- \\
\text { value }\end{array} \\
1.28 \\
\end{array}$} & \multirow{2}{*}{$\begin{array}{c}\begin{array}{c}P- \\
\text { value }\end{array} \\
0.27\end{array}$} & \multirow{2}{*}{$\begin{array}{c}\begin{array}{c}F- \\
\text { value }\end{array} \\
1.43 \\
\end{array}$} & \multirow{2}{*}{$\begin{array}{c}\begin{array}{c}P_{-} \\
\text {value }\end{array} \\
0.24 \\
\end{array}$} \\
\hline & & & & \multicolumn{3}{|c|}{\begin{tabular}{l|l|l}
0.00 & \pm & 0.00
\end{tabular}} & 0.00 & \pm & 0.00 & & & & & & \\
\hline Actinobacteria & 1.00 & \pm & 0.00 & 0.30 & \pm & 0.00 & 0.17 & \pm & 0.00 & 1.09 & 0.30 & 4.65 & 0.04 & 23.99 & $<0.001$ \\
\hline Bacteroidetes & 16.60 & \pm & 0.03 & 16.13 & \pm & 0.02 & 16.57 & \pm & 0.02 & 6.12 & 0.02 & 11.60 & $<0.01$ & 1.27 & 0.27 \\
\hline Cyanobacteria & 0.03 & \pm & 0.00 & 0.02 & \pm & 0.00 & 0.03 & \pm & 0.00 & 0.65 & 0.43 & 3.53 & 0.07 & 0.29 & 0.6 \\
\hline Deferribacteres & 0.00 & \pm & 0.00 & 0.00 & \pm & 0.00 & 0.02 & \pm & 0.00 & 0.38 & 0.54 & 0.55 & 0.46 & 0.52 & 0.47 \\
\hline Firmicutes & 77.47 & \pm & 0.03 & 72.50 & \pm & 0.03 & 77.78 & \pm & 0.02 & 5.20 & 0.03 & 9.38 & $<0.01$ & 0.02 & 0.9 \\
\hline Lentisphaerae & 0.00 & \pm & 0.00 & 0.00 & \pm & 0.00 & 0.00 & \pm & 0.00 & 1.14 & 0.29 & 0.95 & 0.34 & 0.43 & 0.52 \\
\hline Proteobacteria & 1.13 & \pm & 0.00 & 0.88 & \pm & 0.00 & 1.65 & \pm & 0.00 & 0.07 & 0.8 & 1.64 & 0.21 & 1.37 & 0.25 \\
\hline Spirochaetes & 0.00 & \pm & 0.00 & 0.00 & \pm & 0.00 & 0.00 & \pm & 0.00 & 0.26 & 0.61 & 1.62 & 0.21 & 5.88 & 0.02 \\
\hline TM7 & 0.44 & \pm & 0.00 & 0.03 & \pm & 0.00 & 0.00 & \pm & 0.00 & 0.50 & 0.49 & 0.40 & 0.53 & 60.44 & $<0.001$ \\
\hline Tenericutes & 3.10 & \pm & 0.00 & 9.83 & \pm & 0.02 & 2.67 & \pm & 0.01 & 0.94 & 0.34 & 0.03 & 0.87 & 14.31 & $<0.001$ \\
\hline Verrucomicrobia & 0.16 & \pm & 0.00 & 0.27 & \pm & 0.00 & 1.10 & \pm & 0.01 & 0.82 & 0.37 & 0.21 & 0.65 & 2.15 & 0.15 \\
\hline WPS-2 & 0.00 & \pm & 0.00 & 0.00 & \pm & 0.00 & 0.00 & \pm & 0.00 & 1.43 & 0.24 & 0.00 & 0.96 & 0.63 & 0.43 \\
\hline
\end{tabular}

Relative abundance at the taxonomic level of phyla of male rats on day 0 [male control $(0 \%$ taurine); $n=5$, male $0.7 \%$

taurine] and day $84(n=6$, male control, and male $0.7 \%$ taurine). Dietary taurine altered the relative abundance of

Firmicutes in the male rats. The relative abundance of Actinobacteria was significantly different between the male and female rats and was altered by the transition between standard chow to the purified diet. The relative amount of Spriochaetes, TM7, and Tenericutes was significantly altered by the transition between standard chow to the purified diet. Interactions reported in the supplementary tables. Complete dataset available through the MOspace Institutional Repository. 
Table 4.6 Relative abundance at the taxonomic level of OTU that were altered by high dietary taurine in the female rats

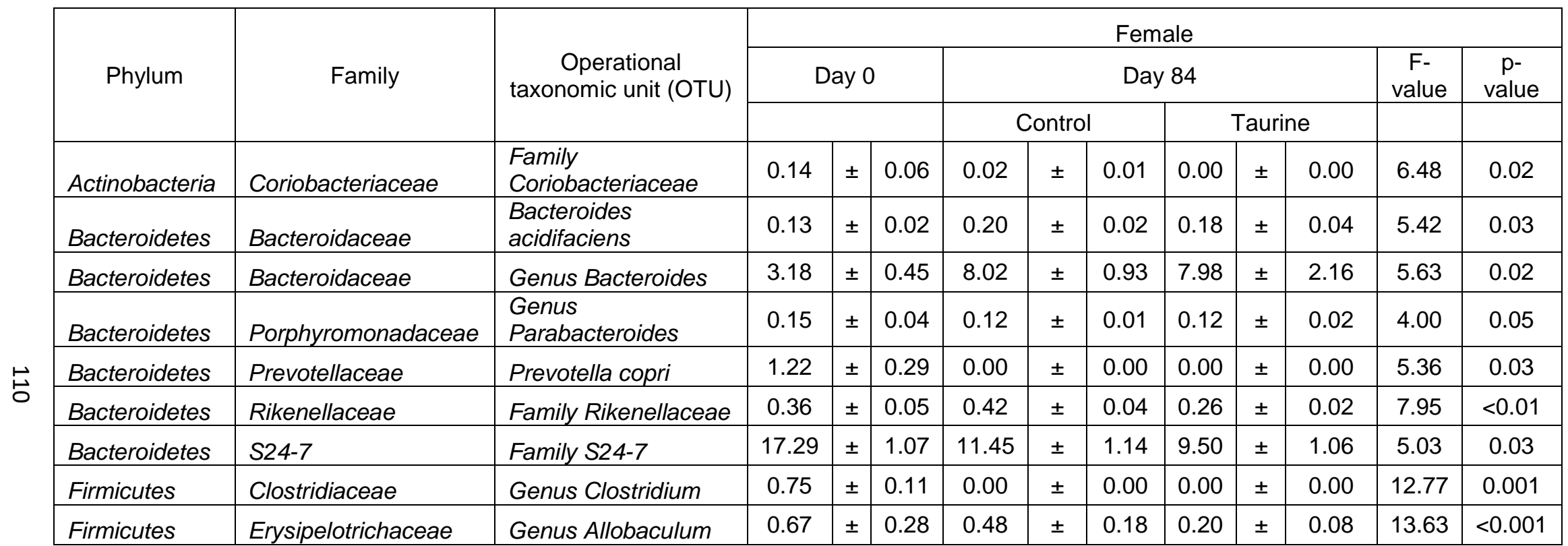
The relative abundance at the taxonomic level of OTU of fecal samples collected from female rats on day 0 [n $=6$, female control ( $0 \%$ taurine); $n=5$, female $0.7 \%$ taurine] and day $84(n=6$, female control; $n=5$, female $0.7 \%$ taurine). Nine OTUs were altered by the presence of taurine in the diet. Interactions for diet and time are reported in the supplementary tables. Complete dataset available through the MOspace Institutional Repository. 
Table 4.7 Relative abundance at the taxonomic level of OTU that were altered by high dietary taurine in the male

rats

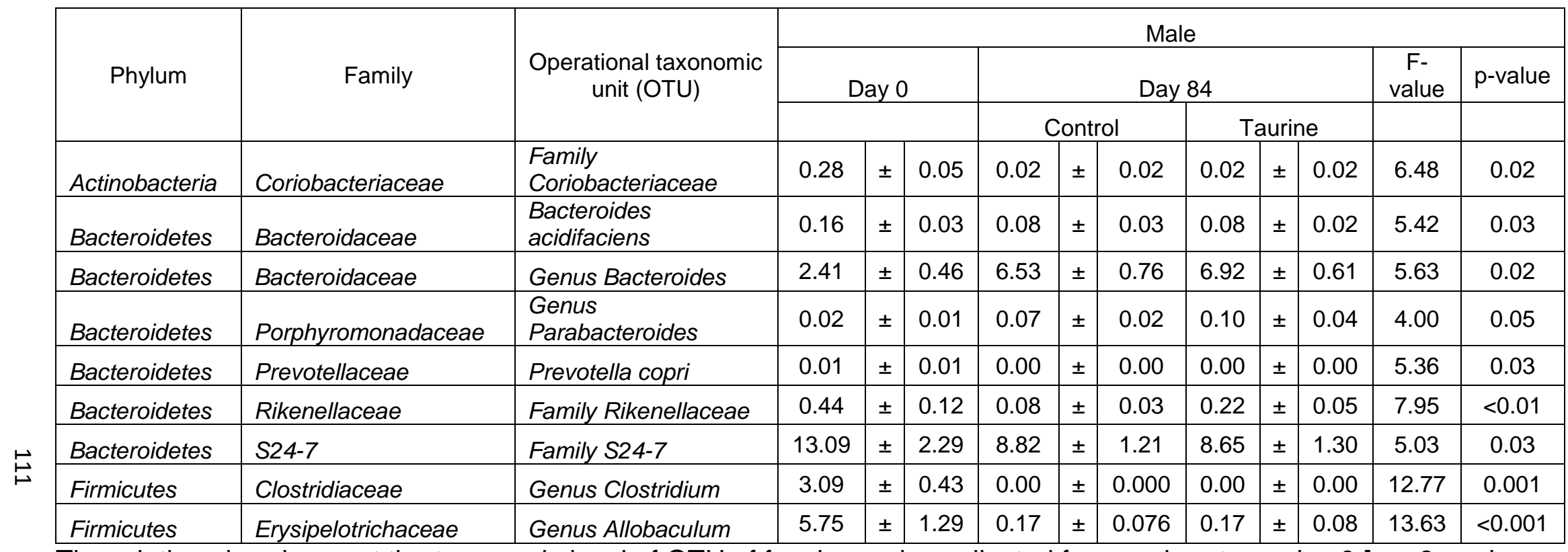

The relative abundance at the taxonomic level of OTU of fecal samples collected from male rats on day $0[n=6$, male control ( $0 \%$ taurine); $n=5$, male $0.7 \%$ taurine] and day $84(n=6)$. Nine OTUs were altered by the presence of taurine in the diet. Complete dataset available through the MOspace Institutional Repository. 
The principal component analysis (PCA) visually revealed the $\beta$-diversity at the OTU level was different between males and females at day 0 and the loss of the sex-difference by day 84 (Fig 4.8). Principal component 1 (PC1) accounted for $59.02 \%$ variance and principal component 2 (PC2) accounted for $8.69 \%$ of the variance. At day 0 , when the rats were on the standard rodent chow, a two-way PERMANOVA of sex and diet, showed a significant difference between the male and female rats $(p<0.01, F=6.80)$ and no diet effect $(p=$ $0.17, F=1.39)$ at the OTU level. At day 84 , the sex effect on $\beta$-diversity was lost $(p=0.12, F=1.46)$ and there was not a diet effect $(p=0.33, F=0.97)$, but there was a sex and diet interaction $(p<0.01, F=0.55)$ at the OTU level. A PERMANOVA looking at the effects of time and diet showed a significant time difference $(p<0.001, F=39.72)$, but there were no diet effects $(p=0.16, F=$ 1.55) at the OTU level. 
Figure 4.8 Principal component analysis

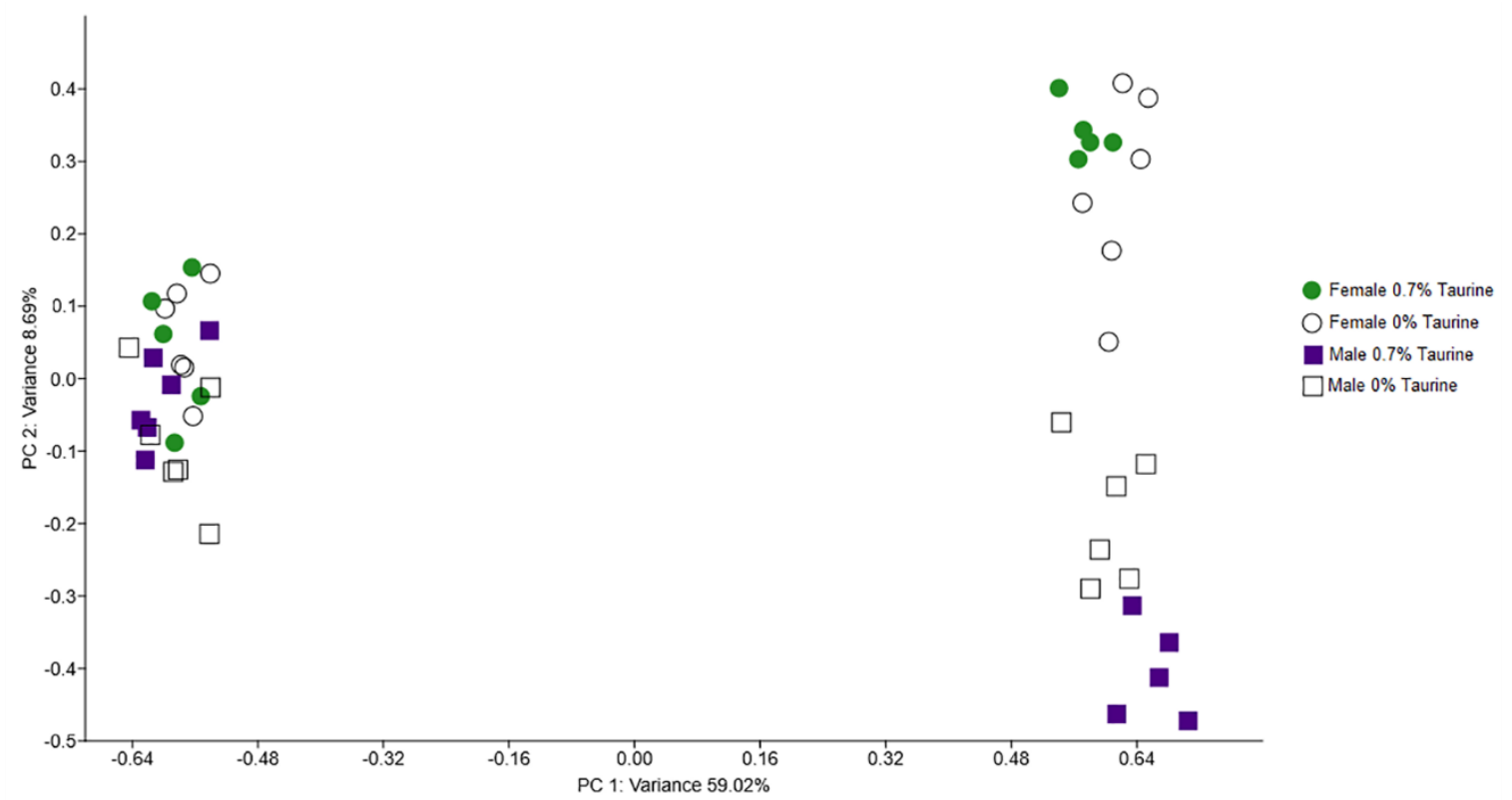

Principal component analysis for all rats at Day 0 showed a visible sex-effect $(p<$ $0.01)(n=6$, female $0 \%$ taurine and male $0 \%$ taurine; $n=5$, female $0.7 \%$ taurine and male $0.7 \%$ taurine) whereas on Day 84 the sex-effect was lost $(p=0.12)(n$ $=6$, female $0 \%$ taurine and male $0 \%$ taurine; $n=5$, female $0.7 \%$ taurine and male $0.7 \%$ taurine).

\section{Discussion}

Researchers and clinicians from a variety of medical disciplines are considering the use of supplemental taurine to optimize health and to help mitigate a variety of health problems such as diabetes (Ito et al. 2012) and coronary heart disease (Wójcik et al. 2010); however, there is a lack of knowledge on potential risks or "side effects" of high supplementation doses. During an investigation of taurine's effect on the thyroid, it was found that high levels of dietary taurine supplementation caused an increase in the body weight of female adult, 17 week-old, rats (Hooper et al. 2017). 
The DXA results of this present study indicate the observation of increased body weight of the female rats on the high taurine diet was likely due to an increase in both fat and lean masses-evidenced by the trend that was observed in these two parameters. Therefore, the rats appeared to become physically larger (Table 4.1, 4.3) while consuming less food than the control rats. To the authors' knowledge, it has never been reported that taurine supplementation can alter the growth of sexually mature rats. Oral maternal taurine supplementation has been shown to significantly increase the body weight of rat pups during the first 12 weeks post-parturition (Hultman et al. 2007). Hultman et al. (2007) suggested the taurine-induced effect on growth of the pups was the result of simulation of the GH/IGF-1 axis.

Transgenic mice deficient in growth hormone receptors (GHR), IGF-1, or both GHR and IGF-1 confirm that GH and IGF-1 have independent and overlapping functions of growth (Lupu et al. 2001). Lupu et al (2001) estimated that the GH/IGF-1 axis contribute to $83 \%$ of post-natal growth with $34 \%$ being attributed to overlapping functions, 35\% to IGF-1 independent actions, and $14 \%$ to GH independent actions. Intravenously administered taurine has been shown to increase growth hormone (lkuyama et al. 1988), and an increase in growth hormone will directly raise the circulating serum IGF-1 concentrations (Kalu et al. 1998). Because Dawson et al. (1999) reported that a trend was observed in taurine's ability to attenuate the age-related decline of circulating serum IGF-1 concentrations in 28 month old rats (Dawson et al. 1999), we expected to see high dietary taurine would cause an increase in circulating IGF-1 and thereby 
explain greater body size in rats given the diet. However, no significant dietary taurine treatment effects on serum IGF-1 concentration in the females or males was detected (Fig 4.5). Our results are similar to those reported by Hultman et al (2007) who also predicted an increase in circulating IGF-1 in rats orally supplemented with taurine, but did not detect an increase. Hultman et al (2007) suggested that IGF-1 was not altered in the larger pups whose mother receive taurine supplementation, because IGF-1 was only measured once and the increase could have occurred prior to the study endpoint. In an effort to capture potential fluxuations in IGF-1, our study measured fasting circulating serum IGF1 concentrations over the duration of the study, when the female rats on the high dietary taurine diet were actively increasing in body weight during 17 to 29 weeks of age. We also chose to measure IGF-1 rather than $\mathrm{GH}$, because $\mathrm{GH}$ has a half-life of approximately 12 minutes (Bright et al. 1999) and is secreted in a pulsatile manner that is highly variable within and between individuals (Tannenbaum and Martin 1976). Whereas, IGF-1 has a fifteen-hour half-life and is not secreted in a pulsatile manner (Brabant 2003) allowing a single time point measurement to be able to more accurately capture a potential effect of taurine on IGF-1. It is possible that taurine caused an increase in circulating serum IGF1 during the 4-hour period of food intake and that we did not detect the rise it as our blood sampling occurred 20 hours later, well past the 15 hours half-life of IGF-1. However, this seems unlikely because the rats receiving taurine compared to the control rats had a significantly greater taurine concentration of 
the liver (Fig 2), and the liver produces the majority of the circulating IGF-1 (Brabant 2003).

Approximately $17 \%$ of growth relies on other physiological processes that are independent of the GH/IGF-1 axis (Lupu et al. 2001). The ending age of the rats in our study were 5.5 months for males and 7.25 months for females. The functional closing of epiphyseal growth plates does not occur until 8 months of age in male rats and 10 month of age in female rats (Shim 2015). Our observation of the increase in mass and the trend observed in lean and BMC as measured by DXA (Table 4.3) indicates that taurine may stimulate osteoblast activity, causing an increase in size. This is further supported by cell culture studies in which taurine has been shown to increase proliferation of human osteoblasts (Jeon et al. 2007) and to promote mesenchymal stem cells to differentiate into osteoblasts (Zhou et al. 2014).

While it is well recognized that the pituitary-hypothalamic-thyroid axis contributes to growth (Gothe et al. 1999), the gut microbiome is beginning to be recognized as another factor contributing to growth (Cardinelli et al. 2015), particularly in neonates (Arboleya et al. 2017). The majority of gut microbiome studies on growth have been descriptive studies linking a decrease of the Bacteroidetes phylum and an increase in Firmicutes phylum to weight gain, or more specifically to obesity (Cardinelli et al. 2015). A single study has been completed on the contribution of the alteration of the microbiome and in particular an increase in relative abundance of Acidaminoccocus sp. bacteria that impedes linear growth (Gough et al. 2015). Our study sought how to understand how 
taurine altered the microbiome to determine if alterations of specific phyla and OTUs could provide be linked to an increase in both lean muscle as well as fat mass in our female rats on the high taurine diet.

The dietary taurine concentration used was shown to decrease the ratio of Bacteroidetes to Firmicutes in the females but not the male rats (Table 4.4-4.5). While a similar ratio change has been linked to obesity in humans and rats (Cláudia Marques 2016; Ley et al. 2006), it remains poorly understood how the fluctuation of individual OTUs, such as Family S24-7 or Bacteroides acidifaciens, affect physiological processes (Ormerod et al. 2016). For example, we observed that Family S24-7 in the Bacteroidetes phylum decreased in relative abundance to being almost undetectable in the female dietary taurine group, but not the female control group and both male treatment groups (Table 4.6-4.7).

Bacteroides acidifaciens increased in the female dietary taurine group, but not in the female control or either male group (Table 4.6-4.7). While both dietary taurine and potentially sex or age influenced the abundance of these OTUs future studies measuring specific biomarkers are needed to understand how Bacteroides acidifaciens and other bacteria contributes to metabolic processes. Such future studies could help to explain the observed beneficial (Ito et al. 2012) or detrimental effects of taurine supplementation (Hultman et al. 2007). Because we did not see an increase in percent fat mass or difference in fad pads weights between dietary treatment groups, the ratio of Bacteroidetes to Firmicutes may not be as important as to how individual OTUs within the Bacteroidetes and Firmicutes phyla fluctuate (Table 4.4-4.6). Alternatively, since oral taurine has 
been linked to promoting obesity (Hultman et al. 2007) it is possible that we did not observe a difference in fat mass due to the rats not having ab lib access to the diet.

The Family Coriobacteriaceae appeared to decline in all groups when the rats were placed on the purified diet, however dietary taurine attenuated the decline in the female rats compared to the female control rats (Table 4.6-4.7). Coriobacteriaceae is within the Actinobacteria phylum, and has previously been shown to stimulate triglyceride synthesis and glycogenesis in the liver in germ free mice (Claus et al. 2011). However, this contradicts the positive clinical outcome of decreased serum triglycerides in taurine treated individuals (Ito et al. 2012) as well in diabetic rats (Goodman and Shihabi 1990). This suggests that both the diet and other gut microbes can play a direct role in the metabolic functions of gut bacteria and germ free mice may be of limited value when determining these complicated relationships.

While the purified diet appeared to have an effect on the Family Coriobacteriaceae, it also appeared to alter the abundance of 55 other bacteria (Table S4.3). Interestingly, transitioning the female rats onto a purified diet also caused a decrease in Bacteroidetes and an increase in Firmicutes (Table 4.44.5). We only completed DXA scans on day 85 , however it would be of value to have conducted DXA scans prior to the start of the study to determine if the purified diet caused a change in the percent fat mass. Future studies should determine if the purified diet pre-disposes rats to exhibit an obesity phenotype. 
Purified diets, specifically the composition of the American Instituted of Nutrition (AIN) purified diets, are defined in detail to allow mechanistic studies of a particular nutrient of interest (e.g. taurine) that can be mixed into the diet (Reeves 1997; Reeves et al. 1993). These diets were formulated prior to the ability of scientists to study the gut microbiome with high-throughput sequencing. Our study suggests that scientists should consider how the gut microbiome may be altered on a purified diet. This is especially important to consider with the new $\mathrm{NIH}$ mandate that both sexes should be represented in animal studies as not only was the $\alpha$-diversity altered by the purified diet, but also the $\beta$-diversity. There were clear sex-differences in beta diversity prior to the start of the experiment that were lost when the rats were on the purified diet (Fig 4.8). This elimination of diversity could be detrimental when trying to determine underlying mechanisms that are sex-specific.

We did not observe an effect of high dietary taurine on fecal microbiome $\beta$-diversity, the diversity between samples. The observation is of particular interest since the female rats consuming the taurine diet gained increased mass. With a dietary taurine-induced increase in lean and likely muscle mass as well as fat mass, it is difficult to correlate particular phyla or OTUs identified within our study that could have caused the increase in lean mass. Because we did see an increase in taurine content in the quadriceps muscle (Fig 4.3), it may be the increase in muscle mass was due to an effect of taurine within the muscle tissue itself. Goodman et al (2009) reported that taurine supplementation did not increase body mass or extensor digital longus muscle mass in rats that were 
similarly aged to the males in this study. However, these investigators found a trend toward higher muscle mass-to-body mass ratio with taurine supplementation (Goodman et al. 2009). Of note, taurine depletion in transgenic mice with disrupted taurine transporter genes have been shown to have poor skeletal muscle function (Warskulat et al. 2004). Additionally, upon histological examination of knock-out TauT transgenic mice the tibial anterior muscle exhibited atrophy and necrotic cells (Ito et al. 2010), so it appears taurine does play a role in skeletal muscle health. It could be taurine has a greater effect in gaining muscle mass in older rats, and a future study should examine the effect of taurine on muscle mass in older animals to determine if a diet rich in taurine could help reverse sarcopenia.

\section{Conclusion}

Our study is the first to show that dietary taurine may increase both the lean muscle mass and fat mass of sexually mature female rats. Both the inclusion of taurine in the diet, and the purified diet itself, caused a decrease in Bacteroidetes phylum and an increase in Firmicutes phylum, likely resulting in the increase in fat mass. Additionally, future studies incorporating AIN-93 purified diets should investigate possible physiologic changes that are caused by the loss fecal microbiota $\beta$-diversity between sexes and the alteration of microbiota $\alpha$-diversity.

\section{Supplemental Tables}




\section{Supplemental Table 4.1}

\begin{tabular}{|c|c|c|c|c|c|c|c|c|c|c|c|c|c|c|c|}
\hline \multirow{4}{*}{$\begin{array}{c}\text { Phyla } \\
\text { Euryarchaeota }\end{array}$} & \multicolumn{9}{|c|}{ Female } & \multirow{2}{*}{\multicolumn{2}{|c|}{ Diet }} & \multirow{2}{*}{\multicolumn{2}{|c|}{ Sex }} & \multirow{2}{*}{\multicolumn{2}{|c|}{ Time }} \\
\hline & \multicolumn{3}{|c|}{ Day 0} & \multirow{2}{*}{\multicolumn{3}{|c|}{$\begin{array}{l}\text { Day } 84 \\
\text { Control }\end{array}$}} & \multirow{2}{*}{\multicolumn{3}{|c|}{$\begin{array}{l}\text { Day } 84 \\
\text { Taurine }\end{array}$}} & & & & & & \\
\hline & & & & & & & & & & $\begin{array}{c}\mathrm{F}- \\
\text { value }\end{array}$ & $\begin{array}{c}P- \\
\text { value }\end{array}$ & $\begin{array}{c}\mathrm{F}- \\
\text { value }\end{array}$ & $\begin{array}{c}P_{-} \\
\text {value }\end{array}$ & $\begin{array}{c}\mathrm{F}- \\
\text { value }\end{array}$ & P-value \\
\hline & 0.00 & \pm & 0.00 & 0.00 & \pm & 0.00 & 0.00 & \pm & 0.00 & 1.28 & 0.27 & 1.28 & 0.27 & 1.43 & 0.24 \\
\hline Actinobacteria & 0.60 & \pm & 0.00 & 0.20 & \pm & 0.00 & 0.14 & \pm & 0.00 & 1.09 & 0.3 & 4.65 & 0.04 & 23.99 & $<0.001$ \\
\hline Bacteroidetes & 24.40 & \pm & 0.01 & 21.50 & \pm & 0.02 & 18.86 & \pm & 0.03 & 6.12 & 0.02 & 11.60 & $<0.01$ & 1.27 & 0.27 \\
\hline Cyanobacteria & 0.15 & \pm & 0.00 & 0.10 & \pm & 0.00 & 0.10 & \pm & 0.00 & 0.65 & 0.43 & 3.53 & 0.07 & 0.29 & 0.6 \\
\hline Deferribacteres & 0.06 & \pm & 0.00 & 0.02 & \pm & 0.00 & 0.20 & \pm & 0.00 & 0.38 & 0.54 & 0.55 & 0.46 & 0.52 & 0.47 \\
\hline Firmicutes & 69.07 & \pm & 0.02 & 71.48 & \pm & 0.03 & 71.60 & \pm & 0.04 & 5.20 & 0.03 & 9.38 & $<0.01$ & 0.02 & 0.9 \\
\hline Lentisphaerae & 0.00 & \pm & 0.00 & 0.00 & \pm & 0.00 & 0.00 & \pm & 0.00 & 1.14 & 0.29 & 0.95 & 0.34 & 0.43 & 0.52 \\
\hline Proteobacteria & 1.55 & \pm & 0.00 & 0.95 & \pm & 0.00 & 0.70 & \pm & 0.00 & 0.07 & 0.8 & 1.64 & 0.21 & 1.37 & 0.25 \\
\hline Spirochaetes & 0.00 & \pm & 0.00 & 0.00 & \pm & 0.00 & 0.00 & \pm & 0.00 & 0.26 & 0.61 & 1.62 & 0.21 & 5.88 & 0.02 \\
\hline TM7 & 0.51 & \pm & 0.00 & 0.00 & \pm & 0.00 & 0.00 & \pm & 0.00 & 0.50 & 0.49 & 0.40 & 0.53 & 60.44 & $<0.001$ \\
\hline Tenericutes & 3.26 & \pm & 0.01 & 5.60 & \pm & 0.01 & 7.00 & \pm & 0.01 & 0.94 & 0.34 & 0.03 & 0.87 & 14.31 & $<0.001$ \\
\hline Verrucomicrobia & 0.35 & \pm & 0.00 & 0.15 & \pm & 0.00 & 1.40 & \pm & 0.01 & 0.82 & 0.37 & 0.21 & 0.65 & 2.15 & 0.15 \\
\hline WPS-2 & 0.00 & \pm & 0.00 & 0.00 & \pm & 0.00 & 0.00 & \pm & 0.00 & 1.43 & 0.24 & 0.00 & 0.96 & 0.63 & 0.43 \\
\hline
\end{tabular}

The relative abundance at the taxonomic level of OTU of fecal samples collected from female rats on day 0 [ $\mathrm{n}=6$, female control ( $0 \%$ taurine); $n=5$, female $0.7 \%$ taurine] and day $84(n=6$, female control; $n=5$, female $0.7 \%$ taurine).

Complete dataset available through the MOspace Institutional Repository. 


\begin{tabular}{|c|c|c|c|c|c|c|c|c|c|c|c|c|c|c|c|c|c|}
\hline \multirow{3}{*}{$\begin{array}{l}\text { Phyla } \\
\text { varchaeota }\end{array}$} & \multicolumn{9}{|c|}{ Female } & \multirow{2}{*}{\multicolumn{2}{|c|}{$\operatorname{Diet}^{\star}$ Sex }} & \multirow{2}{*}{\multicolumn{2}{|c|}{ Time*Diet }} & \multirow{2}{*}{\multicolumn{2}{|c|}{ Time*Sex }} & \multirow{2}{*}{\multicolumn{2}{|c|}{ Time* Diet $^{\star}$ Sex }} \\
\hline & \multicolumn{3}{|c|}{ Day 0} & \multirow{2}{*}{\multicolumn{3}{|c|}{$\begin{array}{l}\text { Day } 84 \\
\text { Control }\end{array}$}} & \multirow{2}{*}{\multicolumn{3}{|c|}{$\begin{array}{l}\text { Day } 84 \\
\text { Taurine }\end{array}$}} & & & & & & & & \\
\hline & 0.00 & \pm & 0.00 & & & & & & & \begin{tabular}{|c|}
$\begin{array}{c}\mathrm{F}- \\
\text { value }\end{array}$ \\
1.28
\end{tabular} & $\begin{array}{c}\begin{array}{c}\mathrm{P}- \\
\text { value }\end{array} \\
0.27 \\
\end{array}$ & $\begin{array}{c}\begin{array}{c}\text { F- } \\
\text { value }\end{array} \\
0.01 \\
\end{array}$ & $\begin{array}{c}\begin{array}{c}\mathrm{P}- \\
\text { value }\end{array} \\
0.92 \\
\end{array}$ & $\begin{array}{c}\begin{array}{c}F- \\
\text { value }\end{array} \\
0.06 \\
\end{array}$ & $\begin{array}{c}\begin{array}{c}\mathrm{P}- \\
\text { value }\end{array} \\
0.81\end{array}$ & $\begin{array}{c}\begin{array}{c}\mathrm{F}- \\
\text { value }\end{array} \\
0.7 \\
\end{array}$ & $\begin{array}{c}\begin{array}{c}P- \\
\text { value }\end{array} \\
0.41 \\
\end{array}$ \\
\hline Actinobacteria & 0.60 & \pm & 0.00 & 0.20 & \pm & 0.00 & 0.14 & \pm & 0.00 & 0.02 & 0.88 & 1.21 & 0.28 & 1.55 & 0.22 & 0.00 & 0.99 \\
\hline Bacteroidetes & 24.40 & \pm & 0.01 & 21.50 & \pm & 0.02 & 18.86 & \pm & 0.03 & 10.55 & $<0.01$ & 2.12 & 0.15 & 1.81 & 0.19 & 7.62 & $<0.01$ \\
\hline Cyanobacteria & 0.15 & \pm & 0.00 & 0.10 & \pm & 0.00 & 0.10 & \pm & 0.00 & 1.32 & 0.26 & 0.61 & 0.44 & 0.12 & 0.73 & 0.83 & 0.37 \\
\hline Firmicutes & 69.07 & \pm & 0.02 & 71.48 & \pm & 0.03 & 71.60 & \pm & 0.04 & 8.57 & 0.01 & 0.98 & 0.33 & 1.76 & 0.19 & 2.19 & 0.15 \\
\hline Lentisphaerae & 0.00 & \pm & 0.00 & 0.00 & \pm & 0.00 & 0.00 & \pm & 0.00 & 0.91 & 0.35 & 3.67 & 0.06 & 0.48 & 0.49 & 0.59 & 0.45 \\
\hline Proteobacteria & 1.55 & \pm & 0.00 & 0.95 & \pm & 0.00 & 0.70 & \pm & 0.00 & 2.66 & 0.11 & 0.12 & 0.74 & 3.27 & 0.08 & 4.86 & 0.03 \\
\hline Spirochaetes & 0.00 & \pm & 0.00 & 0.00 & \pm & 0.00 & 0.00 & \pm & 0.00 & 0.26 & 0.61 & 0.71 & 0.40 & 0.75 & 0.39 & 5.78 & 0.02 \\
\hline TM7 & 0.51 & \pm & 0.00 & 0.00 & \pm & 0.00 & 0.00 & \pm & 0.00 & 2.67 & 0.11 & 0.09 & 0.76 & 0.25 & 0.62 & 1.57 & 0.22 \\
\hline
\end{tabular}

The relative abundance at the taxonomic level of OTU of fecal samples collected from female rats on day $0[n=6$, female control ( $0 \%$ taurine); $n=5$, female $0.7 \%$ taurine] and day $84(n=6$, female control; $n=5$, female $0.7 \%$ taurine).

Complete dataset available through the MOspace Institutional Repository. 


\begin{tabular}{|c|c|c|c|c|c|c|c|c|c|c|c|c|c|c|c|}
\hline \multirow{3}{*}{ Phyla } & \multicolumn{9}{|c|}{ Male } & \multirow{2}{*}{\multicolumn{2}{|c|}{ Diet }} & \multirow{2}{*}{\multicolumn{2}{|c|}{ Sex }} & \multirow{2}{*}{\multicolumn{2}{|c|}{ Time }} \\
\hline & \multicolumn{3}{|c|}{ Day 0} & \multirow{2}{*}{\multicolumn{3}{|c|}{$\begin{array}{l}\text { Day } 84 \\
\text { Control }\end{array}$}} & \multirow{2}{*}{\multicolumn{3}{|c|}{$\begin{array}{l}\text { Day } 84 \\
\text { Taurine }\end{array}$}} & & & & & & \\
\hline & & & & & & & & & & F-value & P-value & F-value & P-value & F-value & P-value \\
\hline Euryarchaeota & 0.00 & \pm & 0.00 & 0.00 & \pm & 0.00 & 0.00 & \pm & 0.00 & 1.28 & 0.27 & 1.28 & 0.27 & 1.43 & 0.24 \\
\hline Actinobacteria & 1.00 & \pm & 0.00 & 0.30 & \pm & 0.00 & 0.17 & \pm & 0.00 & 1.09 & 0.3 & 4.65 & 0.04 & 23.99 & $<0.001$ \\
\hline Bacteroidetes & 16.60 & \pm & 0.03 & 16.13 & \pm & 0.02 & 16.57 & \pm & 0.02 & 6.12 & 0.02 & 11.60 & $<0.01$ & 1.27 & 0.27 \\
\hline Cyanobacteria & 0.03 & \pm & 0.00 & 0.02 & \pm & 0.00 & 0.03 & \pm & 0.00 & 0.65 & 0.43 & 3.53 & 0.07 & 0.29 & 0.6 \\
\hline Deferribacteres & 0.00 & \pm & 0.00 & 0.00 & \pm & 0.00 & 0.02 & \pm & 0.00 & 0.38 & 0.54 & 0.55 & 0.46 & 0.52 & 0.47 \\
\hline Firmicutes & 77.47 & \pm & 0.03 & 72.50 & \pm & 0.03 & 77.78 & \pm & 0.02 & 5.20 & 0.03 & 9.38 & $<0.01$ & 0.02 & 0.9 \\
\hline Lentisphaerae & 0.00 & \pm & 0.00 & 0.00 & \pm & 0.00 & 0.00 & \pm & 0.00 & 1.14 & 0.29 & 0.95 & 0.34 & 0.43 & 0.52 \\
\hline Proteobacteria & 1.13 & \pm & 0.00 & 0.88 & \pm & 0.00 & 1.65 & \pm & 0.00 & 0.07 & 0.8 & 1.64 & 0.21 & 1.37 & 0.25 \\
\hline Spirochaetes & 0.00 & \pm & 0.00 & 0.00 & \pm & 0.00 & 0.00 & \pm & 0.00 & 0.26 & 0.61 & 1.62 & 0.21 & 5.88 & 0.02 \\
\hline TM7 & 0.44 & \pm & 0.00 & 0.03 & \pm & 0.00 & 0.00 & \pm & 0.00 & 0.50 & 0.49 & 0.40 & 0.53 & 60.44 & $<0.001$ \\
\hline Tenericutes & 3.10 & \pm & 0.00 & 9.83 & \pm & 0.02 & 2.67 & \pm & 0.01 & 0.94 & 0.34 & 0.03 & 0.87 & 14.31 & $<0.001$ \\
\hline Verrucomicrobia & 0.16 & \pm & 0.00 & 0.27 & \pm & 0.00 & 1.10 & \pm & 0.01 & 0.82 & 0.37 & 0.21 & 0.65 & 2.15 & 0.15 \\
\hline WPS-2 & 0.00 & \pm & 0.00 & 0.00 & \pm & 0.00 & 0.00 & \pm & 0.00 & 1.43 & 0.24 & 0.00 & 0.96 & 0.63 & 0.43 \\
\hline
\end{tabular}

$\underset{\omega}{\tilde{w}}$ The relative abundance at the taxonomic level of OTU of fecal samples collected from male rats on day 0 [ $n=6$, male control ( $0 \%$ taurine); $n=5$, male $0.7 \%$ taurine] and day $84(n=6)$. Complete dataset available through the MOspace Institutional Repository. 


\begin{tabular}{|c|c|c|c|c|c|c|c|c|c|c|c|c|c|c|c|c|c|}
\hline \multirow{3}{*}{$\begin{array}{c}\text { Phyla } \\
\text { Euryarchaeota }\end{array}$} & \multicolumn{9}{|c|}{ Male } & \multirow{2}{*}{\multicolumn{2}{|c|}{ Diet $^{\star}$ Sex }} & \multirow{2}{*}{\multicolumn{2}{|c|}{ Time*Diet }} & \multirow{2}{*}{\multicolumn{2}{|c|}{ Time*Sex }} & \multirow{2}{*}{\multicolumn{2}{|c|}{ Time ${ }^{\star}$ Diet $^{\star}$ Sex }} \\
\hline & \multicolumn{3}{|c|}{ Day 0} & \multirow{2}{*}{\multicolumn{3}{|c|}{$\begin{array}{l}\text { Day } 84 \\
\text { Control }\end{array}$}} & \multirow{2}{*}{\multicolumn{3}{|c|}{$\begin{array}{l}\text { Day } 84 \\
\text { Taurine }\end{array}$}} & & & & & & & & \\
\hline & 0.00 & \pm & 0.00 & & & & & & & $\begin{array}{c}\begin{array}{c}F- \\
\text { value }\end{array} \\
1.28 \\
\end{array}$ & $\begin{array}{c}\begin{array}{c}P- \\
\text { value }\end{array} \\
0.27\end{array}$ & $\begin{array}{c}\begin{array}{c}\mathrm{F}- \\
\text { value }\end{array} \\
0.01\end{array}$ & $\begin{array}{c}\begin{array}{c}\mathrm{P}- \\
\text { value }\end{array} \\
0.92 \\
\end{array}$ & $\begin{array}{c}\begin{array}{c}F- \\
\text { value }\end{array} \\
0.06\end{array}$ & $\begin{array}{c}\begin{array}{c}P- \\
\text { value }\end{array} \\
0.81 \\
\end{array}$ & $\begin{array}{c}\begin{array}{c}\text { F- } \\
\text { value }\end{array} \\
0.7\end{array}$ & $\begin{array}{c}\begin{array}{c}P- \\
\text { value }\end{array} \\
0.41\end{array}$ \\
\hline Actinobacteria & 1.00 & \pm & 0.00 & 0.30 & \pm & 0.00 & 0.17 & \pm & 0.00 & 0.02 & 0.88 & 1.21 & 0.28 & 1.55 & 0.22 & 0.00 & 0.99 \\
\hline Bacteroidetes & 16.60 & \pm & 0.03 & 16.13 & \pm & 0.02 & 16.57 & \pm & 0.02 & 10.55 & $<0.01$ & 2.12 & 0.15 & 1.81 & 0.19 & 7.62 & $<0.01$ \\
\hline Firmicutes & 77.47 & \pm & 0.03 & 72.50 & \pm & 0.03 & 77.78 & \pm & 0.02 & 8.57 & 0.01 & 0.98 & 0.33 & 1.76 & 0.19 & 2.19 & 0.15 \\
\hline Lentisphaerae & 0.00 & \pm & 0.00 & 0.00 & \pm & 0.00 & 0.00 & \pm & 0.00 & 0.91 & 0.35 & 3.67 & 0.06 & 0.48 & 0.49 & 0.59 & 0.45 \\
\hline Proteobacteria & 1.13 & \pm & 0.00 & 0.88 & \pm & 0.00 & 1.65 & \pm & 0.00 & 2.66 & 0.11 & 0.12 & 0.74 & 3.27 & 0.08 & 4.86 & 0.03 \\
\hline Spirochaetes & 0.00 & \pm & 0.00 & 0.00 & \pm & 0.00 & 0.00 & \pm & 0.00 & 0.26 & 0.61 & 0.71 & 0.40 & 0.75 & 0.39 & 5.78 & 0.02 \\
\hline TM7 & 0.44 & \pm & 0.00 & 0.03 & \pm & 0.00 & 0.00 & \pm & 0.00 & 2.67 & 0.11 & 0.09 & 0.76 & 0.25 & 0.62 & 1.57 & 0.22 \\
\hline
\end{tabular}

The relative abundance at the taxonomic level of OTU of fecal samples collected from male rats on day 0 [n $=6$, male control ( $0 \%$ taurine); $n=5$, male $0.7 \%$ taurine] and day $84(n=6)$. Complete dataset available through the MOspace Institutional Repository. 


\section{Supplemental Table 4.2}

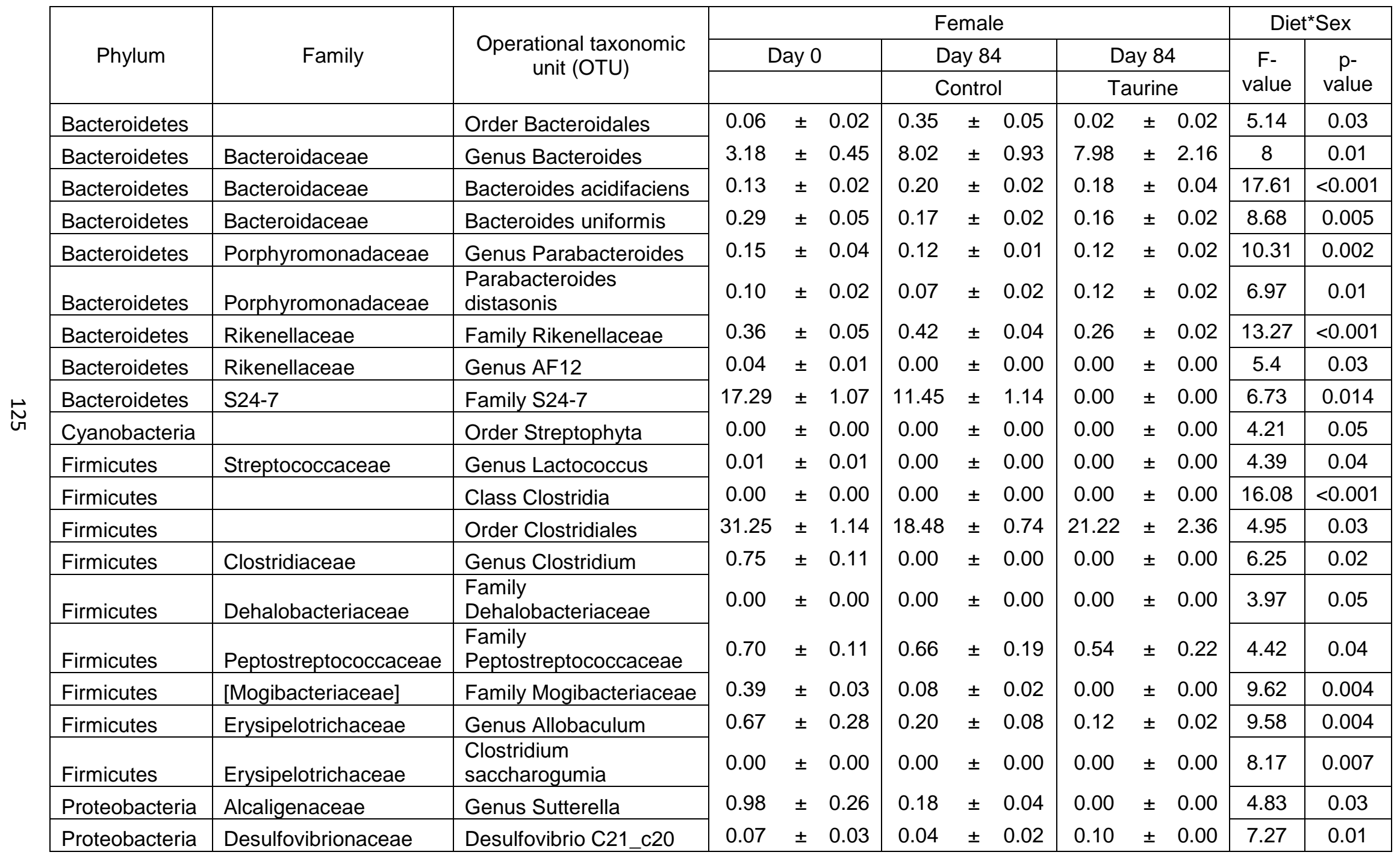




\begin{tabular}{|c|c|c|c|c|c|c|c|c|c|c|c|c|}
\hline \multirow{4}{*}{$\begin{array}{c}\text { Phylum } \\
\text { Bacteroidetes } \\
\end{array}$} & \multirow{4}{*}{ Family } & \multirow{4}{*}{$\begin{array}{c}\begin{array}{c}\text { Operational taxonomic } \\
\text { unit (OTU) }\end{array} \\
\text { Order Bacteroidales } \\
\end{array}$} & \multicolumn{8}{|c|}{ Male } & \multicolumn{2}{|c|}{ Diet ${ }^{\star}$ Sex } \\
\hline & & & \multirow{2}{*}{\multicolumn{2}{|c|}{ Day 0}} & \multirow{2}{*}{\multicolumn{3}{|c|}{$\begin{array}{l}\text { Day } 84 \\
\text { Control }\end{array}$}} & \multirow{2}{*}{\multicolumn{3}{|c|}{$\begin{array}{l}\text { Day } 84 \\
\text { Taurine }\end{array}$}} & \multirow{3}{*}{$\begin{array}{c}\begin{array}{c}\mathrm{F}- \\
\text { value }\end{array} \\
5.14 \\
\end{array}$} & \multirow{3}{*}{$\begin{array}{c}\begin{array}{c}p- \\
\text { value }\end{array} \\
0.03 \\
\end{array}$} \\
\hline & & & & & & & & & & & & \\
\hline & & & \multirow{2}{*}{\multicolumn{2}{|c|}{$\begin{array}{l}0.12 \pm 0.06 \\
2.41+0.46\end{array}$}} & \multirow{2}{*}{$\begin{array}{l}0.22 \\
6.53\end{array}$} & \multicolumn{2}{|c|}{ \pm 0.04} & \multirow{2}{*}{\multicolumn{3}{|c|}{$\begin{array}{lll}0.17 & \pm & 0.03 \\
6.92 & \pm & 0.61\end{array}$}} & & \\
\hline Bacteroidetes & Bacteroidaceae & Genus Bacteroides & & & & \pm & 0.76 & & & & 8 & 0.01 \\
\hline Bacteroidetes & Bacteroidaceae & Bacteroides acidifaciens & 0.16 & \pm 0.03 & 0.08 & \pm & 0.03 & 0.08 & \pm & 0.02 & 17.61 & $<0.001$ \\
\hline Bacteroidetes & Bacteroidaceae & Bacteroides uniformis & 0.13 & \pm 0.03 & 0.13 & \pm & 0.02 & 0.12 & \pm & 0.02 & 8.68 & 0.005 \\
\hline Bacteroidetes & Porphyromonadaceae & Genus Parabacteroides & 0.02 & \pm 0.01 & 0.07 & $t$ & 0.02 & 0.10 & 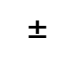 & 0.04 & 10.31 & 0.002 \\
\hline Bacteroidetes & Porphyromonadaceae & $\begin{array}{l}\text { Parabacteroides } \\
\text { distasonis }\end{array}$ & 0 & 21 & 0.05 & \pm & 2 & 0.08 & \pm & .02 & 6.97 & 0.01 \\
\hline Bacteroidetes & Rikenellaceae & Family Rikenellaceae & 0.44 & \pm 0.12 & 0.08 & \pm & 0.03 & 0.22 & \pm & 0.05 & 13.27 & $<0.001$ \\
\hline Bacteroidetes & Rikenellaceae & Genus AF12 & 0.01 & \pm 0.01 & 0.00 & \pm & 0.00 & 0.00 & \pm & 0.00 & 5.4 & 0.03 \\
\hline Bacteroidetes & S24-7 & Family S24-7 & 13.09 & \pm 2.29 & 8.82 & \pm & 1.21 & 8.65 & \pm & 1.30 & 6.73 & 0.014 \\
\hline Cyanobacteria & & Order Streptophyta & 0.00 & \pm 0.00 & 0.00 & \pm & 0.00 & 0.00 & \pm & 0.00 & 4.21 & 0.05 \\
\hline Firmicutes & Streptococcaceae & Genus Lactococcus & 0.00 & \pm 0.00 & 0.00 & \pm & 0.00 & 0.00 & \pm & 0.00 & 4.39 & 0.04 \\
\hline Firmicutes & & Class Clostridia & 0.00 & \pm 0.00 & 0.00 & \pm & 0.00 & 0.00 & \pm & 0.00 & 16.08 & $<0.001$ \\
\hline Firmicutes & & Order Clostridiales & 29.85 & \pm 1.40 & 22.57 & \pm & 3.27 & 20.82 & \pm & 1.76 & 4.95 & 0.03 \\
\hline Firmicutes & Clostridiaceae & Genus Clostridium & 3.09 & \pm 0.43 & 0.00 & 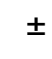 & 0.00 & 0.00 & \pm & 0.00 & 6.25 & 0.02 \\
\hline Firmicutes & Dehalobacte & $\begin{array}{l}\text { Family } \\
\text { Dehalobacteriaceae }\end{array}$ & 0.00 & \pm 0.00 & 0.00 & \pm & 0.00 & 0.00 & - & 0.00 & 3.97 & 0.05 \\
\hline Firmicutes & Peptostreptococcaceae & $\begin{array}{l}\text { Family } \\
\text { Peptostreptococcaceae }\end{array}$ & 0.40 & \pm 0.08 & 0.25 & \pm & 0.07 & 0.48 & $\underline{1}$ & 0.13 & 4.42 & 0.04 \\
\hline Firmicutes & [Mogibacteriaceae] & Family Mogibacteriaceae & 0.46 & \pm 0.03 & 0.12 & \pm & 0.08 & 0.08 & 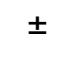 & 0.02 & 9.62 & 0.004 \\
\hline Firmicutes & Erysipelotrichaceae & Genus Allobaculum & 5.75 & \pm 1.29 & 0.17 & - & 0.08 & 0.17 & - & 0.08 & 9.58 & 0.004 \\
\hline Firmicutes & Erysipelotrichaceae & $\begin{array}{l}\text { Clostridium } \\
\text { saccharogumia }\end{array}$ & 0.00 & \pm & 0.00 & \pm & 0.00 & 0.00 & \pm & 0.00 & 8.17 & 0.007 \\
\hline Proteobacteria & Alcaligenaceae & Genus Sutterella & 0.58 & \pm 0.23 & 0.22 & \pm & 0.05 & 0.23 & \pm & 0.10 & 4.83 & 0.03 \\
\hline Proteobacteria & Desulfovibrionaceae & Desulfovibrio C21_c20 & 0.42 & \pm 0.09 & 0.00 & \pm & 0.00 & 0.00 & \pm & 0.00 & 7.27 & 0.01 \\
\hline
\end{tabular}




\section{Supplemental Table 4.3}

\begin{tabular}{|c|c|c|c|c|c|c|c|c|c|c|c|c|c|}
\hline \multirow{3}{*}{ Phylum } & \multirow{3}{*}{ Family } & \multirow{3}{*}{$\begin{array}{c}\text { Operational taxonomic } \\
\text { unit (OTU) }\end{array}$} & \multicolumn{9}{|c|}{ Female } & \multicolumn{2}{|c|}{ Time } \\
\hline & & & \multirow{2}{*}{\multicolumn{3}{|c|}{ Day 0}} & \multirow{2}{*}{\multicolumn{3}{|c|}{$\begin{array}{l}\text { Day } 84 \\
\text { Control }\end{array}$}} & \multirow{2}{*}{\multicolumn{3}{|c|}{$\begin{array}{l}\text { Day } 84 \\
\text { Taurine }\end{array}$}} & \multirow{3}{*}{$\begin{array}{c}\begin{array}{c}\text { F- } \\
\text { value }\end{array} \\
11.73\end{array}$} & \multirow{2}{*}{$\mathrm{p}$-value } \\
\hline & & & & & & & & & & & & & \\
\hline Actinobacteria & Bifidobacteriaceae & Genus Bifidobacterium & 0.31 & \pm & 0.11 & 0.10 & + & 0.02 & 0.06 & + & 0.04 & & 0.001 \\
\hline Actinobacteria & Coriobacteriaceae & Genus Adlercreutzia & 0.14 & \pm & 0.01 & 0.07 & \pm & 0.02 & 0.06 & 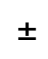 & 0.02 & 37.7 & $<0.001$ \\
\hline Bacteroidetes & & Order Bacteroidales & 0.06 & \pm & 0.02 & 0.35 & \pm & 0.05 & 0.02 & 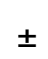 & 0.02 & 6.73 & 0.01 \\
\hline Bacteroidetes & Bacteroidaceae & Bacteroides uniformis & 0.29 & \pm & 0.05 & 0.17 & \pm & 0.02 & 0.16 & \pm & 0.02 & 5.54 & 0.02 \\
\hline Bacteroidetes & Prevotellaceae & Genus Prevotella & 0.86 & \pm & 0.12 & 0.07 & \pm & 0.03 & 0.10 & \pm & 0.08 & 29.01 & $<0.0001$ \\
\hline Bacteroidetes & Prevotellaceae & Prevotella copri & 1.22 & \pm & 0.29 & 0.00 & \pm & 0.00 & 0.00 & \pm & 0.00 & 16.31 & $<0.001$ \\
\hline Bacteroidetes & Rikenellaceae & Family Rikenellaceae & 0.36 & \pm & 0.05 & 0.42 & \pm & 0.04 & 0.26 & \pm & 0.02 & 6.55 & 0.01 \\
\hline Bacteroidetes & Rikenellaceae & Genus AF12 & 0.04 & \pm & 0.01 & 0.00 & \pm & 0.00 & 0.00 & \pm & 0.00 & 40.56 & $<0.0001$ \\
\hline Bacteroidetes & [Odoribacteraceae] & Genus Odoribacter & 0.07 & \pm & 0.03 & 0.00 & \pm & 0.00 & 0.00 & \pm & 0.00 & 4.57 & 0.04 \\
\hline Bacteroidetes & [Paraprevotellaceae] & Genus Paraprevotella & 0.00 & \pm & 0.00 & 0.00 & \pm & 0.00 & 0.00 & \pm & 0.00 & 12.58 & 0.001 \\
\hline Bacteroidetes & Cryomorphaceae & Genus Fluviicola & 0.06 & \pm & 0.02 & 0.00 & \pm & 0.00 & 0.00 & \pm & 0.00 & 16.18 & $<0.001$ \\
\hline Firmicutes & Lactobacillaceae & Genus Lactobacillus & 2.94 & \pm & 0.66 & 0.02 & \pm & 0.01 & 0.08 & \pm & 0.08 & 22.28 & $<0.001$ \\
\hline Firmicutes & Streptococcaceae & Genus Lactococcus & 0.01 & \pm & 0.01 & 0.00 & \pm & 0.00 & 0.00 & \pm & 0.00 & 11.03 & 0.002 \\
\hline Firmicutes & Streptococcaceae & Genus Streptococcus & 0.00 & \pm & 0.00 & 0.02 & \pm & 0.01 & 0.02 & \pm & 0.02 & 7.19 & 0.01 \\
\hline Firmicutes & Turicibacteraceae & Genus Turicibacter & 0.15 & \pm & 0.02 & 0.02 & \pm & 0.01 & 0.02 & \pm & 0.02 & 23.04 & $<0.0001$ \\
\hline Firmicutes & & Class Clostridia & 0.00 & \pm & 0.00 & 0.00 & \pm & 0.00 & 0.00 & \pm & 0.00 & 9.96 & 0.003 \\
\hline Firmicutes & & Order Clostridiales & 31.25 & \pm & 1.14 & 18.48 & \pm & 0.74 & 21.22 & \pm & 2.36 & 47.16 & $<0.0001$ \\
\hline
\end{tabular}




\begin{tabular}{|l|l|l|} 
Firmicutes & Christensenellaceae & $\begin{array}{l}\text { Family } \\
\text { Christensenellaceae }\end{array}$ \\
\hline Firmicutes & Christensenellaceae & $\begin{array}{l}\text { Genus } \\
\text { Christensenellaceae }\end{array}$ \\
\hline Firmicutes & Clostridiaceae & Family Clostridiaceae \\
\hline Firmicutes & Clostridiaceae & $\begin{array}{l}\text { Genus Candidatus } \\
\text { Arthromitus }\end{array}$ \\
\hline Firmicutes & Clostridiaceae & Genus Clostridium \\
\hline Firmicutes & Clostridiaceae & Genus SMB53 \\
\hline Firmicutes & Dehalobacteriaceae & $\begin{array}{l}\text { Family } \\
\text { Dehalobacteriaceae }\end{array}$ \\
\hline Firmicutes & Dehalobacteriaceae & Genus Dehalobacterium \\
\hline Firmicutes & Eubacteriaceae & Genus Anaerofustis \\
\hline Firmicutes & Gracilibacteraceae & Genus Gracilibacter \\
\hline Firmicutes & Lachnospiraceae & Genus Anaerostipes \\
\hline Firmicutes & Lachnospiraceae & Genus Coprococcus \\
\hline Firmicutes & Lachnospiraceae & Genus Roseburia \\
\hline Firmicutes & Lachnospiraceae & Genus Ruminococcus \\
\hline Firmicutes & Lachnospiraceae & Ruminococcus gnavus \\
\hline Firmicutes & Ruminococcaceae & $\begin{array}{l}\text { Family } \\
\text { Ruminococcaceae }\end{array}$ \\
\hline Firmicutes & Ruminococcaceae & Genus Anaerotruncus \\
\hline Firmicutes & Ruminococcaceae & Genus Oscillospira \\
\hline Firmicutes & Ruminococcaceae & Genus Ruminococcus \\
\hline Firmicutes & Ruminococcaceae & $\begin{array}{l}\text { Ruminococcus } \\
\text { flavefaciens }\end{array}$ \\
\hline Firmicutes & {$[$ Mogibacteriaceae] } & Family Mogibacteriaceae \\
\hline Firmicutes & & Order SHA-98 \\
\hline Firmicutes & Erysipelotrichaceae & Genus Allobaculum \\
\hline Firmicutes & Erysipelotrichaceae & $\begin{array}{l}\text { Clostridium } \\
\text { saccharogumia }\end{array}$ \\
\hline & & \\
\hline
\end{tabular}

\begin{tabular}{|c|c|c|c|c|c|c|c|c|c|c|}
\hline 0.15 & \pm & 0.02 & 0.20 & \pm & 0.00 & 0.24 & \pm & 0.04 & 8.29 & 0.007 \\
\hline 0.00 & \pm & 0.00 & 0.00 & \pm & 0.00 & 0.00 & \pm & 0.00 & 8.2 & 0.007 \\
\hline 0.17 & \pm & 0.02 & 0.10 & \pm & 0.04 & 0.06 & \pm & 0.02 & 36 & $<0.0001$ \\
\hline 0.00 & \pm & 0.00 & 0.00 & \pm & 0.00 & 0.00 & \pm & 0.00 & 5.09 & 0.03 \\
\hline 0.75 & \pm & 0.11 & 0.00 & \pm & 0.00 & 0.00 & \pm & 0.00 & 78.61 & $<0.0001$ \\
\hline 0.00 & \pm & 0.00 & 0.00 & \pm & 0.00 & 0.00 & \pm & 0.00 & 10.16 & 0.003 \\
\hline 0.00 & \pm & 0.00 & 0.00 & \pm & 0.00 & 0.00 & \pm & 0.00 & 27.9 & $<0.0001$ \\
\hline 0.20 & \pm & 0.03 & 0.08 & \pm & 0.01 & 0.12 & \pm & 0.02 & 4.7 & 0.04 \\
\hline 0.00 & \pm & 0.00 & 0.00 & \pm & 0.00 & 0.00 & \pm & 0.00 & 4.47 & 0.04 \\
\hline 0.00 & \pm & 0.00 & 0.00 & \pm & 0.00 & 0.00 & \pm & 0.00 & 6.53 & 0.01 \\
\hline 0.00 & \pm & 0.00 & 0.00 & \pm & 0.00 & 0.00 & \pm & 0.00 & 33.96 & $<0.0001$ \\
\hline 1.83 & \pm & 0.46 & 1.08 & \pm & 0.26 & 4.62 & \pm & 1.55 & 5.68 & 0.02 \\
\hline 0.42 & \pm & 0.06 & 0.08 & \pm & 0.03 & 0.06 & \pm & 0.02 & 28.46 & $<0.0001$ \\
\hline 0.00 & \pm & 0.00 & 0.00 & \pm & 0.00 & 0.00 & \pm & 0.00 & 5.97 & 0.02 \\
\hline 0.32 & \pm & 0.06 & 0.03 & \pm & 0.02 & 0.06 & \pm & 0.02 & 17.21 & $<0.001$ \\
\hline 11.23 & \pm & 0.79 & 41.30 & \pm & 2.00 & 34.06 & \pm & 4.25 & 176.38 & $<0.0001$ \\
\hline 0.00 & \pm & 0.00 & 0.00 & \pm & 0.00 & 0.00 & \pm & 0.00 & 13.66 & $<0.001$ \\
\hline 7.77 & \pm & 0.74 & 2.02 & \pm & 0.25 & 4.18 & \pm & 0.50 & 35.62 & $<0.0001$ \\
\hline 4.39 & \pm & 0.51 & 2.70 & \pm & 0.45 & 2.26 & \pm & 0.34 & 16.22 & $<0.001$ \\
\hline 1.03 & \pm & 0.14 & 0.98 & \pm & 0.46 & 0.50 & \pm & 0.30 & 6.69 & 0.01 \\
\hline 0.39 & \pm & 0.03 & 0.08 & \pm & 0.01 & 0.08 & \pm & 0.02 & 122.2 & $<0.001$ \\
\hline 0.00 & \pm & 0.00 & 0.00 & \pm & 0.00 & 0.00 & \pm & 0.00 & 23.38 & $<0.0001$ \\
\hline 0.67 & \pm & 0.28 & 0.48 & \pm & 0.18 & 0.20 & \pm & 0.08 & 27.59 & $<0.0001$ \\
\hline 0.00 & \pm & 0.00 & 0.00 & \pm & 0.00 & 0.00 & \pm & 0.00 & 29.75 & $<0.0001$ \\
\hline
\end{tabular}




\begin{tabular}{|c|c|c|c|c|c|c|c|c|c|c|c|c|c|}
\hline Firmicutes & Erysipelotrichaceae & Genus L7A_E11 & 0.00 & \pm & 0.00 & 0.00 & \pm & 0.00 & 0.00 & \pm & 0.00 & 4.84 & 0.03 \\
\hline Proteobacteria & Alcaligenaceae & Genus Sutterella & 0.98 & \pm & 0.26 & 0.50 & \pm & 0.19 & 0.18 & \pm & 0.04 & 6.24 & 0.02 \\
\hline Proteobacteria & Desulfovibrionaceae & $\begin{array}{l}\text { Family } \\
\text { Desulfovibrionaceae }\end{array}$ & 0.04 & \pm & 0.01 & 0.10 & - & 0.02 & 0.16 & \pm & 0.04 & 38.37 & $<0.0001$ \\
\hline Proteobacteria & Desulfovibrionaceae & Genus Desulfovibrio & 0.28 & \pm & 0.08 & 0.13 & \pm & 0.02 & 0.10 & \pm & 0.00 & 4.96 & 0.03 \\
\hline Proteobacteria & Desulfovibrionaceae & Desulfovibrio C21_c20 & 0.07 & \pm & 0.03 & 0.02 & \pm & 0.01 & 0.04 & \pm & 0.02 & 22.08 & $<0.0001$ \\
\hline Proteobacteria & Pasteurellaceae & $\begin{array}{l}\text { Aggregatibacter } \\
\text { pneumotropica }\end{array}$ & 0.00 & \pm & 0 & 0.00 & - & 0 & 0.00 & \pm & 00 & 12.84 & 0.001 \\
\hline Proteobacteria & Moraxellaceae & Psychrobacter sanguinis & 0.00 & \pm & 0.00 & 0.00 & - & 0.00 & 0.00 & \pm & 0.00 & 5.34 & 0.03 \\
\hline Spirochaetes & Spirochaetaceae & Genus Treponema & 0.00 & \pm & 0.00 & 0.00 & \pm & 0.00 & 0.00 & \pm & 0.00 & 5.88 & 0.02 \\
\hline TM7 & F16 & Family F16 & 0.51 & \pm & 0.10 & 0.00 & \pm & 0.00 & 0.00 & \pm & 0.00 & 60.44 & $<0.0001$ \\
\hline Tenericutes & Anaeroplasmataceae & Genus Anaeroplasma & 0.00 & \pm & 0.00 & 0.00 & \pm & 0.00 & 0.00 & \pm & 0.00 & 12.88 & 0.001 \\
\hline Tenericutes & & Order RF39 & 3.25 & \pm & 0.47 & 5.60 & \pm & 0.97 & 6.96 & \pm & 0.89 & 14.18 & $<0.001$ \\
\hline
\end{tabular}

The relative abundance at the taxonomic level of OTU of fecal samples collected from female rats on day $0[\mathrm{n}=6$, female

$\stackrel{\vec{\sigma}}{6}$ control ( $0 \%$ taurine); $n=5$, female $0.7 \%$ taurine] and day $84(n=6$, female control; $n=5$, female $0.7 \%$ taurine).

Complete dataset available through the MOspace Institutional Repository. 


\section{Supplemental Table 4.4}

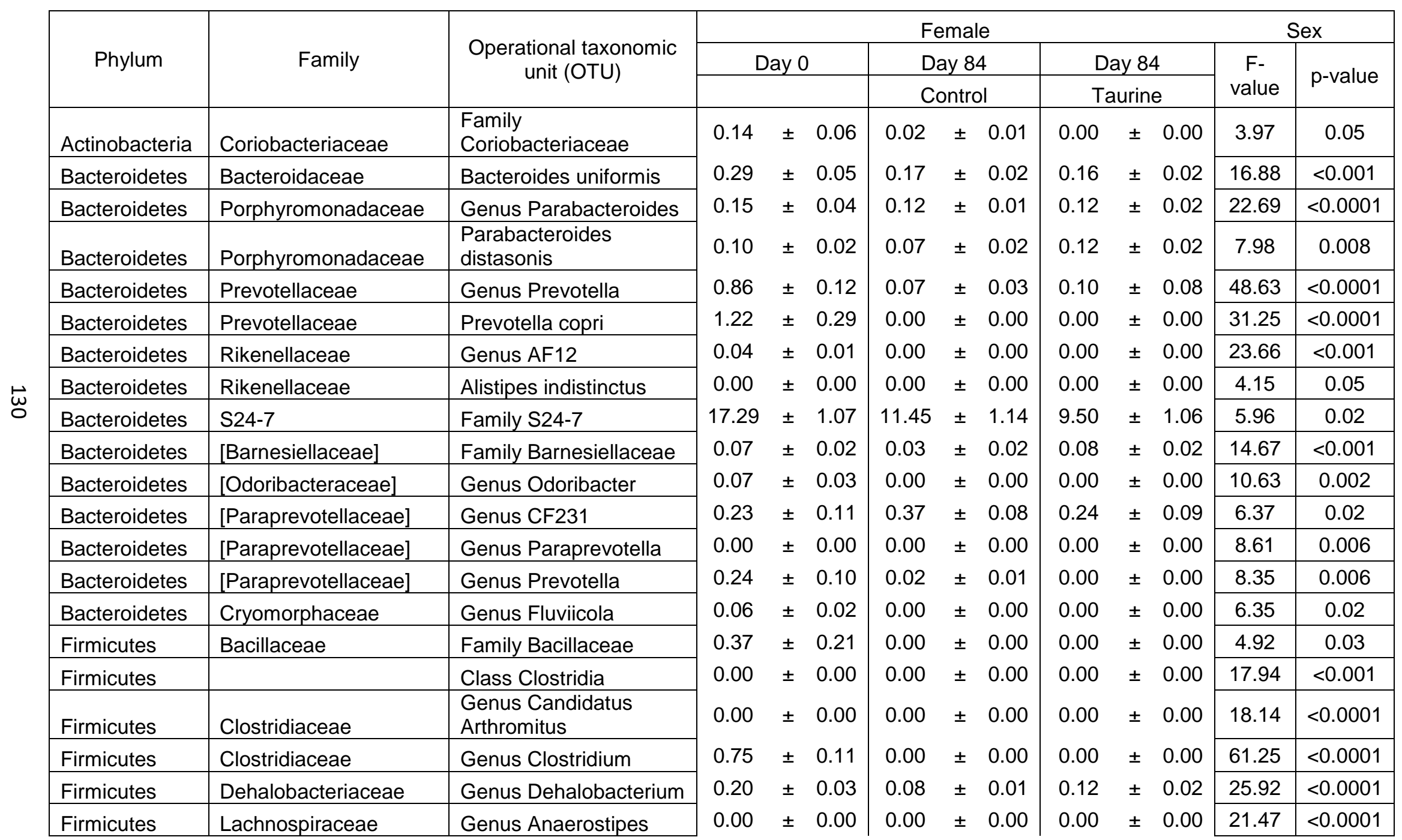




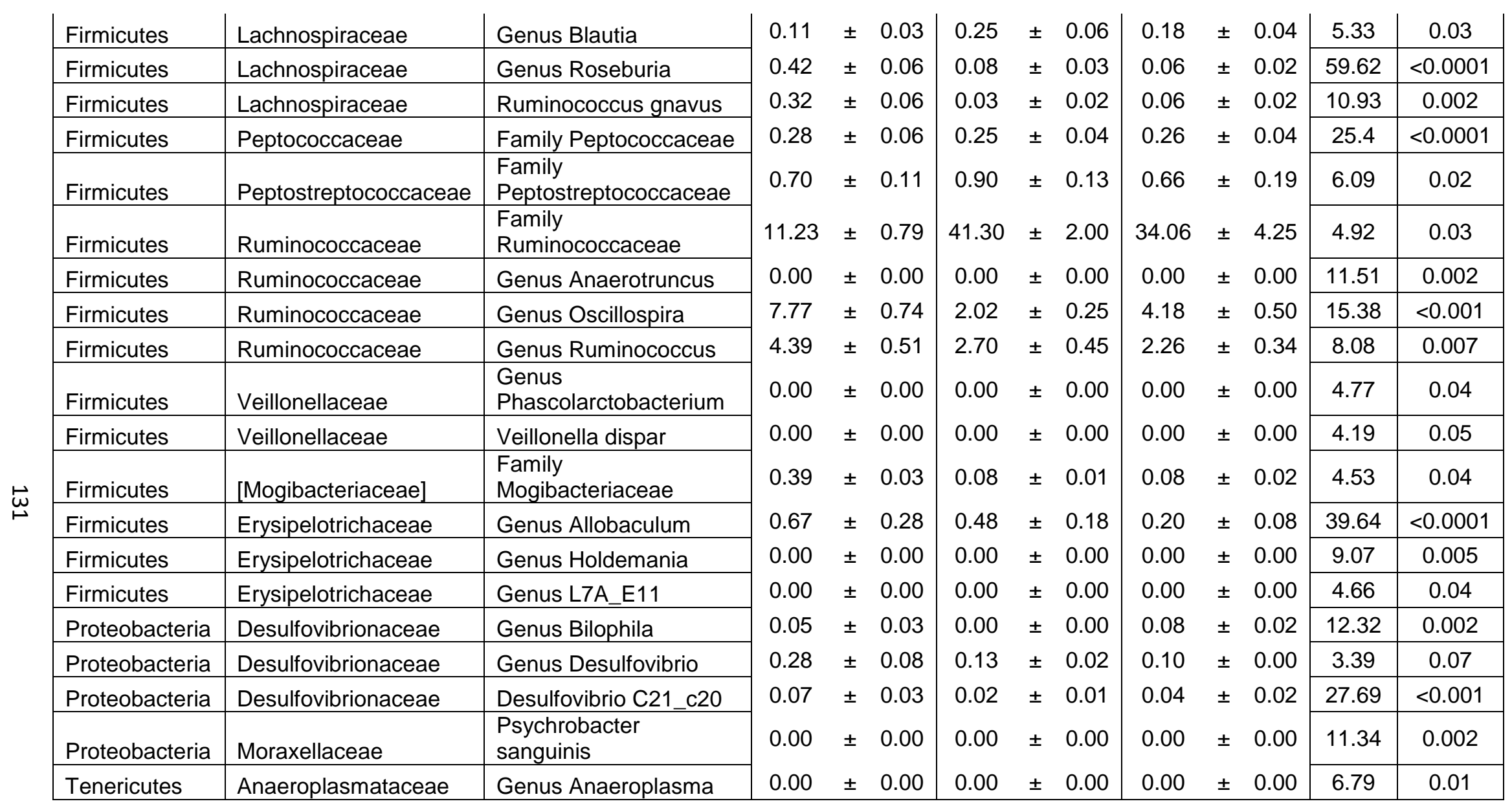

The relative abundance at the taxonomic level of OTU of fecal samples collected from female rats on day $0[n=6$, female control ( $0 \%$ taurine); $n=5$, female $0.7 \%$ taurine] and day $84(n=6$, female control; $n=5$, female $0.7 \%$ taurine). Complete dataset available through the MOspace Institutional Repository. 


\begin{tabular}{|c|c|c|c|c|c|c|c|c|c|c|c|c|c|}
\hline \multirow{4}{*}{$\begin{array}{c}\text { Phylum } \\
\text { Actinobacteria } \\
\end{array}$} & \multirow{4}{*}{$\begin{array}{c}\text { Family } \\
\text { Coriobacteriaceae } \\
\end{array}$} & \multirow{4}{*}{$\begin{array}{l}\begin{array}{c}\text { Operational taxonomic } \\
\text { unit (OTU) }\end{array} \\
\text { Family } \\
\text { Coriobacteriaceae } \\
\end{array}$} & \multicolumn{9}{|c|}{ Male } & \multicolumn{2}{|c|}{ Sex } \\
\hline & & & \multicolumn{3}{|c|}{ Day 0} & \multirow{2}{*}{\multicolumn{3}{|c|}{$\begin{array}{l}\text { Day } 84 \\
\text { Control }\end{array}$}} & \multirow{2}{*}{\multicolumn{3}{|c|}{$\begin{array}{l}\text { Day } 84 \\
\text { Taurine }\end{array}$}} & \multirow{3}{*}{$\begin{array}{c}\text { F-value } \\
3.97 \\
\end{array}$} & \multirow{3}{*}{$\begin{array}{c}p \text {-value } \\
0.05 \\
\end{array}$} \\
\hline & & & \multirow{3}{*}{$\begin{array}{l}0.28 \\
0.13\end{array}$} & \multirow{3}{*}{$\begin{array}{l} \pm \\
\pm\end{array}$} & & & & & & & & & \\
\hline & & & & & & 0.02 & \pm & 0.02 & 0.02 & & 0.02 & & \\
\hline Bacteroidetes & Bacteroidaceae & Bacteroides uniformis & & & 0.03 & 0.13 & \pm & 0.02 & 0.12 & \pm & 0.02 & 16.88 & $<0.001$ \\
\hline Bacteroidetes & Porphyromonadaceae & Genus Parabacteroides & 0.02 & \pm & 0.01 & 0.07 & \pm & 0.02 & 0.10 & + & 0.04 & 22.69 & $<0.0001$ \\
\hline Bacteroidetes & Porphyromonadaceae & $\begin{array}{l}\text { Parabacteroides } \\
\text { distasonis }\end{array}$ & 0.04 & \pm & 0.01 & 0.05 & \pm & 0.02 & 0.08 & - & .02 & 7.98 & 0.008 \\
\hline Bacteroidetes & Prevotellaceae & Prevotella copri & 0.01 & \pm & 0.01 & 0.00 & \pm & 0.00 & 0.00 & \pm & 0.00 & 31.25 & $<0.0001$ \\
\hline Bacteroidetes & Rikenellaceae & Genus AF12 & 0.01 & \pm & 0.01 & 0.00 & \pm & 0.00 & 0.00 & \pm & 0.00 & 23.66 & $<0.001$ \\
\hline Bacteroidetes & Rikenellaceae & Alistipes indistinctus & 0.00 & \pm & 0.00 & 0.00 & \pm & 0.00 & 0.00 & \pm & 0.00 & 4.15 & 0.05 \\
\hline Bacteroidetes & S24-7 & Family S24-7 & 13.09 & \pm & 2.29 & 8.82 & \pm & 1.21 & 8.65 & \pm & 1.30 & 5.96 & 0.02 \\
\hline Bacteroidetes & [Barnesiellaceae] & Family Barnesiellaceae & 0.01 & \pm & 0.01 & 0.05 & \pm & 0.02 & 0.12 & \pm & 0.02 & 14.67 & $<0.001$ \\
\hline Bacteroidetes & [Paraprevotellaceae] & Genus Prevotella & 0.00 & \pm & 0.00 & 0.00 & \pm & 0.00 & 0.00 & \pm & 0.00 & 8.35 & 0.006 \\
\hline Bacteroidetes & Cryomorphaceae & Genus Fluviicola & 0.04 & \pm & 0.01 & 0.00 & \pm & 0.00 & 0.00 & \pm & 0.00 & 6.35 & 0.02 \\
\hline Firmicutes & Bacillaceae & Family Bacillaceae & 0.00 & \pm & 0.00 & 0.00 & \pm & 0.00 & 0.07 & \pm & 0.07 & 4.92 & 0.03 \\
\hline Firmicutes & & Class Clostridia & 0.00 & \pm & 0.00 & 0.00 & \pm & 0.00 & 0.00 & \pm & 0.00 & 17.94 & $<0.001$ \\
\hline Firmicutes & Clostridiaceae & $\begin{array}{l}\text { Genus Candidatus } \\
\text { Arthromitus }\end{array}$ & 0.00 & \pm & 0.00 & 0.00 & \pm & 0.00 & 0.00 & $\underline{I}$ & 0.00 & 18.14 & $<0.0001$ \\
\hline Firmicutes & Clostridiaceae & Genus Clostridium & 3.09 & \pm & 0.43 & 0.00 & \pm & 0.00 & 0.00 & \pm & 0.00 & 61.25 & $<0.0001$ \\
\hline Firmicutes & Dehalobacteriaceae & Genus Dehalobacterium & 0.06 & \pm & 0.01 & 0.08 & \pm & 0.02 & 0.10 & \pm & 0.00 & 25.92 & $<0.0001$ \\
\hline Firmicutes & Lachnospiraceae & Genus Anaerostipes & 0.03 & \pm & 0.01 & 0.00 & \pm & 0.00 & 0.00 & \pm & 0.00 & 21.47 & $<0.0001$ \\
\hline Firmicutes & Lachnospiraceae & Genus Blautia & 0.32 & \pm & 0.06 & 0.23 & \pm & 0.14 & 0.18 & \pm & 0.03 & 5.33 & 0.03 \\
\hline Firmicutes & Lachnospiraceae & Genus Roseburia & 0.03 & \pm & 0.01 & 0.00 & \pm & 0.00 & 0.02 & \pm & 0.02 & 59.62 & $<0.0001$ \\
\hline
\end{tabular}




\begin{tabular}{|c|c|c|c|c|c|c|c|c|c|c|c|c|c|}
\hline Firmicutes & Lachnospiraceae & Ruminococcus gnavus & 0.14 & \pm & 0.02 & 0.07 & \pm & 0.03 & 0.05 & \pm & 0.03 & 10.93 & 0.002 \\
\hline Firmicutes & Peptococcaceae & Family Peptococcaceae & 0.01 & \pm & 0.01 & 0.03 & \pm & 0.02 & 0.05 & \pm & 0.02 & 25.4 & $<0.0001$ \\
\hline Firmicutes & Peptostreptococcaceae & $\begin{array}{l}\text { Family } \\
\text { Peptostreptococcaceae }\end{array}$ & 0.40 & \pm & 0.08 & 0.25 & \pm & 0.07 & 0.48 & \pm & 0.13 & 6.09 & 0.02 \\
\hline Firmicutes & Ruminococcaceae & Genus Anaerotruncus & 0.00 & \pm & 0.00 & 0.00 & \pm & 0.00 & 0.00 & \pm & 0.00 & 11.51 & 0.002 \\
\hline Firmicutes & Ruminococcaceae & Genus Oscillospira & 4.81 & \pm & 0.34 & 3.75 & \pm & 0.90 & 2.58 & \pm & 0.26 & 15.38 & $<0.001$ \\
\hline Firmicutes & Veillonellaceae & Veillonella dispar & 0.00 & \pm & 0.00 & 0.00 & \pm & 0.00 & 0.00 & \pm & 0.00 & 4.19 & 0.05 \\
\hline Firmicutes & [Mogibacteriaceae] & $\begin{array}{l}\text { Family } \\
\text { Mogibacteriaceae }\end{array}$ & 0.46 & \pm & 0.03 & 0.12 & \pm & 0.08 & 0.08 & \pm & 0.02 & 4.53 & 0.04 \\
\hline Firmicutes & Erysipelotrichaceae & Genus Allobaculum & 5.75 & \pm & 1.29 & 0.17 & \pm & 0.08 & 0.17 & \pm & 0.08 & 39.64 & $<0.0001$ \\
\hline Firmicutes & Erysipelotrichaceae & Genus Holdemania & 0.00 & \pm & 0.00 & 0.00 & \pm & 0.00 & 0.00 & \pm & 0.00 & 9.07 & 0.005 \\
\hline Proteobacteria & Desulfovibrionaceae & Desulfovibrio C21_c20 & 0.42 & \pm & 0.09 & 0.00 & \pm & 0.00 & 0.00 & \pm & 0.00 & 27.69 & $<0.001$ \\
\hline Proteobacteria & Moraxellaceae & Psychrobacter sanguinis & 0.00 & \pm & 0.00 & 0.00 & \pm & 0.00 & 0.00 & \pm & 0.00 & 11.34 & 0.002 \\
\hline Tenericutes & Anaeroplasmataceae & Genus Anaeroplasma & 0.00 & \pm & 0.00 & 0.00 & \pm & 0.00 & 0.00 & \pm & 0.00 & 6.79 & 0.01 \\
\hline
\end{tabular}

The relative abundance at the taxonomic level of OTU of fecal samples collected from male rats on day $0[n=6$, male control ( $0 \%$ taurine); $n=5$, male $0.7 \%$ taurine] and day $84(n=6)$. Complete dataset available through the MOspace Institutional Repository. 


\section{Supplemental Table 4.5}

\begin{tabular}{|c|c|c|c|c|c|c|c|c|c|c|c|}
\hline \multirow{4}{*}{$\begin{array}{c}\text { Phylum } \\
\text { Bacteroidetes } \\
\end{array}$} & \multirow{4}{*}{ Family } & \multirow{4}{*}{$\begin{array}{c}\begin{array}{c}\text { Operational taxonomic } \\
\text { unit (OTU) }\end{array} \\
\text { Order Bacteroidales } \\
\end{array}$} & \multicolumn{7}{|c|}{ Female } & \multicolumn{2}{|c|}{ Time*Diet ${ }^{\star}$ Sex } \\
\hline & & & \multirow{2}{*}{\multicolumn{2}{|c|}{ Day 0}} & \multirow{2}{*}{\multicolumn{2}{|c|}{$\begin{array}{l}\text { Day } 84 \\
\text { Control } \\
\end{array}$}} & \multirow{2}{*}{\multicolumn{3}{|c|}{$\begin{array}{c}\text { Day } 84 \\
\text { Taurine }\end{array}$}} & \multirow{3}{*}{$\begin{array}{c}\begin{array}{c}\text { F- } \\
\text { value }\end{array} \\
10.67 \\
\end{array}$} & \multirow{3}{*}{\begin{tabular}{|c|c}
$\begin{array}{c}p- \\
\text { value }\end{array}$ \\
0.002 \\
\end{tabular}} \\
\hline & & & & & & & & & & & \\
\hline & & & \multirow{2}{*}{$\begin{array}{l}0.06 \\
3.18\end{array}$} & \multirow{2}{*}{$\begin{array}{l} \pm 0.02 \\
\pm 0.45\end{array}$} & \multirow{2}{*}{\multicolumn{2}{|c|}{$\begin{array}{lll}0.35 & \pm & 0.05 \\
8.02 & \pm & 0.93\end{array}$}} & \multirow{2}{*}{\multicolumn{3}{|c|}{$\begin{array}{l}0.02 \pm 0.02 \\
798\end{array}$}} & & \\
\hline Bacteroidetes & Bacteroidaceae & Genus Bacteroides & & & & & & & & 4.83 & 0.03 \\
\hline Bacteroidetes & Bacteroidaceae & Bacteroides acidifaciens & 0.13 & \pm 0.02 & 0.20 & \pm 0.02 & 0.18 & \pm & 0.04 & 15.64 & $<0.001$ \\
\hline Bacteroidetes & Bacteroidaceae & Bacteroides uniformis & 0.29 & \pm 0.05 & 0.17 & \pm 0.02 & 0.16 & \pm & 0.02 & 4.47 & 0.04 \\
\hline Bacteroidetes & S24-7 & Family S24-7 & 17.29 & \pm 1.07 & 11.45 & \pm 1.14 & 9.50 & \pm & 1.06 & 4.81 & 0.03 \\
\hline Bacteroidetes & [Barnesiellaceae] & Family Barnesiellaceae & 0.07 & \pm 0.02 & 0.03 & \pm 0.02 & 0.08 & \pm & 0.02 & 5.03 & 0.03 \\
\hline Firmicutes & & Class Clostridia & 0.00 & \pm 0.00 & 0.00 & \pm 0.00 & 0.00 & \pm & 0.00 & 8.84 & 0.005 \\
\hline Firmicutes & & Order Clostridiales & 31.25 & \pm 1.14 & 18.48 & \pm 0.74 & 21.22 & \pm & 2.36 & 5.6 & 0.02 \\
\hline Firm & Peptostreptococcaceae & \begin{tabular}{|l|} 
Family \\
Peptostreptococcaceae
\end{tabular} & 0.70 & \pm 0.11 & 0.90 & \pm 0.13 & 0.66 & \pm & 0.19 & 6.51 & 0.02 \\
\hline Firmicutes & Veillonellaceae & $\begin{array}{l}\text { Genus } \\
\text { Phascolarctobacterium }\end{array}$ & 0.00 & \pm 0.00 & 0.00 & \pm 0.00 & 0.00 & \pm & 0.00 & 0.45 & 0.05 \\
\hline Firmicutes & [Mogibacteriaceae] & Family Mogibacteriaceae & 0.39 & \pm 0.03 & 0.08 & \pm 0.01 & 0.08 & \pm & 0.02 & 6.83 & 0.01 \\
\hline Firmicutes & Erysipelotrichaceae & Genus Allobaculum & 0.67 & \pm 0.28 & 0.48 & \pm 0.18 & 0.20 & \pm & 0.08 & 4.4 & 0.04 \\
\hline Proteobacteria & Alcaligenaceae & Genus Sutterella & 0.98 & \pm 0.26 & 0.50 & \pm 0.19 & 0.18 & \pm & 0.04 & 4.1 & 0.05 \\
\hline Proteobacteria & Desulfovibrionaceae & Genus Desulfovibrio & 0.28 & \pm 0.08 & 0.13 & \pm 0.02 & 0.10 & \pm & 0.00 & 4.32 & 0.04 \\
\hline Proteobacteria & Desulfovibrionaceae & Desulfovibrio C21_c20 & 0.07 & \pm 0.03 & 0.02 & \pm 0.01 & 0.04 & \pm & 0.02 & 4.45 & 0.04 \\
\hline Spirochaetes & Spirochaetaceae & Genus Treponema & 0.00 & \pm 0.00 & 0.00 & \pm 0.00 & 0.00 & \pm & 0.00 & 5.78 & 0.02 \\
\hline Tenericutes & & Order RF39 & 3.25 & \pm 0.47 & 5.60 & \pm 0.97 & 6.96 & \pm & 0.89 & 6.29 & 0.02 \\
\hline
\end{tabular}




\begin{tabular}{|c|c|c|c|c|c|c|c|c|c|c|c|c|c|}
\hline \multirow{4}{*}{$\begin{array}{c}\text { Phylum } \\
\text { Bacteroidetes } \\
\end{array}$} & \multirow{4}{*}{ Family } & \multirow{4}{*}{$\begin{array}{c}\begin{array}{c}\text { Operational taxonomic } \\
\text { unit (OTU) }\end{array} \\
\text { Order Bacteroidales } \\
\end{array}$} & \multicolumn{9}{|c|}{ Male } & \multicolumn{2}{|c|}{ Time*Diet ${ }^{\star}$ Sex } \\
\hline & & & \multirow{2}{*}{\multicolumn{3}{|c|}{ Day 0}} & \multirow{2}{*}{\multicolumn{3}{|c|}{$\begin{array}{l}\text { Day } 84 \\
\text { Control }\end{array}$}} & \multirow{2}{*}{\multicolumn{3}{|c|}{$\begin{array}{l}\text { Day } 84 \\
\text { Taurine }\end{array}$}} & \multirow{3}{*}{$\begin{array}{c}\begin{array}{c}F- \\
\text { value }\end{array} \\
10.67 \\
\end{array}$} & \multirow{3}{*}{$\begin{array}{c}\begin{array}{c}p- \\
\text { value }\end{array} \\
0.002 \\
\end{array}$} \\
\hline & & & & & \multirow[b]{2}{*}{0.06} & & & & & & & & \\
\hline & & & 0.12 & \pm & & 0.22 & \pm & 0.04 & 0.17 & \pm & 0.03 & & \\
\hline Bacteroidetes & Bacteroidaceae & Genus Bacteroides & 2.41 & \pm & 0.46 & 6.53 & \pm & 0.76 & 6.92 & \pm & 0.61 & 4.83 & 0.03 \\
\hline Bacteroidetes & Bacteroidaceae & Bacteroides acidifaciens & 0.16 & \pm & 0.03 & 0.08 & \pm & 0.03 & 0.08 & \pm & 0.02 & 15.64 & $\begin{array}{c}<0.00 \\
1\end{array}$ \\
\hline Bacteroidetes & Bacteroidaceae & Bacteroides uniformis & 0.13 & \pm & 0.03 & 0.13 & \pm & 0.02 & 0.12 & \pm & 0.02 & 4.47 & 0.04 \\
\hline Bacteroidetes & Rikenellaceae & Family Rikenellaceae & 0.44 & \pm & 0.12 & 0.08 & \pm & 0.03 & 0.22 & \pm & 0.05 & 13.87 & $\begin{array}{c}<0.00 \\
1\end{array}$ \\
\hline Bacteroidetes & $\mathrm{S} 24-7$ & Family S24-7 & 13.09 & \pm & 2.29 & 8.82 & \pm & 1.21 & 8.65 & \pm & 1.30 & 4.81 & 0.03 \\
\hline Bacteroidetes & [Barnesiellaceae] & Family Barnesiellaceae & 0.01 & \pm & 0.01 & 0.05 & \pm & 0.02 & 0.12 & \pm & 0.02 & 5.03 & 0.03 \\
\hline Firmicutes & & Class Clostridia & 0.00 & \pm & 0.00 & 0.00 & \pm & 0.00 & 0.00 & \pm & 0.00 & 8.84 & 0.005 \\
\hline Firmicutes & & Order Clostridiales & 29.85 & - & .40 & 22.57 & \pm & 3.27 & $\begin{array}{c}20.8 \\
2\end{array}$ & \pm & .76 & 5.6 & 0.02 \\
\hline Firmicutes & Ruminococcaceae & $\begin{array}{l}\text { Papillibacter } \\
\text { cinnamivorans }\end{array}$ & 0.00 & \pm & 0.00 & 0.00 & \pm & 0.00 & 0.00 & \pm & 0.00 & 4.29 & 0.05 \\
\hline Firmicutes & Veillonellaceae & $\begin{array}{l}\text { Genus } \\
\text { Phascolarctobacterium }\end{array}$ & 0.00 & \pm & 0.00 & 0.00 & \pm & 0.00 & 0.00 & \pm & 0.00 & 0.45 & 0.05 \\
\hline Firmicutes & [Mogibacteriaceae] & $\begin{array}{l}\text { Family } \\
\text { Mogibacteriaceae }\end{array}$ & 0.46 & \pm & 0.03 & 0.12 & \pm & 0.08 & 0.08 & \pm & 0.02 & 6.83 & 0.01 \\
\hline Firmicutes & Erysipelotrichaceae & Genus Allobaculum & 5.75 & \pm & 1.29 & 0.17 & \pm & 0.08 & 0.17 & \pm & 0.08 & 4.4 & 0.04 \\
\hline Proteobacteria & Alcaligenaceae & Genus Sutterella & 0.58 & \pm & 0.23 & 0.22 & \pm & 0.05 & 0.23 & \pm & 0.10 & 4.1 & 0.05 \\
\hline Proteobacteria & Desulfovibrionaceae & Genus Desulfovibrio & 0.03 & \pm & 0.01 & 0.30 & \pm & 0.11 & 0.88 & \pm & 0.27 & 4.32 & 0.04 \\
\hline Proteobacteria & Desulfovibrionaceae & Desulfovibrio C21_c20 & 0.42 & \pm & 0.09 & 0.00 & \pm & 0.00 & 0.00 & \pm & 0.00 & 4.45 & 0.04 \\
\hline Spirochaetes & Spirochaetaceae & Genus Treponema & 0.00 & \pm & 0.00 & 0.00 & \pm & 0.00 & 0.00 & \pm & 0.00 & 5.78 & 0.02 \\
\hline
\end{tabular}


The relative abundance at the taxonomic level of OTU of fecal samples collected from female rats on day 0 [ $n=6$, female control ( $0 \%$ taurine); $n=5$, female $0.7 \%$ taurine] and day $84(n=6$, female control; $n=5$, female $0.7 \%$ taurine). The relative abundance at the taxonomic level of OTU of fecal samples collected from male rats on day $0[\mathrm{n}=6$, male control $(0 \%$ taurine); $n=5$, male $0.7 \%$ taurine] and day $84(n=6)$. Complete dataset available through the MOspace Institutional Repository. 


\section{References}

Altschul SF, Madden TL, Schaffer AA, Zhang J, Zhang Z, Miller W, Lipman DJ (1997) Gapped BLAST and PSI-BLAST: a new generation of protein database search programs Nucleic Acids Res 25:3389-3402

Arboleya S, Martinez-Camblor P, Solis G, Suarez M, Fernandez N, de Los Reyes-Gavilan CG, Gueimonde M (2017) Intestinal Microbiota and Weight-Gain in Preterm Neonates Front Microbiol 8:183 doi:10.3389/fmicb.2017.00183

Brabant G (2003) Insulin-like growth factor-I: marker for diagnosis of acromegaly and monitoring the efficacy of treatment European journal of endocrinology / European Federation of Endocrine Societies 148 Suppl 2:S15-20

Bradford MM (1976) A rapid and sensitive method for the quantitation of microgram quantities of protein utilizing the principle of protein-dye binding Analytical biochemistry 72:248-254

Bright GM, Veldhuis JD, Iranmanesh A, Baumann G, Maheshwari H, Lima J (1999) Appraisal of Growth Hormone (GH) Secretion: Evaluation of a Composite Pharmacokinetic Model That Discriminates Multiple Components of GH Input1 The Journal of Clinical Endocrinology \& Metabolism 84:3301-3308 doi:10.1210/jcem.84.9.5960

Caporaso JG et al. (2011) Global patterns of 16S rRNA diversity at a depth of millions of sequences per sample Proceedings of the National Academy of Sciences of the United States of America 108 Suppl 1:4516-4522 doi:10.1073/pnas.1000080107 
Cardinelli CS, Sala PC, Alves CC, Torrinhas RS, Waitzberg DL (2015) Influence of Intestinal Microbiota on Body Weight Gain: a Narrative Review of the Literature Obesity Surgery 25:346-353 doi:10.1007/s11695-014-1525-2 Cláudia Marques MM, Sónia Norberto, Joana Leite, Joana Freitas, Diogo Pestana, Ana Faria \& Conceição Calhau (2016) High-fat diet-induced obesity Rat model: a comparison between Wistar and Sprague-Dawley Rat Adipocyte 5:11-21 doi:10.1080/21623945.2015.1061723

Claus SP et al. (2011) Colonization-Induced Host-Gut Microbial Metabolic Interaction mBio 2:e00271-00210 doi:10.1128/mBio.00271-10

Dawson R, Jr., Liu S, Eppler B, Patterson T (1999) Effects of dietary taurine supplementation or deprivation in aged male Fischer 344 rats Mechanisms of ageing and development 107:73-91

DeSantis TZ et al. (2006) Greengenes, a chimera-checked 16S rRNA gene database and workbench compatible with ARB Applied and environmental microbiology 72:5069-5072 doi:10.1128/AEM.03006-05

Durelli L, Mutani R, Fassio F (1983) The treatment of myotonia: evaluation of chronic oral taurine therapy Neurology 33:599-603

Ericsson AC et al. (2015) Effects of Vendor and Genetic Background on the Composition of the Fecal Microbiota of Inbred Mice PloS one 10:e0116704 doi:10.1371/journal.pone.0116704

Goodman CA, Horvath D, Stathis C, Mori T, Croft K, Murphy RM, Hayes A (2009) Taurine supplementation increases skeletal muscle force production and protects muscle function during and after high-frequency in 
vitro stimulation Journal of Applied Physiology 107:144-154

doi:10.1152/japplphysiol.00040.2009

Goodman HO, Shihabi ZK (1990) Supplemental taurine in diabetic rats: effects on plasma glucose and triglycerides Biochem Med Metab Biol 43:1-9

Gothe S et al. (1999) Mice devoid of all known thyroid hormone receptors are viable but exhibit disorders of the pituitary-thyroid axis, growth, and bone maturation Genes Dev 13:1329-1341

Gough EK, Stephens DA, Moodie EEM, Prendergast AJ, Stoltzfus RJ, Humphrey $\mathrm{JH}$, Manges AR (2015) Linear growth faltering in infants is associated with Acidaminococcus sp. and community-level changes in the gut microbiota Microbiome 3:24 doi:10.1186/s40168-015-0089-2

Hammer $\varnothing$, Harper, D.A.T., Ryan, P.D. (2001) PAST: Paleontological statistics software package for education and data analysis. Palaeontologia Electronica 4(1), http://palaeo-electronica.org/2001 1/past/issue1 01.htm Hart ML, Meyer A, Johnson PJ, Ericsson AC (2015) Comparative Evaluation of DNA Extraction Methods from Feces of Multiple Host Species for Downstream Next-Generation Sequencing PloS one 10:e0143334 doi:10.1371/journal.pone.0143334

Holmes E, Li JV, Athanasiou T, Ashrafian H, Nicholson JK (2011) Understanding the role of gut microbiome-host metabolic signal disruption in health and disease Trends Microbiol 19:349-359 doi:10.1016/j.tim.2011.05.006 Hooper S, Mori L, Backus R (2014) Effects of bisphenol-A and estradiol ingested with food on plasma concentrations of glucose, insulin, and thyroid-axis 
hormones in cats Journal of Animal Physiology and Animal Nutrition 98:1188 doi:10.1111/jpn.12269

Hooper S, Amelon S, Korte S, O'Connor E, Backus, R (2017) Inter- and intraindividual variation in circulating thyroid hormones of Sprague Dawley rats (Rattus norvegicus) with circulating serum triiodothyronine correlating with plasma taurine in female rats. In Review

Hultman K, Alexanderson C, Manneras L, Sandberg M, Holmang A, Jansson T (2007) Maternal taurine supplementation in the late pregnant rat stimulates postnatal growth and induces obesity and insulin resistance in adult offspring The Journal of physiology 579:823-833

doi:10.1113/jphysiol.2006.124610

Ikuyama S, Okajima T, Kato K, Ibayashi H (1988) Effect of taurine on growth hormone and prolactin secretion in rats: possible interaction with opioid peptidergic system Life sciences 43:807-812

Ito T et al. (2010) Cardiac and skeletal muscle abnormality in taurine transporterknockout mice Journal of Biomedical Science 17:S20 doi:10.1186/14230127-17-S1-S20

Ito T, Schaffer SW, Azuma J (2012) The potential usefulness of taurine on diabetes mellitus and its complications Amino acids 42:1529-1539 doi:10.1007/s00726-011-0883-5

Jacobsen JG, Smith LH (1968) Biochemistry and physiology of taurine and taurine derivatives Physiological reviews 48:424-511 
Jeon S-H et al. (2007) Taurine increases cell proliferation and generates an increase in [Mg2+]i accompanied by ERK 1/2 activation in human osteoblast cells FEBS letters 581:5929-5934 doi:http://dx.doi.org/10.1016/.j.febslet.2007.11.035

Jhiang SM, Fithian L, Smanik P, McGill J, Tong Q, Mazzaferri EL (1993) Cloning of the human taurine transporter and characterization of taurine uptake in thyroid cells FEBS letters 318:139-144

Kalu DN, Orhii PB, Chen C, Lee DY, Hubbard GB, Lee S, Olatunji-Bello Y (1998) Aged-rodent models of long-term growth hormone therapy: lack of deleterious effect on longevity The journals of gerontology Series A, Biological sciences and medical sciences 53:B452-463

Laidlaw SA, Grosvenor M, Kopple JD (1990) The taurine content of common foodstuffs JPEN Journal of parenteral and enteral nutrition 14:183-188

Ley RE, Turnbaugh PJ, Klein S, Gordon JI (2006) Microbial ecology: Human gut microbes associated with obesity Nature 444:1022-1023 doi:http://www.nature.com/nature/journal/v444/n7122/suppinfo/4441022a $\underline{\text { S1.html }}$

Lourenco R, Camilo ME (2002) Taurine: a conditionally essential amino acid in humans? An overview in health and disease Nutricion hospitalaria 17:262270

Lupu F, Terwilliger JD, Lee K, Segre GV, Efstratiadis A (2001) Roles of Growth Hormone and Insulin-like Growth Factor 1 in Mouse Postnatal Growth 
Developmental Biology 229:141-162

doi:http://dx.doi.org/10.1006/dbio.2000.9975

Magoc T, Salzberg SL (2011) FLASH: fast length adjustment of short reads to improve genome assemblies Bioinformatics 27:2957-2963

doi:10.1093/bioinformatics/btr507

Martin FP et al. (2007) A top-down systems biology view of microbiome-

mammalian metabolic interactions in a mouse model Mol Syst Biol 3:112 doi:10.1038/msb4100153

Militante JD, Lombardini JB (2002) Treatment of hypertension with oral taurine: experimental and clinical studies Amino acids 23:381-393 doi:10.1007/s00726-002-0212-0

Ock S et al. (2013) IGF-1 receptor deficiency in thyrocytes impairs thyroid hormone secretion and completely inhibits TSH-stimulated goiter FASEB journal : official publication of the Federation of American Societies for Experimental Biology 27:4899-4908 doi:10.1096/fj.13-231381

Ormerod KL et al. (2016) Genomic characterization of the uncultured Bacteroidales family S24-7 inhabiting the guts of homeothermic animals Microbiome 4:36 doi:10.1186/s40168-016-0181-2

Reeds PJ (2000) Dispensable and indispensable amino acids for humans J Nutr 130:1835S-1840S

Reeves PG (1997) Components of the AIN-93 Diets as Improvements in the AIN76A Diet The Journal of Nutrition 127:838S-841S 
Reeves PG, Nielsen FH, Fahey GC, Jr. (1993) AIN-93 purified diets for laboratory rodents: final report of the American Institute of Nutrition ad hoc writing committee on the reformulation of the AIN-76A rodent diet $\mathrm{J}$ Nutr 123:1939-1951

Ridlon JM, Kang DJ, Hylemon PB, Bajaj JS (2014) Bile Acids and the Gut Microbiome Current opinion in gastroenterology 30:332-338 doi:10.1097/MOG.0000000000000057

Rose BS, Flatt WP, Martin RJ, Lewis RD (1998) Whole body composition of rats determined by dual energy X-ray absorptiometry is correlated with chemical analysis J Nutr 128:246-250

Satsu H, Kobayashi Y, Yokoyama T, Terasawa E, Shimizu M (2002) Effect of dietary sulfur amino acids on the taurine content of rat tissues Amino acids 23:447-452 doi:10.1007/s00726-002-0214-y

Schaffer SW, Shimada K, Jong CJ, Ito T, Azuma J, Takahashi K (2014) Effect of taurine and potential interactions with caffeine on cardiovascular function Amino acids 46:1147-1157 doi:10.1007/s00726-014-1708-0

Shao A, Hathcock JN (2008) Risk assessment for the amino acids taurine, Iglutamine and I-arginine Regulatory Toxicology and Pharmacology 50:376-399 doi:http://dx.doi.org/10.1016/i.yrtph.2008.01.004

Shim KS (2015) Pubertal growth and epiphyseal fusion Annals of Pediatric Endocrinology \& Metabolism 20:8-12 doi:10.6065/apem.2015.20.1.8 
Tannenbaum GS, Martin JB (1976) Evidence for an endogenous ultradian rhythm governing growth hormone secretion in the rat Endocrinology 98:562-570 doi:10.1210/endo-98-3-562

Walters WA, Caporaso JG, Lauber CL, Berg-Lyons D, Fierer N, Knight R (2011) PrimerProspector: de novo design and taxonomic analysis of barcoded PCR primers Bioinformatics doi:10.1093/bioinformatics/btr087

Warskulat U et al. (2004) Taurine transporter knockout depletes muscle taurine levels and results in severe skeletal muscle impairment but leaves cardiac function uncompromised FASEB journal : official publication of the Federation of American Societies for Experimental Biology 18:577-579 doi:10.1096/fj.03-0496fje

Wójcik OP, Koenig KL, Zeleniuch-Jacquotte A, Costa M, Chen Y (2010) The potential protective effects of taurine on coronary heart disease Atherosclerosis 208:19-25

doi:http://dx.doi.org/10.1016/i.atherosclerosis.2009.06.002

Wu G (2009) Amino acids: metabolism, functions, and nutrition Amino acids 37:1-17 doi:10.1007/s00726-009-0269-0

Wu G (2010) Functional amino acids in growth, reproduction, and health Adv Nutr 1:31-37 doi:10.3945/an.110.1008

Wu G, Bazer FW, Dai Z, Li D, Wang J, Wu Z (2014) Amino acid nutrition in animals: protein synthesis and beyond Annu Rev Anim Biosci 2:387-417 doi:10.1146/annurev-animal-022513-114113 
Zhou C, Zhang X, Xu L, Wu T, Cui L, Xu D (2014) Taurine promotes human mesenchymal stem cells to differentiate into osteoblast through the ERK pathway Amino acids 46:1673-1680 doi:10.1007/s00726-014-1729-8 


\section{CHAPTER 5}

\section{Dietary taurine and the feline thyroid axis}

\section{Introduction}

Approximately $10 \%$ of domestic cats over 10 years of age are estimated to be afflicted by feline hyperthyroidism (Peterson 2012), making the disease the most commonly diagnosed endocrine disorder of domestic cats in the US (Broussard et al. 1995; Peterson 2012). Worldwide, feline hyperthyroidism continues to increase in prevalence. Eight countries including Canada (Taylor et al. 1989), the United Kingdom (Thoday and Mooney 1992), and Germany (Kohler et al. 2016) also now recognize feline hyperthyroidism as the most commonly occurring spontaneous endocrine disorder of domestic cats.

Feline hyperthyroidism is caused by hyperplastic, autonomously functioning thyroid nodules (Hoenig et al. 1982; Peterson and Ward 2007). These nodules, unresponsive to thyroid stimulating hormone (TSH), continuously produce the thyroid hormones thyroxine (T4) and triiodothyronine (T3) (Gerber et al. 1994; Peterson et al. 1987). This excessive thyroid hormone production causes circulating serum $\mathrm{T} 4$ to be elevated above the laboratory reference range in over $90 \%$ of cats diagnosed with feline hyperthyroidism and approximately $75 \%$ of these cats concurrently have elevated circulating serum T3 (Broussard et al. 1995; Peterson et al. 2001); therefore, an elevation of circulating serum T4 or T3 above the reference range is considered diagnostic for feline hyperthyroidism as no false positives have ever been reported (Peterson 2006). When hyperthyroidism is suspected, but circulating T4 and T3 are within reference 
range, then circulating serum concentrations of free $\mathrm{T} 4(\mathrm{FT} 4)$ can be used as a companion diagnostic test (Peterson 2006; Peterson et al. 2001). However, FT4 is not as sensitive as T4. FT4 is elevated in $98.5 \%$ of hyperthyroid cats, but FT4 can also be elevated in cats with non-thyroidal illness (Peterson et al. 2001).

The incidence rate of spontaneously occurring feline hyperthyroidism has skyrocketed since the initial case report in 1979 (Edinboro et al. 2004; Peterson et al. 1979; Scarlett et al. 1988). The ever increasing prevalence rate has caused many epidemiological studies to be undertaken to determine the risk factors associated with feline hyperthyroidism. Consistently, all epidemiological studies conducted in North America and Europe have identified consumption of canned cat food to be a significant risk factor for the development of feline hyperthyroidism (Edinboro et al. 2004; Gójska-Zygner et al. 2014; Kass et al. 1999; Martin et al. 2000; Olczak et al. 2005; Scarlett et al. 1988; Wakeling et al. 2009). The flavors fish and liver and giblets as well as those canned diets in pop-top cans have been found to further increase the risk of the development of hyperthyroidism (Edinboro et al. 2004; Martin et al. 2000).

Due to the lack of prospective studies on the matrix and constituents contained within canned food, the veterinary community has only been able to speculate the link between canned food and the development of hyperthyroidism. Thyroid-disruption contaminants such as bisphenol-A (BPA) (Peterson 2012; Schecter et al. 2010), phyto-estrogens such as isoflavones, and nutrients such as selenium (van Hoek et al. 2015) have all been implicated as causative factors within canned cat foods. 
Taurine, a $\beta$-amino acid, has not previously been speculated to be involved in the etiopathogensis of feline hyperthyroidism; however, it is found in canned cat food at concentrations as high as $7000 \mathrm{mg} / \mathrm{kg}$ dry matter (Purina Nutrition 2015). Taurine was determined to be a nutritionally essential amino acid for felines in the mid to late 1970's when feline central retinal degeneration was determined to be caused by taurine deficiency (Hayes et al. 1975; National Research Council 1978). Through the use of sulfate and cysteine radioisotopes, it was concluded that domestic cats could not adequately produce taurine via the cysteine sulfinic acid decarboxylase pathway; therefore, cats must consume adequate levels of taurine in the diet (Knopf et al. 1978). Subsequently, a series of studies determined that the taurine requirement for cats depended upon the dietary matrix, the quality of the protein, and processing of the diet (Backus et al. 1998; Morris et al. 1994).

Taurine is found in high concentrations in the thyroid gland and other tissues that generate free radicals and oxidants (Jacobsen and Smith 1968; Wright et al. 1986). It has been suggested that taurine may be protective of thyroid cellular proliferation through its role in membrane stabilization, detoxification, anti-oxidation, and osmoregulation (Jhiang et al. 1993). Nuclear magnetic resonance studies have revealed that malignant thyroid tumors contain relatively higher concentrations of taurine compared to benign thyroid tumors (Torregrossa et al. 2012) and in vitro work has demonstrated that the proliferation rate of thyroid cells from two human cell lines increased with increasing taurine 
uptake (Jhiang et al. 1993). It is unknown if taurine causes a proliferation of thyroid cells in vivo or affects the production of thyroid hormones.

The establishment of the essentiality of dietary taurine and subsequent supplementation of taurine in commercial cat foods occurred shortly before the first clinical description of feline hyperthyroidism (National Research Council 1978; Peterson et al. 1979). Edinoboro et al. (2004) documented the increasing prevalence rate of feline hyperthyroidism from 1979 to 1997 . Concurrently, the National Research Council (NRC) changed the original recommended dietary taurine content of $500 \mathrm{mg} / \mathrm{kg}$ on a dry matter basis (National Research Council 1981) to the current recommended minimum dietary taurine concentrations at $500 \mathrm{mg} / \mathrm{kg}$ for purified diets, $1000 \mathrm{mg} / \mathrm{kg}$ for dry diets, and $2500 \mathrm{mg} / \mathrm{kg}$ for canned diets (National Research Council 2006). However, most commercial cat diets commonly contain taurine concentrations that are double to triple the minimum recommended levels (Hill's Pet Nutrition Inc. 2017; Purina Nutrition 2015). Since it is unknown if high dietary taurine affects the hypothalamicpituitary-thyroid axis, the purpose of this study was to determine if excessive dietary taurine could alter the thyroid axis by leading to a rise in the production of circulating thyroid hormones T4, T3, FT4, and free T3 (FT3). Additionally, because IGF-1 plays a role in the thyroid axis and is elevated in human hyperthyroid patients (Miell et al. 1993), the secondary aim of this study was to determine if excessive dietary taurine causes an increase in insulin-like growth factor 1 (IGF-1). 


\section{Materials and Methods}

Ethics: All procedures performed were approved by the University of Missouri Animal Care and Use Committee in accordance with the Guide for the Care and Use of Laboratory Animals (National Institutes of Health 2011) and the Animal Welfare Act and Regulations (United States Department of Agriculture 2013).

Animals: Ten, adult (7-11 yr), lean (BCS of 4-5/9), purpose bred, neutered male, domestic short-haired cats were deemed healthy on physical exam, complete blood cell count, and serum clinical biochemistry (University of Missouri Veterinary Diagnostic Laboratory, Columbia, MO, USA) findings prior to the start of the study. All cats were individually housed approximately 8 hours each day in individual $1.2 \times 1.8$ meter runs during food presentation. After food presentation, cats were socially housed by allowing access among all runs. At all times, cats had ad lib access to water.

Diets: A custom formulated purified diet was initially investigated for use because all commercially available feline diets were deemed to contain taurine in excess of that desired and the matrix of such diets unpredictably affect taurine bioavailability in cats. A nutritionally complete and balanced purified diet previously described by Backus et al. (2007) was adapted for this study (table 5.1-5.3). Seven of the ten cats did not consume the diet adequately to maintain their body weight. Cats were transitioned from the purified diet to a commercially available canine adult, "weight management", dry-expanded diet (Purina Pro Plan Focus Adult Weight Management Formula, Nestlé Purina Pet Care Company, Saint Louise, MO, USA) (Table 5.4). The commercial diet was 
nutritionally complete and balanced as substantiated from passage of feeding trials as described by American Association of Feed Control Officials (AAFCO). The diet was selected to serve as a base diet to which taurine would be added because the kibble size and palatability were uniformly accepted by the ten cats. Taurine in the diet was assumed to be low as it was not listed as an ingredient. The nutrient profile provided by the manufacturer was in excess of that recommended by AAFCO (2013) and NRC (2006). The batch of the base diet used served as a "control" diet which was determined to contain $0.25 \%$ taurine (2.5 g/kg DM) (Experimental Station Chemical Laboratory, University of Missouri, Columbia, MO, USA), an amount in excess of the AAFCO recommendation for feline extruded diets (American Association of Feed Control Officials 2013). The "high taurine" diet was the base diet supplemented to contain $0.7 \%$ taurine $(7$ $\mathrm{g} / \mathrm{kg} \mathrm{DM}$ ), and was prepared by top-dressing the base diet with finely milled crystalline taurine (Dyets Inc, Bethlehem, PA, USA) dispersed in a cornstarch hydrolysate powder, dyetrose (Dyets Inc, Bethlehem, PA, USA), to ensure even distribution and coating of the kibble during batch mixing. The cats underwent an adaption period of 40 weeks on the diet prior to the start of the study. During this adaption period it was determined that the base diet required a taurine content of $0.35 \%$ (3.5 g/kg DM) to maintain adequate plasma taurine concentrations $>40$ $\mathrm{nmol} / \mathrm{mL}$ (Delaney et al. 2003; University of California-Davis Amino Acids Laboratory 2017) in all cats. Cats were maintained on the base diet containing $0.35 \%$ taurine for 12 weeks prior to the start of the study and during the washout period. 


\section{Table 5.1 Feline purified diet}

\begin{tabular}{|c|c|}
\hline Ingredient & Amount $(\mathrm{g} / \mathrm{kg})$ \\
\hline Casein (30 mesh) & 180 \\
\hline Soy protein isolate & 180 \\
\hline Maize starch & 219 \\
\hline Chicken fat & 237 \\
\hline L-Methionine & 0.25 \\
\hline L-Threonine & 0.84 \\
\hline Potassium & 13 \\
\hline Magnesium Sulfate & 5.4 \\
\hline Omega-3 fatty acids & 0.327 \\
\hline - Docosahexaenoic acid (DHA) & 0.125 \\
\hline - Eicosapentaenoic acid (EPA) & 0.114 \\
\hline Calcium & 5.4 \\
\hline Trical & 2.8 \\
\hline Sucrose & 46 \\
\hline Sodium propionate & 10 \\
\hline Mineral mixture* & 50 \\
\hline Vitamin mixture $^{\dagger}$ & 50 \\
\hline
\end{tabular}




\section{Table 5.2 Mineral mixture}

\begin{tabular}{lc} 
Ingredient & Amount $(\mathrm{g} / \mathrm{kg})$ \\
\hline Ferric citrate $(17.3 \% \mathrm{Fe})$ & 8.283 \\
Zinc carbonate $(60.4 \% \mathrm{Zn})$ & 2.724 \\
Cupric carbonate $(57.47 \% \mathrm{Cu})$ & 0.101 \\
Manganese carbonate $(47.79 \% \mathrm{Mn})$ & 0.245 \\
Sodium selenate $(41.79 \% \mathrm{Se})$ & 0.014 \\
Sucrose & 988.633
\end{tabular}

Custom mineral mixture for cats (Dyet\# 270004, Dyets Inc, Bethlehem, PA, USA)

Table 5.3 Vitamin mixture

\begin{tabular}{|c|c|}
\hline Ingredient & Amount $(\mathrm{g} / \mathrm{kg})$ \\
\hline Vitamin A Palmitate $(500000 \mathrm{IU} / \mathrm{g})$ & 0.174 \\
\hline Vitamin D3 (400000 IU/g) & 0.018 \\
\hline Vitamin E Acetate $(500 \mathrm{lU} / \mathrm{g})$ & 2.088 \\
\hline Vitamin K1/Dextrose Mix (10 mg/g) & 2.100 \\
\hline Thiamine $\mathrm{HCl}$ & 0.142 \\
\hline Riboflavin & 0.100 \\
\hline Niacin & 1.002 \\
\hline Folic Acid Premix (5 mg/g) & 2.371 \\
\hline Pyridoxine $\mathrm{HCl}$ & 0.065 \\
\hline Vitamin B12 (0.1\%) & 0.513 \\
\hline Biotin Premix (1 mg/g) & 0.660 \\
\hline Calcium Pantothenate & 0.142 \\
\hline Sucrose & 990.625 \\
\hline
\end{tabular}




\section{Table 5.4 Proximate and taurine analysis of the control (low taurine diet)}

\begin{tabular}{lc} 
Nutrient & Amount $(\mathrm{g} / 100 \mathrm{~g})$ \\
\hline Crude protein & 27.87 \\
Crude fat & 4.68 \\
Crude fiber & 2.68 \\
Moisture & 8.83 \\
Ash & 5.33 \\
Taurine & 0.25
\end{tabular}

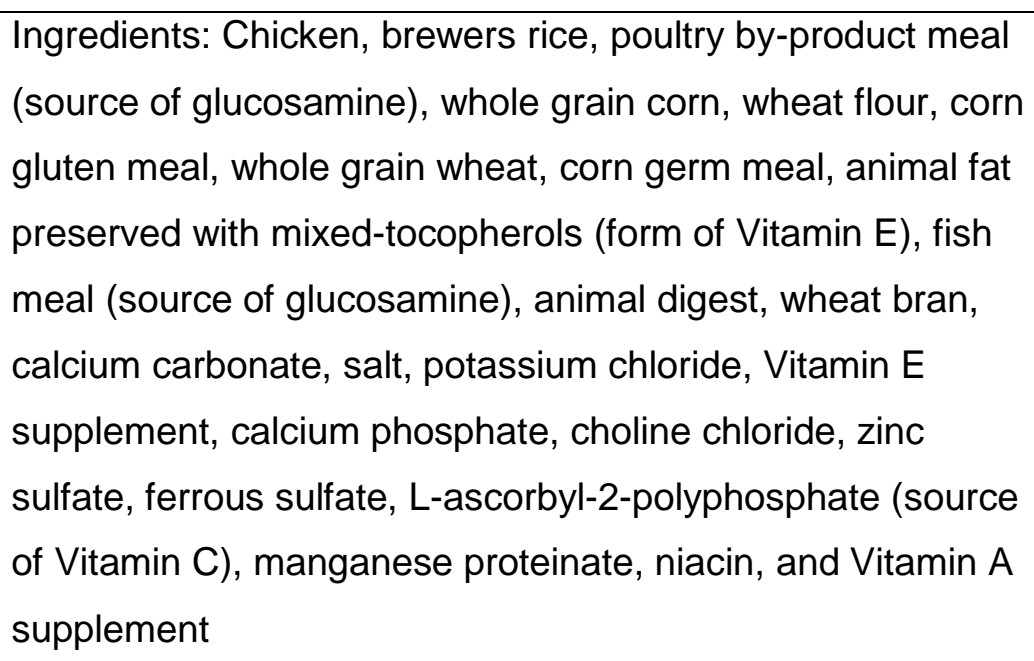

Proximate analysis performed at the University of Missouri-Columbia Experimental Station Chemical Laboratories on an as is basis. Metabolizable energy is $3579 \mathrm{kcal} / \mathrm{kg}$.

Study design: Using a cross-over design, each cat was randomly assigned to one of two dietary treatments, 1$)$ control $(0.25 \%$ taurine $)$ or 2$)$ high taurine ( $0.70 \%$ taurine). Diet-presentation blocks were 42 days (6 weeks) in duration. After the first block the washout period was 63 days ( 9 weeks) during which cats were presented with the base diet top-dressed to contain a taurine content of 
$0.35 \%$. Prior to the start of the study, the cats were pre-fed the base diet topdressed with the same amount of taurine as that used in the washout period for more than 9 weeks. During day 28 thru day 38 of the washout period all cats received a once daily $50 \mathrm{mg} / \mathrm{kg}$ oral dose of fenbendazole as part of a University wide treatment for Giardia despite the cats not testing positive nor exhibiting clinical signs of Giardia infection. Daily, the cats were presented an allotted amount of diet in order to maintain a stable weight and an ideal body condition score of 5/9 (Laflamme 1997). The dry matter amount of diet offered to each cat was not changed during the study or washout period and dietary intake was recorded daily. Cats were weighed weekly. Jugular venous blood was collected in the morning (0830 to 1000 hours) on day $0,14,28$, and 42 of each dietary block. Jugular venous blood was also collected approximately 4-5 hours after initial food presentation (1400 to 1500 hours) on day 0 and 42 of each dietary block. A 3-mL BD vacutainer containing lithium heparin (Becton, Dickinson, and Company, Franklin Lakes, NJ, USA) was used for obtaining whole blood and plasma samples. Ten milliliter plain (serum) BD vacutainers (Becton, Dickinson, and Company, Franklin Lakes, NJ, USA) were used to collect blood for obtaining serum samples. Blood was allowed to clot at room temperature for 1 hour prior to centrifugation at $1200 \mathrm{xg}$ for $10 \mathrm{~min}$ for extraction of serum. Whole blood, extracted serum, and extracted plasma was stored in $0.5-1.0 \mathrm{~mL}$ aliquots at $20^{\circ} \mathrm{C}$ until analyses.

Thyroid hormone analysis: Fasting serum samples from day $0,14,28$, and 42 and post-prandial samples on day 0 and 42 of each dietary block were sent 
overnight on dry ice to Michigan State University's Diagnostic Center for Population and Animal Health (DCPAH) for measurements of total T4 (TT4), total T3 (TT3), free T4 (fT4), and free T3 (fT3).

Insulin-like growth factor 1 (IGF-1) analysis: Fasting serum samples from day 0 and 42 were sent overnight on dry ice to DCPAH for measurements of IGF-1 using the assay described by Reusch et al. (2006).

Plasma and whole blood taurine analysis: Plasma and whole blood taurine concentrations were measured on days $0,14,28$, and 42 of each block using high pressure liquid chromatography (HPLC) methods described by Hooper et al. (2017). In brief, whole blood samples were frozen and thawed 3 times before extraction for taurine analysis to help ensure cells were lysed. Fifty microliters of plasma or whole blood were deproteinized by adding $50 \mu \mathrm{L}$ of acetonitrile with $100 \mathrm{ng} / \mathrm{mL}$ trans-4-hydroxy-L-proline added as internal standard. Samples were centrifuged for $15 \mathrm{~min}$ at $16,000 \times \mathrm{g}$. Fifty microliters of resulting supernatant were transferred to a $13 \times 100 \mathrm{~mm}$ glass tube and evaporated by centrifugal evaporation. Fifty microliters of a coupling solution $(1: 1: 1, \mathrm{v} / \mathrm{v}$, triethylamine:water:methanol) was added to the dried residue, and subsequently evaporated to dryness. Then, $50 \mu \mathrm{L}$ of derivatization solution (20:5:5:2, $\mathrm{v} / \mathrm{v}$, methanol:water:triethylamine:phenylisothiocyanate) was added to each tube and tubes were covered with parafilm and left at ambient temperature. After 20 minutes, samples were evaporated to dryness and redisolved in $400 \mu \mathrm{L}$ of sample diluent (710 mg disodium hydrogen phosphate, $950 \mathrm{~mL}$ water, $5 \mathrm{~mL}$ acetonitrile, adjusted to $\mathrm{pH} 5.4$ with phosphoric acid). The reconstituted samples 
were transferred to centrifuge tube with a $0.2 \mu \mathrm{m}$ centrifuge tube filter (Corning ${ }^{\circledR}$ Costar ${ }^{\circledR}$ SpinX centrifuge tube filters, Sigma Aldrich, St. Louis, MO, USA) and spun for $15 \mathrm{~min}$ at $15,000 \times \mathrm{g}$. Samples were injected into a C18 column (Microsorb 100-5 C18, 250 x 4.6 mm Varian Inc. Lake Forest, CA, USA) and the $U V_{265 n}$ absorbance of the phenylisothiocyanate derivatives of taurine and internal standard were quantified.

Statistical Analyses: We used SAS 9.3 software package (SAS Institute Inc., Cary, NC, USA) to perform all statistical analysis and significance was calculated at alpha $=0.05$. All outcome variables were determined to be normally distributed. The Proc MIXED procedure with repeated measures and differences of the least square means was used to evaluate effect of dietary taurine concentration, sampling time, time-diet interactions on variables of interest: serum TT4, TT3, fT4, and fT3 concentrations; diet consumption; body weight; and plasma and whole blood taurine concentrations.

\section{Results}

During the period when the dietary taurine concentration to be used in the study was being determined, two cats developed feline lower urinary tract disease (feline idiopathic cystitis) and were not included in the study. During the study, one cat, deemed healthy prior to the start of the study, developed clinical signs of renal failure including elevated creatinine and blood urea nitrogen (BUN) values which were above the laboratory reference range, lethargy, decreased grooming, and weight lost. A retrospective review of serum creatinine and urea nitrogen concentrations annually determined for the prior 2 years indicated that 
the values were within the reference range however showed a progressively diminishing kidney function. His participation in the study was discontinued.

Seven of the ten cats completed both dietary blocks and were included in the analysis. The seven cats adapted to the commercial canine diet. There were no difference in feed intakes during the dietary blocks $(p=0.96$, table 3$)$. There was a trending increase in body weight when the cats were on the high taurine $\operatorname{diet}(p=0.07)$.

Table 5.3 Summary of food intake, metabolizable energy, and weight over the duration of the study

\begin{tabular}{lcccccc}
\hline $\begin{array}{c}\text { Dietary } \\
\text { Treatment }\end{array}$ & $\begin{array}{c}\text { Dietary } \\
\text { taurine } \\
(\mathrm{DM})\end{array}$ & $\begin{array}{c}\text { Food } \\
\text { Intake } \\
(\mathrm{g} / \mathrm{d} \text { day })\end{array}$ & $\begin{array}{c}\text { Metabolizable } \\
\text { energy } \\
(\mathrm{kcal} / \mathrm{day})\end{array}$ & $\begin{array}{c}\text { Weight } \\
\text { Day 0 } \\
(\mathrm{kg})\end{array}$ & $\begin{array}{c}\text { Weight } \\
\text { Day 42 } \\
(\mathrm{kg})\end{array}$ & $\begin{array}{c}\text { Weight } \\
\text { change } \\
(\%)\end{array}$ \\
\hline Control & $0.25 \%$ & $62.3 \pm$ & $222 \pm 11.8$ & $\begin{array}{c}5.53 \pm \\
0.26\end{array}$ & $\begin{array}{c}5.53 \pm \\
0.25\end{array}$ & $0.00 \%$ \\
Taurine & $0.70 \%$ & $62.1 \pm$ & $223 \pm 12.0$ & $\begin{array}{c}5.43 \pm \\
0.35\end{array}$ & $\begin{array}{c}5.51 \pm \\
0.23\end{array}$ & $1.58 \% *$ \\
& & 3.30 & & 0.24 & 0.23 &
\end{tabular}

${ }^{\star}$ There is an interaction trend $(p=0.07)$ between the body weight and time when the cats were on the high taurine diet.

The 12 week adaption period and 9 week washout period prior to the start of the study were adequate as the plasma taurine and whole blood concentrations were not significantly different at week $0(p=0.40 ; p=0.98)$. By week 2, the cats on the high taurine diet had significantly higher plasma and whole blood taurine concentrations than when the cats were on the control diet ( $p$ $<0.001$, Fig 5.1) 
Figure 5.1 Plasma and whole blood taurine concentrations
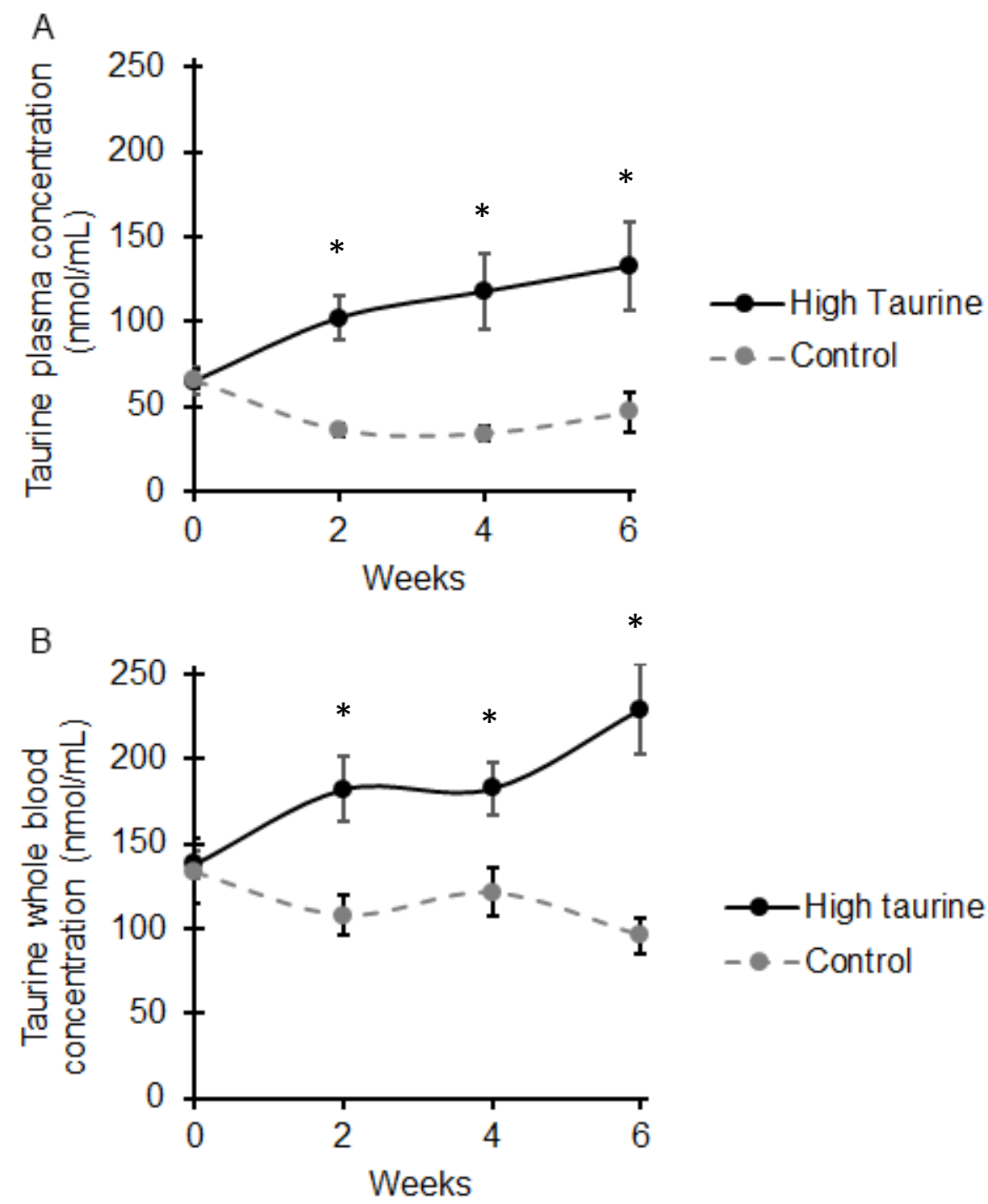

(A) Circulating plasma taurine concentrations $(n=7)$ and $(B)$ whole blood taurine concentrations $(n=7)$ were not significantly different at week $0(p=0.40 ; p=$ 0.98). By week 2 , the circulating taurine concentrations were significantly different $(p<0.001)$ between the high taurine and control. * indicates significant difference $(p<0.001)$

Dietary taurine did not alter the thyroid hormone concentrations (Table 5.4, Figure 5.2), however the circulating serum concentrations of TT4, TT3, and 
FT3 from the morning fasted samples varied each week for all treatment groups (Table 5.4). The TT4, TT3, and FT4 concentrations were significantly elevated 4 hours after initial food presentation compared to the morning fasted circulating thyroid hormones $(p<0.05$, Figure 5.2)

Table 5.4 Thyroid hormone concentrations of morning fasted samples

\begin{tabular}{|c|c|c|c|c|c|c|}
\hline $\begin{array}{l}\text { Thyroid } \\
\text { Hormone }\end{array}$ & Day & Control & High Taurine & $\begin{array}{l}\text { Treatment } \\
\text { p-value }\end{array}$ & $\begin{array}{c}\text { Week } \\
\text { p-value }\end{array}$ & $\begin{array}{c}\text { Treatment }{ }^{\star} W e e k \\
\mathrm{p} \text {-value }\end{array}$ \\
\hline \multirow{4}{*}{$\begin{array}{c}\text { TT4 } \\
\text { (nmol/L) }\end{array}$} & 0 & $17.9 \pm 1.2$ & $18.4 \pm 0.3$ & \multirow{4}{*}{0.84} & \multirow{4}{*}{$<0.01$} & \multirow{4}{*}{0.73} \\
\hline & 14 & $17 \pm 0.7$ & $16.4 \pm 1.3$ & & & \\
\hline & 28 & $18 \pm 0.8$ & $17.3 \pm 1.4$ & & & \\
\hline & 42 & $19.6 \pm 0.8$ & $20.4 \pm 1.9$ & & & \\
\hline \multirow{4}{*}{$\begin{array}{c}\text { TT3 } \\
\text { (nmol/L) }\end{array}$} & 0 & $0.59 \pm 0.04$ & $0.63 \pm 0.04$ & \multirow{4}{*}{0.65} & \multirow{4}{*}{$<0.01$} & \multirow{4}{*}{0.51} \\
\hline & 14 & $0.60 \pm 0.03$ & $0.59 \pm 0.03$ & & & \\
\hline & 28 & $0.66 \pm 0.04$ & $0.63 \pm 0.04$ & & & \\
\hline & 42 & $0.56 \pm 0.04$ & $0.57 \pm 0.05$ & & & \\
\hline \multirow{4}{*}{$\begin{array}{c}\text { FT4 } \\
(\mathrm{pmol} / \mathrm{L})\end{array}$} & 0 & $20.4 \pm 1.0$ & $21.4 \pm 1.1$ & \multirow{4}{*}{0.81} & \multirow{4}{*}{0.25} & \multirow{4}{*}{0.64} \\
\hline & 14 & $20.3 \pm 1.3$ & $18.7 \pm 1.3$ & & & \\
\hline & 28 & $20.1 \pm 1.0$ & $19.6 \pm 1.5$ & & & \\
\hline & 42 & $21.3 \pm 0.6$ & $21.4 \pm 1.5$ & & & \\
\hline \multirow{4}{*}{$\begin{array}{c}\mathrm{FT3} \\
\text { (pmol/L) }\end{array}$} & 0 & $1.2 \pm 0.2$ & $1.1 \pm 0.2$ & \multirow{4}{*}{0.17} & \multirow{4}{*}{0.03} & \multirow{4}{*}{0.14} \\
\hline & 14 & $0.8 \pm 0.1$ & $1.0 \pm 0.1$ & & & \\
\hline & 28 & $1.1 \pm 0.1$ & $1.1 \pm 0.1$ & & & \\
\hline & 42 & $1.1 \pm 0.1$ & $1.4 \pm 0.1$ & & & \\
\hline
\end{tabular}


Figure 5.2 Day 0 and 42 fasting and post-prandial thyroid hormone measurements
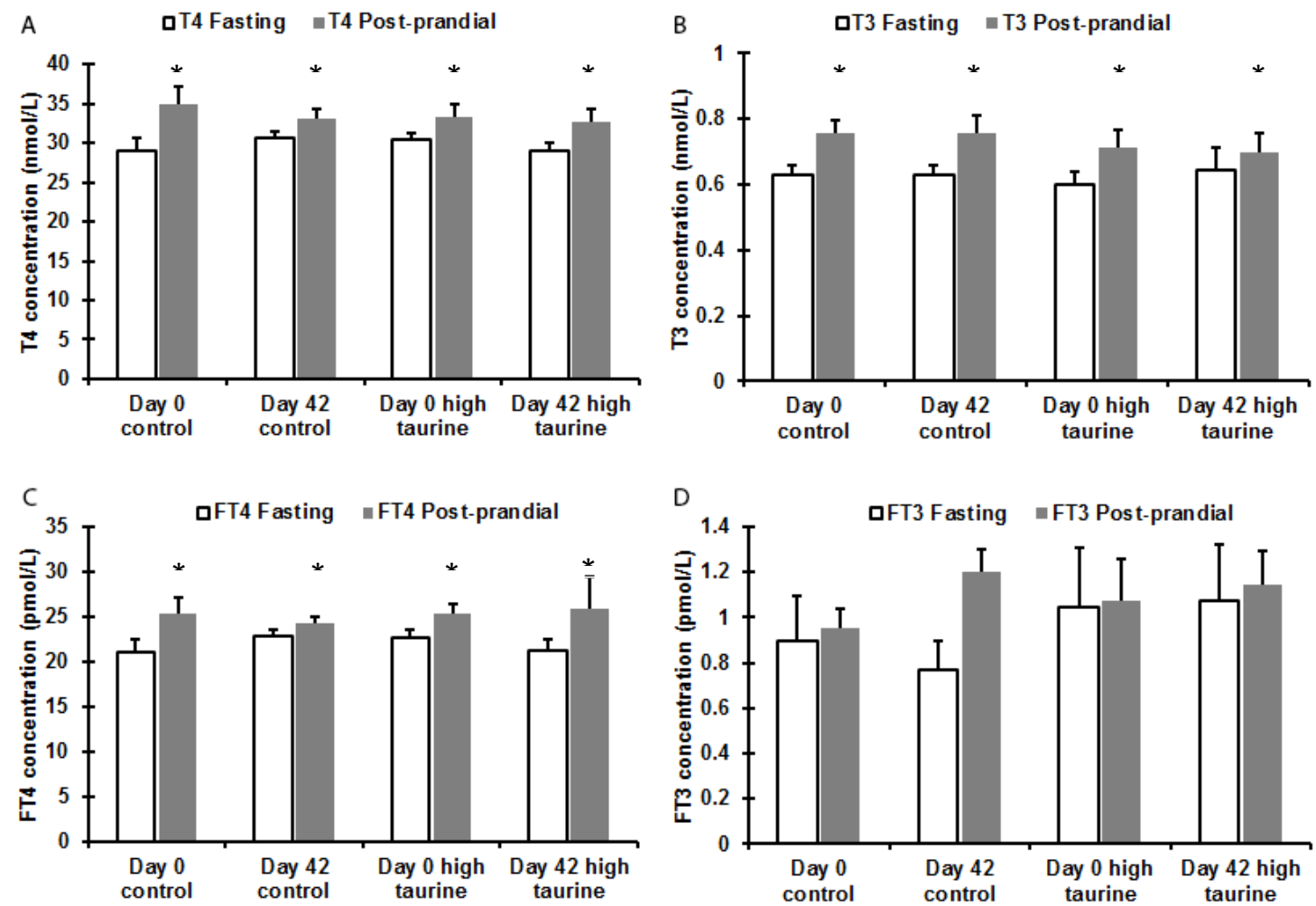

Post-prandial thyroid hormone samples significantly increase for serum TT4, TT3, and FT4 concentrations $(p<0.05)$.

Dietary taurine did not significantly alter the circulating IGF-1

concentrations, however the mean for all samples were elevated about the reference range of the laboratory $(12-92 \mathrm{nmol} / \mathrm{L})$.

Table 5.5 Circulating serum IGF-1 concentration

\begin{tabular}{|c|c|c|c|c|c|}
\hline Day & $\begin{array}{c}\text { Control } \\
(\mathrm{nmol} / \mathrm{L})\end{array}$ & $\begin{array}{c}\text { High } \\
\text { Taurine } \\
(\mathrm{nmol} / \mathrm{L})\end{array}$ & $\begin{array}{c}\text { Treatment } \\
\mathrm{p} \text {-value }\end{array}$ & $\begin{array}{c}\text { Week } \\
\mathrm{p}- \\
\text { value }\end{array}$ & $\begin{array}{c}\text { Treatment }{ }^{\star} \text { Week } \\
\mathrm{p} \text {-value }\end{array}$ \\
\hline 0 & $95 \pm 8.8$ & $99 \pm 11$ & 0.77 & 0.91 & 0.61 \\
\hline 42 & $98 \pm 11$ & $93 \pm 10$ & 0.77 & 0.06 \\
\hline
\end{tabular}

The reported reference range based upon 38 healthy cats is $12-92 \mathrm{nmol} / \mathrm{L}$ (Reusch et al. 2006). 


\section{Discussion}

By the mid-1980's, two commonly occuring domestic cat diseases, central retinal degeneration and dilated cardiac myopathy, were determined to be caused by taurine deficiency (Hayes et al. 1975; Pion et al. 1987). The formation of taurine from the amino acid L-cysteine is dependent upon a series of reactions involving cysteine sulphinic acid decarboxylase (CSAD)(Earle and Smith 1992). The lack of CSAD activity in domestic cats prevents them from synthesizing adequate amounts; therefore, taurine is required in the diet of cats (de la Rosa and Stipanuk 1985; Earle and Smith 1992). After taurine was determined to be an essential dietary nutrient for domestic cats, comercial pet food manufacturers began supplementing feline diets with taurine (National Research Council 1981). The emergence of hyperthyroidism began to occur in the late 1970's and early 1980's (Edinboro et al. 2004; Peterson et al. 1979) which coincided with the start of supplementation of taurine into commercial cat food (National Research Council 1981).

The purpose of this study was to determine if high dietary taurine alters the function of the hypothalamic-pituitary-thyroid axis, leading to an increase in thyroid hormone production. We chose to supplement the base diet with taurine at $0.70 \% \mathrm{DM}$ as this concentration is found within commercial canned diets (Hill's Pet Nutrition Inc. 2017; Purina Nutrition 2014). This supplementation is approximately $300-700 \%$ of the recommendations set forth by both the National Research Council (NRC) and the American Association of Feed Control Officials (AAFCO) who recommend a dietary taurine level of $0.10 \%$ DM in commercial dry 
diets and $0.25 \%$ DM in commercial canned diets (National Research Council 2006; American Association of Feed Control Officials 2013). The higher recommendation for canned diets is based the processing of the diet (Backus RC 1998) and upon the increased microbial degradation of taurine in the gastrointestinal tract as the composition of the microflora is criticial in determining the taurine status of cats (Morris et al. 1994).

The best clinical method to monitor taurine status is measuring both plasma and whole blood (Pacioretty et al. 2001). Plasma taurine is used for monitoring acute depleting trends of taurine status whereas whole blood is better for monitoring acute repleting trends of taurine status (Pacioretty et al. 2001). Despite the cats being on a high taurine diet containing $0.70 \%$ taurine, the plasma and whole blood taurine concentrations in this study (Fig 5.1) were lower than expected during the dietary blocks. Heinze et al (2009) reported the taurine blood concentrations of domestic cats fed commercial canned and dry extruded diets (taurine content unknown) were $80-120 \mathrm{nmol} / \mathrm{mL}$ for plasma taurine and $300-600 \mathrm{nmol} / \mathrm{mL}$ for whole blood taurine concentration (Heinze et al. 2009). Douglas et al. (1991) reported that cat's fed dry commercial diets at $0.055 \%$ and $0.14 \%$ taurine had a mean plasma taurine concentration of $51 \mu \mathrm{mol} / \mathrm{L}(51$ $\mathrm{nmol} / \mathrm{mL}$ ) and $107 \mu \mathrm{mol} / \mathrm{L}(107 \mathrm{nmol} / \mathrm{mL})$ at 7 weeks (Douglass et al. 1991). These same cats at 4 weeks had whole blood taurine concentrations reported to be $335 \mu \mathrm{mol} / \mathrm{L}(335 \mathrm{nmol} / \mathrm{mL})$ and $490 \mu \mathrm{mol} / \mathrm{L}(590 \mathrm{nmol} / \mathrm{mL})$ (Douglass et al. 1991). At the end of 6 weeks, our mean plasma taurine concentration for cats on 
the $0.70 \%$ taurine diet was $132 \mathrm{nmol} / \mathrm{mL}$ and $229 \mathrm{nmol} / \mathrm{mL}$ for whole blood (Fig $5.1)$.

The low plasma and whole blood taurine concentrations are likely due to the diet selected for the study. The six week duration of each dietary block should have been adequate for taurine repletion to occur, because the reported half-life for taurine repletion for plasma is 3.5 weeks and 0.74 weeks for whole blood (Pacioretty et al. 2001). The diet, a canine weight loss maintenance commerical dry food, has a higher fiber content than most commercial cat foods. Soluble fiber such as pectin and guar gum has been shown to delplete hepatic taurine content (Baker 1991). Fiber has also been shown to alter the bile acid metabolism (Eastwood 1992; Meyer et al. 1979; Story and Kritchevsky 1978). In cats, secondary bile acids are formed almost exclusively through conjugation with taurine (Rabin et al. 1976). Fibers that bind to bile acids, reduce the reabsoprtion and cause an increased loss of bile acids in the feces (Eastwood 1992). Similar to when cats are given Cholestyramine ${ }^{\odot}$, an anion exchange resin that binds bile acids, the loss of bile acids causes plasma and whole blood taurine concentrations to become depleted (Morris et al. 1994). Throughout the 40 week acclimation period to the canine diet and the study, it is likely that the high fiber content of the diet caused a chronic increased loss of taurineconjugated bile acids, this would help explain the low plasma and whole blood taurine levels observed. The fiber content is also likely to help explain why the cats would be considered taurine deficient (defined as less than $40 \mathrm{nmol} / \mathrm{mL}$ for plasma and $200 \mathrm{nmol} / \mathrm{mL}$ for whole blood (National Research Council 2006)) 
after 6 weeks on the control diet despite containing $0.25 \%$ taurine, well above the minimium recommended dietary taurine concentration for dry diets (National Research Council 2006).

In addition to altering the bile acid pool, it has also been suggested that fiber alters the gut microflora, causing an increase in bacterial cholylhydrolase (National Research Council 2006; Morris et al. 1994). This increase of cholylhydrolase, causes increased cleavege of taurocholic acid in the illeum and increased oxidation of taurine (National Research Council 2006; Morris et al. 1994). The oxidation causes taurine to be unavailable for enterohepatic reuitilization (Morris et al. 1994) and therefore increases the loss of taurine by the body.

Despite the taurine concentration in the plasma and whole blood being lower than expected, the circulating concentrations were clearly significanlty different when the cats were on the high taurine diet compaired to the control diet (Fig 5.1). The fasting levels of of TT4, TT3, and FT3 varried significantly by week, but they were not influenced by dietary taurine (Table 5.4). While our central hypothesis was that excessive dietary taurine would determine alter the hypothalamic-pituitary-thyroid axis and lead to a rise in the production of circulating thyroid hormones T4, T3, FT4, and FT3, we had several underlying hypothesis about how taurine might alter the function of the thyroid axis which our study design did not adequately address.

Taurine supplementation has been shown to increase the bile acid pool (Bellentani et al. 1987; Hickman et al. 1992). Bile acid abundance has been 
shown to affect thyroid hormone production (Ockenga et al. 2012). Because the increase in the bile acid pool would cause an increase in the enterohepatic circuation of taurine-conjugated secondary bile acids, we hypothesized that circulating T4 and T3 would increase due to serum bile acids stimulating thyroid hormone production. Unfortunately, we did not measure the bile acid pool and were unable to measure serum bile acids within our laboratory, so we do not know if the bile acid pool or circulating serum bile acids were altered. Addtionally the selection of the high fiber weight loss diet was a confounding variable. It is plausable that we did not see an increase in thyroid hormone due to the diet inhibiting the expansion of the bile acid pool and negatively impacting the reabsorption of bile acids into enterohepatic circulation.

In additional to taurine altering bile acid metabolism, we hypothesized that excessive dietary taurine would result in a proliferation of thyroid cells and the formation of hyperfuncting thyroid nodules. These hyperfunctioning thyroid nodules would yield an inappropriate rise in the production of the thyroid homones T4 and T3. Our hypothesis was based upon the report by Jhiang et al. (1993) that the proliferation rate of thyroid cells from two human cell lines increased with increasing taurine in vitro (Jhiang et al. 1993). While euthanasia would be required to grossely and histologically examine the thyroids for thyroid nodules, we elected to not euthanize the cats. As an alternative to euthanasia, our laboratory conducted pilot work to determine if magnetic resonance imaging (MRI) coupled with mass resonance spectroscopy (MRS) could be used to nonterminally examine the thyroid gland and measure the concentration of taurine in 
the thyroid gland. MRI/MRS has been successfully used to quantify metabolites, including taurine, in brain tissue (Tong et al. 2004). In our pilot study of two cats, we determined that the microchips embended in the subcutaneous tissue within the neck region caused interference and the thyroids could not be visualized (Hooper and Backus 2015, unpublished data). The thyroid glands could be imaged on cats who did not have a microchip, however the imaging quality was not adequate to detect small hyperfunctioning thyroid nodules. Additionally, it was determined that the region of interest $(\mathrm{ROI})$ of the MRS was too large and could not isolate the thyroid gland from the muscle. With the high taurine content of the muscle, we were unable to measure the thyroid taurine content. Future studies may be able to incorporate this technology, however the animals cannot be microchipped and a MRI of sufficient strength and MRS capabilities will need to be used.

While it is unknown if the high dietary taurine caused formation of thyroid nodules in our cats, it is likely that the formation of thyroid nodules occurs with chronic exposure rather than an acute exposure of six week duration. Hyperthyroidism generally affects cats 7 years or older (Mooney 2012), therefore a more long-term study is most likely needed to understand the effects of high dietary taurine on the thyroid gland. When designing a long-term study, it may be worthwhile to include a group which receives fluctiations in taurine concentrations as fluctuations in dietary iodine have been suggested as a risk factor for the development of hyperthyroidism (Edinboro et al. 2013), but to date no studies have evaluated this hypothesis. 
A single study conducted by our laboratory reported that T4 and T3 were increased post prandially (Hooper et al. 2014). The present study confirms that T4, T3, as well as FT4 increase signficantly 4 hours post-prandially (Fig 5.2). It remains unclear if this elevation could contribute to the pathopsyiology of feline hyperthyroidism. Future studies should evaluate when is the optimal time to collect blood for studying the effects of dietary nutrients on thyroid hormone production. If high levels of taurine or other suspected dietary constitutents alter the maximal peak of circulating thyroid hormones it could be important to understand if the fluxations in thyroid hormones play a role in the etiopathophysiology of feline hyperthyroidism.

The secondary aim of this study was to determine if excessive dietary taurine caused an increase in circulating serum IGF-1. While IGF-1 and insulinlike growth factor binding protein-1 are elevated in human hyperthyroid patients (Miell et al. 1993), it is unknown whether IGF-1 levels are elevated during the development of hyperthyroidism or if IGF-1 levels are elevated in subclinical hyperthyroidism. Some evidence exists that IGF-1 affects thyroid function based upon knockout mouse studies that showed TSH and IGF-1 are both required to regulate thyroid growth (Ock et al. 2013). Additionally, intravenously administered taurine has been shown to increase growth hormone (Ikuyama et al. 1988). If dietary taurine can cause an increase in growth hormone (GH), then an increase in GH will directly raise the circulating serum IGF-1 concentrations (Kalu et al. 1998). We chose to measure IGF-1 rather than GH for several reasons. IGF-1 has a fifteen-hour half-life wheras $\mathrm{GH}$ has a half-life of 
approximately 12 minutes (Bright et al. 1999). GH is secreted in a pulsatile manner that is highly variable within and between individuals (Tannenbaum and Martin 1976) whereas IGF-1 is not secreted in the pulsatile manner (Brabant 2003). Additionally, there are no diagnostic labs or commerical assays available to measure feline $\mathrm{GH}$. A feline specific IGF-1 assay was developed and validated by Michigan State Diagnostic Center for Population and Animal Health in collaboration with other researchers and diagnostic laboratories (Reusch et al. 2006).

We did not observe a dietary taurine effect on IGF-1 (Table 5.5), however the mean IGF-1 concentrations when the cats were on the control and high taurine diet were considered elevated. The reference for this assay is quite large and based upon 38 healthy cats, a relatively small sample size (Reusch et al. 2006). IGF-1 is typically only measured in cats that are diabetic and/or are suspected to have acromegaly, an endocrine disorder characterized by excessive growth hormone secretion caused by a functional somatotrophic adenoma in the pars distalis of the anterior pituitary gland (Niessen et al. 2007). The acromegaly diagnosis is supported by a combination of clinical symptoms and circulating IGF-1 concentrations above $1,000 \mathrm{ng} / \mathrm{mL}$ (131 nmol/L). We suspect the values obtained were normal individual variation of IGF-1.

\section{Conclusion}

Our study documents that feline thyroid hormones are affected by feed consumption. It has been hypothesized, though not tested, that fluxations in dietary iodine could contribute to the development of feline hyperthyroidism (Edinboro et al. 2013). Understanding the effects of dietary constituents on post- 
prandial thyroid hormone concentrations should be pursued in future studies as it is unknown if post-prandial thyroid hormone elevations play a role in the development of feline hyperthyroidism. While this study did not support excessive taurine as a risk factor for the development of feline hyperthyroidism, another study looking at chronic taurine administration and utilizing a feline diet without excessive fiber or a purrified diet would be of value to the veterinary community to better address this study's hypothesis. 


\section{References}

American Association of Feed Control Officials (2013) Home Page. AAFCO. www.aafco.org. Accessed 11/29/13

Backus RC, Cave NJ, Keisler DH (2007) Gonadectomy and high dietary fat but not high dietary carbohydrate induce gains in body weight and fat of domestic cats The British journal of nutrition 98:641-650 doi:10.1017/S0007114507750869

Backus RC MJ, Kim SW, O’Donnell JA, Hickman MA, Kirk CA, Cooke JA, Rogers QR (1998) Dietary taurine needs of cats varies with dietary protein quality and concentration Veterinary Clinical Nutrition:18-22

Baker DH (1991) Comparative nutrition of cats and dogs Annual review of nutrition 11:239-263 doi:10.1146/annurev.nu.11.070191.001323

Bellentani S et al. (1987) Taurine increases bile acid pool size and reduces bile saturation index in the hamster Journal of lipid research 28:1021-1027

Brabant G (2003) Insulin-like growth factor-I: marker for diagnosis of acromegaly and monitoring the efficacy of treatment European journal of endocrinology / European Federation of Endocrine Societies 148 Suppl 2:S15-20

Bright GM, Veldhuis JD, Iranmanesh A, Baumann G, Maheshwari H, Lima J (1999) Appraisal of Growth Hormone (GH) Secretion: Evaluation of a Composite Pharmacokinetic Model That Discriminates Multiple Components of GH Input1 The Journal of Clinical Endocrinology \& Metabolism 84:3301-3308 doi:10.1210/jcem.84.9.5960 
Broussard JD, Peterson ME, Fox PR (1995) Changes in clinical and laboratory findings in cats with hyperthyroidism from 1983 to 1993 Journal of the American Veterinary Medical Association 206:302-305

de la Rosa J, Stipanuk MH (1985) Evidence for a rate-limiting role of cysteinesulfinate decarboxylase activity in taurine biosynthesis in vivo Comparative biochemistry and physiology $\mathrm{B}$, Comparative biochemistry $81: 565-571$

Delaney SJ, Kass PH, Rogers QR, Fascetti AJ (2003) Plasma and whole blood taurine in normal dogs of varying size fed commercially prepared food $\mathrm{J}$ Anim Physiol Anim Nutr (Berl) 87:236-244

Douglass GM, Fern EB, Brown RC (1991) Feline plasma and whole blood taurine levels as influenced by commercial dry and canned diets J Nutr 121:S179180

Earle KE, Smith PM (1992) The Effect of Dietary Supplementation with Cysteic Acid on the Plasma Taurine Concentration of Cats Maintained on a Taurine-Restricted Diet. In: Lombardini J, Schaffer S, Azuma J (eds) Taurine, vol 315. Advances in Experimental Medicine and Biology. Springer US, pp 23-32. doi:10.1007/978-1-4615-3436-5_4 Eastwood MA (1992) The Physiological Effect of Dietary Fiber: An Update Annual review of nutrition 12:19-35 doi:10.1146/annurev.nu.12.070192.000315 
Edinboro CH, Pearce EN, Pino S, Braverman LE (2013) lodine concentration in commercial cat foods from three regions of the USA, 2008-2009 J Feline Med Surg 15:717-724 doi:10.1177/1098612X13477855

Edinboro CH, Scott-Moncrieff JC, Janovitz E, Thacker HL, Glickman LT (2004)

Epidemiologic study of relationships between consumption of commercial canned food and risk of hyperthyroidism in cats Journal of the American Veterinary Medical Association 224:879-886

doi:10.2460/javma.2004.224.879

Gerber H, Peter H, Ferguson DC, Peterson ME (1994) Etiopathology of feline toxic nodular goiter The Veterinary clinics of North America Small animal practice 24:541-565

Gójska-Zygner O, Lechowski R, Zygner W (2014) Prevalence of feline hyperthyroidism in mature cats in urban population in Warsaw Bulletin of the Veterinary Institute in Puławy =

Hayes KC, Carey RE, Schmidt SY (1975) Retinal degeneration associated with taurine deficiency in the cat Science 188:949-951

Heinze CR, Larsen JA, Kass PH, Fascetti AJ (2009) Plasma amino acid and whole blood taurine concentrations in cats eating commercially prepared diets American journal of veterinary research 70:1374-1382 doi:10.2460/ajvr.70.11.1374

Hickman MA, Bruss ML, Morris JG, Rogers QR (1992) Dietary protein source (soybean vs. casein) and taurine status affect kinetics of the enterohepatic circulation of taurocholic acid in cats J Nutr 122:1019-1028 
Hill's Pet Nutrition Inc. (2017) Hill's Key to Clinical Nutrition Accessed https://www.hillsvet.com. 7/20/17

Hoenig M, Goldschmidt MH, Ferguson DC, Koch K, Eymontt MJ (1982) Toxic nodular goitre in the cat The Journal of small animal practice 23:1-12 Hooper S, Mori L, Backus RC (2014) Effects of bisphenol-A and estradiol ingested with food on plasma concentrations of glucose, insulin, and thyroid-axis hormones in cats Journal of Animal Physiology and Animal Nutrition 98:1188 doi:10.1111/jpn.12269

Ikuyama S, Okajima T, Kato K, Ibayashi H (1988) Effect of taurine on growth hormone and prolactin secretion in rats: possible interaction with opioid peptidergic system Life sciences 43:807-812

Jacobsen JG, Smith LH (1968) Biochemistry and physiology of taurine and taurine derivatives Physiological reviews 48:424-511

Jhiang SM, Fithian L, Smanik P, McGill J, Tong Q, Mazzaferri EL (1993) Cloning of the human taurine transporter and characterization of taurine uptake in thyroid cells FEBS letters 318:139-144

Kalu DN, Orhii PB, Chen C, Lee DY, Hubbard GB, Lee S, Olatunji-Bello Y (1998) Aged-rodent models of long-term growth hormone therapy: lack of deleterious effect on longevity The journals of gerontology Series A, Biological sciences and medical sciences 53:B452-463

Kass PH, Peterson ME, Levy J, James K, Becker DV, Cowgill LD (1999) Evaluation of environmental, nutritional, and host factors in cats with 
hyperthyroidism Journal of veterinary internal medicine / American College of Veterinary Internal Medicine 13:323-329

Knopf K, Sturman JA, Armstrong M, Hayes KC (1978) Taurine: an essential nutrient for the cat The Journal of nutrition 108:773-778

Kohler I, Ballhausen BD, Stockhaus C, Hartmann K, Wehner A (2016) Prevalence of and risk factors for feline hyperthyroidism among a clinic population in Southern Germany Tierarztl Prax Ausg K Kleintiere Heimtiere 44 doi:10.15654/TPK-150590

Laflamme D (1997) Nutritional management The Veterinary clinics of North America Small animal practice 27:1561-1577

Martin KM, Rossing MA, Ryland LM, DiGiacomo RF, Freitag WA (2000) Evaluation of dietary and environmental risk factors for hyperthyroidism in cats Journal of the American Veterinary Medical Association 217:853-856 Meyer PD, DenBesten L, Mason EE (1979) The effects of a high-fiber diet on bile acid pool size, bile acid kinetics, and biliary lipid secretory rates in the morbidly obese Surgery 85:311-316

Miell JP, Taylor AM, Zini M, Maheshwari HG, Ross RJ, Valcavi R (1993) Effects of hypothyroidism and hyperthyroidism on insulin-like growth factors (IGFs) and growth hormone- and IGF-binding proteins The Journal of clinical endocrinology and metabolism 76:950-955 doi:10.1210/jcem.76.4.7682563 
Mooney CaPM (2012) Feline Hyperthyroidism. In: Peterson CMaM (ed) Manual of Canine and Feline Endocrinology. 4th edn. British Small Animal Veterinary Association, Quedgeley, Gloucester, UK, pp 199-203 Morris JG, Rogers QR, Kim SW, Backus RC (1994) Dietary taurine requirement of cats is determined by microbial degradation of taurine in the gut Advances in experimental medicine and biology 359:59-70

National Institutes of Health (2011) Guide for the care and use of laboratory animals. 8th Edition. NIH publication. U.S. Dept. of Health and Human Services, Public Health Service, Bethesda, Md.

National Research Council (revised 1978) Nutrient requirements of cats : revised 1978 / Panel on Cat Nutrition, Subcommittee on Laboratory Animal Nutrition, Committee on Animal Nutrition, Board on Agriculture and Renewable Resources, National Research Council. Nutrient requirements of domestic animals ; no. 13. National Academy of Sciences, 1978, United States

National Resarch Council (2006) Nutrient Requirements of Dogs and Cats. The National Academies Press, Washington, DC. doi:doi:10.17226/10668 National Research Council (1981) Taurine Requirement of the Cat. The National Academies Press, Washington, DC. doi:10.17226/19715

Niessen SJ, Petrie G, Gaudiano F, Khalid M, Smyth JB, Mahoney P, Church DB (2007) Feline acromegaly: an underdiagnosed endocrinopathy? Journal of veterinary internal medicine / American College of Veterinary Internal Medicine 21:899-905 
Ock S et al. (2013) IGF-1 receptor deficiency in thyrocytes impairs thyroid hormone secretion and completely inhibits TSH-stimulated goiter FASEB journal : official publication of the Federation of American Societies for Experimental Biology 27:4899-4908 doi:10.1096/fj.13-231381

Ockenga $\mathrm{J}$ et al. (2012) Plasma bile acids are associated with energy expenditure and thyroid function in humans The Journal of clinical endocrinology and metabolism 97:535-542 doi:10.1210/jc.2011-2329

Olczak J, Jones BR, Pfeiffer DU, Squires RA, Morris RS, Markwell PJ (2005) Multivariate analysis of risk factors for feline hyperthyroidism in New Zealand New Zealand veterinary journal 53:53-58 doi:10.1080/00480169.2005.36469

Pacioretty L, Hickman MA, Morris JG, Rogers QR (2001) Kinetics of taurine depletion and repletion in plasma, serum, whole blood and skeletal muscle in cats Amino acids 21:417-427

Peterson M (2012) Hyperthyroidism in cats: what's causing this epidemic of thyroid disease and can we prevent it? J Feline Med Surg 14:804-818 doi:10.1177/1098612X12464462

Peterson M, Johnson G, Andrews L Spontaneous hyperthyroidism in the cat. In: Proceedings of the American College of Veterinary Internal Medicine Forum, 1979. p 108

Peterson ME (2006) Diagnostic Tests for Hyperthyroidism in Cats Clinical techniques in small animal practice $21: 2-9$ doi:http://dx.doi.org/10.1053/j.ctsap.2005.12.001 
Peterson ME, Graves TK, Cavanagh I (1987) Serum thyroid hormone concentrations fluctuate in cats with hyperthyroidism Journal of veterinary internal medicine / American College of Veterinary Internal Medicine $1: 142-146$

Peterson ME, Melian C, Nichols R (2001) Measurement of serum concentrations of free thyroxine, total thyroxine, and total triiodothyronine in cats with hyperthyroidism and cats with nonthyroidal disease Journal of the American Veterinary Medical Association 218:529-536

Peterson ME, Ward CR (2007) Etiopathologic Findings of Hyperthyroidism in Cats Veterinary Clinics of North America: Small Animal Practice 37:633645 doi:http://dx.doi.org/10.1016/j.cvsm.2007.05.001

Pion PD, Kittleson MD, Rogers QR, Morris JG (1987) Myocardial failure in cats associated with low plasma taurine: a reversible cardiomyopathy Science $237: 764-768$

Purina Nutrition (2014) Purina Foods Product Guide DM Dietetic Management® Feline Formula. https://www.purinaveterinarydiets.com/Product/DMDieteticManagementCa tFood.aspx. Accessed 10/30/2014

Purina Nutrition (2015) Purina Product Guide for Veterinary Clinics vol July 2015. Rabin B, Nicolosi RJ, Hayes KC (1976) Dietary influence on bile acid conjugation in the cat J Nutr 106:1241-1246 
Reusch CE, Kley S, Casella M, Nelson RW, Mol J, Zapf J (2006) Measurements of growth hormone and insulin-like growth factor 1 in cats with diabetes mellitus The Veterinary record 158:195-200

Scarlett JM, Moise NS, Rayl J (1988) Feline hyperthyroidism: A descriptive and case-control study Preventive veterinary medicine 6:295-309

Schecter A, Malik N, Haffner D, Smith S, Harris TR, Paepke O, Birnbaum L (2010) Bisphenol A (BPA) in U.S. Food Environmental science \& technology 44:9425-9430 doi:10.1021/es102785d

Story JA, Kritchevsky D (1978) Bile acid metabolism and fiber The American journal of clinical nutrition 31:S199-S202

Tannenbaum GS, Martin JB (1976) Evidence for an endogenous ultradian rhythm governing growth hormone secretion in the rat Endocrinology 98:562-570 doi:10.1210/endo-98-3-562

Taylor JA, Jacobs RM, Lumsden JH, Bonnett BN (1989) Perspectives on the diagnosis of feline hyperthyroidism The Canadian Veterinary Journal $30: 477$

Thoday K, Mooney C (1992) Historical, clinical and laboratory features of 126 hyperthyroid cats The Veterinary record 131:257-264

Tong Z, Yamaki T, Harada K, Houkin K (2004) In vivo quantification of the metabolites in normal brain and brain tumors by proton MR spectroscopy using water as an internal standard Magn Reson Imaging 22:735-742 doi:10.1016/j.mri.2004.02.006 
Torregrossa L et al. (2012) Toward the reliable diagnosis of indeterminate thyroid lesions: a HRMAS NMR-based metabolomics case of study J Proteome Res 11:3317-3325 doi:10.1021/pr300105e

UC Davis Amino Acid Laboratory (2017) Normal Taurine Values for Cat and Dog. http://www.vetmed.ucdavis.edu/vmb/labs/aal/. Accessed 7-10-17

United States Department of Agriculture (2013) Animal Welfare Act and Animal Welfare Regulations. United States Code

van Hoek I, Hesta M, Biourge V (2015) A critical review of food-associated factors proposed in the etiology of feline hyperthyroidism J Feline Med Surg 17:837-847 doi:10.1177/1098612X14556558

Wakeling J, Everard A, Brodbelt D, Elliott J, Syme H (2009) Risk factors for feline hyperthyroidism in the UK The Journal of small animal practice 50:406414 doi:10.1111/j.1748-5827.2009.00756.x

Wright CE, Tallan HH, Lin YY, Gaull GE (1986) Taurine: biological update Annu Rev Biochem 55:427-453 doi:10.1146/annurev.bi.55.070186.002235 


\section{APPENDIX}

\section{Taurine HPLC assay}

Serum/plasma/whole blood sample prep

- Freeze-thaw three times whole blood samples to help lyse cells (whole blood only)

- Equal volume of acetonitrile with standard and sample (50 $\mu \mathrm{L} \mathrm{ACN}$ and $50 \mu \mathrm{L}$ sample)

o Acetonitrile containing $100 \mathrm{ng} / \mathrm{mL}$ trans-4-hydroxy-L-proline internal standard

- Ensure 2 quality control samples are prepared to run before and after samples

- Vortex thoroughly, centrifuge at $16 \mathrm{~g}$ for $15 \mathrm{~min}$

- Take $50 \mu \mathrm{L}$ to use, and transfer to a labeled $13 \times 100 \mathrm{~mm}$ glass tube

- Spiked standards containing $100 \mathrm{ng} / \mathrm{mL}$ trans-4-hydroxy-L-proline internal standard and taurine should be included

- Continue to Drying and Derivatization below

Tissue homogenate sample prep

- One whole thyroid gland

- homogenize in $1 \mathrm{~mL}$ of distilled water

- Approximately 50 grams of the frozen liver and kidney

○ homogenize in $1.5 \mathrm{~mL}$ of distilled water

- Approximately 25 grams of quadriceps muscle

○ homogenize in $500 \mu \mathrm{L}$ of distilled water 
- Equal volume of acetonitrile with standard and homogenized sample (50 $\mu \mathrm{L} A C N$ and $50 \mu \mathrm{L}$ sample)

- Acetonitrile containing $100 \mathrm{ng} / \mathrm{mL}$ proline internal standard

- Ensure 2 quality control samples are prepared to run before and after samples

- Vortex thoroughly, centrifuge at $16 \mathrm{~g}$ for $15 \mathrm{~min}$

- Take $50 \mu \mathrm{L}$ to use, and transfer to a labeled $13 \times 100 \mathrm{~mm}$ glass tube

o Spiked standards containing $100 \mathrm{ng} / \mathrm{mL}$ trans-4-hydroxy-L-proline internal standard and taurine should be included

- Continue to Drying and Derivatization below

Drying and Derivatization

- After adding $50 \mu \mathrm{L}$ of sample to tubes

- Evaporate to dryness at $35^{\circ} \mathrm{C}$ for 15 minutes

- After dry add $50 \mu \mathrm{L}$ of 1:1:1 of methanol +water + TEA $(50 \mu \mathrm{L}$ of each in $\operatorname{mix})$

- Increase amount as needed for number of samples

- Evaporate to dryness at $35^{\circ} \mathrm{C}$ for 15 minutes

- Derivatization, prepare after samples dry and immediately before use

- $200 \mu \mathrm{L}$ methanol $+50 \mu \mathrm{L}$ water $+50 \mu \mathrm{L}$ TEA $+20 \mu \mathrm{L}$ PITC

- Increase amount as needed for number of samples

- $50 \mu \mathrm{L}$ of derivatization into each tube, leave $20 \mathrm{~min}$ at room temp

- Cover with parafilm or cap 
- After $20 \mathrm{~min}$, evaporate to dryness at $35^{\circ} \mathrm{C}$ for 60 minutes (sometimes takes longer for samples based upon number of samples)

- Redesolve samples in $200 \mu \mathrm{L}$ of sample diluent

○ Sample diluent $=710 \mathrm{mg}$ disodium hydrogen +1 liter wateracetonitrile (19+1) and adjust to $\mathrm{pH} 5.4$ with phosphoric acid

○ $100 \mathrm{~mL}=71 \mathrm{mg}+95 \mathrm{~mL} \mathrm{H} 2 \mathrm{O}+5 \mathrm{~mL}$ acetonitrile

- Transfer to $0.2 \mu \mathrm{m}$ filter ependorfs

- Centrifuge for $15 \mathrm{~min}$ at $15 \mathrm{~g}$

- Transfer to HPLC vials

- Centrifuge for $10 \mathrm{~min}$ at $3 \mathrm{~g}$

- Inject $5 \mu \mathrm{L}$ of sample into HPLC

\section{Solvent A}

- Sodium acetate HPLC 11.45 grams

- $\mathrm{ddH} 2 \mathrm{O} 900 \mathrm{~mL}$

- Acetonitrile $15 \mathrm{~mL}$ LC-MS grade

- TEA $0.5 \mathrm{~mL}$

- adjust to $\mathrm{pH} 5.4$ with glacial acetic acid

Solvent B

- $410 \mathrm{~g} \mathrm{H} 2 \mathrm{O}$

- $475 g$ acetonitrile

- This is 1:1 water:acetonitrile

- Filter solvents with Millipore $0.2 \mu \mathrm{m}$ filter, carefully pour to avoid air. HPLC Column Varian Miscrosorb $100-5 \mathrm{C} 18$, temperature should be $45^{\circ} \mathrm{C}$ 


\section{Gilkson HPLC}

- Turn on column heater and assure that it is set to $45^{\circ} \mathrm{C}$

- Allow column to heat for a minimum of 30 minutes prior to first sample run

- Turn on pumps, injector, detector

- Ensure waste contains are empty and/or open

- Make sure Solvent A and B are on the system

- Ensure that new solvents are primed through system

- Open valve $\rightarrow$ Prime $\rightarrow$ Run for pump A, then stop and change pumps to B to run, then stop $\rightarrow$ close valve

- Condition column

o Condition $\rightarrow$ enter 3.5 minutes for the time $\rightarrow$ Flow $\rightarrow 1.0 \mathrm{ml} / \mathrm{min}$ $\rightarrow \% \mathrm{~B}$ should be at 0 automatically

- Program 4 will be used for taurine

- Make sure that you edit the number of loops you want to run

- File $\rightarrow$ edit $\rightarrow$ enter \# of loops

- While column conditions for 15-20 minutes

- Turn on computer $\rightarrow$ start Peak simple program $\rightarrow$ Open control file "Taurine" $\rightarrow$ ensure axis are 0 to 45 on $x$ axis, and 120 on y axis

- Make sure that you can see the entire run (0-45 minutes)

- Overall $\rightarrow$ enter "0" for start time and " 45 " for end time

- Make sure to change post-run to today's date and auto increment is on 
- i.e. 2016_7_22

- Run time will be 45 minutes

- Zero detector

- Injector file is also \#4

○ Injection is $5 \mu \mathrm{L}$ with a run time of 45 minutes

- Make sure detector is not running, then press "run" for program 4 on pumps

- Subsequently press run on the injector and choose the number of samples you have prepared

- Ensure that sample injects and detector is running okay after injection

Peak Simple Analysis of samples

- Choose overall and view only in 10 and 25 min region

- Right click on screen above peak of interest $\rightarrow$ choose add component

- Add component for both taurine and proline peaks

- See next page for example of where Taurine and proline peaks are

- First chromatogram is a cat consuming a "high taurine" diet and the second chromatogram is a cat consuming a "low taurine". Both are plasma samples

- After peaks have component above them choose "results"

- Record the area on an Excel spread sheet to allow calculations 


\section{HPLC Appendix Figure 1 Example chromatograph}

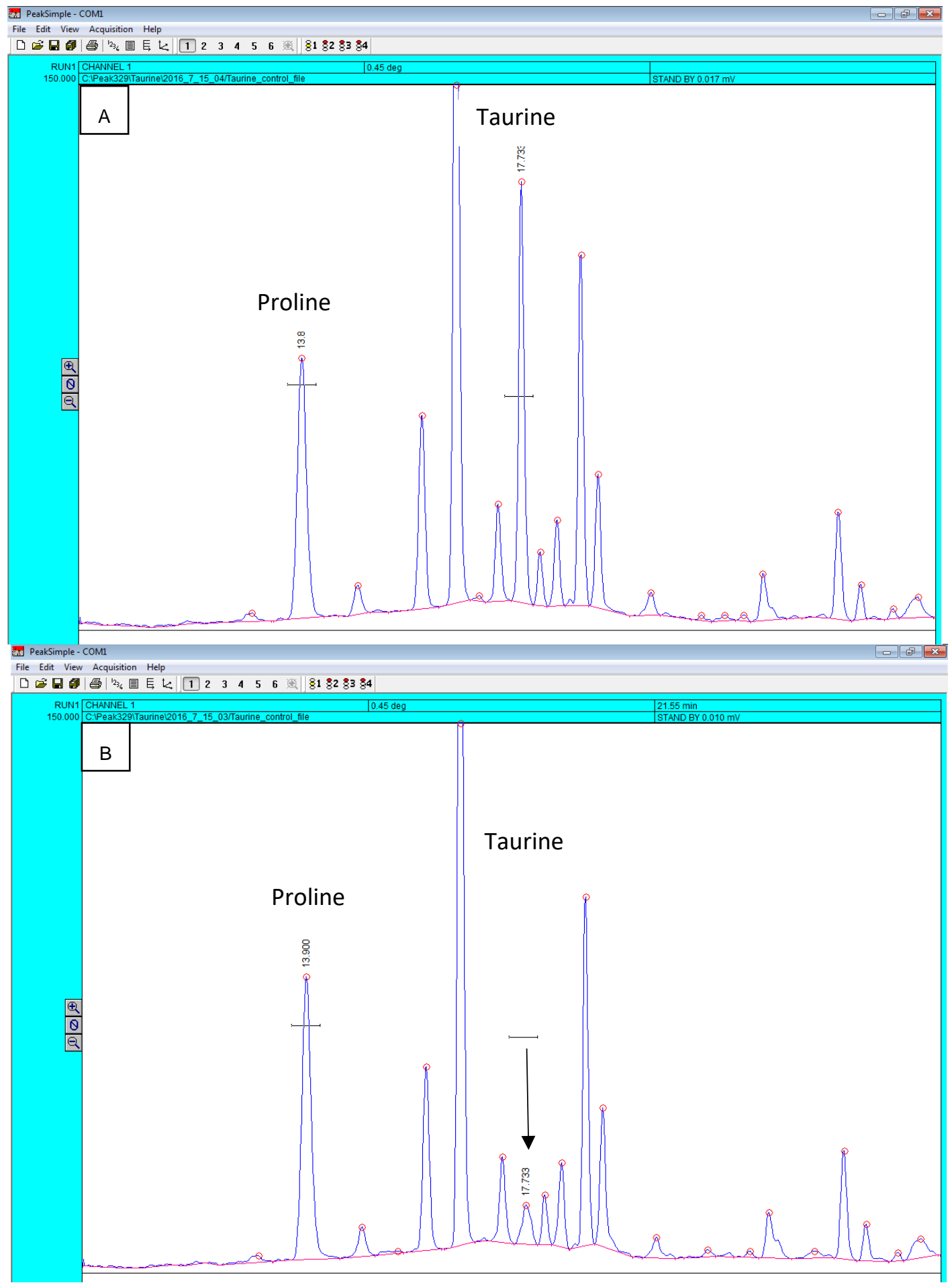

A representative example of the plasma taurine peak from a rat on the $(A)$ high taurine diet and (B) low taurine diet. 


\section{Microbiome Extraction Protocol}

As described in (Hart et al. 2015)

Cell Lysis

- Make cell lysis buffer

- $500 \mathrm{mM} \mathrm{NaCl}, 50 \mathrm{mM}$ Tris- $\mathrm{HCl} \mathrm{pH}$ 8.0, $50 \mathrm{mM}$ EDTA, and 4\% sodium dodecyl sulfate (SDS)

- Warm lysis buffer in $37^{\circ} \mathrm{C}$ water bath until SDS is completely suspended

- Place 1-2 fecal pellets or entire cecal contents in $2.0 \mathrm{~mL}$ round-bottom tube with ball bearing

- Add $800 \mu$ Lof cell lysis buffer to tube

- Homogenize at maximum speed for 3 minutes in TissueLyser

- Incubate at $70^{\circ} \mathrm{C}$ for 20 minutes with brief vortexing every 5-10 minutes

- Spin at room temperature for 5 minutes at $5000 \times g$

- Transfer entire supernatant to fresh $1.5 \mathrm{~mL}$ Eppendorf tube Precipitation of Nucleic Acids

- Place isopropanol on ice (approximately $800 \mu \mathrm{L}$ per sample to be extracted)

- Add $200 \mu \mathrm{L}$ of $10 \mathrm{mM}$ ammonium acetate to lysate (supernatant that was transferred to fresh Eppendorf tube) and mix well

- Incubate on ice for 5 minutes

- Spin at room temperature for 5 minutes at $5,000 \times g$

- Transfer $750 \mu \mathrm{L}$ of supernatant to new $1.5 \mathrm{~mL}$ Eppendorf tube 
- Add $750 \mu \mathrm{L}$ (or one volume) chilled isopropanol to each tube and vortex well

- Incubate on ice for 30 minutes (30 minutes is minimum, up to 1.5 hours)

- Spin at $4^{\circ} \mathrm{C}$ for 15 minutes at $16,000 \times g$ (temperature is critical)

- Aspirate supernatant and discard

- Add $150 \mu \mathrm{L}$ of $70 \% \mathrm{EtOH}$ to nucleic acid pellet; aspirate (avoiding the nucleic acid pellet) and discard EtOH (quick in and out rinse)

- Resuspend pellet in $150 \mu \mathrm{L}$ of Tris-EDTA (may help to place in $37^{\circ} \mathrm{C}$ water bath for 10-30 minutes with intermittent vortexing or pipetting to loosen DNA pellet) up to one hour

Removal of RNA, protein, and purification

- All of the following reagents, buffers, and columns are from the Qiagen DNeasy extraction kit (blood and tissue kit)

- Add $15 \mu \mathrm{L}$ of proteinase $\mathrm{K}$ and $200 \mu \mathrm{L}$ of Buffer $\mathrm{AL}$ and mix well

- Incubate at $70^{\circ} \mathrm{C}$ for 10 minutes

- Add $200 \mu \mathrm{L}$ of $100 \% \mathrm{EtOH}$ and mix well

- Transfer to DNeasy column and spin at $16,000 \times g$ for 1 minute

- Discard flow-through and collection tube, add $500 \mu \mathrm{L}$ of Buffer AW1 and spin at $16,000 \times \mathrm{g}$ for 1 minute at room temp

- Discard flow-through and collection tube, add $500 \mu \mathrm{L}$ of Buffer AW2 and spin at $16,000 \times \mathrm{g}$ for 3 minutes at room temp

- Transfer column to clean $1.5 \mathrm{ml}$ Eppendorf tube

- Add $200 \mu \mathrm{L}$ of EB buffer and incubate at room temp. for 2 minutes 
- Spin at $16,000 \times g$ at room temp. for 1 minute to elute DNA; discard column

- Store DNA at $-80^{\circ} \mathrm{C}$ for long-term storage or refrigerate if analyzing within 2-3 weeks

- The extracted DNA is submitted through the MU Metagenomics Core 


\section{Thyroid hormone liver extraction protocol}

Adapted from (Morreale de Escobar et al. 1985)

Day 1

- Weigh out 1 gram liver

- $\mathrm{MeOH}$ should be prepared with $1 \mathrm{mM}$ 6-propyl-2-thiouracil (PTU) to prevent degradation of $\mathrm{T} 4$ to $\mathrm{T} 3$

- Homogenize in $1 \mathrm{~mL} \mathrm{MeOH}$ in silanized glass tube

- Add 2,000 counts per minute (CPM) T4 or T3 I'125

- Transfer homogenate to Teflon stoppered, salinized glass tube

- Rinse tube used for homogenate in $1 \mathrm{~mL}$ aliquots to bring $\mathrm{MeOH}$ up to $4 \mathrm{~mL}$ total in the stoppered glass tube

- To the liver-MeOH homogenate in the glass tube add chloroform $2 x$ the volume of $\mathrm{MeOH}$

- So add $8 \mathrm{~mL}$ of chloroform to the $4 \mathrm{~mL}$ of $\mathrm{MeOH}$

- Cap tightly and shake for 30 seconds

- Centrifuge at 2,000g for 15 minutes

- Remove upper layer and place in stoppered, silanized glass tube

$\circ$ Repeat

- Add chloroform 2x the volume of $\mathrm{MeOH}$

- (so add $8 \mathrm{~mL}$ of chloroform to the $4 \mathrm{~mL}$ of $\mathrm{MeOH}$ )

- Cap tightly and shake for 30 seconds

$\circ$ Centrifuge at 2,000g for 15 minutes

- Remove upper layer and place in stoppered, silanized glass tube 
- Discard $\mathrm{MeOH}: \mathrm{CHCl}_{3}$ in appropriate waste container

- To the upper layer that was removed add $0.05 \% \mathrm{CaCl}_{2}$ and shake

- $2 \mathrm{~mL}$ of $\mathrm{CaCl}_{2}$ per $10 \mathrm{~mL}$ extract

- Allow to sit on ice for 30 minutes

○ Repeat by adding $0.05 \% \mathrm{CaCl}_{2}$, shake and transfer to new silanized glass vial

- Repeat with pure upper phase $1 \mathrm{x}$ to $2 \mathrm{x}$

- $\mathrm{CHCl}_{3}: \mathrm{CH}_{3} \mathrm{OH}: 0.05 \% \mathrm{CaCl}_{2}(3: 49: 48)$

- Determine percent recovery by counting the $0.05 \% \mathrm{CaCl}_{2}$ and the pure upper phase $\left(\mathrm{CHCl}_{3}: \mathrm{CH}_{3} \mathrm{OH}: 0.05 \% \mathrm{CaCl}_{2}\right)$

- Place in fridge overnight

Day 2

- Evaporate extract from previous day until $\sim 0.5 \mathrm{~mL}$ of solution remains

- While this is occurring construct resin columns and make reagents

- Construct resin column

- Pack glass wool in bottom of column

- Add $1 \mathrm{~mL}$ of Bio-RAD AG 1 x 2, 200-400 mesh, acetate resin

- First hydrate resin in $0.2 \mathrm{M}$ acetic acid solution

- Do not use chloride form or other brands

- Make the following reagents

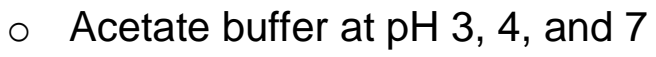

- Use $0.2 \mathrm{M}$ sodium acetate and $0.2 \mathrm{M}$ acetic acid

- $18 \mathrm{~mL}$ sodium acetate and $82 \mathrm{~mL}$ acetic acid for $\mathrm{pH} 4$ 
- Use $\mathrm{NaOH}$ to obtain acetate buffer at $\mathrm{pH} 3$

- $100 \%$ EtOH with $0.1 \mathrm{mM}$ PTU

- Prep column by running $5 \mathrm{~mL}$ of acetic acid followed by $5 \mathrm{~mL}$ acetate buffer $\mathrm{pH} 7$

- Place day 1 , concentrated $(\sim 1 \mathrm{~mL})$ thyroid hormone extract directly on resin

$\circ \quad 0.1-0.2 \mathrm{~mL} / \mathrm{min}$

- Use syringe pump for $0.2 \mathrm{~mL} / \mathrm{min}$ flow rate for all of the following wash steps

- $2 \mathrm{~mL}$ acetate buffer $\mathrm{pH} 7$

○ $2 \mathrm{~mL}$ EtOH-0.1mM PTU

- $4 \mathrm{~mL}$ acetate buffer $\mathrm{pH} 7$

○ $2 \mathrm{~mL}$ EtOH-0.1mM PTU

- $2 \mathrm{~mL}$ acetate buffer $\mathrm{pH} 7$

- $2 \mathrm{~mL}$ acetate buffer $\mathrm{pH} 4$

- $2 \mathrm{~mL}$ acetate buffer $\mathrm{pH} 3$

○ $2 \mathrm{~mL} 1 \%$ acetic acid

- $2 \mathrm{~mL} 35 \%$ acetic acid

- Collect the following wash step in a plastic tube

○ $3 \mathrm{~mL}$ of $70 \%$ acetic acid

- Evaporate and cover tube with parafilm before placing in fridge

- Can also put $25 \mu \mathrm{L}$ of $0 \mathrm{ng} / \mathrm{mL}$ T4 human serum

- Or $100 \mu \mathrm{L}$ of $0 \mathrm{ng} / \mathrm{mL}$ T3 human serum 


\section{Day 3}

- Determine number of RIA coated antibody tubes required to run each standard twice (in duplicate)

- Evaporate $3 \mathrm{~mL}$ of $70 \%$ acetic acid in a plastic tube for each of the standard tubes

- After the acetic acid has fully evaporated pipet the standard according to the manufacturer's recommendations into these tubes prior to pipetting the standards into the antibody coated RIA tubes

- Follow directions for assay procedure according to the manufacture's recommendation 


\section{Validation of MP Biomedicals total thyroxine and triiodothyronine radioimmunoassay (RIA) kit}

This validation project was selected for funding by the University of Missouri College of Veterinary Medicine Phi Zeta Chapter.

\section{Background}

In the United States, it is currently estimated that over $10 \%$ of the adult feline population has clinical hyperthyroidism (Edinboro et al. 2004; Kass et al. 1999; Martin et al. 2000; Peterson 2012). With such a high prevalence, both the American Association of Feline Practitioners and the American Animal Hospital Association (AAHA) have recommended that total thyroxine (T4) testing be considered a baseline test which should be done yearly in all senior cats (Epstein et al. 2005; Pittari et al. 2009). Total T4 is recommended as when hyperthyroidism develops, the thyroid hormone thyroxine (T4) becomes significantly elevated in $90 \%$ of hyperthyroid cats with clinical signs (e.g. weight loss with voracious appetite) (Peterson 2013). In 70-75\% of hyperthyroid cats, the thyroid hormone triiodothyronine (T3) will also become elevated (Peterson et al. 2001) and thyroid stimulating hormone (TSH) becomes low or undetectable (Wakeling et al. 2007). With the large demand for measuring the thyroid hormones T4 and T3, there are four main diagnostic assay techniques, radioimmunoassays (RIA), homogenous enzyme immunoassays (EIA), and chemiluminescent enzyme immunoassays (CEIA), and enzyme-linked 
immunosorbent assays (ELISA) that are marketed to diagnostic labs, veterinary clinics, and researchers.

Since the development of RIAs in the 1960s, they have served as the gold standard for measuring total T4 and total T3. RIAs are usually very sensitive and specific to the antigen of interest such as thyroid hormones (Goldsmith 1975). As depicted in the schematic diagram (figure 1), RIAs are a competitive binding assay. The radioactive antigen (the "tracer") competes with endogenous T4 and T3 in the serum samples for a limited number of antibody or receptor binding sites that are coated on the tube. As the endogenous T4 and T3 (nonradioactive antigen) increases in our samples there is a direct decrease in the tracer binding. After an incubation period the tube is decanted and the amount of radioactivity emitting from the tube is counted (counts per minute, CPM). The concentrations of the endogenous thyroid hormones are calculated based upon the generation of a standard curve from known sample concentrations (Feldman 2004; Peterson 2013). 
RIA Validation Appendix Figure 1 Schematic diagram of a radioimmuno assay

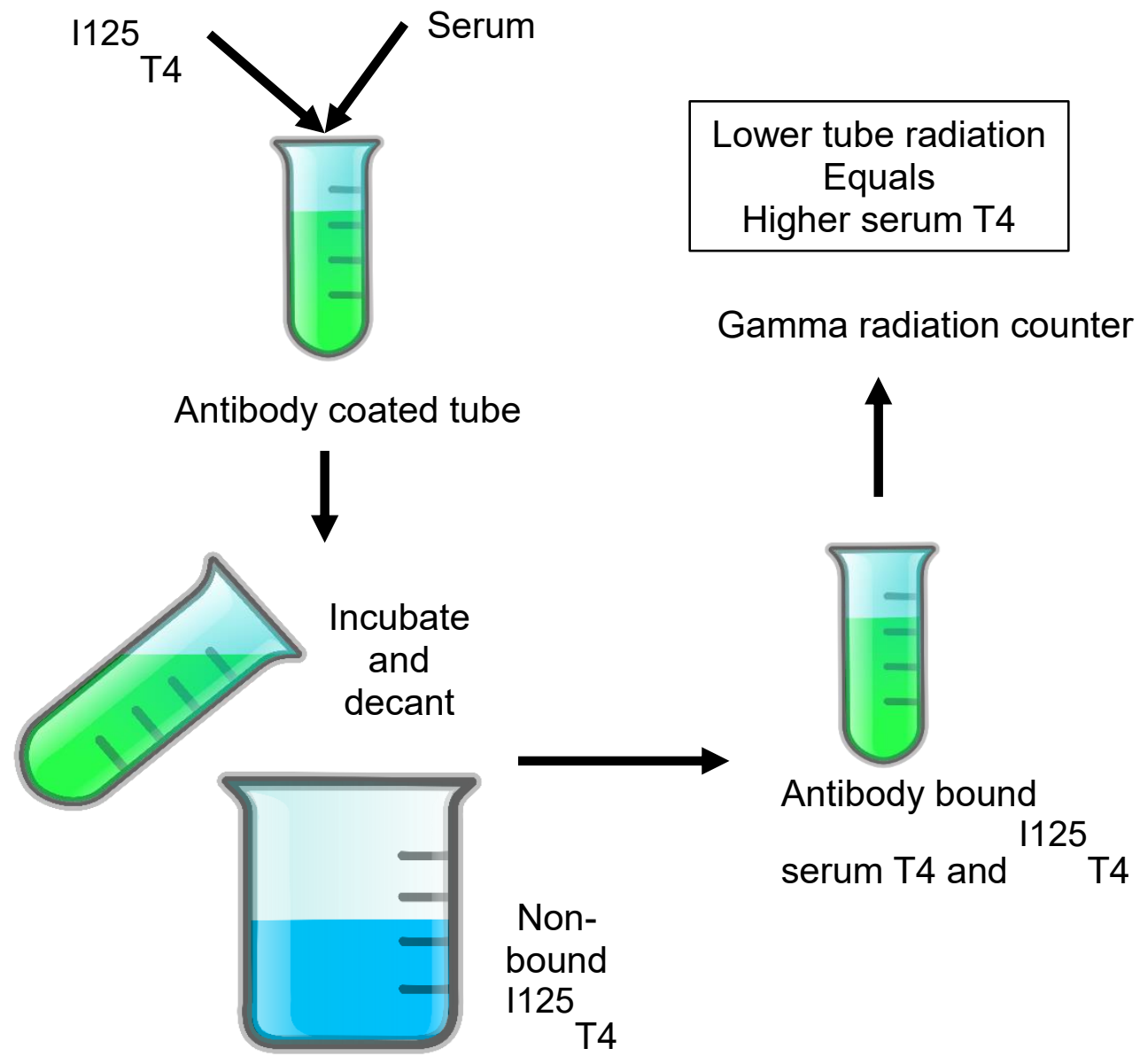

The tracer is thyroxine labelled with radioactive iodine (1125). This diagram was created using images on https://openclipart.org under Creative Commons Zero 1.0 Public Domain License.

Since RIAs employ radioactive isotopes, there is interest in developing alternative assay techniques that do not rely on radioactive reagents and this is why the company manufacturing the validated canine and feline thyroid RIAs discontinued the production abruptly this fall. Prior to the discontinuation of the validated RIAs, a chemiluminescent enzyme assay (CEIA) was validated for 
canine and feline T4 measurements. This particular CEIA assay employs the same antibody as the RIA (Peterson 2013), but rather than a radioactive tracer, there is a chemiluminescent substrate used that emits light when it reacts with the bound label (Peterson 2013; Singh et al. 1997). The concentration of T4 in the sample is directly proportional from the amount of light emitted (Peterson 2013). The major drawback for using this method, especially for smaller laboratories and researchers, is the cost to purchase the specific machine and maintain it (Singh et al. 1997). Due to this cost these CEIA assays are only economically viable for large commercial veterinary laboratories that receive a high volume of samples. Also, to the primary investigator's $(\mathrm{PI})$ knowledge technique has not been validated for T3 measurements in felines.

In addition to CEIA assays, there have been various attempts to validate a variety of ELISA kits for use with feline plasma and serum, however the published attempts have been contradictory. One paper reported that when ELISA kits were compared to the validated RIAs, the results were similar and highly correlative (Kemppainen and Birchfield 2006). Another paper reported substantial differences between the measured concentrations of T4. This paper also determined that the ELISA results would have resulted in an inappropriate clinical decision for 25 of the 50 feline samples (Lurye et al. 2002).

The last analysis method which is currently employed by several large commercial veterinary laboratories is the homogenous enzyme immunoassay (EIA). This method uses recombinant fragments of E.coli Beta-galactosidase which become an active enzyme when the different fragments are combined. 
When a patient's serum is added to select $E$-coli fragments, the T4 becomes covalent bond to one type of recombinant fragments. When all recombinant $E$ coli fragments and the feline serum are exposed to a monoclonal antibody solution, the T4 can bind to the antibody which blocks the formation of the active enzyme. The amount of active enzyme is directly proportional to the concentration of the T4 in the feline blood sample and is measured through hydrolysis of a component of the reaction substrate (Horney et al. 1999; Peterson 2013). This technique has been validated for canine and feline T4, but to the PIs knowledge this technique has not been validated for T3 in feline plasma.

With the current lack of a commercially available validated assay for T3, and with the lack of a commercially available "gold standard" assay for T4, this project seeks to fill that void. Our hypothesis is that commercially available human T4 and T3 RIA kits can be used to measure feline T4 and T3. While there is a difference in thyroid binding proteins between cats and human, the structures of T4 and T3 are identical between the two species (Fig 2) (Wang and Stapleton 2010). Therefore, we expect the kits to exhibit good cross-reactivity to feline T4 and T3, because these RIA kits are designed to measure both bound and free thyroid hormones; the antibody is not designed to measure the proteins. 


\section{RIA Validation Appendix Figure 2 Chemical structure of the thyroid hormones T4 and T3}

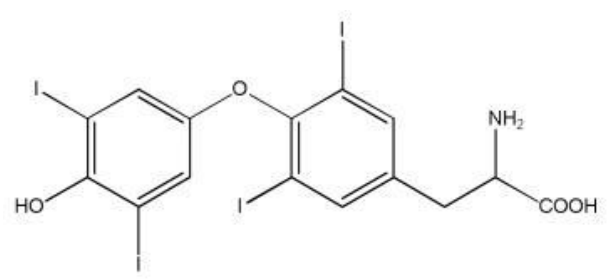

Thyroxine(T4)

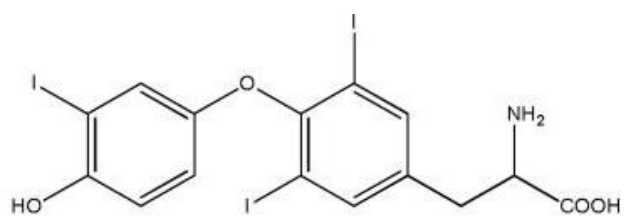

3,3',5-triiodothyronine (T3)

Description of experiment 1: The first study completed was a dilutional parallelism study.

Animals: Three, purpose-bred, University-owned, adult ( $>1 \mathrm{yr})$, lean $(<30 \%$ body fat), neutered male, domestic short-hair cats presently being studied by the PI. Three milliliters of blood was collected from the jugular vein of each cat and left at room temperature for 30 minutes to allow a clot to form. The serum was extracted after centrifuging the blood at $3,000 \times \mathrm{g}$ for 10 minutes.

Techniques: Commercially available human RIA T4 and T3 kits (MP Biomedicals LLC, Santa Ann, CA, USA) were used for this study. The serum from the three cats was diluted with a standard solution. The standard solution concentrations were $18 \mu \mathrm{g} / \mathrm{dL}$ for T4 and $700 \mathrm{ng} / \mathrm{dL}$ for T3 which were made utilizing HPLC grade T4 and T3 (Sigma Aldrich, St. Louis, MO, USA). The dilutions and the five expected concentrations are shown in table 1. 
RIA Validation Appendix Table 1 Serial dilution of feline serum samples expected concentrations

\begin{tabular}{cccl}
\hline Sample & $\begin{array}{c}\text { Percent } \\
\text { serum }\end{array}$ & $\begin{array}{c}\text { Percent } \\
\text { standard } \\
\text { concentration }\end{array}$ & Expected concentration T4/T3 \\
\hline $\mathbf{1}$ & $100 \%$ & $0 \%$ & Endogenous concentration $(\mathrm{EC})$ \\
$\mathbf{2}$ & $75 \%$ & $25 \%$ & $\mathrm{EC}+4.5 \mu \mathrm{g} / \mathrm{dL} / \mathrm{EC}+175 \mathrm{ng} / \mathrm{dL}$ \\
$\mathbf{3}$ & $50 \%$ & $50 \%$ & $\mathrm{EC}+9.0 \mu \mathrm{dL} / \mathrm{EC}+350 \mathrm{ng} / \mathrm{dL}$ \\
$\mathbf{4}$ & $25 \%$ & $75 \%$ & $\mathrm{EC}+13.5 \mu \mathrm{g} / \mathrm{dL} / \mathrm{EC}+525 \mathrm{ng} / \mathrm{dL}$ \\
$\mathbf{5}$ & $0 \%$ & $100 \%$ & $\mathrm{EC}+18 \mu \mathrm{g} / \mathrm{dL} / \mathrm{EC}+700 \mathrm{ng} / \mathrm{dL}$ \\
\hline
\end{tabular}

The five dilutions were chosen based upon the T4 assay range of 0-20 $\mu \mathrm{g} / \mathrm{dl}$ and the T3 assay range of $0-800 \mathrm{ng} / \mathrm{dl}$ as well as the Food and Drug Administration's (FDA) Guidance for Industry Bioanalytical Method Validation. The FDA guidelines recommend a minimum of three concentrations representing the entire range of the standard curve (Food and Drug Administration 1998). After the samples were serially diluted, a standard curve was established and the feline samples run in duplicate following the kit directions. After the completion of the assay procedure, the radioactive counts per minute (CPM) of the standard curve vials and the feline serum samples were measured using an automated gamma counter (Beckman Coulter, Brea, CA, USA). The standard curve CPM data was logit transformed to generate a standard curve. The values on the $y$ axis were the logit and the values on the $\mathrm{x}$-axis were calculated from the natural log of the known concentration (equation 1) (Grutzner et al. 2013).

Equation 1: $Y=\log _{e}\left[\left(B_{\text {standard }} / B_{\text {zero }}\right) /\left(1-\left(B_{\text {standard }} / B_{\text {zero }}\right)\right]\right.$

Expected data: Based upon previous values obtained from the validated RIA (Hooper et. al. 2014), we expected euthyroid cat serum to have values in the 
bottom $25 \%$ of the standard curve. With the addition of the standard, we expected the highest dilution ( $100 \%$ standard) to be near the top of the standard curve and the subsequent dilutions to span the entire standard curve. We expect the accuracy and precision to be similar to the specific performance characteristics provided by the manufacturer for human sera.

\section{Actual data:}

RIA Validation Appendix Table 2 Serial dilution of pooled feline serum samples measured T4 concentrations

\begin{tabular}{|c|c|c|}
\hline \multirow{2}{*}{ Expected concentration T4 } & \multicolumn{2}{|c|}{ Measured concentration } \\
\cline { 2 - 3 } & $\mathrm{nmol} / \mathrm{L}$ & $\mu \mathrm{g} / \mathrm{dL}$ \\
\hline Endogenous concentration $(\mathrm{EC})$ & 69.5 & 5.4 \\
\hline $\mathrm{EC}+4.5 \mu \mathrm{g} / \mathrm{dL}$ & 127.4 & 9.9 \\
\hline $\mathrm{EC}+9.0 \mu \mathrm{g} / \mathrm{dL}$ & 141.6 & 11.0 \\
\hline $\mathrm{EC}+13.5 \mu \mathrm{g} / \mathrm{dL}$ & 180.2 & 14.0 \\
\hline $\mathrm{EC}+18 \mu \mathrm{g} / \mathrm{dL}$ & 244.6 & 19.0 \\
\hline
\end{tabular}

RIA Validation Appendix Table 3 Serial dilution of pooled feline serum samples measured T3 concentrations

\begin{tabular}{|c|c|c|}
\hline \multirow{2}{*}{ Expected concentration T3 } & \multicolumn{2}{|c|}{ Measured concentration } \\
\cline { 2 - 3 } & $\mathrm{nmol} / \mathrm{L}$ & $\mathrm{ng} / \mathrm{dL}$ \\
\hline Endogenous concentration $(\mathrm{EC})$ & 1.2 & 77 \\
\hline $\mathrm{EC}+175 \mathrm{ng} / \mathrm{dL}$ & 4.8 & 311 \\
\hline $\mathrm{EC}+350 \mathrm{ng} / \mathrm{dL}$ & 7.9 & 516 \\
\hline $\mathrm{EC}+525 \mathrm{ng} / \mathrm{dL}$ & 10.5 & 681 \\
\hline $\mathrm{EC}+700 \mathrm{ng} / \mathrm{dL}$ & 14.0 & 909 \\
\hline
\end{tabular}




\section{Brief discussion}

Siemens Coat-a-Count ${ }^{\circledR}$ thyroxine and triiodothyronine radioimmunoassay kits were validated by Peterson et al. (1994) to measure T4 and T3 in feline serum. In 2014, Siemens Healthcare discontinued producing radioimmunoassays and replaced the assays with veterinary specific nonradioactive chemiluminescent immunoassays which utilized their IMMULITE ${ }^{\odot}$ immunoassay systems. These chemiluminescent analyzers are cost prohibitive for in-house laboratories as they are expensive to purchase and maintain (Higgs et al. 2014), hence the purpose of this study.

The endogenous T4 concentration in the pooled serum was elevated compared to samples previously run on the Siemen's validated RIA kits. Typically T4 over $60 \mathrm{nmol} / \mathrm{L}$ is considered diagnostic for feline hyperthyroidism (Peterson et al. 2001), therefore our cats would be considered hyperthyroid based upon the results. Therefore, the following experiments were undertaken to determine if the kit performance could be improved by altering the incubation time and if the endogenous $\mathrm{T} 4$ was truly being measured.

The endogenous T3 concentration was not elevated above the reference range; however, cat's diagnosed with mild hyperthyroidism have been observed to have similar serum T3 concentrations (Peterson et al. 2001).

Description of experiment 2: The second study completed was to assess the performance of the assay at 2 and 3 hour incubation times.

Techniques: Using the same commercially available human RIA T4 and T3 kits (MP Biomedicals LLC, Santa Ann, CA, USA) and feline serum as in experiment 
1, the samples were measured in duplicate. The kit directions were modified by incubating the samples for 2 or 3 hours rather than the 1 hour as suggested. After the completion of the assay procedure, the radioactive counts per minute (CPM) of the standard curve vials and the feline serum samples were measured using an automated gamma counter (Beckman Coulter, Brea, CA, USA). The standard curve CPM data was logit transformed to generate a standard curve as in experiment 1.

\section{Results}

RIA Validation Appendix Table 4 Serial dilution of pooled feline serum samples measured T4 concentrations

\begin{tabular}{|c|c|c|c|c|}
\hline Expected concentration T4 & \multicolumn{2}{l|}{$\begin{array}{l}\text { Measured } \\
\text { concentration } \\
\text { 2 hour incubation }\end{array}$} & \multicolumn{2}{l|}{$\begin{array}{l}\text { Measured } \\
\text { concentration 3 } \\
\text { hour incubation }\end{array}$} \\
\cline { 2 - 5 } & $\mathrm{nmol} / \mathrm{L}$ & $\mu \mathrm{g} / \mathrm{dL}$ & $\mathrm{nmol} / \mathrm{L}$ & $\mu \mathrm{g} / \mathrm{dL}$ \\
\hline Endogenous concentration $(\mathrm{EC})$ & 60.5 & 4.7 & 20.6 & 1.6 \\
\hline $\mathrm{EC}+4.5 \mu \mathrm{g} / \mathrm{dL}$ & 109.4 & 8.5 & - & - \\
\hline $\mathrm{EC}+9.0 \mu \mathrm{g} / \mathrm{dL}$ & 168.6 & 13.1 & - & - \\
\hline $\mathrm{EC}+13.5 \mu \mathrm{g} / \mathrm{dL}$ & 208.5 & 16.2 & - & - \\
\hline $\mathrm{EC}+18 \mu \mathrm{g} / \mathrm{dL}$ & 260 & 20.2 & - & - \\
\hline
\end{tabular}


RIA Validation Appendix Table 5 Serial dilution of pooled feline serum samples measured $\mathrm{T} 3$ concentrations

\begin{tabular}{|c|c|c|c|c|}
\hline \multirow{2}{*}{ Expected concentration T4 } & \multicolumn{2}{|c|}{$\begin{array}{c}\text { Measured } \\
\text { concentration } \\
2 \text { hour incubation }\end{array}$} & \multicolumn{2}{c|}{$\begin{array}{c}\text { Measured } \\
\text { concentration 3 } \\
\text { hour incubation }\end{array}$} \\
\cline { 2 - 5 } & $\mathrm{nmol} / \mathrm{L}$ & $\mathrm{ng} / \mathrm{dL}$ & $\mathrm{nmol} / \mathrm{L}$ & $\mathrm{ng} / \mathrm{dL}$ \\
\hline Endogenous concentration (EC) & 0.80 & 52 & 0.86 & 56 \\
\hline $\mathrm{EC}+175 \mathrm{ng} / \mathrm{dL}$ & 4.19 & 273 & 4.27 & 278 \\
\hline $\mathrm{EC}+350 \mathrm{ng} / \mathrm{dL}$ & 7.79 & 507 & 7.19 & 468 \\
\hline $\mathrm{EC}+525 \mathrm{ng} / \mathrm{dL}$ & 11.51 & 749 & 10.18 & 663 \\
\hline $\mathrm{EC}+700 \mathrm{ng} / \mathrm{dL}$ & 16.16 & 1052 & 15.19 & 989 \\
\hline
\end{tabular}

\section{Brief Discussion}

Since T3 was minimally altered by incubation time, we pursued measuring T3 with the RIA kits using samples that were previously measured using the validated Siemen's T3 RIA kit (Hooper et al. 2014). This was completed in experiment 3.

The measured endogenous concentrations of T4 were altered based upon the incubation time. It may be a compound within the serum caused interference with the binding of the T4 to the antibody coated tube or the compound itself could bind to the antibody (cross-reactivity). Interference can lead to falsely elevated or falsely low analyte concentration depending on the site of the interference in the immunoassay reaction (Tate and Ward 2004).

Description of experiment 3: The purpose of this third study was to measure the T3 concentrations in cat serum with a known quantity of T3.

Techniques: Using the same commercially available human RIA T3 kit (MP Biomedicals LLC, Santa Ann, CA, USA) as in experiment 1, cat serum from a 
previously reported study (Hooper et al. 2014) were measured in duplicates following the RIA kit directions. After the completion of the assay procedure, the radioactive counts per minute (CPM) of the standard curve vials and the feline serum samples were measured using an automated gamma counter (Beckman Coulter, Brea, CA, USA). The standard curve CPM data was logit transformed to generate a standard curve as in experiment 1.

Expected data: We did not expect any statistically significant differences between values measured with the different assays and we expect the data to be similarly distributed for both assay methods. We believe the two methods will have a good correlation with an $r_{s}$ of 0.80 to 0.92 .

\section{Actual data:}

RIA Validation Appendix Table 6 Comparison of T3 concentrations measured by RIA

\begin{tabular}{|c|c|c|c|}
\hline \multicolumn{2}{|c|}{$\begin{array}{c}\text { Previously } \\
\text { measured } \\
\text { concentration }\end{array}$} & \multicolumn{2}{c|}{$\begin{array}{c}\text { Measured } \\
\text { concentration }\end{array}$} \\
\hline $\mathrm{nmol} / \mathrm{L}$ & $\mathrm{ng} / \mathrm{dL}$ & $\mathrm{nmol} / \mathrm{L}$ & $\mathrm{ng} / \mathrm{dL}$ \\
\hline 0.67 & 43.5 & 1.04 & 68 \\
\hline 0.84 & 54.8 & 1.73 & 112.4 \\
\hline 0.81 & 53.0 & 2.23 & 145.1 \\
\hline 0.65 & 42.3 & 0.64 & 41.5 \\
\hline 0.56 & 36.4 & 1.57 & 102.1 \\
\hline 0.49 & 32.0 & 2.23 & 144.9 \\
\hline 0.57 & 36.9 & 0.63 & 40.7 \\
\hline
\end{tabular}

Brief discussion: Our results were inconsistent with the previously measured T3 concentrations. A diagnostic lab also looking for a replacement for the Siemens Coat-a-Count ${ }^{\oplus}$ kits completed a charcoal-separation step as described by Refsal 
et al. (1991), however the lab reported the MP Biomedicals kit performance did not improve. The diagnostic lab decided to not further pursue the use of the MP Biomedical's kit to measure feline T3. We decided to conduct one additional experiment to determine if using a resin to purify our feline samples would be feasible.

Experiment 4: The purpose of this study was to determine the feasibility of using a resin to extract T3 from the serum matrix.

Techniques: Following day 2 and day 3 of the liver thyroid hormone extraction protocol (Appendix), T4 was extracted from cat serum samples. The samples selected were from a previously reported study (Hooper et al. 2014), because T4 was previously measured using the validated Siemen's T4 RIA kits. The T4 in the samples was measured in duplicate using the MP Biomedicals T4 RIA kit following the kit directions.

\section{Results}

RIA Validation Appendix Table 7 T3 concentration measured after resin purrification

\begin{tabular}{|c|c|c|c|c|c|c|}
\hline \multicolumn{2}{|c|}{$\begin{array}{c}\text { Previously } \\
\text { measured TT3 } \\
\text { Concentration }\end{array}$} & \multicolumn{2}{c|}{$\begin{array}{c}\text { Measured } \\
\text { concentration }\end{array}$} & \multicolumn{2}{c|}{$\begin{array}{c}\text { Measured } \\
\text { concentration after } \\
\text { resin extraction }\end{array}$} & Recovery \\
\hline $\mathrm{nmol} / \mathrm{L}$ & $\mathrm{ng} / \mathrm{dL}$ & $\mathrm{nmol} / \mathrm{L}$ & $\mathrm{ng} / \mathrm{dL}$ & $\mathrm{nmol} / \mathrm{L}$ & $\mathrm{ng} / \mathrm{dL}$ & $\%$ \\
\hline 0.84 & 54.8 & 1.73 & 112.4 & 0.56 & 36.2 & 64 \\
\hline 0.81 & 53.0 & 2.23 & 145.1 & 0.52 & 33.7 & 68 \\
\hline 0.65 & 42.3 & 0.63 & 41.5 & 0.45 & 29.6 & 55 \\
\hline
\end{tabular}

These samples were run in duplicate with the mean value reported. 


\section{Brief discussion}

The results obtained using the resin to extract the T3 from the serum matrix, appear that this antibody used in the MP Biomedicals kit detects T3 similar to the discontinued Siemen's RIA kits. However, it appears that the antibody is not as specific for T3 due to interference caused by cross-reactivity of an unknown

compound in the serum matrix. Because of the multi-day process and the limited number of samples that could be processed, it is more cost-efficient to submit samples to a diagnostic lab who use feline specific in-house validated RIA kits (e.g. Michigan State Diagnostic Center for Population and Animal Health) or nonRIA based validated thyroid hormone assays (e.g. IDEXX). 


\section{References}

Edinboro CH, Scott-Moncrieff JC, Janovitz E, Thacker HL, Glickman LT (2004) Epidemiologic study of relationships between consumption of commercial canned food and risk of hyperthyroidism in cats Journal of the American Veterinary Medical Association 224:879-886

Epstein M, Kuehn NF, Landsberg G, Lascelles BD, Marks SL, Schaedler JM, Tuzio H (2005) AAHA senior care guidelines for dogs and cats Journal of the American Animal Hospital Association 41:81-91 doi:10.5326/0410081

Feldman EaL, RW (2004) Canine and Feline Endocrinology and Reproduction.

Third edn. Elsevier Health Sciences, United States of America

Food and Drug Administration (1998) Guidance for Industry. General

Considerations for Pediatric Pharmacokinetic Studies for Drugs and Biological Products. Draft Guidance. Food and Drug Administration, Goldsmith SJ (1975) Radioimmunoassay: Review of basic principles Seminars in Nuclear Medicine 5:125-152 doi:10.1016/S0001-2998(75)80028-6

Grutzner N, Hang I, Heilmann RM, Spillmann T, Suchodolski JS, Steiner JM (2013) Analytical validation of radioimmunoassays for the quantification of select pancreatic enzymes in jejunal fluid and fecal extracts from dogs Veterinary journal 198:200-205 doi:10.1016/j.tvjl.2013.07.022

Hart ML, Meyer A, Johnson PJ, Ericsson AC (2015) Comparative Evaluation of DNA Extraction Methods from Feces of Multiple Host Species for Downstream Next-Generation Sequencing PloS one 10:e0143334 doi:10.1371/journal.pone.0143334 
Higgs P, Costa M, Freke A, Papasouliotis K (2014) Measurement of thyroxine and cortisol in canine and feline blood samples using two immunoassay analysers Journal of Small Animal Practice 55:153-159 doi:10.1111/jsap.12181

Hooper S, Mori, L., Backus, R. (2014) Effects of bisphenol-A and estradiol ingested with food on plasma concentrations of glucose, insulin, and thyroid-axis hormones in cats. Abstract Journal of Animal Physiology and Animal Nutrition 98:1187-1201 doi:10.1111/jpn.12269

Horney BS, MacKenzie AL, Burton SA, Olexson DW, Mitton KL, Coty WA, Rinne SG (1999) Evaluation of an automated, homogeneous enzyme immunoassay for serum thyroxine measurement in dog and cat serum Veterinary clinical pathology / American Society for Veterinary Clinical Pathology 28:20-28

Kass PH, Peterson ME, Levy J, James K, Becker DV, Cowgill LD (1999) Evaluation of environmental, nutritional, and host factors in cats with hyperthyroidism Journal of veterinary internal medicine / American College of Veterinary Internal Medicine 13:323-329

Kemppainen RJ, Birchfield JR (2006) Measurement of total thyroxine concentration in serum from dogs and cats by use of various methods American journal of veterinary research 67:259-265 doi:10.2460/ajvr.67.2.259

Lurye JC, Behrend EN, Kemppainen RJ (2002) Evaluation of an in-house enzyme-linked immunosorbent assay for quantitative measurement of 
serum total thyroxine concentration in dogs and cats Journal of the American Veterinary Medical Association 221:243-249

Martin KM, Rossing MA, Ryland LM, DiGiacomo RF, Freitag WA (2000)

Evaluation of dietary and environmental risk factors for hyperthyroidism in cats Journal of the American Veterinary Medical Association 217:853-856

Morreale de Escobar G, Pastor R, Obregon MJ, Escobar del Rey F (1985)

Effects of maternal hypothyroidism on the weight and thyroid hormone content of rat embryonic tissues, before and after onset of fetal thyroid function Endocrinology 117:1890-1900 doi:10.1210/endo-117-5-1890

Peterson M (2012) Hyperthyroidism in cats: what's causing this epidemic of thyroid disease and can we prevent it? J Feline Med Surg 14:804-818 doi:10.1177/1098612X12464462

Peterson ME (2013) Feline focus: Diagnostic testing for feline thyroid disease: hyperthyroidism Compendium 35:E3

Peterson ME, Broussard JD, Gamble DA (1994) Use of the thyrotropin releasing hormone stimulation test to diagnose mild hyperthyroidism in cats Journal of veterinary internal medicine / American College of Veterinary Internal Medicine 8:279-286

Peterson ME, Melian C, Nichols R (2001) Measurement of serum concentrations of free thyroxine, total thyroxine, and total triiodothyronine in cats with hyperthyroidism and cats with nonthyroidal disease Journal of the American Veterinary Medical Association 218:529-536 
Pittari J et al. (2009) American Association of Feline Practitioners: Senior Care Guidelines Journal of Feline Medicine and Surgery 11:763-778 doi:10.1016/j.jfms.2009.07.011

Refsal KR, Nachreiner RF, Stein BE, Currigan CE, Zendel AN, Thacker EL (1991) Use of the triiodothyronine suppression test for diagnosis of hyperthyroidism in ill cats that have serum concentration of iodothyronines within normal range Journal of the American Veterinary Medical Association 199:1594-1601

Singh AK, Jiang Y, White T, Spassova D (1997) Validation of nonradioactive chemiluminescent immunoassay methods for the analysis of thyroxine and cortisol in blood samples obtained from dogs, cats, and horses Journal of veterinary diagnostic investigation : official publication of the American Association of Veterinary Laboratory Diagnosticians, Inc 9:261-268

Tate J, Ward G (2004) Interferences in Immunoassay The Clinical Biochemist Reviews 25:105-120

Wakeling J, Smith K, Scase T, Kirkby R, Elliott J, Syme H (2007) Subclinical hyperthyroidism in cats: a spontaneous model of subclinical toxic nodular goiter in humans? Thyroid : official journal of the American Thyroid Association 17:1201-1209 doi:10.1089/thy.2007.0225

Wang D, Stapleton HM (2010) Analysis of thyroid hormones in serum by liquid chromatography-tandem mass spectrometry Analytical and bioanalytical chemistry 397:1831-1839 doi:10.1007/s00216-010-3705-9 


\section{VITA}

Sarah E. Hooper was born in Roswell, Georgia, and was homeschooled until she entered the University of Georgia College of Agriculture and Environmental Sciences in fall 2006. During the senior year of her undergraduate education, she concurrently completed her first year of veterinary school at the University Of Georgia College of Veterinary Medicine in fall 2009. She graduated as Summa Cum Laude in spring 2010 with an Avian Biology (BSA) degree. Earning her doctor of veterinary medicine degree (DVM) in spring 2013, she immediately entered the University of Missouri Comparative Medicine Program where she completed an American College of Laboratory Animal Medicine (ACLAM) recognized residency program while working towards doctoral degree $(\mathrm{PhD})$. With diverse research interests, she will be able to combine her nutrition doctoral research training with wildlife conservation. In winter 2017, Sarah will enter a post-doctoral research position under a Wildlife Biologist with the U.S. Forest Service focusing on the conservation of animal species, specifically endangered bat species, through nutritional ecology. 